\author{
UNIVERSIDADE DE SÃO PAULO \\ ESCOLA DE ENGENHARIA DE SÃO CARLOS \\ PROGRAMA DE PÓS-GRADUAÇÃO EM ENGENHARIA DE PRODUÇÃO
}

\title{
A IMPLANTAÇÃO DE SISTEMAS APS SOB A PERSPECTIVA DE REDES DE INOVAÇÃO AUTO-ORGANIZADAS
}

Thales Botelho de Sousa

Dissertação apresentada à Escola de Engenharia de São

Carlos da Universidade de São Paulo, como parte dos requisitos para a obtenção do título de Mestre em Engenharia de Produção.

Área de concentração: Processos e Gestão de Operações

Linha de pesquisa: Redes Produtivas e Logística Integrada Orientador: Prof. Associado Fábio Müller Guerrini 



\section{A IMPLANTAÇÃO DE SISTEMAS APS SOB A PERSPECTIVA DE REDES DE INOVAÇÃO AUTO-ORGANIZADAS}

Dissertação apresentada à Escola de Engenharia de São Carlos da Universidade de São Paulo, como parte dos requisitos para a obtenção do título de Mestre em Engenharia de Produção.

Área de concentração: Processos e Gestão de Operações

Orientador: Prof. Associado Fábio Müller Guerrini

São Carlos 
AUTORIZO A REPRODUÇÃO TOTAL OU PARCIAL DESTE TRABALHO, POR QUALQUER MEIO CONVENCIONAL OU ELETRONICO, PARA FINS DE ESTUDO E PESQUISA, DESDE QUE CITADA A FONTE.

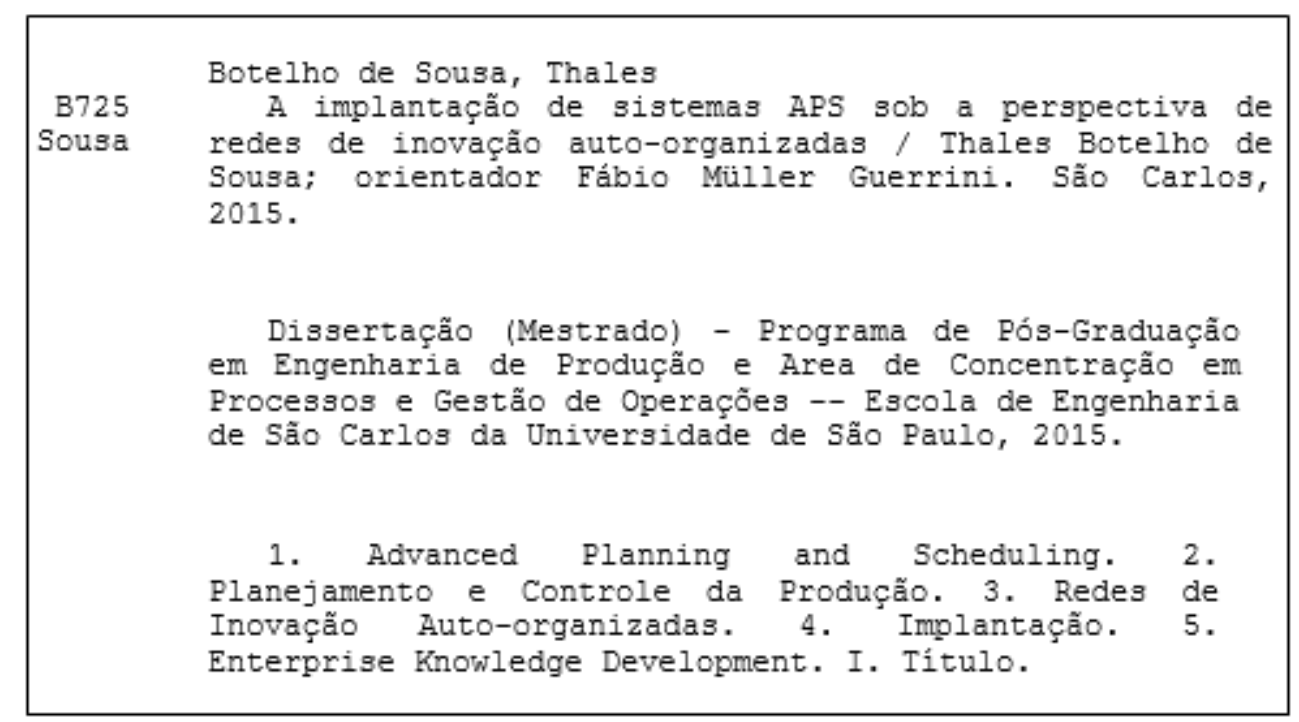




\section{FOLHA DE JULGAMENTO}

Candidato: Engenheiro THALES BOTELHO DE SOUSA.

Título da dissertação: "A implantação de sistemas APS sob a perspectiva de redes de inovação auto-organizadas".

Data da defesa: 15/05/2015

\section{Comissão Julgadora:}

Prof. Associado Fábio Müller Guerrini (Orientador)

(Escola de Engenharia de São Carlos/EESC)

Prof. Dr. Walther Azzolini Júnior

(Escola de Engenharia de São Carlos/EESC)

Prof. Dr. Moacir Godinho Filho

(Universidade Federal de São Carlos/UFSCar)

\section{Resultado:}
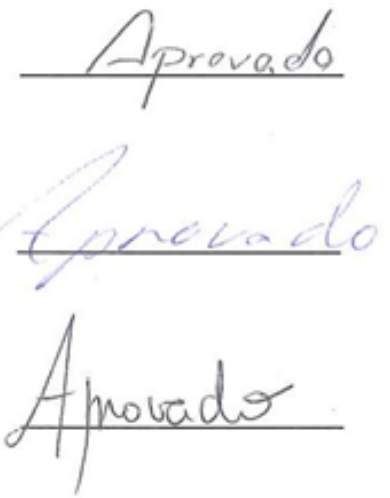

Coordenadora do Programa de Pós-Graduação em Engenharia de Produção:

Profa. Associada Daisy Aparecida do Nascimento Rebelatto

Presidente da Comissão de Pós-Graduação:

Prof. Associado Paulo César Lima Segantine 

A Deus por ter me dado vida, saúde, coragem, força e sabedoria para chegar até aqui; aos meus familiares pelo apoio; aos amigos e colegas do programa pelo companheirismo e auxílio; ao meu orientador e demais professores pela paciência, dedicação e aprendizado; e aos pesquisadores da área e profissionais das empresas estudadas que, de maneira esplêndida, auxiliaram no desenvolvimento deste trabalho. 



\section{AGRADECIMENTOS}

Primeiramente, agradeço a Deus por ter me dado vida, força, coragem, saúde, sabedoria e luz para que eu trilhasse este caminho e superasse todas as dificuldades que surgiram.

Ao meu orientador, o Prof. Assoc. Fábio Müller Guerrini, por ter me proporcionado a oportunidade de ingressar no programa; pelo incentivo, apoio, parceria e paciência durante a realização do projeto e demais atividades correlatas; e também por compartilhar comigo sua sabedoria, experiência profissional e visão analítica da ciência.

À Universidade de São Paulo (USP) pela bolsa do Programa de Aperfeiçoamento de Ensino (PAE) e auxílios financeiros concedidos, bem como pelo suporte físico disponibilizado.

À Coordenação de Apoio de Pessoal de Nível Superior (CAPES) pela bolsa de Mestrado e demais auxílios financeiros disponibilizados para a realização do projeto.

A todos os professores (em especial a Daisy Aparecida do Nascimento Rebelatto, Edson Walmir Cazarini, Henrique Rozenfeld, Kleber Francisco Esposto, Luiz Cesar Ribeiro Carpinetti, Marcel Andreotti Musetti, os quais tive a oportunidade de ser aluno) e funcionários do departamento, pela convivência e cooperação, bem como por todo o empenho e zelo pela manutenção da qualidade do programa.

Aos professores membros da banca de defesa, o Prof. Dr. Moacir Godinho Filho e o Prof. Dr. Walther Azzolini Júnior, pela disponibilidade de participação e pelas valiosas contribuições para o enriquecimento da dissertação.

A todos os colegas atuais e antigos do grupo de pesquisa, especialmente os que tive o prazer de conviver durante a realização do curso (Adauto Lucas da Silva, Lucas Portilho Camargos Gomes, Cristiane Carneiro da Silva, Murilo José Rosa e Heber Lombardi de Carvalho). Obrigado pela amizade, apoio e auxílio no desenvolvimento do projeto.

Aos pesquisadores da área de pesquisa pelas valiosas contribuições para o desenvolvimento do tema e da minha dissertação. 
Aos profissionais das empresas que fizeram parte da pesquisa de campo. Vossa contribuição foi primordial para o desenvolvimento deste projeto.

Aos avaliadores do modelo de referência desenvolvido na pesquisa. A valiosa experiência profissional e acadêmica de vocês foi muito importante para a verificação da confiabilidade do modelo.

Aos meus familiares (especialmente pais e irmãos) e amigos da Igreja Adventista do Sétimo Dia - Movimento de Reforma pelo apoio, orações e auxílio.

Aos amigos dos Programas de Pós-Graduação em Engenharia de Produção da EESC-USP e da UFSCar (Adauto, Alex, Ana Laura, André, Bruno, Caio Lourenço, Caio Marques, Camila Fabrício, Camila Ferreira, Carina, Carlos, Carolin, Carolina, Caroline, Catarina, Cíntia, Cristiane, Daniel, Daniela, Denise, Diego Fogaça, Diego Iritani, Diogo, Enzo, Fabiana, Fábio, Fabrício, Fausto, Felipe, Fernando, Flávia, Gabriel, Gabriela Celestini, Gabriela Mendonça, Geandra, Gisele, Guilherme Roiz, Guilherme Valadão, Helielze, Heloísa, Herick, Hugo, Isotília, José Augusto, José Carlos, Lie, Lilian, Liza, Lucas, Luís Carlos, Luiz Philippsen, Maiara, Marco Zanato, Matheus, Michelle, Miriã, Murilo, Nádia, Nadya, Naja, Paula, Paulo, Pedro, Raphael Cobra, Raphael Tristão, Remo, Roberta Salgado, Roberta Sanches, Roberto, Rodrigo, Sânia, Sílvia, Tatiana, Thiago, Victor e Yovana) pela amizade, auxílio, companheirismo e momentos de lazer.

Aos demais amigos e conhecidos pelo apoio e votos de sucesso. 


\section{EPÍGRAFE}

Alguns homens veem as coisas como são, e dizem 'por quê?' Eu sonho com as coisas que nunca foram e digo 'por que não?'

George Bernard Shaw 



\section{RESUMO}

SOUSA, T. B. A implantação de sistemas APS sob a perspectiva de redes de inovação autoorganizadas. 2015. 230 p. Dissertação (Mestrado em Engenharia de Produção). Escola de Engenharia de São Carlos, Universidade de São Paulo, São Carlos, 2015.

Esta dissertação tem como finalidade analisar a implantação de sistemas APS em empresas sob a perspectiva de redes de inovação auto-organizadas. Considera-se que a implantação do sistema APS representa uma inovação organizacional para a área de planejamento e controle da produção da empresa adquirente do software, pois comparado aos sistemas de planejamento e controle da produção predecessores, supre deficiências referentes às limitações de capacidade da empresa, flexibilidade na geração de estratégias de produção, disponibilização de prazos de entrega mais curtos e maior apoio aos processos de decisão. Considera-se também que o processo de implantação pode ser analisado sob a perspectiva de uma rede auto-organizada, formada pela empresa adquirente, implantadora e desenvolvedora do software, o que permite identificar os nós (empresas), ligações (relacionamentos), posições (atividades das empresas), fluxos tangíveis (recursos físicos) e fluxos intangíveis (troca de conhecimento e informações). A metodologia de pesquisa utilizada compreende um estudo bibliográfico para o embasamento teórico da temática proposta e de sete estudos de caso para a coleta de dados em campo. A análise e discussão do cruzamento entre as evidências teóricas e práticas visa identificar e sistematizar elementos para disponibilizar um modelo de referência para a implantação de sistemas APS. O desenvolvimento do modelo de referência foi orientado pela metodologia Enterprise Knowledge Development (EKD), e o mesmo foi avaliado por profissionais de empresas implantadoras e pesquisadores acadêmicos, a fim de verificar sua consistência e identificar possíveis melhorias.

Palavras-chave: Advanced Planning and Scheduling, Planejamento e Controle da Produção, Redes de Inovação Auto-organizadas, Implantação, Enterprise Knowledge Development. 



\begin{abstract}
SOUSA, T. B. The implementation of APS systems under self-organizing innovation networks perspective. 2015. 230 p. Dissertation (Master's Degree in Industrial Engineering). Escola de Engenharia de São Carlos, Universidade de São Paulo, São Carlos, 2015.

This dissertation aims to analyze the APS systems implementation in companies under the selforganizing innovation networks perspective. It is considered that the APS systems implementation represents an organizational innovation in the area of production planning and control of the software's acquiring company, because compared to the predecessors production planning and control systems, supplies deficiencies relating to capacity constraints of the company, flexibility in the generation of production strategies and greater support to decisionmaking. It is also considered that the implementation process can be analyzed under the perspective of a self-organized network formed by the acquirer, implanter and developer companies of the software, which allows us to identify the nodes (companies), links (relationships), positions (activities of companies), tangible flows (physical resources) and intangible flows (exchange of knowledge and information). The research methodology used comprises a bibliographical study to the theoretical background of the proposed theme and seven case studies to data collection in the field. The analysis and discussion of the intersection between theoretical and practical evidences aims to identify and systematize elements for provide a reference model for the APS systems implementation. The development of the reference model was guided by the Enterprise Knowledge Development (EKD) methodology, and the model was assessed by implementing companies professionals and academic researchers in order to check its consistency and identify possible improvements.
\end{abstract}

Keywords: Advanced Planning and Scheduling, Production Planning and Control, Selforganizing Innovation Networks, Implementation, Enterprise Knowledge Development. 



\section{LISTA DE QUADROS}

Quadro 1 - Descrição das empresas participantes dos estudos de caso...................................37

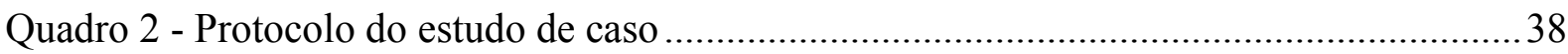

Quadro 3 - Principais benefícios proporcionados pelos sistemas APS ……...........................55

Quadro 4 - Requisitos necessários para a implantação de sistemas APS e elementos de redes de

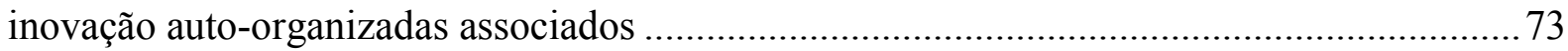

Quadro 5 - Necessidades de mudanças............................................................................ 91 



\section{LISTA DE FIGURAS}

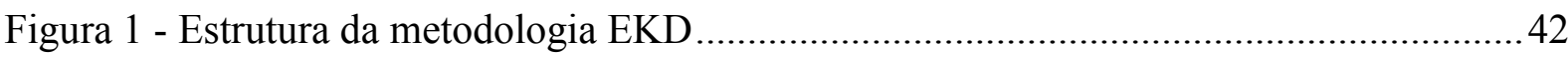

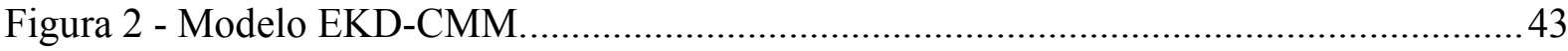

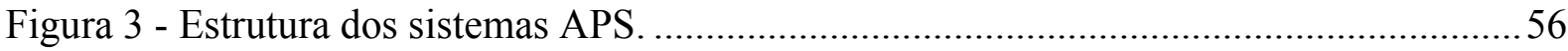

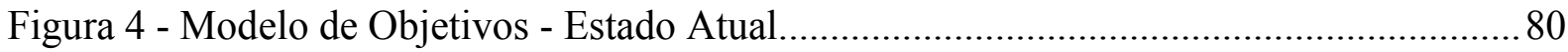

Figura 5 - Modelo de Regras do Negócio - Estado Atual ....................................................... 82

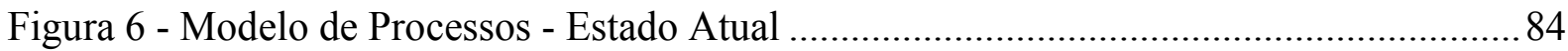

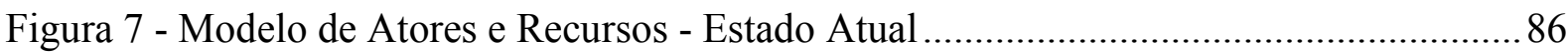

Figura 8 - Modelo de Componentes e Requisitos Técnicos - Estado Atual .............................89

Figura 9 - Modelo de Objetivos - Estado Futuro................................................................ 101

Figura 10 - Modelo de Regras do Negócio - Estado Futuro...................................................... 103

Figura 11 - Modelo de Processos - Estado Futuro ................................................................. 106

Figura 12 - Modelo de Atores e Recursos - Estado Futuro ................................................... 109

Figura 13 - Visão geral do Modelo de Componentes e Requisitos Técnicos - Estado Futuro

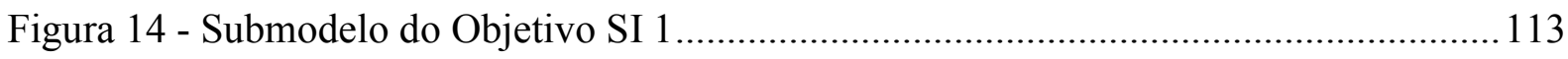

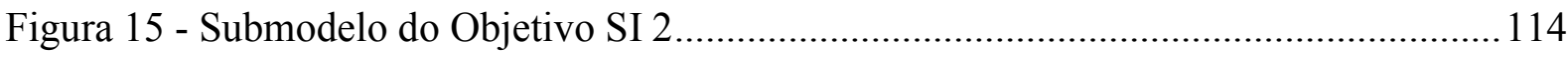

Figura 16 - Modelo de Conceitos - Estado Futuro .................................................................. 116

Figura 17 - Modelo de Objetivos - Empresa 1 .................................................................... 149

Figura 18 - Modelo de Regras do Negócio - Empresa 1 ........................................................... 151

Figura 19 - Modelo de Processos - Empresa 1 ................................................................... 153

Figura 20 - Modelo de Atores e Recursos - Empresa 1 ..................................................... 155

Figura 21 - Modelo de Componentes e Requisitos Técnicos - Empresa 1 ............................ 157

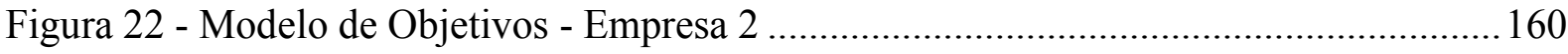

Figura 23 - Modelo de Regras do Negócio - Empresa 2 ......................................................... 162

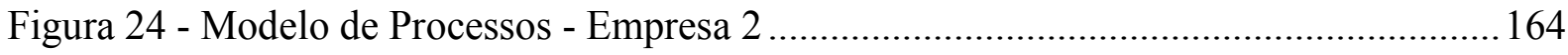

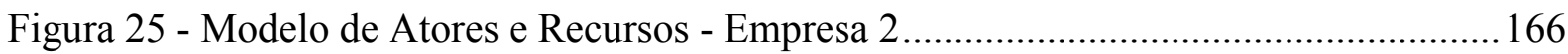

Figura 26 - Modelo de Componentes e Requisitos Técnicos - Empresa 2 ............................. 168

Figura 27 - Modelo de Objetivos - Empresa 3 .................................................................. 171

Figura 28 - Modelo de Regras do Negócio - Empresa 3 ...................................................... 173

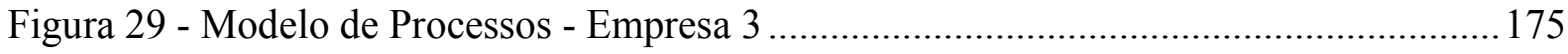




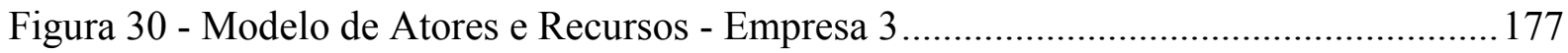

Figura 31 - Modelo de Componentes e Requisitos Técnicos - Empresa 3 ............................. 179

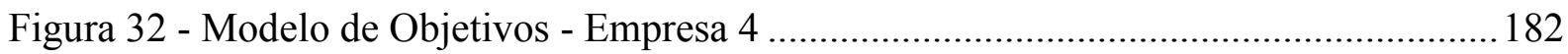

Figura 33 - Modelo de Regras do Negócio - Empresa 4 ..................................................... 184

Figura 34 - Modelo de Processos - Empresa 4 .................................................................... 186

Figura 35 - Modelo de Atores e Recursos - Empresa 4 .................................................... 188

Figura 36 - Modelo de Componentes e Requisitos Técnicos - Empresa 4 ............................. 190

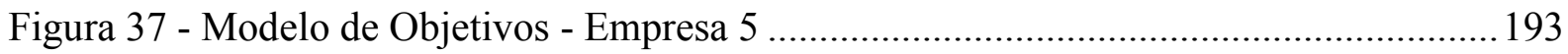

Figura 38 - Modelo de Regras do Negócio - Empresa 5 ....................................................... 195

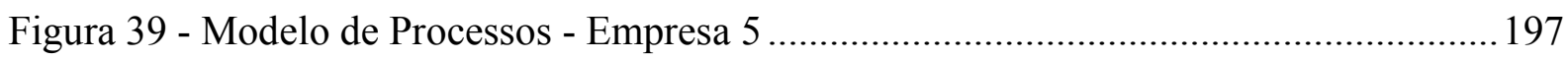

Figura 40 - Modelo de Atores e Recursos - Empresa 5 ........................................................ 199

Figura 41 - Modelo de Componentes e Requisitos Técnicos - Empresa 5 .............................201

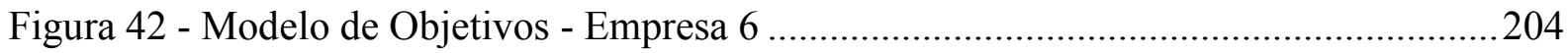

Figura 43 - Modelo de Regras do Negócio - Empresa 6 ........................................................206

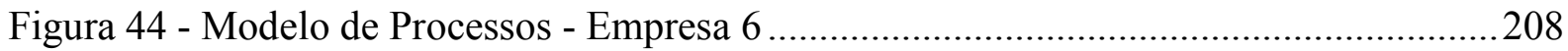

Figura 45 - Modelo de Atores e Recursos - Empresa 6 ......................................................210

Figura 46 - Modelo de Componentes e Requisitos Técnicos - Empresa 6.............................212

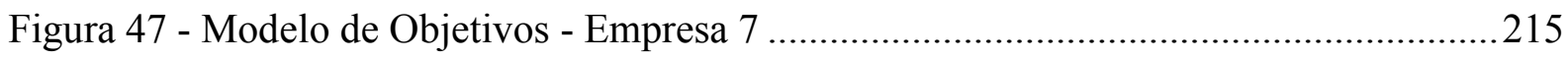

Figura 48 - Modelo de Regras do Negócio - Empresa 7 ......................................................217

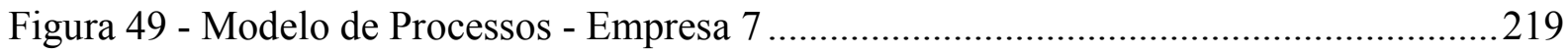

Figura 50 - Modelo de Atores e Recursos - Empresa 7 .......................................................221

Figura 51 - Modelo de Componentes e Requisitos Técnicos - Empresa 7 .............................223 


\section{LISTA DE TABELAS}

Tabela 1 - Resultados da avaliação dos modelos 



\section{LISTA DE GRÁFICOS}

Gráfico 1 - Avaliação do Modelo de Objetivos.................................................................... 119

Gráfico 2 - Avaliação do Modelo de Regras do Negócio..................................................... 120

Gráfico 3 - Avaliação do Modelo de Processos .................................................................... 120

Gráfico 4 - Avaliação do Modelo de Atores e Recursos ......................................................... 121

Gráfico 5 - Avaliação do Modelo de Componentes e Requisitos Técnicos ........................... 121

Gráfico 6 - Avaliação do Modelo de Conceitos ..................................................................... 122 



\section{LISTA DE SIGLAS}

APS Advanced Planning and Scheduling

ATP Available-To-Promise

BOM Bill Of Materials

CNO Collaborative Networked Organisation

CNO Collaborative Networked Organization

CRP Capacity Requirement Planning

CTP Capable-To-Promise

EKD Enterprise Knowledge Development

EKD-CMM Enterprise Knowledge Development - Change Management Method

ERP Enterprise Resources Planning

FIESP Federação das Indústrias do Estado de São Paulo

GCS Gestão da Cadeia de Suprimentos

HPP Hierarchical Production Planning

MES Manufacturing Execution Systems

MRP II Manufacturing Resources Planning

MPS Master Production Scheduling

MRP Material Requirements Planning

MILP Mixed-Integer Linear Programming

OECD Organisation for Economic Co-Operation and Development

PCP Planejamento e Controle da Produção

PTP Profitable-To-Promise

S\&OP Sales \& Operations Planning

WIP Work In Process 



\section{SUMÁRIO}

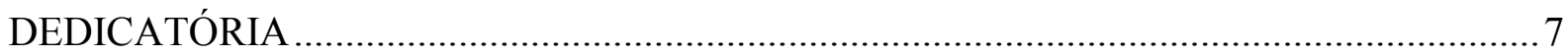

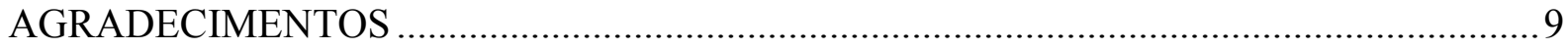

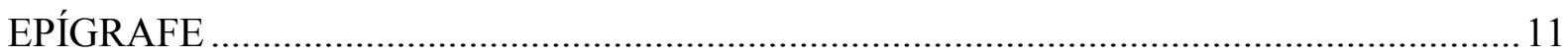

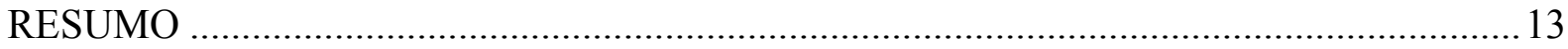

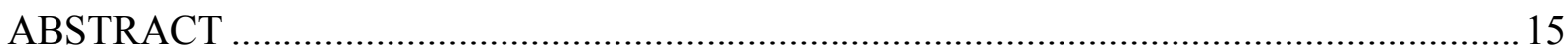

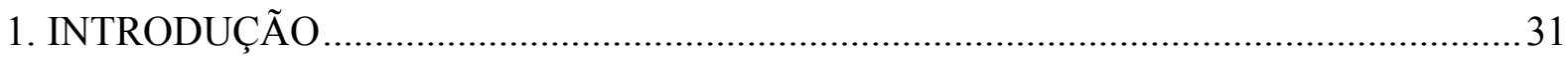

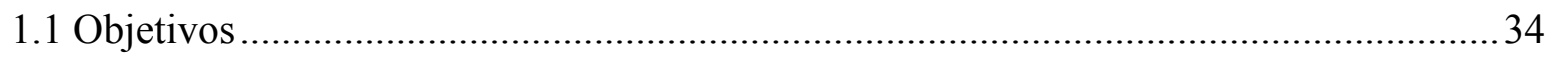

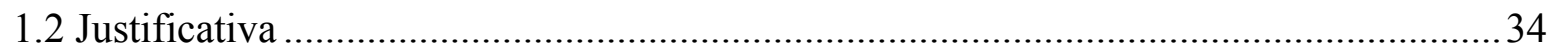

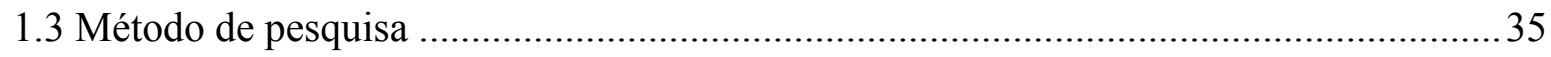

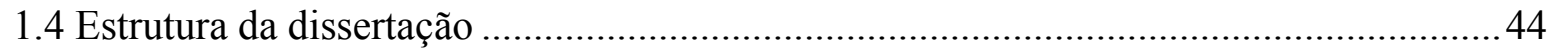

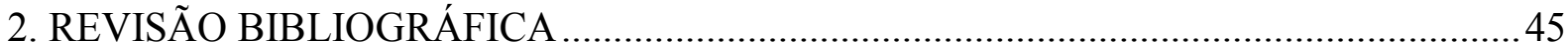

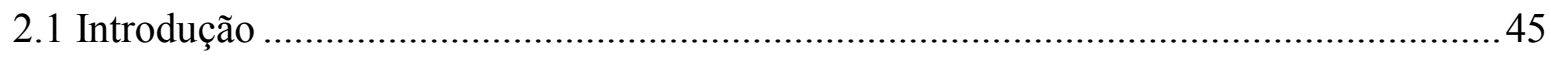

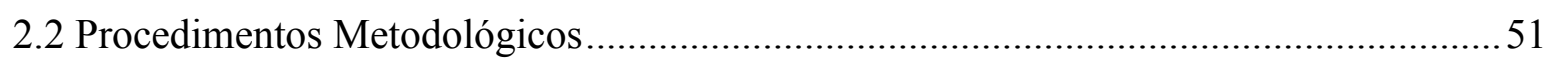

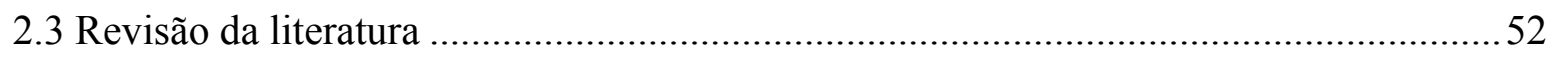

2.3.1 Sistemas APS: caracterização e delimitação ......................................................... 52

2.3.1.1 Implantação de sistemas APS: revisão sistemática da literatura ........................58

2.3.1.1.1 Integração entre o APS e outros sistemas de planejamento.........................58

2.3.1.1.2 Influência da modelagem no processo de implantação ...............................60

2.3.1.1.3 Influência de fatores humanos, organizacionais e tecnológicos no processo

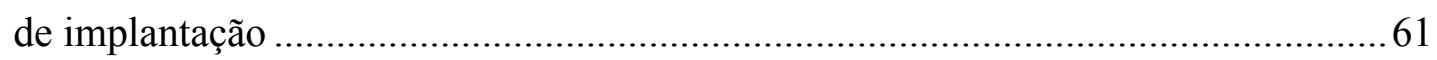

2.3.1.1.4 Principais obstáculos para a implantação bem-sucedida do sistema ..........64

2.3.1.1.5 Problemas nas fases de implantação de sistemas APS ................................65

2.3.1.1.6 Impactos dos sistemas APS nos níveis de planejamento da gestão da cadeia

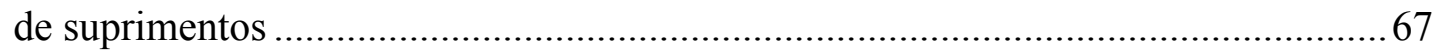

2.3.2 Redes de inovação auto-organizadas: caracterização e conceituação ......................69

2.3.3 Implantação de sistemas APS sob a perspectiva de redes de inovação auto-

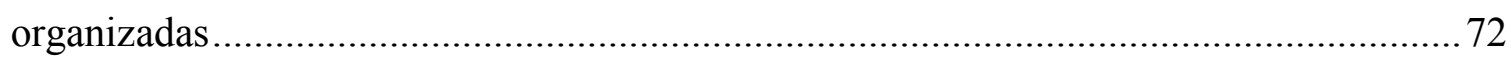

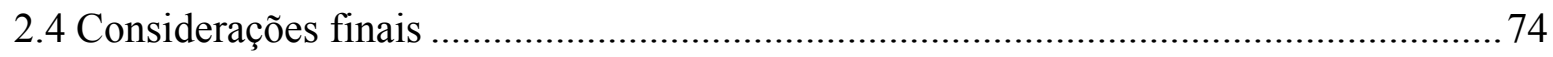


3. ANÁliSE DA SITUAÇÃO ATUAL $(A S-I S)$ E NECESSIDADES DE MUDANÇAS

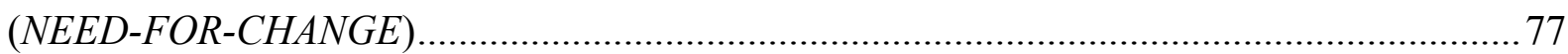

3.1 Modelo $A s-I s$ do processo de implantação de sistemas APS ....................................... 78

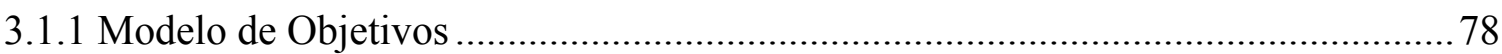

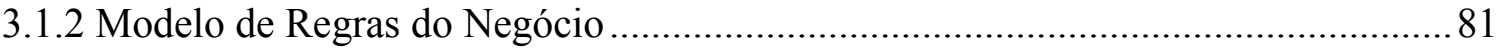

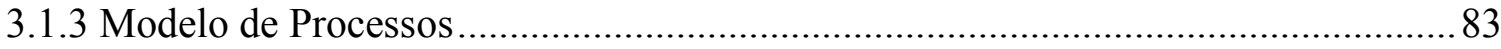

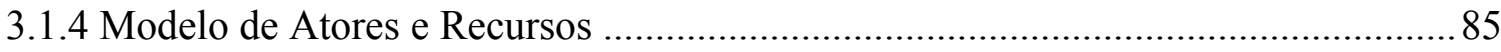

3.1.5 Modelo de Componentes e Requisitos Técnicos.................................................. 87

3.2 Modelo de Necessidades de Mudanças ............................................................................ 90

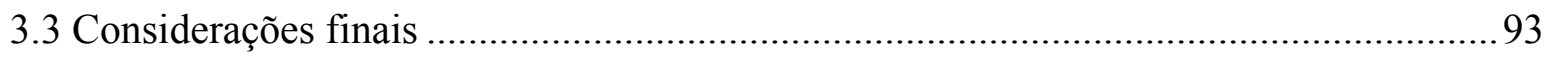

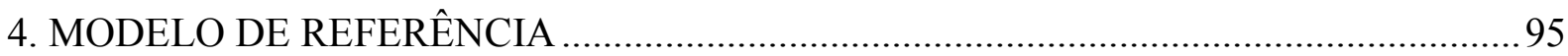

4.1 Modelos de referência: caracterização e conceituação ................................................ 96

4.2 Modelo de referência para a implantação de sistemas APS sob a perspectiva de redes de

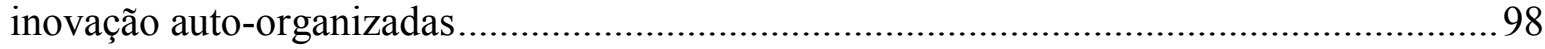

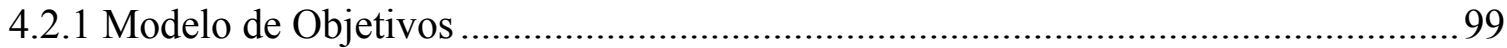

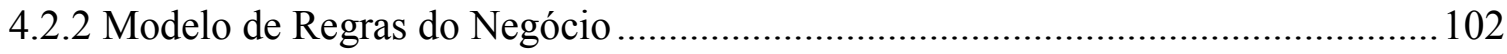

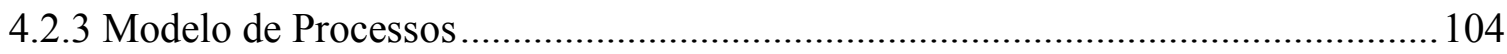

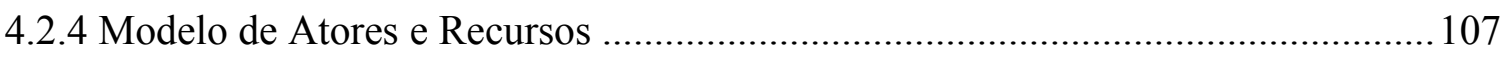

4.2.5 Modelo de Componentes e Requisitos Técnicos.................................................. 110

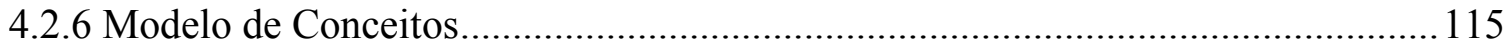

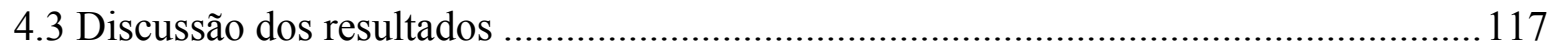

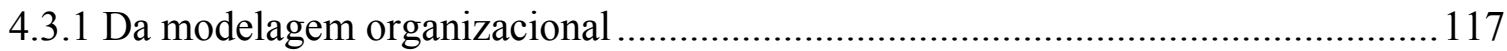

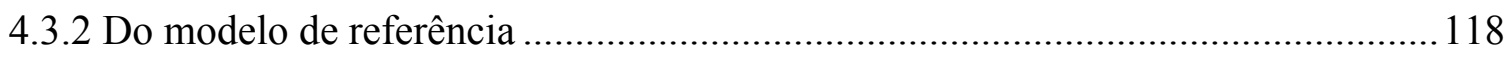

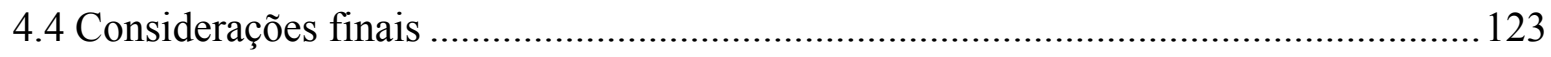

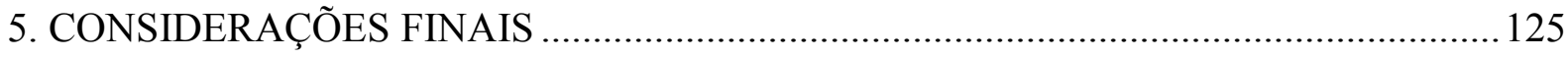

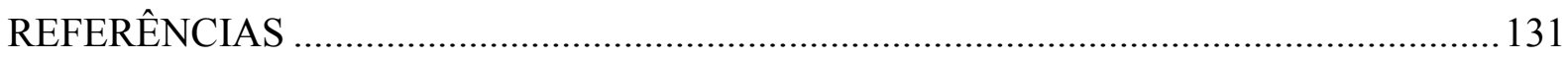

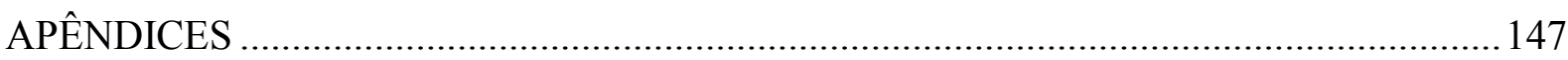

APÊNDICE A - MODELAGEM ORGANIZACIONAL DO PROCESSO DE IMPLANTAÇÃO DE SISTEMAS APS NAS EMPRESAS OBJETO DE ESTUDO....... 147

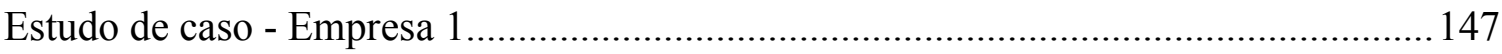

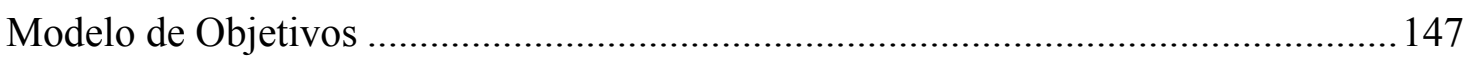

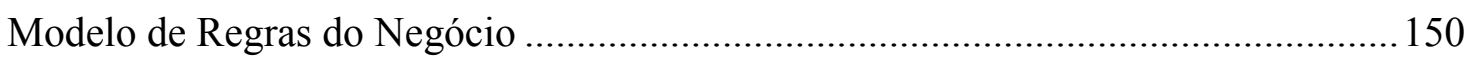

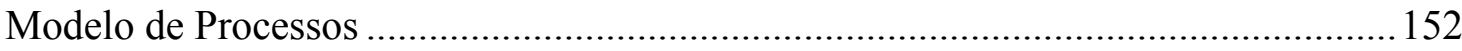




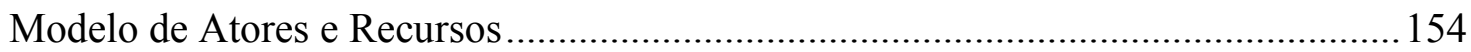

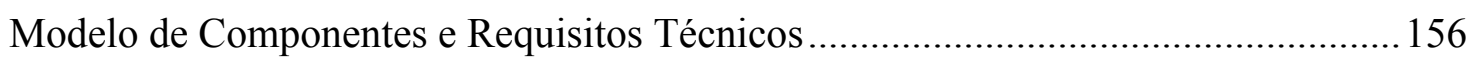

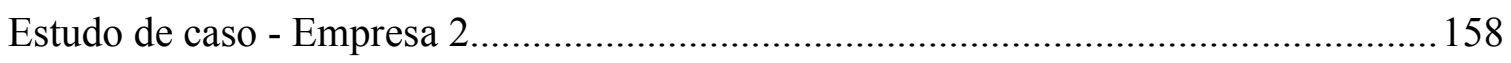

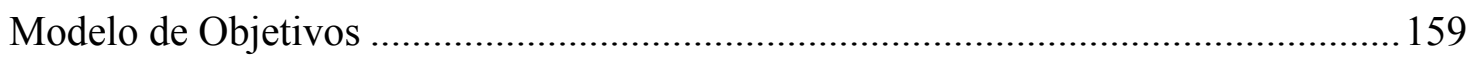

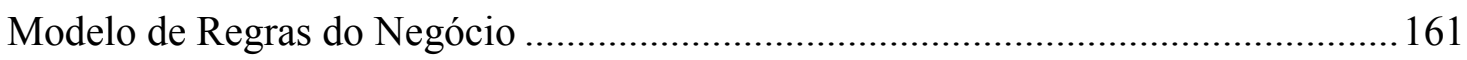

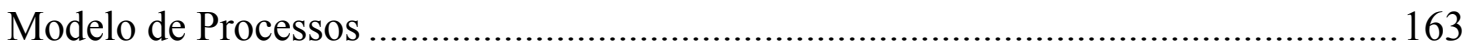

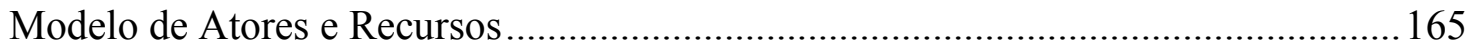

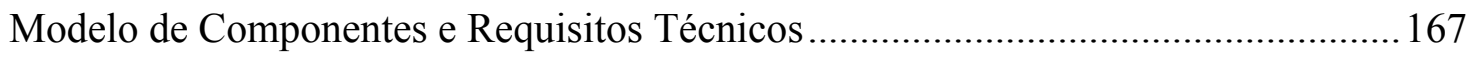

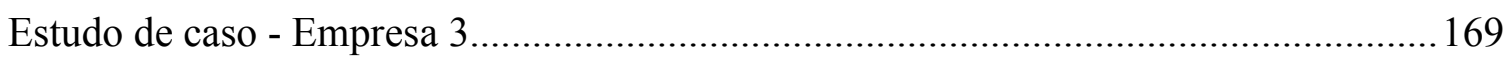

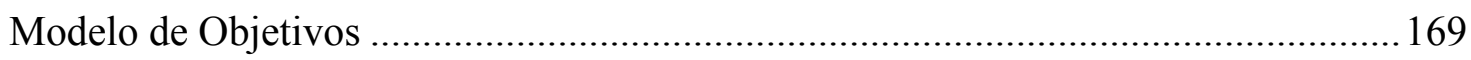

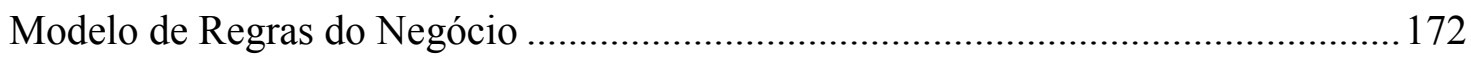

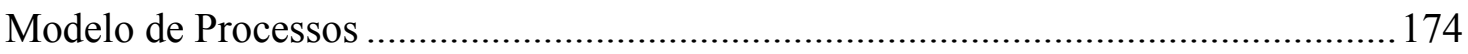

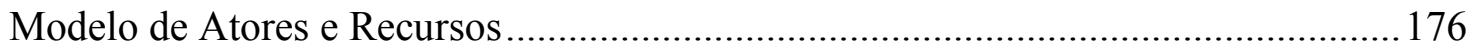

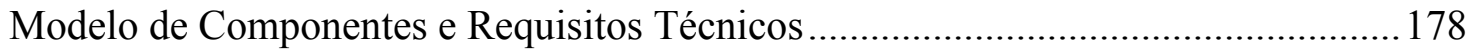

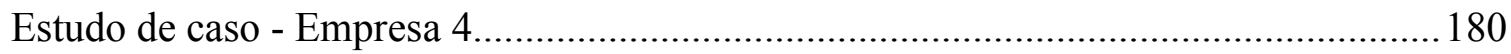

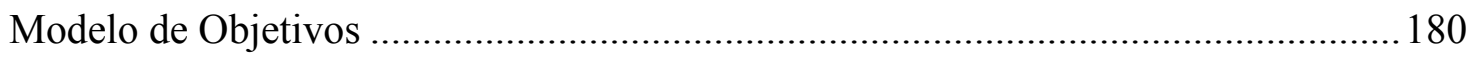

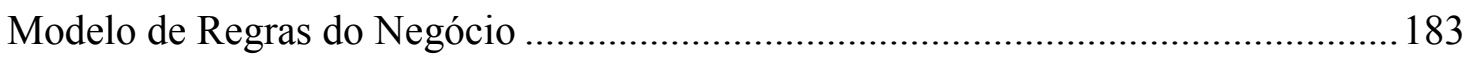

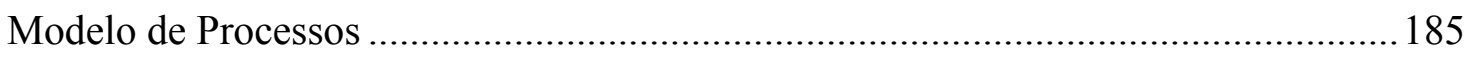

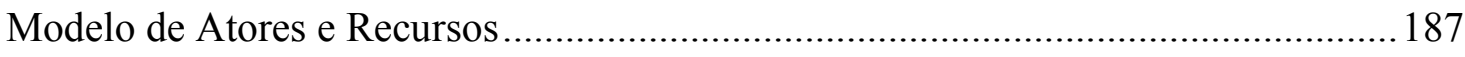

Modelo de Componentes e Requisitos Técnicos ....................................................... 189

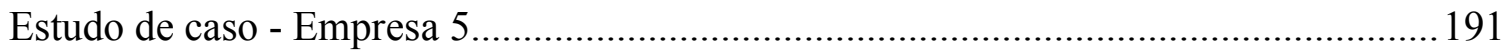

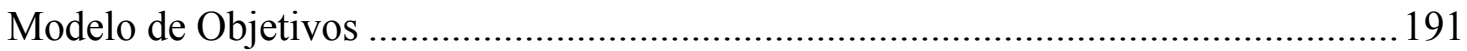

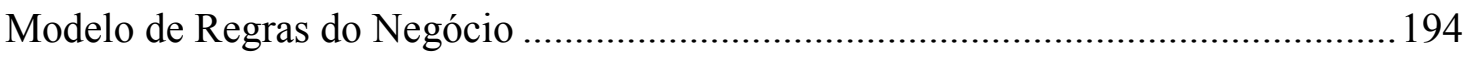

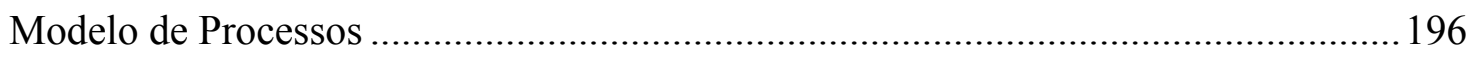

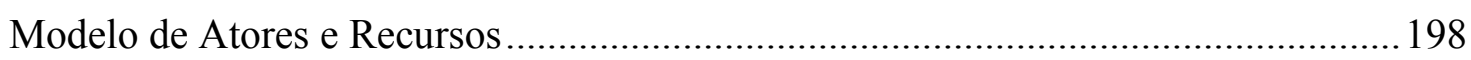

Modelo de Componentes e Requisitos Técnicos ........................................................200

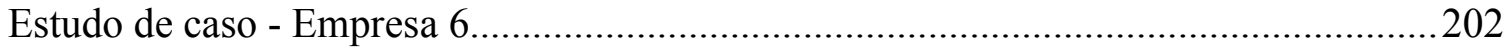

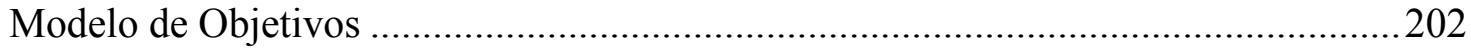

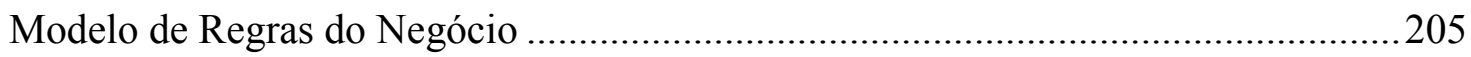

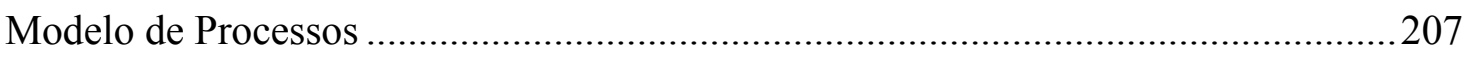

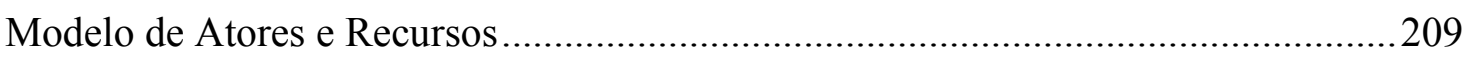

Modelo de Componentes e Requisitos Técnicos ........................................................2211

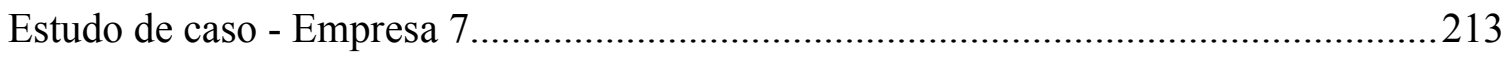


Modelo de Objetivos 213

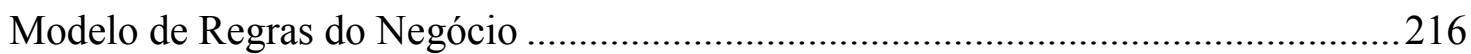

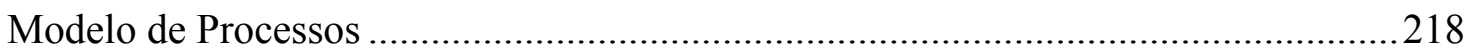

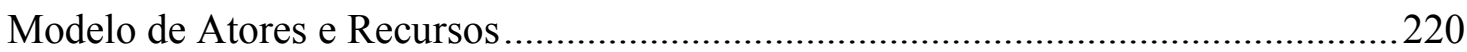

Modelo de Componentes e Requisitos Técnicos ......................................................222

APÊNDICE B - ROTEIRO DE ABORDAGEM PARA ENTREVISTA DE PROFISSIONAIS QUE PARTICIPARAM DO PROCESSO DE IMPLANTAÇÃO DE SISTEMAS APS NAS EMPRESAS DO ESTUDO DE CASOS MÚLTIPLOS ...............224

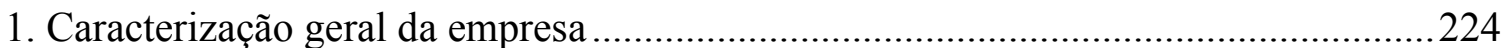

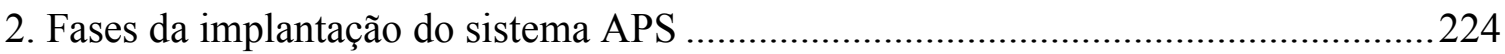

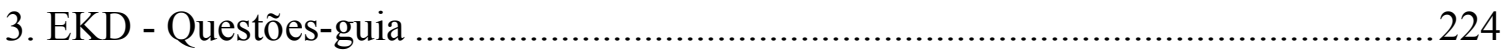

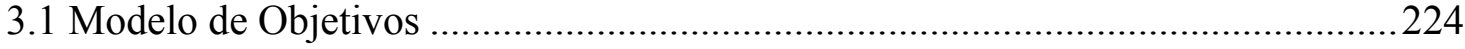

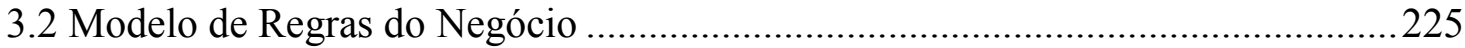

3.3 Modelo de Processos de Negócio .......................................................................225

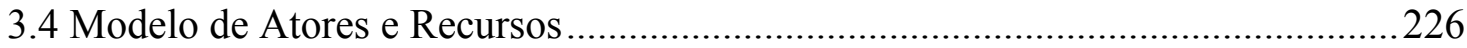

3.5 Modelo de Componentes e Requisitos Técnicos...................................................226

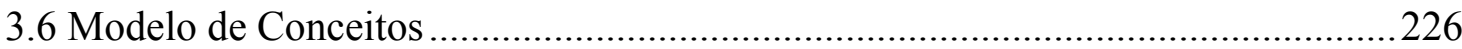

APÊNDICE C - QUESTIONÁRIO ENVIADO A PROFISSIONAIS DAS EMPRESAS ADQUIRENTES, CONSULTORES DE EMPRESAS IMPLANTADORAS DE SISTEMAS APS E ESPECIALISTAS NA ÁREA, PARA VALIDAÇÃO DO MODELO DE REFERÊNCIA DESENVOLVIDO NA PESQUISA .......................................................22 


\section{INTRODUÇÃO}

Com o propósito de manterem-se competitivas, empresas do mundo contemporâneo visam criar uma vantagem competitiva para melhorar seu desempenho. A inovação é uma fonte de vantagem competitiva e cria valor mais alto para os clientes da empresa, os quais estão cada vez mais exigentes (AGERON, LAVASTRE e SPALANZANI, 2013; TSAI, 2009). De acordo com Ebecken (2011), a inovação está no centro do crescimento e desenvolvimento econômico, sendo o resultado de iniciativas de interação entre diferentes atores (ZENG, XIE e TAMC, 2010). A compreensão de como as organizações podem aumentar ou obter inovação é crucial para a sua competitividade e sobrevivência $(\mathrm{HOCH}, 2013)$.

No âmbito interno de uma empresa, para auxílio na obtenção de sucesso no mercado competitivo, os gestores necessitam de sistemas de planejamento e controle da produção eficazes, ágeis e que possuem capacidade de resposta rápida frente aos imprevistos que surgem no cotidiano empresarial. A implantação de sistemas de planejamento e controle da produção pode ser considerada uma inovação organizacional nos sistemas produtivos empresariais, pois segundo Dutra e Erdmann (2007), os mesmos apoiam a construção da estratégia de uma organização, influenciando diretamente a qualidade do bem ou serviço produzido, confiabilidade das informações, aproveitamento dos recursos de produção, cumprimento de prazos, gerenciamento dos insumos, dentre outras atividades.

Os sistemas de planejamento e controle da produção são mecanismos que permitem o planejamento, operação e controle da entrega do produto de uma empresa manufatureira, bem como monitoramento, e, no caso de desvios imprevistos, o reajuste do andamento dos pedidos ou dos planos de produção (WIENDAHL, VON CIEMINSKI e WIENDAHL, 2005). Esses sistemas permitem que a empresa alcance os requisitos de produção com a maior eficiência possível, organizando e disponibilizando os recursos produtivos na quantidade, momento e nível de qualidade adequados (FERNANDES et al., 2007; RODRIGUEZ, COSTA e DO CARMO, 2013).

Conforme afirma Wiendahl, Von Cieminski e Wiendahl (2005), apesar de a teoria e prática de planejamento e controle da produção, bem como a definição de funções-chave adicionais terem progredido desde a década de 1970, grande número de empresas de manufatura 
permanece insatisfeito com o grau de cumprimento de seus objetivos operacionais. De acordo com Giacon e Mesquita (2011), nos atuais sistemas integrados de gestão empresarial, representados pelos sistemas Enterprise Resources Planning (ERP), o módulo de programação detalhada da produção não atende plenamente as necessidades dos usuários. Os sistemas Advanced Planning and Scheduling (APS) surgem como alternativa para resolver problemas mais complexos de planejamento e controle da produção e gestão da cadeia de suprimentos, sendo considerados o estado da arte nessas áreas (BOCCA, RODRIGUES e ARRAES, 2015; BRUN et al., 2006; FRAYRET et al., 2007; GEN, LIN e ZHANG, 2009; PESSOA et al., 2014; SANTA-EULALIA, FRAYRET e D’AMOURS, 2008; STEGER-JENSEN et al., 2011).

Os sistemas APS são um conjunto de aplicações usadas para facilitar três domínios das operações da cadeia de suprimentos: planejamento, programação e execução. Estes sistemas são uma extensão natural dos sistemas Manufacturing Resources Planning (MRP II) e ERP. Enquanto os sistemas APS em si são uma evolução em relação aos seus predecessores, empresas usam a combinação destes sistemas para guiar a colaboração e planejamento da cadeia de suprimentos (SETIA, SAMBAMURTHY e CLOSS, 2008). De acordo com Hvolby e StegerJensen (2010) e Lin et al. (2012), os sistemas APS representam uma abordagem relativamente nova para o planejamento e controle da produção e satisfazem as demandas dos clientes usando a disponibilidade finita de materiais e capacidade de recursos da empresa, levando em conta as restrições no nível empresarial. Materiais e questões de capacidade são considerados simultaneamente; e manufatura, distribuição e questões de transporte são integradas.

O processo de implantação de sistemas APS em uma empresa envolve agentes internos e externos à organização. Os agentes internos são representados pelos profissionais gerenciais e técnicos que constituem a equipe funcional da implantação. Os agentes externos são representados pelos profissionais da empresa desenvolvedora e pelos profissionais da empresa de consultoria que implanta o sistema.

Devido à complexidade da implantação de sistemas de planejamento e controle da produção eles frequentemente falham no propósito de produzir as melhorias substanciais de desempenho que as empresas esperam (WIENDAHL, VON CIEMINSKI e WIENDAHL, 2005). Existem muitas causas para a ocorrência do problema, e como razões para o fracasso podem ser citadas a má gestão do processo de implantação (YUSUF, GUNASEKARAN e ABTHORPE, 2004) e instruções incomuns ou pouco detalhadas para o projeto e implantação dos sistemas (WIENDAHL, VON CIEMINSKI e WIENDAHL, 2005).

A transferência de conhecimento entre os indivíduos que participam de projetos de geração de inovação organizacional e outras atividades realizadas entre duas ou mais empresas 
é primordial para o seu sucesso (JIMÉNEZ-JIMÉNEZ, MARTÍNEZ-COSTA e SANZVALLE, 2014). A cooperação interempresarial pode viabilizar o atendimento de uma série de necessidades das empresas que seriam de difícil satisfação caso as mesmas atuassem isoladamente (AMATO NETO, 2000). Estruturas de rede conectam os vários fluxos de conhecimento existentes em diferentes organizações para facilitar sua troca rápida, representando mecanismos para difusão de inovação por meio da colaboração (PROTOGEROU, CALOGHIROU e SIOKAS, 2013).

Entre os vários tipos de redes de empresas, as redes colaborativas são de particular relevância e têm emergido como um novo e conceituado paradigma para melhorar a competitividade das organizações em um aspecto sustentável nos ambientes cada vez mais dinâmicos (ROMERO, RABELO e MOLINA, 2013). Dentre estas redes, as redes de inovação auto-organizadas representam empresas compostas por grupos auto-organizados de indivíduos altamente motivados que trabalham conjuntamente em direção ao alcance de objetivos comuns, possuem o potencial de combinar e recombinar capacidades de aprendizado sem uma direção gerencial detalhada e centralizada, e são motivadas pela crescente globalização (RYCROFT e $\mathrm{KASH}, 2004)$.

Considerando que na literatura sobre planejamento e controle da produção e sistemas APS existe a necessidade de desenvolver pesquisas sobre implantações bem-sucedidas (HENDRY, HUANG e STEVENSON, 2013; RUDBERG e CEDERBORG, 2011), que muitos processos de implantação de sistemas APS não satisfazem as expectativas iniciais (IVERT, 2012), que a modelagem é um fator essencial para a implantação deste tipo de sistema (ZORYK-SCHALLA, FRANSOO e DE KOK, 2004), que a formação de uma rede de empresas na qual as pessoas participam ativamente do processo de implantação é essencial para o seu sucesso nas indústrias (LIN, HWANG e WANG, 2007), e que deve haver autonomia entre os envolvidos na implantação (IVERT e JONSSON, 2011), identifica-se como lacuna de pesquisa o processo de implantação de sistemas APS sob a perspectiva de redes de inovação autoorganizadas.

O problema proposto na pesquisa é a compreensão do fenômeno de auto-organização no contexto da rede formada entre as empresas participantes do processo de implantação de sistemas APS. Para isso a pesquisa procura responder as seguintes questões:

(1) Quais são os requisitos necessários para a implantação de sistemas APS sinalizados na literatura?

(2) Quais os principais obstáculos para a implantação de sistemas APS? 
(3) Existe algum consenso entre os requisitos para a implantação de sistemas APS e os construtos das redes de inovação auto-organizadas? Se existem, quais são eles?

(4) Analisando esse tipo de implantação sob a perspectiva do recorte analítico de redes de inovação auto-organizadas, quais elementos podem apoiar o processo de implantação?

(5) Quais as vantagens que a propriedade de auto-organização pode apresentar para a implantação de sistemas APS?

\subsection{Objetivos}

Esta dissertação tem como objetivo geral identificar e sistematizar os elementos para disponibilizar um modelo de referência para processos de implantação de sistemas APS sob a perspectiva de redes de inovação auto-organizadas. O recorte analítico de redes de inovação permite verificar as ligações e os relacionamentos entre empresas e entre os departamentos dentro da mesma organização e envolve um ciclo de vida bem definido, compreendendo as etapas de criação, operação, evolução e dissolução.

Como objetivos específicos, a pesquisa visa:

(1) Por meio de estudos de caso conduzidos em sete empresas que implantaram sistemas APS, realizar a modelagem organizacional do estado atual do processo de implantação; visando detectar as principais deficiências deste quando analisado à luz dos elementos e relacionamentos colaborativos necessários para geração de inovação em redes auto-organizadas;

(2) Confrontando os resultados obtidos na modelagem organizacional do processo de implantação no estado atual com as diretrizes apontadas na literatura de redes de inovação auto-organizadas, incorporar os elementos necessários na modelagem organizacional do estado futuro do processo de implantação. A modelagem organizacional do estado futuro representa o modelo de referência desenvolvido na pesquisa.

\subsection{Justificativa}

Os sistemas APS foram desenvolvidos como uma alternativa para resolver problemas complexos de PCP e deficiências dos sistemas anteriores, tais como consideração aos limites de capacidade das empresas e às restrições de disponibilidade de matérias-primas; simulação de diversos cenários de planejamento; fornecimento de lead times flexíveis; ponderação da importância dos produtos, materiais e clientes; integração entre as funções de transporte, 
distribuição e manufatura; e rápida reação a exceções e variabilidade (CHEN, HUANG e LAI, 2009; CHERN e YANG, 2011; DAVID, PIERREVAL e CAUX, 2006; HVOLBY e STEGERJENSEN, 2010).

O processo de implantação de sistemas APS em uma empresa envolve agentes internos e externos à organização. Os agentes internos são representados pelos profissionais do nível gerencial e técnicos que constituem a equipe funcional da implantação da empresa adquirente. Os agentes externos são representados pelos profissionais da empresa que desenvolve e pelos profissionais da empresa de consultoria que implanta o sistema APS.

A configuração formada entre as empresas no processo de implantação pode ser analisada adequadamente sob o recorte analítico de redes de inovação, o qual de acordo com Britto (2002) permite identificar os nós (empresas), ligações (relacionamentos), posições (atividades das empresas), fluxos tangíveis (recursos físicos) e fluxos intangíveis (troca de conhecimento e informações).

As redes de inovação auto-organizadas representam uma vertente do conceito de redes de inovação, e a auto-organização ocorre quando o aprendizado e a criação de novos conhecimentos, fatores-chave para a inovação, conduzem a novos processos e estruturas organizacionais que superam desafios e aproveitam as oportunidades geradas na rede (RYCROFT e KASH, 2004). O objetivo da formação de redes de inovação auto-organizadas no processo de implantação do sistema APS é fomentar o conhecimento da organização entre os atores da rede, o qual mostra quais recursos internos a manufatura deve explorar, como as informações devem fluir, quais atividades devem ser realizadas e como o conhecimento que foi gerado por meio do modelo de referência beneficiará futuros processos de implantação, pois de acordo com Camarinha-Matos e Afsarmanesh (2008) os modelos de referência auxiliam no desenvolvimento mais consistente da área de redes colaborativas por meio de melhor compreensão das entidades envolvidas e seus relacionamentos.

\subsection{Método de pesquisa}

Quanto à natureza, esta pesquisa pode ser classificada como aplicada, pois de acordo com Turrioni e Mello (2012), tem como finalidade gerar conhecimentos para aplicação prática, direcionados para a resolução de problemas específicos, envolvendo verdades e interesses locais.

De acordo com a abordagem, a pesquisa pode ser classificada como qualitativa. A pesquisa qualitativa faz uso de uma série de técnicas de interpretação que visam descrever, traduzir, analisar e apresentar o entendimento das variáveis de determinado fenômeno. Para 
desenvolvê-la no âmbito da engenharia de produção, o pesquisador deve visitar a organização objeto de estudo fazendo observações e coletando evidências dos fatos estudados (MARTINS, 2012).

Com base nos seus objetivos, a pesquisa é classificada como exploratória. De acordo com Gil (2010) as pesquisas exploratórias visam proporcionar maior familiaridade com o problema, a fim de torná-lo mais explícito ou constituir hipóteses, e na visão de Miguel e Sousa (2012) deve ser utilizada quando o tema não se encontra bem formulado ou é emergente. Neste estudo a pesquisa retratará a implantação de um sistema APS em empresas, pois de acordo com Giacon e Mesquita (2011), Hvolby e Steger-Jensen (2010) e Lin et al. (2012), a utilização de sistemas APS em organizações é relativamente nova.

Com relação aos procedimentos técnicos utilizados para a realização da pesquisa, a mesma será concebida através de estudos de caso, alicerçados por pesquisas bibliográficas.

O estudo de caso é um estudo de natureza empírica que investiga um determinado fenômeno (geralmente contemporâneo) dentro de um contexto real de vida, quando as fronteiras entre o fenômeno e o contexto em que ele se insere não são claramente definidas, buscando reunir através de diferentes técnicas de pesquisa o maior número possível de informações minuciosas, tendo como objetivo apreender a totalidade de uma situação e descrever a complexidade de um caso concreto (MIGUEL, 2007). Voss, Tsikriktsis e Frohlich (2002) afirmam que o gerenciamento da produção, de maneira geral, é uma área muito dinâmica, onde novas práticas emergem continuamente, e que o estudo de caso é o modo propício de se estudar essas práticas emergentes, além de ser um instrumento propício para o desenvolvimento de novas teorias em gerenciamento da produção.

Foram realizados estudos de caso em sete empresas. A escolha para tal quantidade de empresas foi baseada nas recomendações de Yin (2010), que afirma que os benefícios e conclusões analíticos de se ter dois ou mais casos são substanciais; Miguel (2007), que argumenta que o uso de estudo de casos múltiplos proporciona maior grau de generalização dos resultados e confiabilidade dos mesmos; e Eisenhardt (1989), que aconselha uma quantidade de quatro a dez casos para a realização de estudo de casos múltiplos.

Para o desenvolvimento dos estudos de caso mapeou-se e explorou-se a literatura existente sobre o tema, planejou-se os estudos de caso, realizou-se visitas técnicas nas empresas objeto de estudo, aplicou-se roteiros de entrevistas aos responsáveis pela administração e coletou-se e analisou-se os dados obtidos.

O Quadro 1 apresenta as características das empresas pesquisadas. 
Quadro 1 - Descrição das empresas participantes dos estudos de caso

\begin{tabular}{|c|c|c|c|c|c|}
\hline Empresa & Localização & Porte & Origem & Ramo & $\begin{array}{l}\text { Número de } \\
\text { funcionários }\end{array}$ \\
\hline 1 & $\begin{array}{l}\text { Guarulhos - } \\
\text { SP }\end{array}$ & Médio & Brasileira & $\begin{array}{l}\text { Fabricação de diversos } \\
\text { segmentos de fios e } \\
\text { cabos elétricos. }\end{array}$ & $\begin{array}{l}\text { 66. Possui apenas uma } \\
\text { unidade industrial. }\end{array}$ \\
\hline 2 & $\begin{array}{l}\text { Araraquara - } \\
\text { SP }\end{array}$ & Médio & $\begin{array}{l}\text { Americana. Possui } \\
\text { unidades industriais } \\
\text { nas Américas, } \\
\text { África, Ásia e } \\
\text { Europa. }\end{array}$ & $\begin{array}{l}\text { Fabricação de máquinas } \\
\text { e equipamentos para a } \\
\text { indústria alimentícia. }\end{array}$ & $\begin{array}{l}270 \text { no Brasil, sendo } 200 \\
\text { em Araraquara e } 70 \mathrm{em} \\
\text { São Paulo. }\end{array}$ \\
\hline 3 & $\begin{array}{l}\text { Porto } \\
\text { Ferreira - SP }\end{array}$ & Médio & Brasileira & $\begin{array}{l}\text { Fabricação de controles } \\
\text { elétricos e eletrônicos. }\end{array}$ & $\begin{array}{l}1350 . \quad \text { Possui uma } \\
\text { unidade produtiva e uma } \\
\text { de montagem em Porto } \\
\text { Ferreira. }\end{array}$ \\
\hline 4 & $\begin{array}{l}\text { Jaguariúna - } \\
\text { SP }\end{array}$ & Médio & Brasileira & $\begin{array}{lr}\text { Fabricação } & \text { de } \\
\text { embalagens } & \text { flexíveis } \\
\text { industriais } & \text { e } \\
\text { comerciais, banners, } \\
\text { bobinas de forração, } \\
\text { envoltórios e serigrafia } \\
\text { para diversos usos e } \\
\text { mercados. }\end{array}$ & $\begin{array}{l}210, \text { sendo } 140 \text { em } \\
\text { Jaguariúna e } 70 \text { em Ouro } \\
\text { Fino - MG. }\end{array}$ \\
\hline 5 & Itu - SP & Grande & $\begin{array}{lr}\text { Japonesa. } & \text { Possui } \\
270 \quad \text { unidades } \\
\text { industriais } & \\
\text { localizadas nas } \\
\text { Américas, Ásia, } \\
\text { Europa e Oceania. }\end{array}$ & Fabricação de bebidas & $\begin{array}{l}11 \text { mil no Brasil, sendo } 2 \\
\text { mil em Itu e o restante em } \\
\text { outras } 12 \text { unidades } \\
\text { industriais localizadas } \\
\text { em diversos estados do } \\
\text { país. }\end{array}$ \\
\hline 6 & Vitória - ES & Grande & $\begin{array}{l}\text { Francesa. Possui } \\
\text { unidades industriais } \\
\text { na França, Brasil, } \\
\text { Malásia, Estados } \\
\text { Unidos, Inglaterra e } \\
\text { Angola; bem como } \\
\text { escritórios } \\
\text { espalhados em mais } \\
\text { de } 40 \text { países. }\end{array}$ & $\begin{array}{l}\text { Fabricação de tubos } \\
\text { flexíveis e tubos } \\
\text { umbilicais para a } \\
\text { indústria petrolífera. }\end{array}$ & $\begin{array}{l}2.300 \text { no Brasil, sendo } 2 \\
\text { mil em sua unidade } \\
\text { industrial localizada em } \\
\text { Vitória. }\end{array}$ \\
\hline 7 & Campos - RJ & Grande & $\begin{array}{l}\text { Francesa. Possui } \\
\text { unidades industriais } \\
\text { na França, Brasil, } \\
\text { Malásia, Estados } \\
\text { Unidos, Inglaterra e } \\
\text { Angola; bem como } \\
\text { escritórios } \\
\text { espalhados em mais } \\
\text { de } 40 \text { países. }\end{array}$ & $\begin{array}{l}\text { Fabricação de tubos } \\
\text { flexíveis e tubos } \\
\text { umbilicais para a } \\
\text { indústria petrolífera. }\end{array}$ & $\begin{array}{l}2.300 \text { no Brasil, sendo } \\
300 \text { em sua unidade } \\
\text { industrial localizada em } \\
\text { Campos. }\end{array}$ \\
\hline
\end{tabular}

Uma pesquisa que envolve estudo de casos múltiplos geralmente combina métodos de coleta de dados tais como entrevistas, questionários, análise de documentos e observações (EISENHARDT, 1989). Neste estudo, para a realização da coleta de dados nas organizações, foram realizadas entrevistas semiestruturadas por meio de um roteiro. Tal roteiro contempla perguntas que permitiram a modelagem organizacional do processo de implantação do sistema APS em cada uma das empresas e a identificação da existência ou inexistência de características 
de redes de inovação auto-organizadas no processo. Foram entrevistados membros que participaram ativamente durante o processo de implantação do sistema, a fim de evitar distorções nas informações.

Em pesquisas que envolvem estudos de casos múltiplos o protocolo de investigação representa um componente essencial. Yin (2010) afirma que o protocolo de investigação ajuda a aumentar a confiabilidade de uma pesquisa, pois fornece os procedimentos padronizados seguidos pelo pesquisador, os quais podem ser repetidos por outros pesquisadores em outras situações similares. O protocolo do estudo de caso deve conter alguns elementos essenciais tais como a definição da questão de pesquisa, identificação das fontes de informação e definição das questões-guia para orientação do pesquisador na condução da coleta de dados. O protocolo do estudo de caso desta pesquisa é apresentado no Quadro 2.

Quadro 2 - Protocolo do estudo de caso

\begin{tabular}{|c|c|}
\hline Tipo de pesquisa & Exploratória. \\
\hline Questões de pesquisa & $\begin{array}{l}\text { Quais os principais obstáculos para a implantação de sistemas APS? } \\
\text { Analisando esse tipo de implantação sob a perspectiva do recorte analítico de } \\
\text { redes de inovação auto-organizadas, quais elementos podem apoiar o processo } \\
\text { de implantação? } \\
\text { Quais as vantagens que a propriedade de auto-organização pode apresentar } \\
\text { para a implantação de sistemas APS? }\end{array}$ \\
\hline Unidade de análise & Empresas que implantaram sistemas APS. \\
\hline Número de casos & Sete. \\
\hline Local & $\begin{array}{l}\text { Empresas localizadas nos estados de São Paulo, Rio de Janeiro e Espírito } \\
\text { Santo. }\end{array}$ \\
\hline Limite de tempo & De maio de 2014 a fevereiro de 2015. \\
\hline $\begin{array}{l}\text { Validade interna do } \\
\text { construto }\end{array}$ & $\begin{array}{l}\text { Revisão bibliográfica sobre o tema explorado, roteiro e procedimento de } \\
\text { abordagem do responsável da empresa e da consultoria do projeto de } \\
\text { implantação com o propósito de abordar o processo de implantação nas } \\
\text { empresas objeto de estudo e realizar a modelagem do processo com a } \\
\text { metodologia EKD. }\end{array}$ \\
\hline $\begin{array}{l}\text { Validade externa do } \\
\text { construto }\end{array}$ & $\begin{array}{l}\text { Padronização dos resultados dos estudos de casos múltiplos, visando } \\
\text { identificar, sistematizar e posteriormente fornecer os elementos para um } \\
\text { modelo de referência para futuras implantações de sistemas APS. }\end{array}$ \\
\hline Confiabilidade & $\begin{array}{l}\text { Utilização de protocolo do estudo de caso e replicação do estudo em sete } \\
\text { organizações para a comprovação das proposições levantadas nas questões de } \\
\text { pesquisa. }\end{array}$ \\
\hline
\end{tabular}

Berio e Vernadat (2001) afirmam que é bastante reconhecido que qualquer abordagem ou arquitetura de modelagem empresarial/organizacional deve levar em consideração os tipos fundamentais de fluxos, as visões da modelagem e os níveis da modelagem. Os fluxos fundamentais compreendem os fluxos de materiais (objetos físicos tais como produtos, ferramentas, matérias-primas, etc.), fluxos de informação (documentos, informações, arquivos de computador, chamadas telefônicas) e os fluxos de decisão e controle (relacionados à sequência de tarefas). As visões da modelagem são relacionadas à visão da função (funcionalidade e comportamento da empresa), visão da informação (objetos a serem 
processados ou usados), visão dos recursos e visão da organização (entidades e seus relacionamentos, bem como demais aspectos envolvidos). Em relação aos níveis da modelagem, deve-se ter atenção à definição dos requisitos, especificação do projeto e descrição da implantação.

De acordo com Bubenko, Persson e Stirna (2001), uma maneira de coordenar o processo de mudança associado à implantação de uma inovação é utilizar um modelo de referência que permita visualizar os estados presente e futuro, os recursos necessários para a transição, os caminhos disponíveis e as justificativas necessárias para a tomada de decisão e obtenção do apoio da alta gerência. Camarinha-Matos e Afsarmanesh (2007) afirmam que no contexto de um sistema complexo como uma rede colaborativa, a modelagem é fundamental para compreender, gerenciar, simular ou prever o comportamento da rede; e, para Camarinha-Matos e Afsarmanesh (2008), além de dirigirem a implementação das redes, os modelos de referência podem servir para avaliá-las e simulá-las.

Um modelo de referência é um modelo que pode ser usado para o desenvolvimento ou avaliação de um modelo particular e que pode ser desenvolvido a partir de situações do mundo real (melhores práticas) ou de teorias (VERNADAT, 1996); e seu principal objetivo consiste em agilizar o projeto de modelos empresariais e habilitar as organizações a aplicarem o conhecimento (MATOOK e INDULSKA, 2009; REINHARTZ-BERGER, SOFFER e STURM, 2010). Para que um modelo de referência seja desenvolvido devem ser seguidas as fases de planejamento, construção, validação, teste e documentação do modelo (AHLEMANN e GASTL, 2007).

Para validar o modelo de referência para processos de implantação de sistemas APS, proposto e desenvolvido nesta pesquisa, foram consultados especialistas na área, e entrevistados os profissionais das sete empresas objeto do estudo de caso que participaram do processo de implantação e profissionais de duas empresas implantadoras destes sistemas, para que os mesmos verifiquem sua consistência. Para testar o modelo, o mesmo será disponibilizado a duas empresas implantadoras de sistemas APS para que ele possa ser replicado em futuros processos de implantação e posteriormente documentado.

Com o propósito de apoiar a implantação do sistema APS sob o recorte analítico de redes de inovação auto-organizadas, os elementos para o modelo de referência serão analisados por meio da metodologia Enterprise Knowledge Development (EKD), pois a mesma constituise em uma abordagem sistemática para analisar, entender, desenvolver e documentar uma empresa e seus componentes por meio da modelagem empresarial (ROLLAND, NURCAN e GROSZ, 2000), contempla os aspectos destacados por Berio e Vernadat (2001), e o resultado 
final é um conjunto de modelos conceituais que examinam a empresa e seus requisitos sob uma série de perspectivas inter-relacionadas (BUBENKO, PERSSON e STIRNA, 2001). Pádua, Cazarini e Inamasu (2004) realizaram um trabalho sobre a captura dos requisitos organizacionais no desenvolvimento de sistemas de informação a partir das técnicas e metodologias de modelagem organizacional, no qual avaliaram as principais técnicas. Como resultado, concluiu-se que o EKD satisfaz 23 dos 28 requisitos técnicos abordados, ao passo que as demais metodologias não chegam a cumprir 13 requisitos.

De acordo com Bubenko, Persson e Stirna (2001), a modelagem organizacional facilita o desenvolvimento do negócio por meio da melhor compreensão geral de determinado domínio e a representação e o compartilhamento do conhecimento disperso pela organização, tendo como resultados a melhoria da comunicação entre os agentes envolvidos e maior apoio às mudanças operacionais e estratégicas pelo maior comprometimento das pessoas. Pádua (2012) afirma que o processo de modelagem organizacional deve trazer respostas a questões tais como por que, o que, quem, qual, quando, onde e como; valendo-se de diversas técnicas de modelagem existentes na literatura.

Utilizar a metodologia EKD para modelagem organizacional fornece uma forma sistemática de documentar e analisar a organização e seus componentes (NURCAN, 1998; ROLLAND, NURCAN e GROSZ, 2000). Para Kirikova (2000), a metodologia EKD é destinada a responder as questões: o que, como, onde, quem, quando e por que, e essas entidades podem ser combinadas de diversas formas para produzir o sistema de informação de interesse da organização.

De acordo com Kavakli et al. (2006), a modelagem do conhecimento organizacional com o EKD é alcançada por meio da modelagem das metas organizacionais (as quais expressam os objetivos intencionais que controlam e governam sua operação), dos processos físicos (os quais colaborativamente operacionalizam as metas organizacionais) e dos sistemas de software (os quais apoiam os processos anteriores).

Para Pádua, Cazarini e Inamasu (2004), a utilização do EKD visa fornecer uma descrição clara e não ambígua de como a organização funciona atualmente, quais são os requisitos e as razões para a mudança, quais alternativas deveriam ser criadas para encontrar esses requisitos e quais são os critérios e argumentos para avaliação dessas alternativas. O EKD é composto por 6 modelos, o Modelo de Objetivos, o Modelo de Regras do Negócio, o Modelo de Processos, o Modelo de Atores e Recursos, o Modelo de Componentes e Requisitos Técnicos e o Modelo de Conceitos (BUBENKO, BRASH e STIRNA, 1998). 
O Modelo de Objetivos descreve a visão da estratégia do negócio, focando nas metas e nos problemas que precisam ser resolvidos para atingir tais metas; esclarece questões sobre os rumos que a empresa deve seguir; define quais objetivos são prioritários; determina quais as relações entre os objetivos e quais os problemas ocultos na realização das metas (BUBENKO, BRASH e STIRNA, 1998).

O Modelo de Regras do Negócio é usado para determinar as regras que controlam a organização no sentido de definir e restringir quais ações podem ser executadas no negócio para atingir as metas e deve ser consistente com o Modelo de Objetivos (BUBENKO, BRASH e STIRNA, 1998; NURCAN e ROLLAND, 1999).

O Modelo de Processos define as atividades organizacionais e a forma pela qual os processos interagem e manipulam informações e materiais, descreve qual a interação entre os processos do negócio, esclarece as entradas e saídas do processo (BAJEC e KRISPER, 2005; BUBENKO, BRASH e STIRNA, 1998), e permite melhorias tais como benchmarking, reengenharia de processos de negócio, gestão por processos e melhoria contínua de processos (GREGORIADES e SUTCLIFFE, 2008; NEUBAUER, 2009).

O Modelo de Atores e Recursos visa descrever como atores são inter-relacionados e os objetivos da organização (NURCAN e ROLLAND, 1999); esclarece a quem é designado determinado processo ou tarefa, qual a responsabilidade de cada ator e por quais recursos ele é responsável (BUBENKO, BRASH e STIRNA, 1998).

O Modelo de Componentes e Requisitos Técnicos permite explicitar o potencial da Tecnologia da Informação para melhoria do processo de negócio, estabelecendo um vocabulário comum que compreende todo o ambiente empresarial; e também permite determinar as estruturas e propriedades que deverão compor um futuro sistema de informação (NEVES e GUERRINI, 2010; ROLLAND, NURCAN e GROSZ, 2000).

O Modelo de Conceitos é usado para definir coisas e fenômenos apresentados nos outros modelos, conceitos e aplicações de dados no nível conceitual (BUBENKO, BRASH e STIRNA, 1998); e também é usado para definir as entidades, atributos e relacionamentos da empresa (NURCAN e ROLLAND, 1999), visando evitar incompreensões e interpretações diferentes dos termos usados no negócio (BAJEC e KRISPER, 2005).

A estrutura da metodologia EKD é apresentada na Figura 1. 


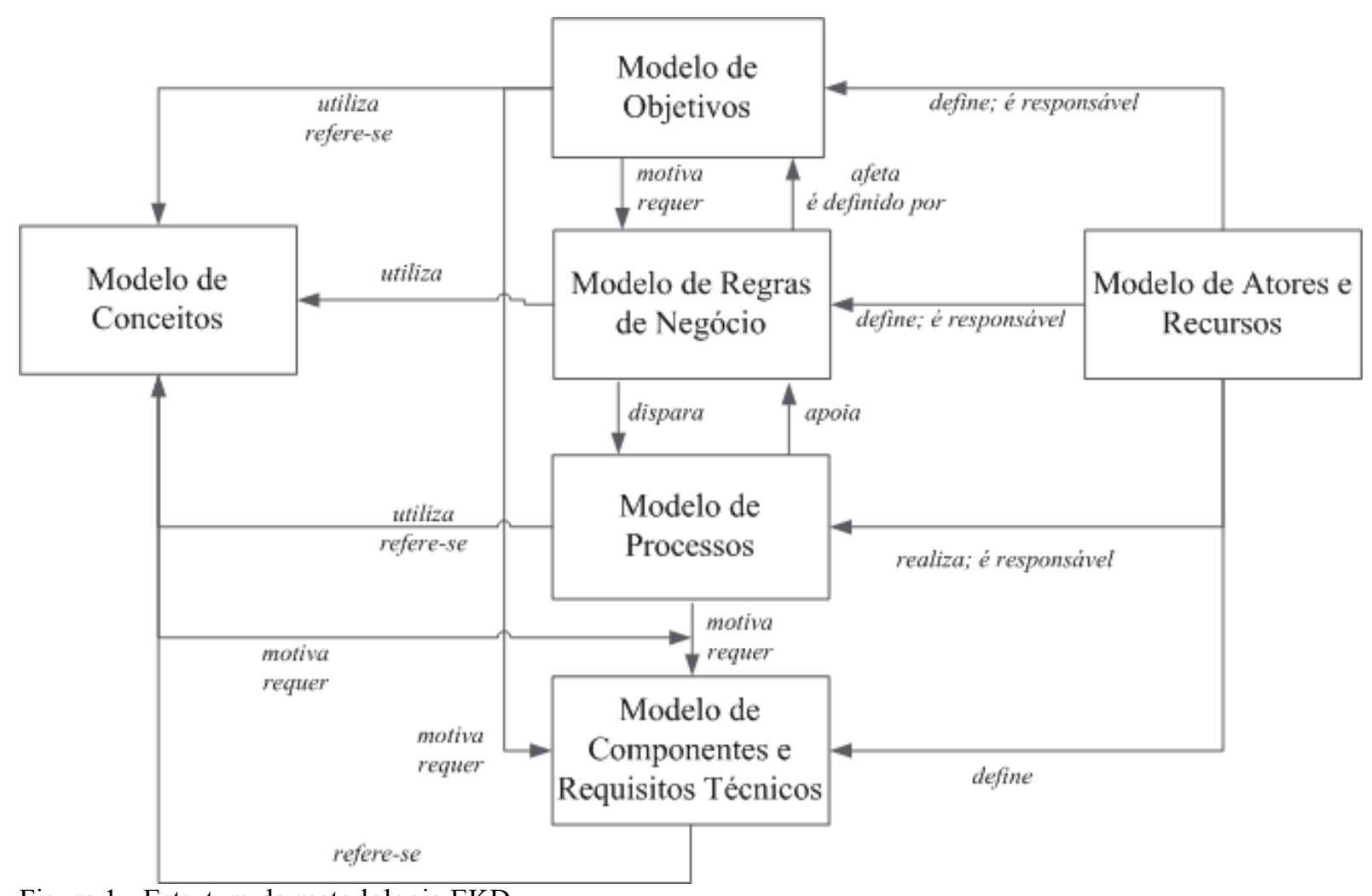

Figura 1 - Estrutura da metodologia EKD.

Fonte: Bubenko, Brash e Stirna (1998).

Bubenko, Brash e Stirna (1998) descrevem as ligações entre os submodelos do EKD como:

- Ligações entre o Modelo de Objetivos e o Modelo de Atores e Recursos podem motivar ou requerer a introdução de novos atores particulares e também podem descrever quais componentes do Modelo de Atores e Recursos são responsáveis por alcançar um objetivo particular ou defini-lo;

- Ligações entre o Modelo de Atores e Recursos e o Modelo de Regras do Negócio descrevem como componentes diferentes do Modelo de Atores e Recursos são relacionados a regras do negócio do Modelo de Processos do Negócio. Exemplos de nomes de ligações são define, é responsável por;

- Ligações entre o Modelo de Objetivos e o Modelo de Conceitos são usadas para descrever componentes do Modelo de Objetivos, que referenciam entidades do Modelo de Conceitos;

- Ligações entre o Modelo de Objetivos e o Modelo de Processos do Negócio relacionam objetivos do Modelo de Objetivos a processos do Modelo de Processos de Negócios com o relacionamento motiva; 
- Ligações entre o Modelo de Objetivos e o Modelo de Regras do Negócio descrevem como componentes diversos do Modelo de Objetivos são implementados em termos de regras do negócio no Modelo de Regras do Negócio;

- Ligações entre o Modelo de Regras do Negócio e o Modelo de Processos do Negócio descrevem como processos do Modelo de Processos do Negócio são disparados pelas regras do negócio do Modelo de Regras do Negócio;

- Ligações entre o Modelo de Processos do Negócio e o Modelo de Conceitos estão entre o conjunto de informações do Modelo de Processos do Negócio e os componentes do Modelo de Conceitos;

- Ligações entre o Modelo de Componentes e Requisitos Técnicos e outros componentes do modelo podem ser mais complexas do que os relacionamentos binários normais. O Modelo de Processos do Negócio motiva os objetivos e os requisitos do sistema de informação.

Nurcan e Rolland (2003) desenvolveram uma adaptação da metodologia EKD, denominada de Enterprise Knowledge Development - Change Management Method (EKDCMM). O EKD-CMM fornece uma abordagem sistemática para desenvolver e documentar o conhecimento empresarial e ajudar as organizações a desenvolver modelos para implementar mudanças, englobando questões relacionadas ao funcionamento atual da organização, quais as necessidades de mudança e quais as razões para tais mudanças, quais alternativas podem ser previstas com o propósito de atingirem essas necessidades e quais critérios validam essas alternativas (NURCAN e ROLLAND, 2003). Esta adaptação encontra-se esquematizada na Figura 2.

Figura 2 - Modelo EKD-CMM.

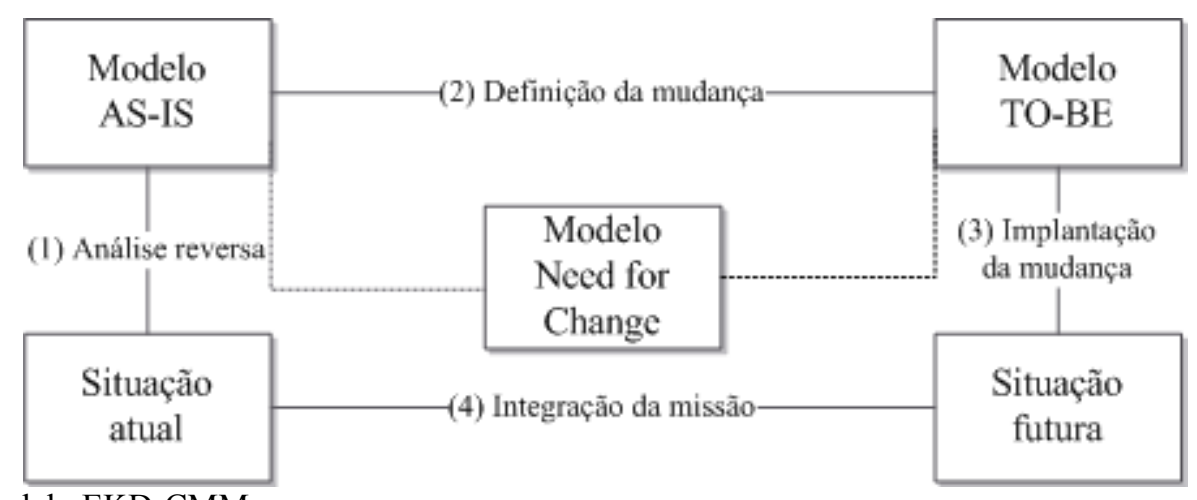

Fonte: Adaptado de Nurcan e Rolland (2003).

A análise reversa apresenta um modelo com o retrato atual da organização, denominado de Modelo $A s$ - $I s$; a definição da mudança apresenta um modelo que visa identificar as mudanças necessárias na organização, denominado de Modelo Need for Change; a implantação das 
mudanças apresenta um modelo que visa retratar a situação futura da empresa após as mudanças terem sido implantadas, sendo denominado de Modelo To-Be; e a integração da missão considera o contexto existente durante a implantação das mudanças (NURCAN e ROLLAND, 2003).

\subsection{Estrutura da dissertação}

A estrutura da dissertação é composta pelos seguintes capítulos:

(1) Introdução, o qual apresenta o contexto no qual está inserida a pesquisa, a justificativa, os objetivos e o método de pesquisa;

(2) Revisão bibliográfica sobre os sistemas APS e seu processo de implantação, redes de inovação auto-organizadas e a contextualização do processo de implantação de sistemas APS na perspectiva de redes de inovação auto-organizadas;

(3) Modelagem organizacional do estado atual (Modelo $A s-I s$ ) do processo de implantação de sistemas APS, com base em dados coletados em sete empresas; e a análise das necessidades de mudanças (Need for Change) do processo, ao incorporar os elementos e relacionamentos colaborativos de redes de inovação autoorganizadas representados na literatura;

(4) Modelagem organizacional do estado futuro (Modelo $\mathrm{To}-\mathrm{Be}$ ) do processo de implantação de sistemas APS, desenvolvido por meio da contextualização do Modelo As-Is com o Modelo Need for Change. Com a construção do Modelo To-Be foi gerado um modelo de referência para implantação de sistemas APS na perspectiva de redes de inovação auto-organizadas, após a realização de todas as etapas sinalizadas por Ahlemann e Gastl (2007);

(5) Considerações finais acerca da pesquisa, onde são apresentadas as conclusões e limitações do trabalho e o foco da contribuição da pesquisa para a temática de sistemas APS e redes de inovação auto-organizadas;

(6) Apêndices, onde são apresentadas as modelagens organizacionais do processo de implantação do sistema APS em cada uma das empresas que foram objeto de análise no estudo de casos múltiplos; o roteiro de abordagem para entrevista de profissionais que participaram do processo de implantação nas empresas; e o questionário enviado a profissionais das empresas adquirentes, consultores de empresas implantadoras do sistema e especialistas na área, para validar o modelo de referência desenvolvido na pesquisa. 


\section{REVISÃO BIBLIOGRÁFICA}

No contexto do desenvolvimento de sistemas de planejamento e controle da produção, nos anos 1990 foram lançados os sistemas APS, os quais representam uma inovação em relação aos seus predecessores, pois consideram os limites de capacidade das empresas e a disponibilidade de matérias-primas, simulam diversos cenários de planejamento, fornecem lead times flexíveis e ponderam a importância dos produtos, materiais e clientes. A implantação de novos sistemas de planejamento e controle da produção tais como sistemas APS representa uma inovação organizacional na empresa, pois são métodos organizacionais que visam a melhoria de desempenho. Por meio de uma revisão da literatura, verifica-se que as implantações de sistemas APS são muito limitadas às características particulares de determinada empresa, as instruções para o processo de implantação não são suficientemente detalhadas e o conhecimento gerado pode não ser adequado a outros processos de implantação. Tendo em vista que a formação de redes de inovação auto-organizadas pode vir a ser um mecanismo adequado para conduzir processos de geração de inovação em empresas, este capítulo do trabalho propõe analisar o processo de implantação de sistemas APS sob a perspectiva de redes de inovação autoorganizadas, visando identificar e sistematizar requisitos apresentados pela literatura. Os resultados da revisão bibliográfica evidenciam que por meio da interseção entre os requisitos necessários para a implantação de sistemas APS e os construtos das redes de inovação autoorganizadas é possível analisar os processos sob a perspectiva de redes; pois esta configuração proporciona, aos atores envolvidos no projeto, benefícios que não são tangíveis no processo tradicional.

\subsection{Introdução}

As últimas décadas têm evidenciado que novas tecnologias estão transformando produtos, processos, mercados e indústrias, revolucionando o ambiente empresarial (DUTRA e ERDMANN, 2007). De acordo com Quetti, Pigni e Clerici (2012), as crescentes complexidade e turbulência dos mercados notoriamente estão formatando um ambiente de negócios altamente competitivo. Em vista disso, as empresas necessitam de constantes inovações, especialmente nas áreas onde estão suas principais competências (NOTEBOOM, 
2004). A capacidade de geração de inovação por parte de uma empresa permite-lhe responder de forma eficaz às exigências de seu ambiente de negócios; e, de acordo com Zeng, Xie e Tamc (2010) é o resultado de iniciativas de interação entre diversos atores. Segundo Bonazzi e Zilber (2014), a busca por inovação remete à criação de valor por meio de alianças estratégicas, aproximação com os clientes e adoção de modelos de negócios diferenciados. A capacidade de geração de inovação por parte das empresas é um dos fatores mais relevantes para que as mesmas se mantenham competitivas no mercado global (ESCHENBÄCHER, SEIFERT e THOBEN, 2011).

Atualmente, as organizações estão imersas em um ambiente de constantes mudanças e intensa competitividade. Neste contexto, a função produção desempenha um importante papel nos objetivos gerais das organizações, pois apoia, implementa e orienta as estratégias organizacionais (DUTRA e ERDMANN, 2007). O Planejamento e Controle da Produção (PCP) desempenha um importante papel em ambientes competitivos, respondendo imediatamente ao mais alto nível de desempenho do serviço, melhor utilização de recursos e menos perdas de materiais (AL-TAHAT e BATAINEH, 2012), visando alinhar o suprimento de uma empresa industrial com a demanda por seus produtos, ao mesmo tempo em que maximiza seu desempenho competitivo em termos de qualidade, custos, velocidade de entrega , flexibilidade com relação às mudanças imprevistas nos status de pedidos e pontualidade nas entregas (MUKHOPADHYAY, DWIVEDY e KUMAR, 1998; PEDROSO E CORRÊA, 1996). O PCP visa alinhar o suprimento de uma empresa industrial com a demanda por seus produtos, ao mesmo tempo em que maximiza o desempenho competitivo da empresa em termos de qualidade, custos e entregas (MUKHOPADHYAY, DWIVEDY e KUMAR, 1998).

De acordo com Mesquita e Castro (2008), a eficácia do PCP implica no alcance dos objetivos de redução dos lead times produtivos, custos de estoque (de matérias-primas, materiais em processo e produtos acabados) e de produção (ociosidade, horas extras, etc.); cumprimento de prazos; e agilidade de resposta diante de alterações em demandas. O PCP apoia a construção da estratégia de uma organização, pois esta função é integrada com todas as áreas funcionais da empresa (MACCARTHY e FERNANDES, 2000), e sua eventual deficiência é projetada imediatamente na qualidade dos bens ou serviços fornecidos, perda de informações confiáveis, pior utilização dos recursos de produção, não cumprimento dos prazos de entregas, má gestão dos suprimentos, entre outros aspectos (DUTRA e ERDMANN, 2007). Neste contexto, o PCP tem sido cada vez mais requerido para contribuir com o aumento da competitividade industrial (FERNANDES e SANTORO, 2005). 
Os sistemas de PCP são os mecanismos centrais de controle corporativo que relacionam a produção e o desempenho logístico de uma empresa com as demandas dos clientes. Eles têm como principais tarefas planejar, iniciar e monitorar a entrega de produtos de empresas industriais por meio da definição das quantidades, tempo e alocação de pedidos, coordenando os recursos necessários para sua conclusão (AZEVEDO e SOUSA, 2000), e, em casos de desvios imprevistos, ajustar o progresso de pedidos ou planos de produção (WIENDAHL, VON CIEMINSKI e WIENDAHL, 2005). Os sistemas de PCP têm um importante papel na busca contínua por melhorias no uso dos recursos de produção (RODRIGUEZ, COSTA e DO CARMO, 2013) e visam planejar e controlar a produção de modo que a empresa alcance os requisitos de produção com a mais alta eficiência possível (FERNANDES et al., 2007). De acordo com Marques e Guerrini (2012), os sistemas de PCP são estabelecidos para alinhar as estratégias da organização e o ambiente de manufatura.

A implantação de sistemas de PCP representa uma inovação organizacional nas empresas, pois os mesmos são métodos organizacionais relacionados a práticas de negócios, organização do local de trabalho e relações externas (OECD, 2005). Embora o PCP seja um tópico relativamente difundido, Hendry, Huang e Stevenson (2013) e Tenhiälä (2011) sinalizaram a necessidade de desenvolver pesquisas sobre implantações bem-sucedidas de métodos apropriados para a área, afirmando que existe uma significativa lacuna na literatura para descrever uma implantação bem-sucedida junto com a compreensão do processo de implantação em si.

A aquisição e implantação eficazes de sistemas de PCP podem ser problemáticas e, para muitas empresas, os benefícios esperados podem não ser obtidos. O potencial para fabricantes ganharem vantagem competitiva com os sistemas é fortemente dependente de sua capacidade de implantá-los de forma bem-sucedida.

Embora a teoria e prática de PCP, bem como a definição de funções-chave adicionais terem progredido desde os anos 1970, um grande número de empresas industriais permanece insatisfeito com o grau de preenchimento de seus objetivos (WIENDAHL, VON CIEMINSKI e WIENDAHL, 2005). O nível de funções requeridas e a limitada duração de alguns sistemas implantados força muitas empresas a reprojetá-los ou substituí-los por outros mais sofisticados e modernos (LUCZAK, NICOLAI e KEES, 1998; MOSCOSO, WÄFLER e WINDISCHER, 1999). Muitas empresas têm reconhecido que os sistemas comumente usados, representados pelos sistemas Manufacturing Resources Planning (MRP II) e Enterprise Resources Planning (ERP) não apoiam o planejamento na questão de considerar apropriadamente as capacidades de recursos durante o processo de planejamento (KRISTIANTO, AJMAL e HELO, 2011). 
Ichimura, Aoki e Song (1994) afirmam que nos anos 1990, devido à diversificação das necessidades dos usuários, rápida inovação tecnológica e internacionalização, muitas empresas precisaram desenvolver um sistema de produção eficaz, com pequenos lotes e curtos lead times de produção. No contexto destes contínuos desenvolvimentos, nos anos 1990 foram lançados os sistemas Advanced Planning and Scheduling (APS), desenvolvidos como uma alternativa para resolver problemas complexos de PCP e deficiências dos sistemas anteriores, tais como consideração aos limites de capacidade das empresas e às restrições de disponibilidade de matérias-primas, simulação de diversos cenários de planejamento, lead times flexíveis, ponderação da importância dos produtos, materiais e clientes (CHEN, HUANG e LAI, 2009; DAVID, PIERREVAL e CAUX, 2006; HVOLBY e STEGER-JENSEN, 2010). Os sistemas APS foram desenvolvidos como uma alternativa para resolver problemas mais complexos de PCP e Gestão da Cadeia de Suprimentos (GCS), e são considerados o estado da arte nessas áreas (BOCCA, RODRIGUES e ARRAES, 2015; BRUN et al., 2006; FRAYRET et al., 2007; GEN, LIN e ZHANG, 2009; PESSOA et al., 2014; SANTA-EULALIA, FRAYRET e D’AMOURS, 2008; STEGER-JENSEN et al., 2011).

Na última década, processos de implantação de sistemas APS têm ocorrido, no entanto, de acordo com uma busca sistemática realizada nas bases de dados SCIELO, SCOPUS e Web of Science, verificou-se que a literatura sobre os aspectos de implantação é limitada, apresentando poucas pesquisas, tais como Brandenburg e Tölle (2009); Garcia-Sabater, Maheut e Garcia-Sabater (2012); Giacon e Mesquita (2011); Ivert e Jonsson (2010); Ivert e Jonsson (2011); Lin, Hwang e Wang (2007); Lupeikiene et al. (2014), Rudberg e Cederborg (2011); Setia, Sambamurthy e Closs (2008); Wiers (2002); Wiers (2009); Zhong et al. (2013); ZorykSchalla, Fransoo e De Kok (2004). Entretanto, nos processos de implantação apresentados nestas pesquisas, foram analisados aspectos relacionados a características particulares de uma determinada empresa ou unidades da empresa e o conhecimento gerado nestes processos pode não ser adequado a outros similares.

Os benefícios de um sistema novo são fortemente dependentes da capacidade de implantá-lo de maneira bem sucedida. Lin, Hwang e Wang (2007) afirmam que para serem relevantes em configurações industriais os sistemas APS devem ser implantados como um componente de uma ampla rede de pessoas que participam ativamente no processo. Ivert e Jonsson (2011) afirmam que estudos mais detalhados sobre gestão do processo de implantação de sistemas APS com foco na dependência entre a empresa implantadora e adquirente do software e questões culturais envolvidas no processo representam uma importante lacuna de pesquisa a ser explorada. 
O processo de gestão da aquisição e incorporação de tecnologia e mudanças organizacionais é uma atividade complexa que envolve diferentes atores, mercados, recursos, processos organizacionais e atitudes relacionadas à cooperação (KARLSSON, TAYLOR e TAYLOR, 2010). Diversas empresas colaboram em uma rede para compartilhar dados e informações, sistemas, riscos e benefícios (PARUNG e BITITCI, 2008). Estruturas de rede conectam os vários fluxos de conhecimento existentes em diferentes organizações para facilitar sua troca rápida, representando mecanismos para difusão de inovação por meio da colaboração (PROTOGEROU, CALOGHIROU e SIOKAS, 2013). De acordo com Serrano e Fischer (2007), a capacidade de colaboração é especialmente importante para a geração de inovação, pois cria novos produtos ou serviços, melhorando processos, introduzindo novos métodos e atividades que necessitam da interação de muitos indivíduos. Uma melhor compreensão de como estruturas de redes colaborativas interorganizacionais estimulam a geração de inovação é importante para compreender o que orienta a inovação e como promovê-la (UPHAM, ROSENKOPF e UNGAR, 2010). O papel de redes na disseminação de informações e ideias (fornecendo acesso a recursos, capacidades e mercados; e permitindo a combinação de diferentes tipos de conhecimento) tem se tornado de importância crucial para a inovação e competitividade econômica (CASSI et al., 2008). O estabelecimento de redes de inovação é estimulado pela crescente complexidade tecnológica de produtos e processos, necessidade de uma resposta mais rápida ao mercado, natureza multidisciplinar de novas tecnologias, e necessidade de mitigar custos e riscos (AMARA e LANDRY, 2005; PATRAKOSOL e OLSON, 2007; THORGREN, WINCENT e ÖRTQVIST, 2009; TSAI, 2009).

Entre os vários tipos de redes, as redes colaborativas são de particular relevância. Redes colaborativas representam entidades organizacionais, infraestrutura, processos de negócio, recursos e relacionamentos que apoiam um esforço compartilhado para fornecer alguns benefícios coletivos, sejam eles produtos, programas e serviços (LAI, TAM e CHAN, 2012). Estas redes manifestam-se em uma ampla variedade de formas, incluindo organizações virtuais, empresas virtuais, cadeias de suprimento dinâmicas, comunidades profissionais virtuais, ciência eletrônica, laboratórios virtuais colaborativos, entre outras, que são largamente autônomas, geograficamente distribuídas e heterogêneas em termos de seu ambiente operacional, cultura, capital social e metas, mas que colaboram para alcançar objetivos comuns ou compatíveis tais como a produção de bens, geração de inovação e resolução de problemas (CAMARINHA-MATOS e AFSARMANESH, 2005; PICARD e RABELO, 2010). As redes colaborativas representam mecanismos eficazes para alcançar competitividade nas condições turbulentas do mercado atual, compreendendo várias entidades com diversas competências 
(complementares) e interesses simbióticos (CHEIKHROUHOU, POULY e MADINABEITIA, 2013; CHITUC e NOF, 2007). De acordo com Abreu, Macedo e Camarinha-Matos (2009), a emergência de várias formas de redes colaborativas é orientada pelas mudanças bruscas que ocorrem no ambiente empresarial nos últimos anos, combinadas com o papel facilitador dos avanços na tecnologia de informação e comunicação. Redes colaborativas têm emergido como um novo e conceitualizado paradigma para melhorar a competitividade das organizações em um aspecto sustentável nos ambientes cada vez mais globalizados e dinâmicos (ROMERO, RABELO e MOLINA, 2013). De acordo com Camarinha-Matos e Afsarmanesh (2003), as principais vantagens que estas redes oferecem são agilidade, papéis complementares, competitividade, otimização de recursos e inovação. Dentre estas redes, as redes de inovação auto-organizadas representam grupos auto-organizados de indivíduos altamente motivados que trabalham juntos em direção ao alcance de objetivos comuns, possuem o potencial de combinar e recombinar capacidades de aprendizado sem uma direção gerencial detalhada e centralizada, e são motivadas pela crescente globalização (RYCROFT e KASH, 2004).

Considerando que a implantação de sistemas APS representa uma inovação organizacional na área de PCP das empresas (SETIA, SAMBAMURTHY e CLOSS, 2008), pois são considerados o estado da arte nesta área (BOCCA, RODRIGUES e ARRAES, 2015; BRUN et al., 2006; FRAYRET et al., 2007; GEN, LIN e ZHANG, 2009; PESSOA et al., 2014; SANTA-EULALIA, FRAYRET e D'AMOURS, 2008; STEGER-JENSEN et al., 2011); que os aspectos de implantação destes sistemas são largamente ignorados pela academia (RUDBERG e CEDERBORG, 2011); que estudos mais detalhados sobre gestão do processo de implantação de sistemas APS com foco na dependência entre a empresa implantadora e adquirente do software e questões culturais envolvidas no processo representam uma importante lacuna de pesquisa a ser explorada (IVERT e JONSSON, 2011); que o estabelecimento de parcerias por meio de redes de empresas representa uma maneira eficaz para geração de inovação em ambientes empresariais (PICARD e RABELO, 2010); e que o fenômeno de auto-organização é cada vez mais presente em redes de inovação (RYCROFT e KASH, 2004); esta pesquisa propõe identificar e sistematizar os requisitos para a implantação de sistemas APS na perspectiva de redes de inovação auto-organizadas. Para isso, na pesquisa procura-se responder as seguintes questões:

(1) Quais são os requisitos necessários para a implantação de sistemas APS sinalizados na literatura?

(2) Existe algum consenso entre os requisitos para a implantação de sistemas APS e os construtos das redes de inovação auto-organizadas? Se existem, quais são eles? 


\subsection{Procedimentos Metodológicos}

Esta pesquisa foi desenvolvida por meio de uma revisão da literatura, buscando o embasamento da lacuna de pesquisa em referências teóricas. É uma pesquisa de abordagem qualitativa, fornecendo maior proximidade entre os pesquisadores e os problemas estudados; bem como possui caráter exploratório, fornecendo correlações entre os objetos de estudo para colaborar com futuras pesquisas.

Para encontrar as fontes bibliográficas apropriadas para o desenvolvimento deste trabalho, foram consultadas, dentre as diversas áreas do conhecimento, as seguintes bases de dados: SCIELO, SCOPUS e Web of Science. Essas bases de dados foram selecionadas em função de seu amplo acesso e impacto na comunidade acadêmica internacional. A busca bibliográfica foi finalizada em fevereiro de 2015, e foram selecionados apenas artigos publicados em periódicos indexados, pois são considerados como as pesquisas de mais alto nível científico (CARNEVALLI e MIGUEL, 2008; NGAI et al., 2008). As buscas foram feitas usando as palavras-chave Advanced Planning and Scheduling, Advanced Planning System*1, Collaborative Network*, Collaborative Networked Organisation* (CNO), Collaborative Networked Organization* (CNO), Competitiveness, Implementation, Innovation, Innovation Network*, Production Planning and Control, Reference Model*, Self-organisation, Selforganization, Self-organising Innovation Network*, Self-organizing Innovation Network*, Selforganising Network* e Self-organizing Network*. Algumas informações extraídas de livros e de artigos publicados em congressos também foram utilizadas, pois apesar de essas fontes terem menor relevância, certamente elas podem ter dados importantes (BORTOLLOSSI e SAMPAIO, 2012).

Utilizando os termos Advanced Planning and Scheduling e Advanced Planning System* foi possível obter acesso a 94 artigos relacionados a sistemas APS, redigidos nas línguas inglesa e/ou portuguesa. Após a realização da pesquisa bibliográfica, procedeu-se à leitura e análise dos artigos encontrados, visando proporcionar uma revisão compreensiva acerca de sistemas APS e uma revisão da literatura sobre processos de implantação. Para analisar as publicações de interesse aos objetivos primordiais desta pesquisa, após aplicação de todos as seleções, foi verificado que dos 94 artigos supracitados, apenas 13 são relacionados a processos de implantação de sistemas APS.

\footnotetext{
${ }^{1} \mathrm{O}$ asterisco $(*)$ foi usado nas buscas bibliográficas para considerar tanto o singular, quanto o plural do substantivo na língua inglesa.
} 
Para a compreensão mais embasada de redes de inovação auto-organizadas e suas características, como foram encontrados apenas 2 artigos relacionados a este termo específico na língua inglesa (Self-organising Innovation Network* e Self-organizing Innovation Network*), a revisão foi complementada com a literatura sobre redes colaborativas (Collaborative Network*), sendo analisados 14 artigos; organizações ligadas em redes colaborativas (Collaborative Networked Organisation* e Collaborative Networked Organization*), sendo analisado 1 artigo; redes auto-organizadas (Self-organising Network* e Self-organizing Network*) sendo analisados 3 artigos; auto-organização em empresas (Selforganisation, Self-organization), sendo analisados 5 artigos; e redes de inovação (Innovation Network* $^{*}$, sendo analisados 11 artigos.

Foram utilizados 8 artigos e informações provenientes de 2 livros para a compreensão mais embasada da estrutura e processo de desenvolvimento de modelos de referência.

\subsection{Revisão da literatura}

Nesta seção é apresentada uma revisão compreensiva sobre sistemas APS e redes de inovação auto-organizadas; e também uma revisão da literatura sobre processos de implantação de sistemas APS. Após a realização das referidas revisão compreensiva e sistemática da literatura, os principais requisitos necessários para a implantação de sistemas APS e os construtos das redes de inovação auto-organizadas aderentes foram sistematizados para justificar a análise na perspectiva levantada.

\subsubsection{Sistemas APS: caracterização e delimitação}

De acordo com Arsovski, Arsovski e Mirovic (2009) e Steger-Jensen et al. (2011), os sistemas de PCP computadorizados foram gradualmente desenvolvidos nos últimos 30 anos, desde os Material Requirements Planning (MRP), Manufacturing Resources Planning (MRP II), Enterprise Resources Planning (ERP) e Advanced Planning and Scheduling (APS). Esses contínuos desenvolvimentos forneceram substanciais melhorias na área de PCP das empresas (NYHUIS e WIENDAHL, 2004).

De acordo com Arsovski, Arsovski e Mirovic (2009) um sistema APS pode ser definido como um software computacional que possui a habilidade de rápida e simultaneamente planejar e programar a demanda dos clientes, considerando as restrições de capacidade e materiais; bem como de reconfigurar planos e programas sincronizados em um tempo de ciclo muito curto. De acordo com Giacon e Mesquita (2011), Hvolby e Steger-Jensen (2010), Ivert (2012), Jonsson, Kjellsdotter e Rudberg (2007), Kallestrup et al. (2014), Kung e Chern (2009), Neumann, 
Schwindt e Trautmann (2002), Peng, Lu e Chen (2014), Rudberg e Thulin (2009) e SantaEulalia et al. (2011a), embora sejam desenvolvidos independentemente por diversas empresas vendedoras de softwares de PCP tais como AspenTech, Asprova, JDA (que adquiriu as concorrentes i2 Technologies, Manugistics e RedPrairie), Lawson (adquirida pela Infor), Linter, Manhattan Associates, Oracle (que adquiriu as concorrentes PeopleSoft, a qual por sua vez havia adquirido a concorrente J.D. Edwards), Ortems, PPI Multitask, Preactor (adquirida pela Siemens AG), Quintic, SAP ${ }^{\circledR}$ e Taylor Group, os sistemas APS exibem uma arquitetura comum baseada nos princípios de planejamento hierárquico (CAPUTO, GALLO e GUIZZI, 2009), são baseados em um modelo do sistema de produção a ser planejado ou programado, contêm funcionalidades de apoio e automatização para gerar planos ou programas, e fornecem interface gráfica ao usuário para apresentar os planos ou programas e possibilitar a manipulação destes (WIERS, 2009).

Os sistemas APS constituem um conjunto de aplicações usado para gerenciar três domínios das operações da cadeia de suprimentos: planejamento, programação e execução (SETIA, SAMBAMURTHY e CLOSS, 2008). Os sistemas APS são considerados como uma abordagem eficaz para gerenciar um plano otimizado de produção, permitindo às empresas a redução de custos industriais por meio da fabricação dos produtos certos nos tempos certos, considerando uma ampla gama de restrições, incluindo disponibilidade de matérias-primas, capacidade dos operadores e máquinas, nível de serviço, nível seguro de estoques, vendas e demanda, lead times e capacidades dos fornecedores, com consequente aumento da satisfação dos clientes (CHEN, HUANG e LAI, 2009; KRUSE, 2000; LIN et al., 2012; STEGERJENSEN e SVENSSON, 2004).

De acordo com Günther e Meyr (2009), os sistemas APS representam aplicações bemsucedidas da gestão da cadeia de suprimentos, e são relacionados a atividades de apoio e tomada de decisão nos níveis estratégico, tático e operacional. Pelos sistemas APS empresas podem otimizar suas cadeias de suprimento, reduzindo custos e níveis de inventário, melhorando margens de produto e aumentando lucros industriais (LEE, JEONG e MOON, 2002). Os sistemas APS são baseados nos princípios de planejamento hierárquico e fazem uso extensivo de abordagens de solução como programação matemática e meta-heurísticas, simulando diferentes cenários de planejamento antes do lançamento de um plano (HVOLBY e STEGERJENSEN, 2010; STADTLER, 2005). Além do mais, eles podem ser configurados para dar alertas às unidades organizacionais apropriadas quando algo incomum ocorre (WEZEL, DONK e GAALMAN, 2006), permitindo ao usuário a modificação das informações de planejamento para a obtenção de um novo cenário (PESSOA et al., 2014). 
Muitas empresas têm reconhecido que os sistemas de PCP comumente usados, representados pelo MRP II e ERP não apoiam o planejamento no sentido de considerar apropriadamente as capacidades de recursos durante o processo (KRISTIANTO, AJMAL e HELO, 2011). Enquanto os sistemas APS são um avanço quando comparados a seus predecessores, empresas usam uma combinação de sistemas para guiar a colaboração e o planejamento da cadeia de suprimentos (SETIA, SAMBAMURTHY e CLOSS, 2008). Eles não foram desenvolvidos para superar os sistemas predecessores, mas para trabalhar colaborativamente com eles, visando gerar resultados excelentes para toda a cadeia de suprimentos (BOCCA, RODRIGUES e ARRAES, 2015).

Os sistemas APS foram desenvolvidos sob a combinação do MRP com o Capacity Requirement Planning (CRP) para permitir a criação de planos adequados de produção e atividades de planejamento para a cadeia de suprimentos como um todo, fornecendo procedimentos e metodologias que são capazes de reagir rapidamente a exceções e variabilidade (CHERN e YANG, 2011; KUNG e CHERN, 2009; ÖZTÜRK e ORNEK, 2014). Ao contrário dos sistemas MRP, os planos de produção do APS são otimizados dentro das fronteiras de restrições de materiais e capacidade, e seus lead times são predeterminados (PENG, LU e CHEN, 2014).

Usando informações de vendas e inventário extraídas dos sistemas MRP II, o APS pode produzir um plano de produção em poucos minutos ou mesmo em segundos. Sistemas APS podem validar os planos gerados pelo MRP II, ou podem realizar o planejamento, eliminando a necessidade por tais módulos, sendo o uso do MRP II direcionado à aquisição de informações do produto, pedido e inventário (CHAMBERS, 1996).

O APS não substitui, mas sim complementa os sistemas ERP (BOCCA, RODRIGUES e ARRAES, 2015; LUPEIKIENE, 2014; STEGER-JENSEN et al., 2011). De acordo com OuYang e Hon (2008), os sistemas APS desenvolvem uma programação de produção apropriada para apoiar pedidos potenciais, enquanto que o ERP é usado para integrar a execução de pedidos relacionados a processos de negócio e manusear as atividades e transações básicas, tais como pedidos do cliente, contabilidade, etc. (STEGER-JENSEN et al., 2011). Um sistema APS extrai informações da base de dados do ERP por meio da interface de entrada com o usuário, realiza seus cálculos e envia os planos resultantes para a distribuição e execução. Em uma empresa o APS envia ao ERP as necessidades de partes fabricadas e/ou compradas e conclusões de pedidos projetados. O ERP envia ao APS as demandas [pedidos dos clientes, previsões, Master Production Scheduling (MPS), pedidos de estoque de segurança e pedidos de fabricação], status de trabalho em processo e trabalhos relançados, trabalhos programados, parâmetros executados, 
calendários, alterações, feriados, e informações sobre itens, listas de materiais, operações, recursos e grupos de recursos (CHEN et al., 2013; RUDBERG e CEDERBORG, 2011).

O Quadro 3 apresenta alguns dos principais benefícios obtidos com a implantação de sistemas APS.

Quadro 3 - Principais benefícios proporcionados pelos sistemas APS

\begin{tabular}{|c|c|}
\hline Benefícios & Autores \\
\hline Gestão mais eficiente das cadeias de suprimento & $\begin{array}{l}\text { Boulaksil, Fransoo e Halm (2009); Brandenburg e } \\
\text { Tölle (2009); David, Pierreval e Caux (2006); Dayou, } \\
\text { Pu e Ji (2009); Garcia-Sabater, Maheut e Garcia- } \\
\text { Sabater (2012); Ivert (2012); Jonsson, Kjellsdotter e } \\
\text { Rudberg (2007); Kristianto, Ajmal e Helo (2011); } \\
\text { Kung e Chern (2009); Lupeikiene et al. (2014); } \\
\text { Neumann, Schwindt e Trautmann (2002); Öztürk e } \\
\text { Ornek (2014); Rudberg e Thulin (2009); Santa-Eulalia } \\
\text { et al. (2011b); Setia, Sambamurthy e Closs (2008); } \\
\text { Shamsuzzoha, Kyllönen e Helo (2009); Zoryk- } \\
\text { Schalla, Fransoo e De Kok (2004) }\end{array}$ \\
\hline Redução de custos e do lead time industrial & $\begin{array}{l}\text { Chen et al. (2013); Chen, Huang e Lai (2009); Dayou, } \\
\text { Pu e Ji (2009); Gen, Ling e Zhang (2009); Ivert (2012); } \\
\text { Lee, Jeong e Moon (2002); Pessoa et al. (2014) }\end{array}$ \\
\hline $\begin{array}{l}\text { Integração com os sistemas ERP, outros módulos de } \\
\text { planejamento ou sistemas de controle de processo }\end{array}$ & $\begin{array}{l}\text { Arsovski, Arsovski e Mirovic (2009); Bruzzone et al. } \\
\text { (2012); Caputo, Gallo e Guizzi (2009); Chambers } \\
\text { (1996); Chen et al. (2013); Garcia-Sabater, Maheut e } \\
\text { Garcia-Sabater (2012); Giacon e Mesquita (2011); } \\
\text { Hvolby e Steger-Jensen (2010); Ivert (2012); Ivert e } \\
\text { Jonsson (2014); Jonsson, Kjellsdotter e Rudberg } \\
\text { (2007); Kuroda, Shin e Zinnohara (2002); McKay e } \\
\text { Wiers (2003); Ou-Yang e Hon (2008); Öztürk e Ornek } \\
\text { (2014); Rudberg e Thulin (2009); Santa-Eulalia, } \\
\text { Frayret e D'Amours (2008); Setia, Sambamurthy e } \\
\text { Closs (2008); Shamsuzzoha, Kyllönen e Helo (2009); } \\
\text { Steger-Jensen et al. (2011); Tonelli et al. (2013); } \\
\text { Wiers (2002); Wiers (2009) }\end{array}$ \\
\hline Grande velocidade de processamento & $\begin{array}{l}\text { Chambers (1996); David, Pierreval e Caux (2006); } \\
\text { Giacon e Mesquita (2011) }\end{array}$ \\
\hline Criação de planos de produção adequados & Chern e Yang (2011) \\
\hline $\begin{array}{l}\text { Consideração às restrições de capacidade e sequências } \\
\text { de operação }\end{array}$ & $\begin{array}{l}\text { Arsovski, Arsovski e Mirovic (2009); Chambers } \\
\text { (1996); Chen e Ji (2007); David, Pierreval e Caux } \\
\text { (2006); Gen e Lin (2014); Hvolby e Steger-Jensen } \\
\text { (2010); Ivert e Jonsson (2014); Kristianto, Ajmal e } \\
\text { Helo (2011); Lupeikiene et al. (2014); Neumann, } \\
\text { Schwindt e Trautmann (2002); Peng, Lu e Chen } \\
\text { (2014); Rudberg e Thulin (2009); Setia, Sambamurthy } \\
\text { e Closs (2008); Shamsuzzoha, Kyllönen e Helo } \\
\text { (2009); Steger-Jensen et al. (2011); Zhong et al. } \\
\text { (2013) }\end{array}$ \\
\hline Aumento dos lucros operacionais & $\begin{array}{l}\text { Arsovski, Arsovski e Mirovic (2009); Chen et al. } \\
\text { (2013); David, Pierreval e Caux (2006); Gen, Lin e } \\
\text { Zhang (2009); Lee, Jeong e Moon (2002); Pessoa et } \\
\text { al. (2014); Rudberg e Thulin (2009); Shamsuzzoha, } \\
\text { Kyllönen e Helo (2009) }\end{array}$ \\
\hline Melhoria nas margens de produtos & $\begin{array}{l}\text { Chen, Huang e Lai (2009); Lee, Jeong e Moon (2002); } \\
\text { Pessoa et al. (2014) }\end{array}$ \\
\hline
\end{tabular}


Quadro 3 - Principais benefícios proporcionados pelos sistemas APS

\begin{tabular}{|c|c|}
\hline Benefícios & Autores \\
\hline Redução nos níveis de inventário & $\begin{array}{l}\text { Chen, Huang e Lai (2009); Gen, Ling e Zhang (2009); } \\
\text { Ivert (2012); Lee, Jeong e Moon (2002); Pessoa et al. } \\
\text { (2014); Rudberg e Thulin (2009); Villegas e Smith } \\
\text { (2006) }\end{array}$ \\
\hline Rápida reação a exceções e variabilidades & $\begin{array}{l}\text { David, Pierreval e Caux (2006); Ivert (2012); Ivert e } \\
\text { Jonsson (2010); Kung e Chern (2009) }\end{array}$ \\
\hline Aumento da satisfação dos clientes & $\begin{array}{l}\text { David, Pierreval e Caux (2006); Dayou, Pu e Ji (2009); } \\
\text { Setia, Sambamurthy e Closs (2008); Steger-Jensen e } \\
\text { Svensson (2004) }\end{array}$ \\
\hline $\begin{array}{l}\text { Apoio aos processos previsão de futuras demandas, } \\
\text { preparo de plano preliminar de entrega, preparo de } \\
\text { plano de produção preliminar, ajuste e configuração de } \\
\text { plano de entrega e de produção do Sales \& Operations } \\
\text { Planning (S\&OP) }\end{array}$ & $\begin{array}{l}\text { David, Pierreval e Caux (2006); Ivert e Jonsson } \\
\text { (2010); Ivert e Jonsson (2014) }\end{array}$ \\
\hline $\begin{array}{l}\text { Melhor e mais frequente comunicação entre várias } \\
\text { funções dentro da empresa }\end{array}$ & $\begin{array}{l}\text { Ivert e Jonsson (2014); Kristianto, Ajmal e Helo } \\
\text { (2011); Lupeikiene et al. (2014); Rudberg e Thulin } \\
\text { (2009) }\end{array}$ \\
\hline Reconfiguração de processos & Setia, Sambamurthy e Closs (2008) \\
\hline Reprogramação de trabalhos & Setia, Sambamurthy e Closs (2008) \\
\hline $\begin{array}{l}\text { Avaliação da lucratividade de diferentes alternativas } \\
\text { de cumprimento dos pedidos dos clientes }\end{array}$ & $\begin{array}{l}\text { Lupeikiene et al. (2014); Quante, Meyr e Fleischmann } \\
\text { (2009) }\end{array}$ \\
\hline $\begin{array}{l}\text { Possibilidades para representação gráfica dos } \\
\text { programas de produção resultantes }\end{array}$ & Brandenburg e Tölle (2009); Ivert e Jonsson (2014) \\
\hline $\begin{array}{l}\text { Modificação manual dos programas de produção } \\
\text { existentes }\end{array}$ & $\begin{array}{l}\text { David, Pierreval e Caux (2006); Brandenburg e Tölle } \\
\text { (2009) }\end{array}$ \\
\hline $\begin{array}{l}\text { Sofisticada representação gráfica } \\
\text { detalhados de programacão }\end{array}$ & Rudberg e Thulin (2009); Wiers (2002) \\
\hline Redução no tempo de resposta ao cliente & $\begin{array}{l}\text { Arsovski, Arsovski e Mirovic (2009); Ivert (2012); } \\
\text { Setia, Sambamurthy e Closs (2008); Shamsuzzoha, } \\
\text { Kyllönen e Helo (2009) }\end{array}$ \\
\hline Melhor apoio à tomada de decisão & Ivert e Jonsson (2010); Meixell e Wu (2005) \\
\hline $\begin{array}{l}\text { Mais rápida atualização e maior precisão das } \\
\text { informações }\end{array}$ & Ivert e Jonsson (2010) \\
\hline
\end{tabular}

Os principais módulos constituintes dos sistemas APS podem visualizados na Figura 3.

Suprimentos Produção $>$ Distribuição


Os sistemas APS oferecem funções que são responsáveis por atividades nos níveis de gestão estratégica (longo prazo), tática (médio prazo) e operacional (curto prazo). O nível estratégico permite a definição das capacidades totais das unidades de produção da cadeia de suprimentos; o nível tático possibilita a implantação dos objetivos estratégicos definidos pela alta administração no plano empresarial, definindo as atividades que devem ser realizadas para alcançar as metas globais; e o nível operacional lida com problemas de PCP em um curto prazo (GENIN, THOMAS e LAMOURI, 2007).

O planejamento estratégico da rede de suprimentos determina a estrutura da cadeia de suprimentos no horizonte de planejamento, incluindo localizações de fábricas e centros de distribuição, escolhe os parceiros certos, e considera um horizonte de planejamento de longo prazo de até dez anos (GIACON e MESQUITA, 2011; KUNG e CHERN, 2009).

Dentro do horizonte de planejamento de médio prazo, o planejamento da produção e vendas visa o uso eficiente das capacidades da empresa e a realização das demandas previstas no horizonte de planejamento de médio prazo, planejando simultaneamente as funções de produção, compras e distribuição (STADTLER, 2005). A gestão da demanda equilibra necessidades dos clientes com as capacidades da cadeia de suprimentos, usando técnicas estatísticas de previsão (CROXTON et al., 2002; KUNG e CHERN, 2009).

O MRP realiza a explosão de necessidades de materiais por meio de informações do MPS, gerando pedidos de montagem, fabricação e compra, visando atender a demanda final de produtos (OMAR e BENNELL, 2009). O MPS define a quantidade de itens finais a ser concluída em cada semana do horizonte de planejamento de curto prazo, atualizando periodicamente os planos após coletar e reconhecer as informações mais recentes (OMAR e BENNELL, 2009).

A programação detalhada da produção é gerada levando em conta a disponibilidade de capacidade e materiais, de acordo com as diretrizes do MPS (GIACON e MESQUITA, 2011). O planejamento da distribuição representa uma das mais importantes atividades na GCS e considera a disponibilidade de estoques e transportes para gerar a programação de entregas (SAFAEI et al., 2010). A programação do transporte considera fatores de curto prazo tais como rota ou disponibilidade de veículos (GIACON e MESQUITA, 2011). O Available-To-Promise (ATP) visa fornecer as solicitações específicas de clientes na data de entrega prometida, considerando a disponibilidade de produtos demandados (JUNG, 2012).

De acordo com Zhong et al. (2013), os benefícios de um sistema novo tal como o APS são fortemente dependentes da capacidade de implantá-lo de maneira bem-sucedida. Na 
próxima subseção é apresentada uma revisão sistemática da literatura sobre processos de implantação de sistemas APS.

\subsubsection{Implantação de sistemas APS: revisão sistemática da literatura}

Brandenburg e Tölle (2009), Garcia-Sabater, Maheut e Garcia-Sabater (2012), Giacon e Mesquita (2011), Ivert e Jonsson (2010), Ivert e Jonsson (2011), Lin, Hwang e Wang (2007), Lupeikiene et al. (2014), Rudberg e Cederborg (2011), Setia, Sambamurthy e Closs (2008), Wiers (2002), Wiers (2009), Zhong et al. (2013) e Zoryk-Schalla, Fransoo e De Kok (2004) realizaram pesquisas para analisar os processos de implantação dos sistemas APS em empresas e seus impactos no chão de fábrica, nos processos produtivos e na gestão da cadeia de suprimentos; os principais obstáculos para a implantação bem-sucedida do sistema; sua integração com outros sistemas de planejamento; e a influência de fatores humanos, organizacionais e tecnológicos no processo de implantação.

\subsection{Integração entre o APS e outros sistemas de planejamento}

Wiers (2002) descreve a implantação de sistemas de informação para apoio às funções de planejamento e programação da produção em duas unidades de uma empresa processadora de aço, analisando a integração entre os sistemas ERP e APS. O sistema ERP foi implantado na empresa para auxiliar a gestão de pedidos, balanceamento das vendas e operações, planejamento da produção, monitoramento financeiro e gestão do produto. Como o ERP não apoia adequadamente as funções de planejamento e controle, as funções de planejamento mestre, programação da produção e sequenciamento do APS foram implantadas. A representação gráfica sofisticada dos problemas detalhados de programação oferecida pelo APS auxiliou fortemente a tomada de decisão para sua implantação. De acordo com os autores, os sistemas APS são operados por poucos funcionários, ao contrário do ERP, já que este abrange diversas áreas da empresa. Os autores afirmam que todas as atividades de planejamento devem ser executadas pelo APS, enquanto que o ERP deve fazer com que estas informações sejam amplamente disponíveis na empresa.

Brandenburg e Tölle (2009) analisaram um problema real de programação em uma empresa química. A busca pelo alcance dos objetivos da gestão da cadeia de suprimentos na empresa resultou em problemas complexos de planejamento, e para manusear essa complexidade, os sistemas APS foram implantados e reforçados por algoritmos de otimização. Os principais usuários do sistema obtiveram redução no trabalho gasto para o planejamento de rotinas e foco mais forte em exceções de planejamento. O APS forneceu um conjunto de 
algoritmos padronizados para a construção e otimização do programa, possibilidades para representação gráfica dos programas de produção resultantes e rápido acesso a informações adicionais dos elementos do programa. Outra forte característica do APS na empresa é sua integração com o ERP e outros módulos de planejamento ou sistemas de controle de processos, o que também foi apontado por Wiers (2002). O APS permitiu que o usuário-chave obtivesse informação sobre os elementos e níveis de inventário de um programa otimizado ou modificasse-o por meio de simples ações.

Ivert e Jonsson (2010) exploraram os principais benefícios que podem ser alcançados usando os sistemas APS no processo de Sales \& Operations Planning (S\&OP), ou planejamento das vendas e operações. Os sistemas APS normalmente incluem demanda, fornecimento e/ou módulos específicos de S\&OP com a funcionalidade necessária para apoiar o processo. $\mathrm{O}$ estudo foi realizado em uma empresa do ramo químico, que tem uma longa e ampla experiência no uso de sistemas APS para apoio à atividades de S\&OP. O sistema APS foi implantado para apoiar a coordenação de fluxos materiais e manter-se sintonizado com as subotimizações em um ambiente caracterizado por tarefas complexas de planejamento. Os módulos de vendas, planejamento da demanda e planejamento mestre de diversos locais dos sistemas APS foram implantados como uma ferramenta de apoio ao processo de planejamento do S\&OP. Como Wiers (2009), Ivert e Jonsson (2010) afirmam que a aceitação do sistema pelos funcionários é um fator de grande importância para o seu sucesso. De acordo com os autores os principais benefícios alcançados com essa integração foram melhor apoio à tomada de decisão, disponibilização de informações mais atualizadas e precisas, identificação e análise de eventos futuros inesperados, eficiência do planejamento, economia de custos e efeitos de aprendizado.

Garcia-Sabater, Maheut e Garcia-Sabater (2012) apresentaram um esquema de planejamento de operações baseado em modelos de programação matemática [especialmente Mixed-Integer Linear Programming (MILP), ou programação linear integrada mista] integrados em um APS habilitado pela web, desenvolvido para e integrado em uma montadora de máquinas que fornece a indústria automotiva. De acordo com os autores, o primeiro estágio para a implantação de sistemas APS é compreender como eles processam as informações para criar planos. O processo de implantação do sistema incluiu aprendizado sobre o melhor aspecto para introduzir custos, atividades planejadas, limites críticos e outras características aparentemente menores. As melhorias mais importantes na empresa após a implantação do sistema foram o manuseamento da complexidade do processo de planejamento operacional no nível de detalhamento do cliente e nível de detalhamento amplo considerando os setups 
dependentes de sequências nas linhas de produção, fornecimento de materiais e outras questões de planejamento, melhor balanceamento do inventário, redução nos níveis de estoque, entre outros.

Zhong et al. (2013) propuseram um sistema APS acoplado ao método de RadioFrequency IDentification (RFID), ou identificação por radiofrequência, e baseado em tempo real para alcançar um universal e ultimamente significativo APS, o RAPShell.

O RFID carecia de um modo colaborativo em termos de procedimentos de tomada de decisão e sistemas de informação correspondentes, causando uma interrupção entre o fluxo de informações altamente sincronizado nas fábricas e procedimentos não padronizados para tomada de decisão. Essa interrupção pôde ser sanada pelos sistemas APS, que fazem planos e programas enquanto consideram a disponibilidade de materiais, funcionários e máquinas (ZHONG et al., 2013).

O RAPShell é um sistema baseado na web, projetado e operado seguindo uma arquitetura orientada no serviço (SOA) padronizada. A implantação baseada na SOA foi realizada em quatro categorias de construtos. A primeira categoria continha um conjunto de serviços web padronizados, pelos quais os algoritmos de otimização da programação e planejamento e suas soluções foram desenvolvidos e desdobrados como software as a service (SaaS), ou sistema como um serviço. A segunda categoria foi o serviço da fonte de informação, um conjunto de serviços web padronizados que são responsáveis por processar vários documentos de informações XML. A terceira categoria incluiu serviços de aplicação desdobrados em servidores específicos para usuários finais. A quarta categoria incluiu um rico conjunto de exploradores de interface com o usuário que interage diretamente com usuários finais para facilitar suas operações e decisões. Os autores afirmam que o uso de RAPShell conduziu ao compartilhamento de informações essenciais e significativas melhorias na tomada de decisão colaborativa entre diferentes unidades de manufatura, bem como eficiência e eficácia operacional (ZHONG et al., 2013).

\subsection{Influência da modelagem no processo de implantação}

Zoryk-Schalla, Fransoo e De Kok (2004) discutem a modelagem do processo de planejamento em sistemas APS. Os autores afirmam que o comprometimento da gestão e objetivos claros de configuração são altamente relevantes na implantação do software. O APS implantado na empresa produtora de bens metálicos e de alumínio é baseado em uma estrutura hierárquica, consistindo de três níveis: planejador da demanda, planejador mestre e planejador da fábrica. De acordo com os autores, o processo de implantação do sistema compreende as 
fases de configuração de critérios e requisitos iniciais, modelagem inicial, modificação do modelo, extensão do modelo, requisitos avançados e configuração de critérios, e modelagem avançada. Como Wiers (2002), os autores afirmam que o sistema deve ser operado por poucos funcionários, sendo que após a implantação, 18 usuários estavam envolvidos no uso do software nos três níveis, sendo 7 no planejador da fábrica, 6 no planejador mestre e 5 no planejador da demanda.

O sistema foi implantado como um simples modelo, pois nem todas as funcionalidades devem implantadas de uma vez. No decorrer do processo, requisitos para o software foram formulados em um alto nível de agregação, os quais incluem objetivos conflitantes tais como minimização de vendas perdidas, maximização de utilização e minimização de custos de inventário. Os resultados afirmam que os problemas que ocorrem são resultantes de erros no processo de modelagem e que nenhuma análise foi feita para avaliar os conflitos que ocorrem no processo de implantação. Os autores afirmam que o APS por si só não é capaz de auxiliar nos processos empresariais, por isso os planejadores devem ser devidamente treinados (ZORYK-SCHALLA, FRANSOO e DE KOK, 2004).

\subsection{Influência de fatores humanos, organizacionais e tecnológicos no processo de implantação}

Lin, Hwang e Wang (2007) apresentaram uma reavaliação sobre sistemas APS em configurações industriais, comparando a situação anterior e posterior ao relançamento do sistema, propondo uma abordagem efetiva para a implantação. Três funções principais realizadas por diferentes organizações de planejamento foram explicitamente identificadas para melhoria no projeto de implantação: geração de Available-To-Promise (ATP), ou disponibilidade para promessa, para entrada de pedidos de clientes; geração de Master Production Schedule (MPS), ou programa mestre de produção; e realização de decisões de rotas para despachar o Work In Process (WIP), ou trabalho em processo das instalações da empresa para as instalações de subcontratantes. Eles avaliaram a influência dos fatores humanos, tecnológicos e organizacionais em cada uma das funções. A dimensão humana é a mais importante, sendo que as pessoas devem participar ativamente do processo de planejamento, interagindo com os sistemas e as organizações. Foram relatadas falhas na implantação relacionadas à dimensão humana, tecnológica e organizacional.

Na dimensão humana o sistema não era totalmente automatizado, as pessoas eram uma parte integral do processo de planejamento e os planejadores estavam no controle. Essa dimensão foi a que obteve a menor importância no processo. Na dimensão tecnológica, as falhas 
eram relativas à gestão de informações, difícil gestão e compreensão dos sistemas dinâmicos do APS, difícil controle do comportamento do sistema dominante do APS e necessidade de complementação dos sistemas formais pelos informais (LIN, HWANG e WANG, 2007).

$\mathrm{Na}$ dimensão organizacional, as falhas diziam respeito à experiência, mudanças nos papéis, responsabilidades e habilidades requeridas, negligência das dificuldades do processo de reengenharia do negócio, fraqueza nos procedimentos de gestão das informações para garantir qualidade e conclusão, e uso de sistemas informais em detrimento do APS para a comunicação e resolução de problemas para situações mal definidas (LIN, HWANG e WANG, 2007).

Os autores afirmam que a reengenharia do negócio é uma das questões mais importantes no processo de implantação de sistemas APS, e deve precedê-lo para racionalizar as três dimensões analisadas nos processos de negócio e superar as falhas identificadas.

A realidade empresarial não é a mesma para todas as organizações, e segundo Lin, Hwang e Wang (2007), bem como Zoryk-Schalla, Fransoo e De Kok (2004) existe uma tendência errônea em acreditar que a solução tecnológica do software por si só resolve problemas interorganizacionais.

Setia, Sambamurthy e Closs (2008) apresentaram dois estudos de caso sobre como tecnologias da cadeia de suprimentos podem aumentar a agilidade de empresas, analisando a implantação de sistemas APS em uma indústria eletrônica e em uma de itens de decoração domiciliar.

De acordo com Setia, Sambamurthy e Closs (2008), a indústria eletrônica iniciou a modificação do processo de gestão de pedidos focando nos requisitos fundamentais da empresa. A introdução dos sistemas APS acompanhou o processo de gestão da mudança na empresa, envolvendo os estágios de avaliação dos processos atuais e comparação com as melhores práticas, desenvolvimento e refinamento de um modelo compreensivo de processos de negócio para a gestão total de pedidos, implantação de mudanças no processo e ferramentas de planejamento, e avaliação dos resultados em termos de capacidade de resposta ao cliente, carregamentos em tempo e giro de estoques.

Os principais desafios que impediram o alcance de bons resultados compreendem fatores organizacionais tais como treinamento, integridade das informações e confiança no sistema. Com relação ao ajuste organizacional, o processo de alocação de demanda facilitado pelo APS forneceu capacidade divisional para compromisso instantâneo de pedidos e comunicação instantânea com outras aplicações organizacionais da tecnologia de informação, o que aumentou a habilidade da empresa em responder a mudanças nas condições de negócio. As melhorias específicas nas operações após a implantação do APS incluíram melhorias na 
precisão de partes de alto volume, redução no tempo de resposta do pedido, melhoria na entrega em tempo, redução nos ativos de equipamento, redução nos ativos de inventário e aumento da satisfação do cliente (SETIA, SAMBAMURTHY e CLOSS, 2008).

A indústria fabricante de produtos para decoração domiciliar devido à crescente complexidade de variedade e volume de produtos e o desejo de não aumentar os ativos de produção decidiu implantar o sistema APS para auxílio na nova estratégia de negócios, principalmente no planejamento da produção e inventário (SETIA, SAMBAMURTHY e CLOSS, 2008).

Os principais resultados obtidos com a implantação do sistema APS foram maior agilidade na empresa, melhoria de 5\% na disponibilidade dos níveis de serviço, declínio nos níveis de inventário, aumento no volume e variedade. Apesar das melhorias alcançadas, os resultados não atenderam os objetivos da empresa. Melhorias relacionadas a aspectos organizacionais e aspectos de assimilação do APS evidenciaram a necessidade de treinamento, integridade de informações e confiança do sistema. O treinamento foi relacionado com a necessidade de gerenciar a grande quantidade de parâmetros de programação, capacidade e inventário que tem que ser refinada periodicamente. A integridade de informações foi relacionada com a definição dos níveis de inventário. Já a confiança do sistema foi evidenciada no relacionamento entre o serviço dos clientes e os planejadores. Como o treinamento, integridade de informações e iniciativas de confiança foram iniciados o desempenho do sistema teve melhorias significativas (SETIA, SAMBAMURTHY e CLOSS, 2008).

Wiers (2009) apresentou dois estudos de caso onde foi investigado o relacionamento entre a autonomia do chão de fábrica e o sucesso do APS. O primeiro estudo de caso foi realizado em uma indústria de produtos metálicos. Antes da implantação do sistema, a empresa estava sofrendo com pobre desempenho de entregas e visão geral de suas operações e os operadores não tinham autonomia para tomar decisões relacionadas à programação. O objetivo da implantação do APS foi obter maior transparência e controle no processo de planejamento e programação, visando tornar claro o status de um pedido em um período específico e que os programadores devem ser capazes de fazer um programa mais confiável. Após poucas semanas da implantação, foi relatado um problema na interface do APS com o Manufacturing Execution System (MES), ou sistema de execução da manufatura. Como resultado, os operadores criaram seus próprios esquemas de trabalho. O uso do APS na empresa foi problemático e os operadores não estavam dispostos a seguir o programa e defenderam sua autonomia.

O segundo estudo de caso foi realizado em uma empresa produtora de alimentos para animais. A empresa perdia muito tempo com a preparação manual dos lotes de produção dos 
alimentos, para evitar problemas de contaminação, pois um ingrediente que é necessário para um tipo de animal pode ser fatal para outro. Somente o programador da produção tinha autonomia no chão de fábrica, pois só ele visualizava os impactos da contaminação nos produtos. O objetivo da implantação do APS na empresa foi aumentar a eficiência do processo de produção evitando tempos de setup e tempos de espera e resolver o problema de contaminação em um aspecto não manual, porém seguro, fornecendo informações detalhadas sobre os estoques e especificando quando e quais lotes manuais são necessários. Neste exemplo, os resultados foram mais satisfatórios, e o programador passou a confiar plenamente no sistema APS (WIERS, 2009).

Os funcionários do chão de fábrica de uma empresa devem ter autonomia, porém isso não gera a solução de problemas. Antes da implantação de sistemas APS é importante existir um acordo entre o que é programado pelo sistema e o que é programado pelos funcionários do chão de fábrica (WIERS, 2009).

\subsection{Principais obstáculos para a implantação bem-sucedida do sistema}

Giacon e Mesquita (2011) visaram identificar as necessidades e dificuldades da programação detalhada da produção, as barreiras de implantação e os benefícios dos sistemas APS, valendo-se para isso de um survey realizado com as empresas filiadas à Federação das Indústrias do Estado de São Paulo (FIESP). No survey realizado, 10 empresas relataram terem implantado sistemas APS. Foi verificado que os objetivos de maior relevância atualmente para a programação detalhada da produção são a data de entrega e o grau de prioridade do cliente, o que pode ser plenamente alcançado pelos sistemas APS, os quais complementam os sistemas MRP e ERP, trabalhando de forma integrada com eles e suprindo suas deficiências. As principais dificuldades apontadas pelas empresas no processo de implantação do sistema foram: adaptação de procedimentos, necessidade de atualização de cadastros, integração entre sistemas, disciplina no cumprimento da programação, capacitação do usuário, apontamento de horas de produção no chão de fábrica, convencimento da alta gerência da necessidade de um sistema complementar e investimento financeiro.

Lupeikiene et al. (2014) discutiram os mais importantes desafios para a implantação e modelagem de sistemas APS, com base em uma ampla revisão da literatura e a experiência adquirida pelos autores durante o processo de desenvolvimento de um sistema APS. De acordo com os autores, existem cinco principais desafios na implantação de sistemas APS, entre eles a integração com o sistema ERP e a necessidade de uma modelagem de referência. Algumas questões de pesquisa propostas para futuros trabalhos sobre integração entre os sistemas APS e 
ERP foram como superar as diferenças entre as lógicas dos dois sistemas, como integrar um sistema APS específico aos variados sistemas ERP, como informações devem ser transferidas e como o trabalho devem ser dividido entre eles. Os autores sinalizaram também algumas questões complexas de pesquisa a serem analisadas em futuros trabalhos sobre modelagem de referência, tais como hierarquia no modelo de referência de um sistema particular, quais os conceitos a serem usados no modelo, como combinar modelos de referência de melhores práticas e modelos de referência orientados no sistema, como comunicar as ideias e conhecimento capturados no modelo de referência aos atores do ambiente, como customizar o conhecimento deste modelo a uma empresa específica e como definir os conceitos usados no modelo.

\subsection{Problemas nas fases de implantação de sistemas APS}

Ivert e Jonsson (2011) examinaram os problemas existentes nas fases de avanço horizontal e vertical da implantação de sistemas APS, como as dimensões individual, tecnológica e organizacional nas fases de implantação influenciam os problemas, e como estes impactam o uso do sistema. O estudo foi realizado em três empresas que usam módulos do APS para apoiar seu planejamento tático (uma empresa alimentícia, uma do ramo químico e outra de cervejaria). Os autores estruturaram a implantação do APS em quatro fases: a fase de autorização do projeto (onde a empresa toma a decisão de instalar um sistema APS), fase de projeto (onde o módulo é projetado e lançado na organização), fase de improviso (na qual a empresa faz a transição da entrada para as operações normais) e fase de avanço horizontal e vertical (na qual a empresa captura a maioria dos resultados).

Atividades típicas da fase de autorização do projeto envolvem análise do estado atual, ideias de adoção do sistema, definição de indicadores-chave de desempenho, condução de um caso de negócios para desenvolvimento do investimento, identificação do gestor do projeto, aprovação do orçamento e programa, e seleção do software. Atividades típicas da fase de projeto abrangem construção do modelo, configuração de estruturas internas de informações e bases de dados, validação/teste e implantação. Atividades típicas da fase de improviso incluem organização de informações e parâmetros, fornecimento de treinamento adicional a usuários e trabalho com vendedores e consultores para resolução de erros do software. Atividades típicas da fase de avanço horizontal e vertical incluem auditoria pós-implantação, melhoria contínua do negócio, atualização técnica e construção de habilidades adicionais do usuário final (IVERT e JONSSON, 2011). 
A dimensão individual é similar ao termo função organizacional; e empoderamento, comprometimento, conhecimento, dinâmicas de grupo e liderança são exemplos de fatores funcionais. Fatores individuais tais como conhecimento do sistema e do planejamento, experiência dos processos sob investigação e projetos de implantação e comprometimento com o projeto são muito importantes em processos de implantação de sistemas APS (IVERT e JONSSON, 2011).

Como Wiers (2009) e Ivert e Jonsson (2010), Ivert e Jonsson (2011) afirmam que a aceitação do sistema pelos funcionários é um fator de grande importância para o seu sucesso e que desacordos ou resistência cultural a mudanças impedem a implantação bem-sucedida do sistema. A dimensão tecnológica é relacionada à funcionalidade do planejamento, usabilidade do sistema, informações de entrada e interface técnica com outros sistemas tais como ERP e sistemas antigos e de armazenamento de dados.

Do mesmo modo que Wiers (2002), Brandenburg e Tölle (2009) e Giacon e Mesquita (2011), Ivert e Jonsson (2011) constataram que uma forte integração entre os sistemas APS e ERP é um pré-requisito para o alcance de planos consistentes.

A dimensão organizacional é relacionada ao modo como as atividades são organizadas e estruturadas, focando nas divisões de trabalho e autoridade entre diversas organizações durante o processo de implantação. Seis principais problemas foram identificados nas três empresas, sendo relacionados ao uso incompleto do sistema, geração de sugestões irreais, dificuldade de progresso, dependência da empresa de consultoria, muito tempo gasto no sistema e uso paralelo de outros sistemas de planejamento para as atividades designadas exclusivamente a certos módulos do APS (IVERT e JONSSON, 2011).

A dimensão individual teve influência em todos os problemas. Nas empresas, na fase de projeto, questões como perda de compreensão de quais informações e parâmetros são importantes, como projetar o modelo e conhecimento do processo de planejamento foram determinantes para a dependência da empresa de consultoria e uso incompleto do potencial do sistema. Na fase de improviso, os usuários não sabiam como interpretar os resultados do sistema e gastaram muito tempo nesta atividade, ou usaram sistemas paralelos. $\mathrm{Na}$ fase de avanço horizontal e vertical os usuários perderam o conhecimento e compreensão do que alguns módulos podem ou não fazer e ficaram desmotivados com o uso do sistema, resultando em planos incorretos, potencial não usado e dificuldades no progresso da implantação (IVERT e JONSSON, 2011).

A dimensão tecnológica foi mais evidente na fase de projeto e houve dificuldades no recebimento de informações, integração com o ERP e armazenamento na funcionalidade de 
planejamento. Problemas como muito tempo gasto no sistema, uso de sistemas paralelos e planos incorretos também foram evidentes. $\mathrm{Na}$ fase de improviso houve perdas na funcionalidade do sistema, devido à falta de geração de relatórios, o que levou ao uso de sistemas paralelos. A dimensão organizacional só não esteve presente na fase de avanço horizontal e vertical. Na fase de autorização a empresa de consultoria executou a maior parte das atividades, o que acarretou sua dependência nas fases posteriores e existiam diversas expectativas por parte dos usuários. $\mathrm{Na}$ fase do projeto as empresas atribuíram papéis não claros de projeto e experimentaram dificuldades em priorizar a implantação de certos módulos específicos (IVERT e JONSSON, 2011).

De acordo com Ivert e Jonsson (2011), a compreensão da otimização reduz os problemas na fase de avanço horizontal e vertical, equipes pequenas e focadas no projeto reduzem a influência negativa da dimensão individual na fase de avanço horizontal e vertical, a prioridade da alta gerência ao projeto reduz os problemas na fase de avanço horizontal e vertical, as dimensões individual e organizacional são mais importantes do que a dimensão tecnológica para a redução dos problemas na fase de avanço horizontal e vertical, a compreensão de como as informações são estruturadas no ERP reduz as inexatidões dos planos do APS, o foco nas dimensões individual, tecnológica e organizacional na fase de autorização reduz os problemas na fase de avanço horizontal e vertical.

Apoio da alta gerência, interação e compreensão apropriadas entre usuário e projetista e bom projeto da tecnologia da informação são bastante relevantes para o sucesso da implantação de sistemas APS (IVERT e JONSSON, 2011).

\subsection{Impactos dos sistemas APS nos níveis de planejamento da gestão da cadeia de suprimentos}

Rudberg e Cederborg (2011) descreveram e analisaram o impacto que a implantação de um sistema APS tem sobre o nível tático de planejamento em uma empresa processadora de aço. A implantação foi necessária para obter controle da demanda diversificada e funções de planejamento mestre. Foram implantados três módulos do APS, o planejador da demanda, planejador da cadeia de suprimentos e cumprimento da demanda. Embora a implantação dos módulos APS tenha fornecido muitos efeitos positivos, existem diversas áreas onde tanto os processos de planejamento em si quanto o uso do software podem ser melhorados. Nos processos de planejamento os autores indicaram possíveis melhorias no planejamento da demanda, planejamento mestre e cumprimento da demanda. 
Segundo Rudberg e Cederborg (2011) o efeito mais importante da implantação do APS foi ter estabelecido um aspecto padronizado para usar sua capacidade limitada e priorizar entre clientes e pedidos de acordo com a estratégia de longo prazo da empresa. Algumas das vantagens do uso do APS na empresa do estudo de caso é que o processo de cumprimento da demanda, em termos de planejamento tornou-se completamente automatizado e com um tempo de resposta mais rápido e a empresa tem também usado o sistema como um meio para forçar planejadores a aderir aos processos padronizados. Alguns problemas foram evidenciados no uso do sistema tais como perda de compreensão do sistema, das possibilidades que o APS oferece em termos de planejamento eficiente e estabelecimento de processos efetivos de planejamento.

Rudberg e Cederborg (2011) afirmam que o treinamento auxilia na resolução destes problemas, mas o treinamento deve ser gerenciado por pessoas que possuem experiência no uso dos sistemas. Assim como Lin, Hwang e Wang (2007), Rudberg e Cederborg (2011) afirmam que o sistema não pode ser utilizado eficientemente sem uma mudança organizacional. Rudberg e Cederborg (2011), bem como Zoryk-Schalla, Fransoo e De Kok (2004) e Setia, Sambamurthy e Closs (2008) afirmam que além do treinamento, apoio da alta gerência e liderança são essenciais para o sucesso da utilização do sistema.

A implantação de sistemas APS em empresas pode ser considerada uma inovação organizacional, pois representa a implantação de um novo método organizacional nas práticas de negócios da empresa, na organização do seu local de trabalho (chão de fábrica), em suas relações externas (gestão da cadeia de suprimentos) e permite aos funcionários maior autonomia na tomada de decisões (simulação de diferentes cenários de planejamento).

O processo de implantação de sistemas APS em uma empresa envolve agentes internos e externos à organização, e que voluntariamente se unem para obter benefícios mútuos. Os agentes internos são representados pelos profissionais gerenciais e técnicos que constituem a equipe funcional de implantação. Os agentes externos são representados pelos profissionais da empresa que desenvolve o sistema APS e pelos profissionais da empresa que o implanta. De acordo com Britto (2002), esta configuração entre empresas durante o processo de implantação pode ser analisada apropriadamente sob a perspectiva de redes de inovação, o que permite identificar os nós (empresas), ligações (relacionamentos), posições (atividades das empresas), fluxos tangíveis (recursos físicos) e fluxos intangíveis (troca de conhecimento e informação). 


\subsubsection{Redes de inovação auto-organizadas: caracterização e conceituação}

A capacidade de geração de inovação é uma das mais relevantes vantagens competitivas das organizações (AGERON, LAVASTRE e SPALANZANI, 2013), e a compreensão de como isso pode ser alcançada muitas vezes é crucial para sua sobrevivência $(\mathrm{HOCH}, 2013)$. A geração de inovação em empresas depende de sua habilidade para criar, reconhecer, reter, transmitir e utilizar o conhecimento (HALIKKAS, KARKKAINEN e LAMPELA, 2009), das múltiplas e heterogêneas fontes de recursos e conhecimentos disponíveis (CORSARO, CANTÙ e TUNISINI, 2012; PALMBERG, 2006) e das características das estruturas colaborativas que ligam as empresas (ZENG, XIE e TAMC, 2010). Diversas empresas colaboram em uma rede para compartilhar dados e informações, sistemas, riscos e benefícios (PARUNG e BITITCI, 2008). Segundo Sacomano Neto e Truzzi (2004), na análise organizacional, a rede como objeto analítico auxilia a compreender como e quais atores ocupam posições privilegiadas em sua estrutura. Estruturas de rede ligam os diversos fluxos de conhecimento existentes em diversas organizações visando facilitar sua troca rápida, representando mecanismos para difusão da inovação por meio da colaboração (PROTOGEROU, CALOGHIROU e SIOKAS, 2013).

De acordo com Britto (2002), as redes de empresas são arranjos baseados em vínculos colaborativos entre empresas formalmente independentes que visam a coordenação de esforços econômicos, compartilhamento de conhecimentos, redução no tempo de lançamento de novos produtos ou integração de competências necessárias para o alcance de novas oportunidades de negócio. O vínculo colaborativo requer o compartilhamento de informações, recursos e responsabilidades para planejar, desenvolver e avaliar em conjunto as atividades necessárias para viabilizar, por meio da colaboração, o alcance dos objetivos (CAMARINHA-MATOS et al., 2009).

Parcerias entre empresas formam as redes interorganizacionais e estas redes formam uma estrutura básica para a geração de sistemas de inovações (FREEMAN, 2004). De acordo com Freel e Harrison (2006), as redes de inovação constituem um tipo específico de redes de empresas e são formadas por um conjunto de instituições ligadas por vínculos colaborativos que por meio de parcerias visam superar as incertezas do processo de inovação, envolvendo-se na geração, comercialização e difusão de produtos, processos e serviços novos ou melhorados. As redes de inovação surgem como resposta a demandas por inovação em ambientes turbulentos, em que a velocidade de geração e a necessidade de absorção de conhecimento são muito altas, o que requer que essas redes aumentem a velocidade de aprendizado - o que dificilmente é atingido por meio de estruturas de controle centralizado e simples divisão de tarefas (MELO e AGOSTINHO, 2007). Redes de inovação compreendem empresas, 
organizações de pesquisa, universidades e agências governamentais que trabalham juntas para desenvolver, adquirir e integrar o conhecimento e habilidades necessárias para criar e trazer soluções complexas ao mercado e alcançar objetivos compartilhados de inovação (CORSARO, CANTÙ e TUNISINI, 2012; RAMPERSAD; QUESTER e TROSHANI, 2010b).

Entre os vários tipos de redes, as redes colaborativas possuem expressiva relevância. Redes colaborativas são formas de organizações independentes que em parceria e por meio da tecnologia de informação e comunicação compartilham recursos e competências essenciais (MAYMAND, FARSIJANI e MOOSAVI, 2012). Para Romero, Rabelo e Molina (2013), as redes colaborativas têm emergido como um novo e conceituado paradigma para melhorar a competitividade das organizações em um aspecto sustentável nos ambientes crescentemente globalizados e dinâmicos. Nos últimos anos, verifica-se um expressivo crescimento nas pesquisas sobre redes colaborativas, consolidando estes estudos como uma nova disciplina (CAMARINHA-MATOS e AFSARMANESH, 2005; CAMARINHA-MATOS e AFSARMANESH, 2008).

Dentre as diversas modalidades de redes colaborativas, as redes de inovação autoorganizadas vêm recebendo relevante destaque, emergindo como novas alianças facilitadoras da difusão de inovação nas empresas. Em uma visão auto-organizada, elas têm o potencial de se transformarem, respeitando as restrições impostas, para se adequarem às mudanças do ambiente em que elas estão inseridas (THARUMARAJAH, 2003; VIANA et al., 2005). Estas redes são caracterizadas por sua gestão não centralizada (RYCROFT e KASH, 2004; WAGNER e LEYDESDORFF, 2005; WANG, CHENG e HUANG, 2013); capacidade de manter sua evolução sem a necessidade de interferências externas significativas (RYCROFT e KASH, 2004); capacidade de rápidas criação, operação e dissolução (QUINN, ANDERSON e FINKELSTEIN, 1996); gerenciamento por meio de capital social coletivo, confiança e ajuda mútua (KASH e RYCROFT, 2002; LOWE et al., 2012); diversos indivíduos que escolhem voluntariamente participar em práticas compartilhadas para obtenção de vantagens mútuas (LOWE et al., 2012); intensa comunicação, participação, relacionamento e evolução conjunta dos atores envolvidos (ANDERSON, 1999; KASH e RYCROFT, 2000); e capacidade de promover o aprendizado entre todos os seus membros por meio da comunicação eficiente, sistematização e disponibilização do conhecimento gerado no desenvolvimento de suas atividades (CROWSTON et al, 2007; DE VANY, 1996; DUTTA, GHOSAL e RAY, 2005; RAMPERSAD; QUESTER e TROSHANI, 2010a; RYCROFT e KASH, 2004; SCHUH et al., 2008a; SØRENSEN, 2007; WAGNER e LEYDESDORFF, 2005). 
$\mathrm{Na}$ estrutura interna das redes, o comportamento de auto-organização passa pela avaliação e reconhecimento dos diversos tipos de relacionamentos (financeiro, legal, pessoal, promotor de inovação), da identificação da intensidade das trocas e controle adequados, o que por meio do estabelecimento de prioridades nos relacionamentos, reduz a complexidade do processo de auto-organização (ESCHENBÄCHER, SEIFERT e THOBEN, 2011).

As redes de inovação auto-organizadas lidam com rápida incerteza (tais como a dificuldade em prever exatamente quais combinações de conhecimento, know-how e habilidades serão necessárias) e grande flexibilidade. A confiança mútua e os relacionamentos informais são as principais razões pelas quais as redes de inovação são capazes de aprender e se auto-organizar (RYCROFT e KASH, 2004).

De acordo com Rycroft e Kash (2004), quanto mais uma rede de inovação se expande, maior é a necessidade de um senso compartilhado de confiança, reciprocidade, informalidade e comunhão entre seus membros. Com a confiança os esforços organizacionais podem ser focados no processo de aquisição de novos conhecimentos e ideias, permitindo que os envolvidos superem a rivalidade interorganizacional e minimizem a necessidade de constante monitoramento e sanções a comportamentos menos oportunistas. Ollus et al. (2011) afirmam que para a confiança deve haver alinhamento dos parceiros em relação ao projeto (objetivos, processos e tarefas) e em relação a si mesmos (competências e comprometimento), e este alinhamento necessita ser frequente para garantir autonomia harmoniosa, requerendo comunicação eficiente (LEE e YONG, 2010).

As redes de inovação auto-organizadas possuem alto potencial de aprendizado e podem rapidamente identificar os conhecimentos necessários para a resolução de problemas e procedimentos onde quer que eles estejam localizados (RYCROFT e KASH, 2004). Elas também podem reduzir os custos operacionais, automatizando funcionalidades de otimização usualmente realizadas manualmente em extensos períodos de tempo e podem reduzir custos financeiros, minimizando o número de locais a serem desenvolvidos inicialmente, garantindo a segurança necessária com a qualidade de serviço desejada pelos envolvidos (SÁNCHEZGONZÁLEZ et al., 2013).

Uma característica essencial de auto-organização em organizações autônomas é a cooperação. As organizações cooperam por meio de autocontrole e autocoordenação, trabalhando conjuntamente para superar os problemas associados ao alcance das tarefas e objetivos comuns (THARUMARAJAH, 2003).

De acordo com Barco, Lázaro e Muñoz (2012), as principais funcionalidades das redes auto-organizadas são a autoconfiguração (funções para a implantação da rede e configuração 
de seus parâmetros), auto-otimização (autoajuste de parâmetros, os quais devem ser dinamicamente recalculados quando o tráfico e condições da rede mudam), e autorrestauração (funções para lidar com a degradação ou interrupção do serviço, incluindo falhas na detecção e diagnóstico e mecanismos para compensar a interrupção).

Os membros das redes de inovação auto-organizadas constantemente avaliam seu desempenho para verificar se os processos colaborativos auto-organizados têm enfraquecido ou aprimorado seus recursos organizacionais e tecnológicos (RYCROFT e KASH, 2004). O retorno não linear e a evolução conjunta são os mecanismos centrais das redes de inovação auto-organizadas. O retorno não linear representa a capacidade das pessoas envolvidas darem e receberem respostas sobre o comportamento dos agentes da rede. A evolução conjunta representa a evolução mútua que é gerada a partir desses retornos (ESPINOSA e PORTER, 2011).

De acordo com Kash e Rycroft (2002), os fatores interligados mais evidentes no processo de auto-organização de redes são capacidades essenciais, ativos complementares, aprendizado organizacional, dependências da trajetória e seleção do ambiente. As capacidades essenciais de uma rede auto-organizada possuem dimensões organizacionais e tecnológicas e devem permitir a ela ser excelente em alguns aspectos da inovação. Os ativos complementares podem ser genéricos ou especializados. Os genéricos não necessitam ser adaptados a um processo particular de inovação, enquanto os especializados devem ser ajustados e integrados no projeto geral da inovação. O aprendizado organizacional deve desenvolver, acumular e transferir conhecimentos e habilidades da rede, bem como modificar seu comportamento e estrutura para refletir novas ideias. Os aspectos de auto-organização da rede são dependentes da trajetória, o que pode ter impacto em sua competitividade. A seleção do ambiente leva em consideração o fato de que o ato de adotar ou não uma inovação pode envolver preferências do cliente, políticas governamentais e uma ampla gama de fatores mercadológicos.

\subsubsection{Implantação de sistemas APS sob a perspectiva de redes de inovação auto- organizadas}

O processo de implantação de sistemas APS, assim como todo processo de gestão da aquisição e incorporação de tecnologia e mudanças organizacionais (KARLSSON, TAYLOR e TAYLOR, 2010), é uma atividade complexa que envolve diferentes atores, competências, recursos, processos organizacionais e atitudes relacionadas à cooperação. De acordo com Dangelico, Pontrandolfo e Pujari (2013), quando as empresas não têm os recursos e competências necessários para a geração de inovação por si próprias, elas apoiam-se em 
capacidades integradoras externas. A criação de redes de inovação representa uma dessas capacidades e permite que a empresa acesse fontes externas e atue como um adesivo absorvendo conhecimento e recursos críticos.

Como a geração de inovação é caracterizada por processos auto-organizados em empresas e outros atores inovadores, e a evidência de auto-organização é mais óbvia em atividades colaborativas interorganizacionais (RYCROFT e KASH, 2004), a implantação de sistemas APS pode ser analisada sob a perspectiva de redes de inovação auto-organizadas. As ligações entre duas ou mais empresas em um ou mais níveis podem ser analisadas por meio da ótica de redes (CHITUC, AZEVEDO e TOSCANO, 2009; ZAIDAT, BOUCHER e VINCENT, 2005).

A interseção entre os requisitos necessários para a implantação de sistemas APS e os construtos das redes de inovação auto-organizadas evidencia uma região conceitual comum a ambas as áreas de pesquisa. O Quadro 4 apresenta os requisitos necessários para a implantação de sistemas APS e os elementos das redes de inovação auto-organizadas associados.

Quadro 4 - Requisitos necessários para a implantação de sistemas APS e elementos de redes de inovação autoorganizadas associados

\begin{tabular}{|c|c|}
\hline Requisito para a implantação de sistemas APS & Elemento de redes de inovação auto-organizadas \\
\hline $\begin{array}{l}\text { Integração com o MRP II, ERP e outros sistemas de } \\
\text { planejamento e controle da produção (ARSOVSKI, } \\
\text { ARSOVSKI e MIROVIC, 2009; BOULAKSIL, } \\
\text { FRANSOO e HALM, 2009; CAPLINSKAS et al., } \\
\text { 2012; CAPUTO, GALLO e GUIZZI, 2009; } \\
\text { CHAMBERS, 1996; CHEN et al., 2013; GARCIA- } \\
\text { SABATER, MAHEUT e GARCIA-SABATER, 2012; } \\
\text { GIACON e MESQUITA, 2011; HVOLBY e } \\
\text { STEGER-JENSEN, 2010; IVERT, 2012; IVERT e } \\
\text { JONSSON, 2010; IVERT e JONSSON, 2011; IVERT } \\
\text { e JONSSON, 2014; JONSSON, KJELLSDOTTER e } \\
\text { RUDBERG, 2007; KRISTIANTO, AJMAL e HELO, } \\
\text { 2011; KURODA, SHIN e ZINNOHARA, 2002; } \\
\text { LUPEIKIENE et al., 2014; MCKAY e WIERS, 2003; } \\
\text { OU-YANG e HON, 2008; ÖZTÜRK e ORNEK, } \\
\text { 2014; SANTA-EULALIA, FRAYRET } \\
\text { D'AMOURS, 2008; SETIA, SAMBAMURTHY e } \\
\text { CLOSS, 2008; SHAMSUZZOHA, KYLLÖNEN e } \\
\text { HELO, 2009; STEGER-JENSEN et al., 2011; } \\
\text { TONELLI et al., 2013; WIERS, 2002; WIERS, 2009) }\end{array}$ & $\begin{array}{l}\text { Integração entre diversos sistemas (OSÓRIO e } \\
\text { CAMARINHA-MATOS, 2008; SIWEK, OSOWSKI } \\
\text { e SZUPILUK, 2009) }\end{array}$ \\
\hline $\begin{array}{l}\text { Consistente e correta modelagem organizacional } \\
\text { (HVOLBY e STEGER-JENSEN, 2010; IVERT e } \\
\text { JONSSON, 2014; ZORYK-SCHALLA, FRANSOO e } \\
\text { DE KOK, 2004) }\end{array}$ & $\begin{array}{l}\text { Consistente e correta modelagem organizacional } \\
\text { (BRAHA, STACEY e BAR-YAM, 2011) }\end{array}$ \\
\hline $\begin{array}{l}\text { Comprometimento e apoio da alta gerência (GIACON } \\
\text { e MESQUITA, 2011; IVERT e JONSSON, 2011; } \\
\text { IVERT e JONSSON, 2014; RUDBERG e } \\
\text { CEDERBORG, 2011; ZORYK-SCHALLA, } \\
\text { FRANSOO e DE KOK, 2004) }\end{array}$ & $\begin{array}{l}\text { Comprometimento e apoio da alta gerência (LEE, LEE } \\
\text { e FEIOCK, 2012; PEKKOLA, 2013, RAMPERSAD, } \\
\text { QUESTER e TROSHANI, 2010a) }\end{array}$ \\
\hline
\end{tabular}


Quadro 4 - Requisitos necessários para a implantação de sistemas APS e elementos de redes de inovação autoorganizadas associados

Conclusão

\begin{tabular}{|c|c|}
\hline Requisito para a implantação de sistemas APS & Elemento de redes de inovação auto-organizadas \\
\hline $\begin{array}{l}\text { Configuração clara dos objetivos (IVERT e } \\
\text { JONSSON, 2011; IVERT e JONSSON, 2014; } \\
\text { ZORYK-SCHALLA, FRANSOO e DE KOK, 2004) }\end{array}$ & $\begin{array}{l}\text { Configuração clara dos objetivos (CAMARINHA- } \\
\text { MATOS e AFSARMANESH, 2005) }\end{array}$ \\
\hline $\begin{array}{l}\text { Uso das telecomunicações } \\
\text { TATSIOPOULOS, 2004) }\end{array}$ & $\begin{array}{l}\text { Uso das telecomunicações (CAMARINHA-MATOS } \\
\text { e AFSARMANESH, 2005; CAMARINHA-MATOS } \\
\text { et al., 2009; LEE e YONG, 2010; RAMPERSAD, } \\
\text { QUESTER e TROSHANI, 2010a) }\end{array}$ \\
\hline $\begin{array}{l}\text { Treinamento dos usuários finais do sistema } \\
\text { (GARCIA-SABATER, MAHEUT e GARCIA- } \\
\text { SABATER, 2012; GIACON e MESQUITA, 2011; } \\
\text { HVOLBY e STEGER-JENSEN, 2010; IVERT e } \\
\text { JONSSON, 2010; IVERT e JONSSON, 2011; } \\
\text { JONSSON, KJELLSDOTTER e RUDBERG, 2007; } \\
\text { RUDBERG e CEDERBORG, 2011; SETIA, } \\
\text { SAMBAMURTHY e C CLOSS, } 2008 \text {; } \\
\text { SHAMSUZZOHA, KYLLÖNEN e HELO, 2009) }\end{array}$ & $\begin{array}{l}\text { Treinamento dos membros da rede para aumento do } \\
\text { aprendizado organizacional, cooperação entre os } \\
\text { envolvidos no processo e transferência de } \\
\text { conhecimento (LOWE et al., 2012; MELO e } \\
\text { AGOSTINHO, 2007; RYCROFT e KASH, 2004; } \\
\text { SØRENSEN, 2007; THARUMARAJAH, 2003) }\end{array}$ \\
\hline $\begin{array}{lccc}\text { Padronização de procedimentos } & \text { (GIACON e } \\
\text { MESQUITA, 2011) } & & & \\
\end{array}$ & $\begin{array}{l}\text { ação de procedimentos (BARCO, LÁZARO } \\
O Z, 2012)\end{array}$ \\
\hline $\begin{array}{l}\text { Autonomia (IVERT, 2012; IVERT e JONSSON, } \\
\text { 2010; IVERT e JONSSON, 2011; LIN, HWANG e } \\
\text { WANG, 2007; SETIA, SAMBAMURTHY e CLOSS, } \\
\text { 2008; WIERS, 2009; } \quad \text { ZORYK-SCHALLA, } \\
\text { FRANSOO e DE KOK, 2004) }\end{array}$ & $\begin{array}{l}\text { Descentralização da gestão da rede (MELO e } \\
\text { AGOSTINHO, 2007; RYCROFT e KASH, 2004; } \\
\text { WAGNER e LEYDESDORFF, 2005) }\end{array}$ \\
\hline $\begin{array}{l}\text { Avaliação dos processos atuais da empresa (IVERT e } \\
\text { JONSSON, 2011; SETIA, SAMBAMURTHY e } \\
\text { CLOSS, 2008) }\end{array}$ & $\begin{array}{l}\text { Adequação às mudanças impostas pelo ambiente } \\
\text { (RYCROFT e KASH, 2004; THARUMARAJAH, } \\
\text { 2003) }\end{array}$ \\
\hline $\begin{array}{l}\text { Cooperação com uma empresa de consultoria (IVERT } \\
\text { e JONSSON, 2011; LIN, HWANG e WANG, 2007; } \\
\text { ZORYK-SCHALLA, FRANSOO e DE KOK, 2004) }\end{array}$ & $\begin{array}{l}\text { Colaboração entre empresas (FREEMAN, 2004; } \\
\text { LOWE et al., 2012; RYCROFT e KASH, 2004; } \\
\text { THARUMARAJAH, 2003) }\end{array}$ \\
\hline
\end{tabular}

\subsection{Considerações finais}

A inovação é reconhecidamente um dos fatores mais relevantes para a manutenção e crescimento da competitividade das empresas. Os sistemas de planejamento e controle da produção são fortemente ligados com a competitividade das empresas, pois são eles que orientam as estratégias que elas devem seguir em seus processos produtivos. A implantação de novos sistemas de planejamento e controle da produção representa uma inovação organizacional nas empresas, pois visam a melhoria do desempenho de uma empresa por meio da redução de custos, suprimento das deficiências dos sistemas predecessores e cumprimento dos objetivos logísticos e produtivos da gestão da cadeia de suprimentos.

A implantação de sistemas APS representa uma inovação para a área de planejamento e controle da produção das empresas que adquirem o software, pois os mesmos suprem muitas deficiências dos sistemas predecessores, tais como gestão mais eficiente das cadeias de suprimento, redução de custos e lead times industriais, grande velocidade de processamento das informações, criação de planos de produção adequados, consideração às restrições de 
capacidade da empresa, melhor sequenciamento das operações, aumento dos lucros operacionais e da satisfação do cliente, redução dos níveis de estoques e inventário, integração com outros sistemas de planejamento, dentre outros benefícios.

$\mathrm{Na}$ literatura, existem poucos trabalhos que apresentam processos de implantação de sistemas APS em empresas. Estes trabalhos apresentam implantações direcionadas a uma única organização ou unidades da organização, os aspectos de implantação são largamente ignorados e o conhecimento gerado nem sempre é adequado para outros processos. Com base nestas afirmativas, esta pesquisa propôs analisar a implantação de sistemas APS sob a perspectiva de redes de inovação auto-organizadas, pois os relacionamentos colaborativos formados entre as organizações participantes do processo de implantação constituem redes de empresas. O recorte analítico sob a ótica de redes de inovação auto-organizadas se deu pelo fato de que o gerenciamento dos processos de implantação é descentralizado, com divisão da autonomia, permitindo que cada ator se autocoordene.

A interseção dos principais requisitos necessários para a implantação de sistemas APS com os principais construtos das redes de inovação auto-organizadas representa a principal contribuição acadêmica deste trabalho. Nesta interseção, procurou-se evidenciar a relação conceitual entre estas duas áreas de pesquisa, para que a ótica de redes de inovação autoorganizadas seja incorporada na literatura de sistemas APS.

Por meio da revisão da literatura constata-se que a análise sob a perspectiva de redes de inovação auto-organizadas é adequada para evidenciar as interações entre as empresas envolvidas no processo de implantação de sistemas APS, pois, conforme as informações apresentadas no Quadro 4, os requisitos necessários à implantação são inter-relacionados com os construtos das redes de inovação auto-organizadas. A formação da rede de inovação autoorganizada permite a promoção de aprendizado organizacional, cooperação e transferência de conhecimento entre os atores envolvidos no processo de implantação do sistema APS, a modelagem organizacional do processo, a análise de quais competências as empresas devem explorar e como se adequar às necessárias e possíveis mudanças, como o treinamento dos usuários finais durante o processo promoverá melhorias no uso do sistema implantado e a sistematização do processo de implantação por meio dos requisitos apresentados pela literatura.

A revisão da literatura apresentada neste capítulo do trabalho representa um ponto de partida para futuras pesquisas sobre implantação de sistemas APS sob a perspectiva de redes de inovação auto-organizadas. Esta nova abordagem pode ser melhor analisada por meio de estudos de caso, pois este procedimento metodológico é bastante adequado para analisar processos onde a experiência é rara e as condições contextuais são desconhecidas. O uso das 
informações do Quadro 4 no(s) estudo(s) de caso permitirá verificar se e como a autoorganização se apresenta na rede de inovação formada entre as empresas participantes do processo de implantação do sistema APS, como os atores e elementos de apoio interagem e de que modo este recorte analítico pode beneficiar futuros processos de implantação. 


\section{ANÁliSE DA SITUAÇÃo ATUAL (AS-IS) E NECESSIDADES DE MUDANÇAS (NEED-FOR- CHANGE)}

No âmbito dos contínuos desenvolvimentos dos sistemas de PCP, nos anos 1990 foram lançados os sistemas APS, os quais representam uma inovação em relação aos seus predecessores, pois consideram os limites de capacidade das empresas, a disponibilidade de matérias-primas e outros recursos produtivos; simulam diversos cenários de planejamento; fornecem lead times flexíveis; ponderam a importância dos produtos, materiais e clientes; e trabalham de maneira integrada com eles. A implantação de ferramentas sofisticadas tais como sistemas APS representa uma inovação organizacional na empresa, pois são métodos organizacionais que visam a melhoria de desempenho. Tendo em vista que a formação de redes auto-organizadas representa um mecanismo adequado para conduzir processos de geração de inovação em empresas, este capítulo do trabalho analisa o processo de implantação de sistemas APS sob a perspectiva de redes de inovação auto-organizadas. Tal análise foi desenvolvida por meio de revisão da literatura destas áreas de pesquisa; e por meio da modelagem organizacional do processo de implantação com a metodologia EKD-CMM, com base nos dados coletados em estudos de caso realizados em sete empresas. Como resultados, foram gerados o Modelo $A s-I S$ do processo de implantação de sistemas APS, o qual representa como ele é realizado atualmente nas empresas; e o Modelo de Necessidades de Mudanças, o qual sinaliza as mudanças necessárias, após a situação atual do processo ser confrontada com as recomendações da literatura de redes de inovação auto-organizadas.

Nesta etapa, enfatizou-se a modelagem do estado atual (Modelo $A s-I s$ ) do processo de implantação de sistemas APS, com base nas informações obtidos em campo por meio dos sete estudos de caso realizados. O objetivo do estado atual está na compreensão dos processos realizados nas organizações durante a implantação do sistema, os objetivos do projeto e as regras de negócio inerentes, os atores e recursos envolvidos e os sistemas de informação de apoio. O Modelo $A s-I s$ foi desenvolvido por meio da esquematização dos modelos específicos desenvolvidos com base nas informações disponibilizadas por cada uma das sete empresas. É 
importante ressaltar que os modelos específicos de cada empresa foram apresentados aos profissionais participantes da entrevista durante sua realização, para que os mesmos pudessem validá-los.

Para a composição do Modelo de Necessidades de Mudanças (Modelo Need for Change) foi feita uma comparação entre a situação apresentada no Modelo $A s-I s$ e as principais recomendações sinalizadas na literatura de redes de inovação auto-organizadas, a qual foi disponibilizada no Quadro 5, localizado na seção 3.2. No Quadro 5, encontram-se informações que a literatura sinaliza, confrontadas com as informações das empresas.

\subsection{Modelo $A s-I s$ do processo de implantação de sistemas APS}

Nesta seção é apresentado o Modelo $A s-I s$ do processo de implantação de sistemas APS em empresas, com base nos dados coletados nos sete estudos de caso. Este modelo apresenta a sistematização do processo de implantação de sistemas APS em empresas por meio da modelagem organizacional realizada com a metodologia EKD-CMM, visando permitir uma pronta avaliação do processo e demonstrar as mudanças necessárias neste quando analisado sob a perspectiva de redes de inovação auto-organizadas. O modelo apresentado contempla cinco dos seis submodelos da metodologia EKD, sendo eles o Modelo de Objetivos, Modelo de Regras do Negócio, Modelo de Processos, Modelo de Atores e Recursos e Modelo de Componentes e Requisitos Técnicos. O único submodelo da metodologia EKD que não foi contemplado na modelagem do estado atual do processo de implantação de sistemas APS foi o Modelo de Conceitos, pois com base na revisão da literatura e nos sete estudos de caso, verificou-se que estes processos não são analisados sob a perspectiva de redes de inovação autoorganizadas, e também foi verificado nos estudos de caso que os profissionais envolvidos não dão atenção à necessidade de apresentação clara dos principais fundamentos dos sistemas APS durante o projeto.

\subsubsection{Modelo de Objetivos}

Este modelo foi desenvolvido com base nas informações obtidas nos sete estudos de caso. Foi feita uma sistematização dos objetivos apresentados por cada empresa, a qual levou em conta a frequência de cada objetivo nos casos relatados. Tal modelo encontra-se esquematizado na Figura 4.

Como pode ser visto na Figura 4, com a implantação de sistemas APS, as empresas visam garantir maior produtividade e excelência no ambiente de trabalho (Objetivo 5), o que é possível com a garantia de maior eficácia (Objetivo 5.1) e maior eficiência (Objetivo 5.2); o 
que gera redução de custos na empresa (Oportunidade 5) e resulta em melhor organização industrial (Oportunidade 4). Porém, para que isso seja alcançado, é necessário enfrentar a resistência cultural dos funcionários (Restrição 1) no que se refere ao receio à mudanças nos processos produtivos (Restrição 1.1) e receio à informática (Restrição 1.2).

A garantia de maior produtividade e excelência no ambiente de trabalho (Objetivo 5) apoia a eliminação das perdas por espera nos processos produtivos (Objetivo 6), o que ajuda a garantir balanceamento da cadeia de suprimentos (Objetivo 7).

A integração entre os sistemas APS, ERP e outros sistemas de PCP visa garantir maior integração entre as operações produtivas (Objetivo 4), especialmente as realizadas nas unidades de Produção (Objetivo 4.1), Aquisições (Objetivo 4.2), Comercial (Objetivo 4.3) e Distribuição (Objetivo 4.4). Tal integração ajuda a garantir balanceamento da cadeia de suprimentos (Objetivo 7).

Com a utilização dos sistemas APS é possível garantir melhor programação da produção (Objetivo 3), o que é o resultado da garantia de melhor sequenciamento (Objetivo 3.1), garantia de melhor alocação de carga (Objetivo 3.2), garantia de coleta rápida de informações (Objetivo 3.3), garantia de melhor planejamento das aquisições (Objetivo 3.4), garantia de atualização instantânea das ordens de produção (Objetivo 3.5) e garantia de ajuste automático (Objetivo $3.6)$.

A garantia de melhor programação da produção (Objetivo 3) e a garantia de balanceamento da cadeia de suprimentos (Objetivo 7) auxiliam a garantir prazos de entrega mais curtos (Objetivo 2), o que gera melhoria do atendimento aos clientes (Oportunidade 2), e aumento e antecipação do faturamento (Oportunidade 3).

A garantia de prazos de entrega mais curtos (Objetivo 2) ajuda a garantir confiabilidade no planejamento de longo prazo (Objetivo 1), o que apoia o aumento da satisfação dos clientes (Oportunidade 1), consequentemente, melhorando a imagem da empresa no mercado. 


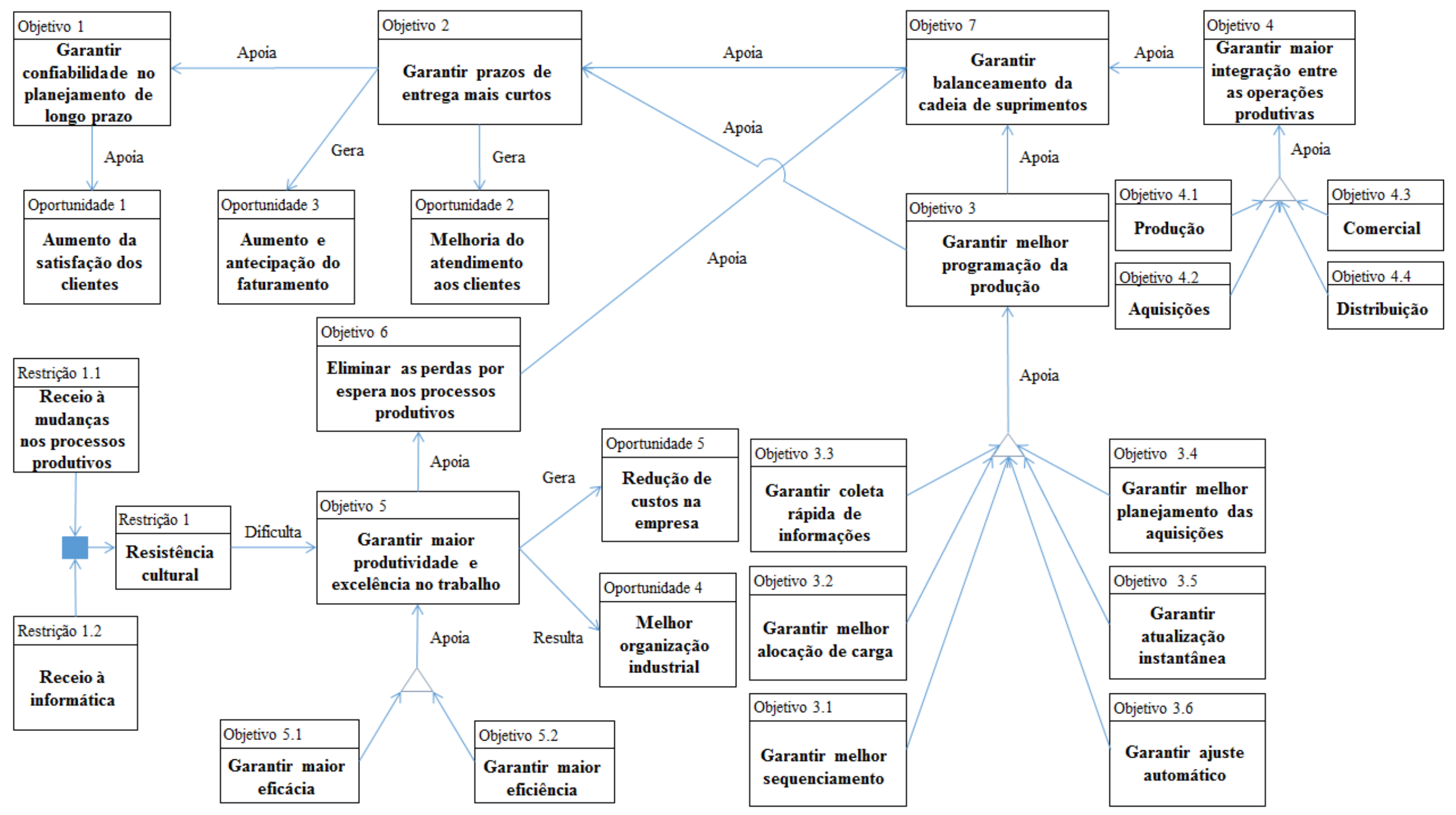

Figura 4 - Modelo de Objetivos - Estado Atual 


\subsubsection{Modelo de Regras do Negócio}

O Modelo de Regras do Negócio mostra a influência das regras do processo de implantação do sistema APS sobre os objetivos do processo. Tal modelo está representado na Figura 5.

O treinamento dos usuários finais para o uso do sistema (Regra 1.1) apoia a ampliação do conhecimento do sistema (Regra 1), o que é necessário para garantir maior produtividade e excelência no trabalho (Objetivo 5), apoiar a eliminação das perdas por espera nos processos produtivos (Objetivo 6), apoiar a garantia de balanceamento da cadeia de suprimentos (Objetivo 7) e apoiar a garantia de confiabilidade no planejamento de longo prazo (Objetivo 1).

A adaptação da solução do sistema às necessidades da empresa (Regra 2.1) e o fornecimento de diversas informações (Regra 2.2) apoiam a ampliação do conhecimento dos processos produtivos (Regra 2), o que apoia a garantia de maior integração entre as operações produtivas (Objetivo 4) e é necessário para garantir melhor programação da produção (Objetivo $3)$.

A realização de testes durante o processo de implantação do sistema (Regra 3) verifica se com sua utilização é possível garantir melhor programação da produção (Objetivo 3).

A integração com o ERP e outros sistemas de PCP (Regra 4) e a parametrização do sistema (Regra 5) são condições necessárias para garantir melhor programação da produção (Objetivo 3) e garantir maior integração entre as operações produtivas (Objetivo 4).

O cumprimento dos prazos de entrega (Regra 6) é uma condição necessária para garantir prazos de entrega mais curtos (Objetivo 2). 


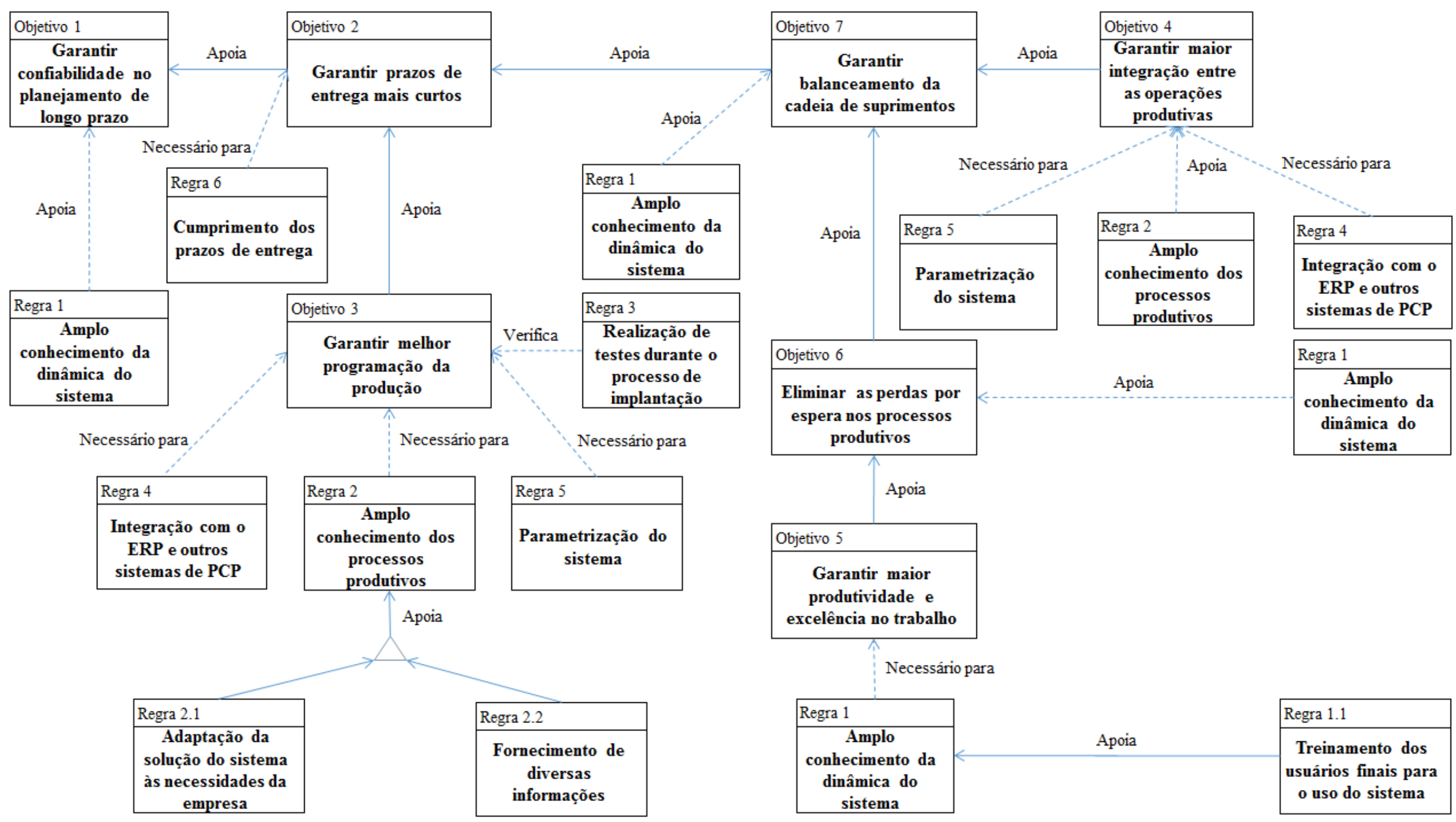

Figura 5 - Modelo de Regras do Negócio - Estado Atual 


\subsubsection{Modelo de Processos}

De modo geral, com base nas informações obtidas em campo nas sete empresas, durante o processo de implantação de sistemas APS, a equipe de implantação realiza 10 principais processos, os quais estão representados na Figura 6.

Após estarem cientes da necessidade de aquisição de um sistema de PCP mais eficiente e eficaz, funcionários da área pertinente e profissionais envolvidos com projetos de melhoria nas empresas realizam a apresentação do sistema APS para a Diretoria (InfoSet 1), e após isso, tem origem a negociação da aquisição do sistema (Processo 1).

Com a autorização da aquisição do sistema (InfoSet 2) por parte da Diretoria, dá-se início à negociação da aquisição do sistema com a empresa implantadora (Processo 2), tendo como resultado o contrato de aquisição (InfoSet 3).

Após a conclusão de todos os acordos legais, é designada a equipe do processo de implantação do sistema (Processo 3), a qual necessita que os profissionais envolvidos possuam amplo conhecimento da dinâmica do sistema (Regra 1) e amplo conhecimento dos processos produtivos (Regra 2). Esta designação resulta na equipe formada (InfoSet 4).

Com a equipe de implantação integrada, são avaliadas as necessidades da empresa quanto à customização do sistema (Processo 4). A conclusão dessa avaliação e de todas as atividades inerentes resulta na modelagem do sistema (InfoSet 5).

Após o sistema estar devidamente modelado (InfoSet 5), são selecionados os produtos e/ou processos a serem utilizados nos testes (Processo 5), o que resulta na parametrização inicial do sistema (InfoSet 6). Com o sistema inicialmente parametrizado (InfoSet 6), são executados os testes iniciais (Processo 6), sendo que após sua conclusão, a equipe do processo de implantação disponibiliza um relatório sobre as funcionalidades do sistema (InfoSet 7).

Um dos processos mais relevantes do projeto de implantação do sistema APS é a geração de interface parametrizada com o ERP e outros sistemas de PCP (Processo 7). Com a integração devida e corretamente concluída, é gerada a parametrização final do sistema (InfoSet 8).

Após a geração desta parametrização, são executados os testes finais (Processo 8), e com o sistema devidamente parametrizado (InfoSet 9), os usuários finais do sistema recebem o treinamento (Processo 9).

Após a conclusão do treinamento, o projeto de implantação é validado pela Diretoria da empresa (InfoSet 10), e é gerada uma apostila, por parte da equipe de implantação, para auxílio aos futuros usuários do sistema (Processo 10). 

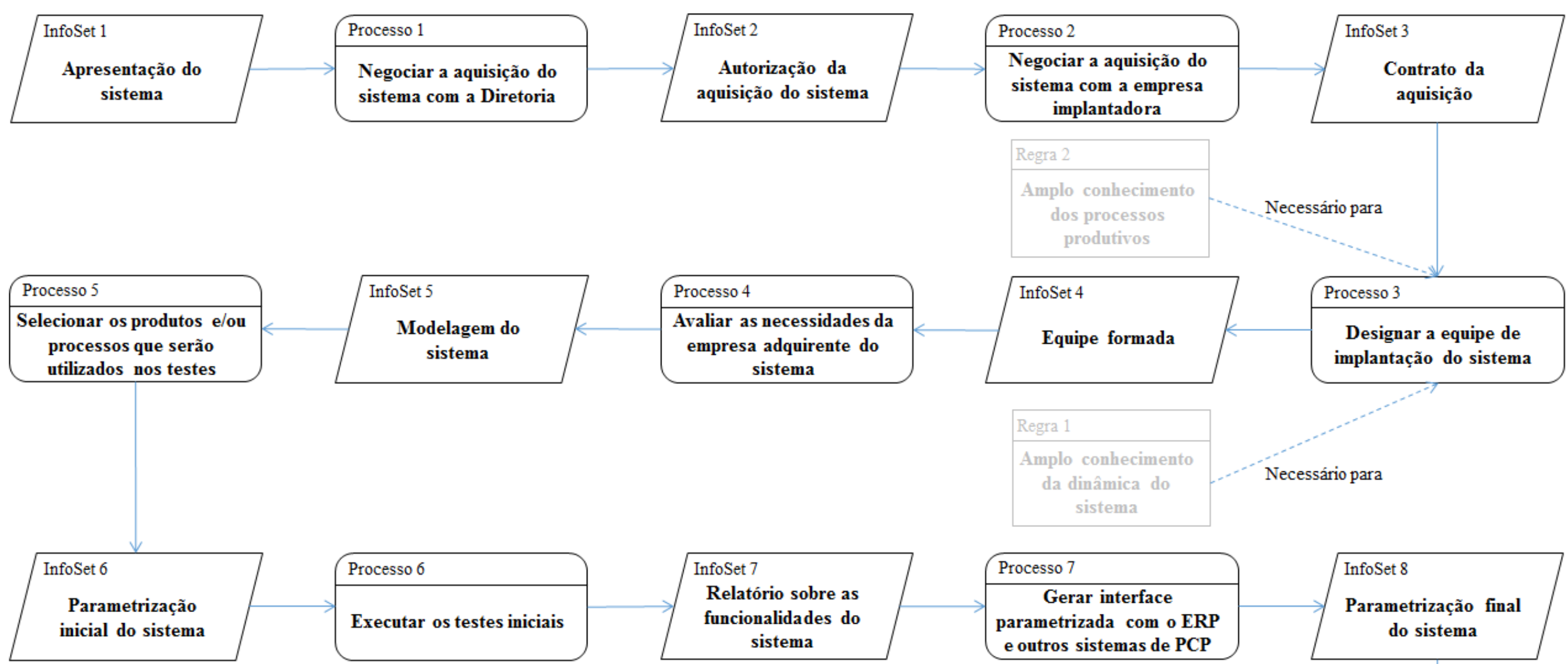

Designar a equipe de sistema

\begin{tabular}{|c|}
\hline $\begin{array}{c}\text { Processo } 10 \\
\begin{array}{c}\text { Gerar apostila para } \\
\text { ou futuros usuários } \\
\text { do sistema }\end{array}\end{array} \quad \begin{array}{c}\text { InfoSet } 10 \\
\text { Validação da } \\
\text { Diretoria }\end{array}$ \\
\hline
\end{tabular}

$k \quad$ Proc

\begin{tabular}{|c|}
\hline Processo 9 \\
\hline $\begin{array}{c}\text { Treinar os usuários finais } \\
\text { do sistema }\end{array}$ \\
\hline
\end{tabular}

$\leftarrow \quad \begin{gathered}\text { SnfoSet } 9 \\ \text { Sistema } \\ \text { devidamente } \\ \text { parametrizado }\end{gathered}$

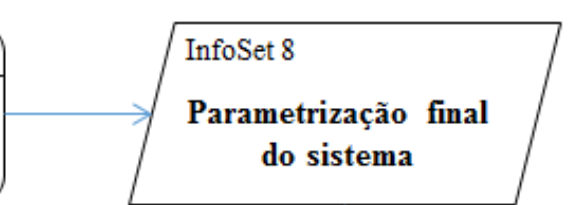

Figura 6 - Modelo de Processos - Estado Atual 


\subsubsection{Modelo de Atores e Recursos}

Neste modelo está descrito o papel dos principais envolvidos nas etapas do processo de implantação de sistemas APS, tomando como base os profissionais das empresas dos estudos de caso. A Figura 7 apresenta a visão geral do modelo.

O Diretor (Unidade Individual 1) da empresa adquirente do sistema APS (Unidade Organizacional 1) elabora as metas e objetivos do processo de implantação do sistema (Papel 1), aprova o orçamento (Recurso 1) e libera os recursos financeiros necessários para a sua aquisição (Recurso 2).

O Engenheiro de Produção (Unidade Individual 2) da empresa adquirente do sistema APS (Unidade Organizacional 1) realiza a apresentação do sistema para a Diretoria (Papel 2), exerce a função de coordenador do projeto de implantação (Papel 3), realiza os testes do sistema na empresa (Recurso 5), participa do treinamento dos usuários finais do sistema (Recurso 7) e realiza a validação do projeto (Recurso 8).

O Analista de PCP (Unidade Individual 3) da empresa adquirente do sistema APS (Unidade Organizacional 1) realiza a modelagem do sistema (Recurso 3), realiza os testes do sistema na empresa (Recurso 5), assim como o Analista de Produção (Unidade Individual 4) e o Analista de Vendas (Unidade Individual 6) recebe o treinamento dos usuários finais do sistema (Recurso 7), e junto com o Analista de Produção (Unidade Individual 4) exerce a função de usuário final (Papel 4).

O Analista de Tecnologia da Informação (Unidade Individual 5) da empresa adquirente do sistema APS (Unidade Organizacional 1) realiza a modelagem do sistema (Recurso 3), gera a interface parametrizada com o ERP e outros sistemas de PCP (Recurso 4), realiza os testes do sistema na empresa (Recurso 5), realiza a parametrização do sistema (Recurso 6) e é responsável pelo treinamento dos usuários finais (Recurso 7).

O Diretor (Unidade Individual 7) da empresa implantadora do sistema APS (Unidade Organizacional 2) define o orçamento (Recurso 1) e recebe os recursos financeiros (Recurso 2) da empresa adquirente do sistema APS (Unidade Organizacional 1).

O Consultor (Unidade Individual 8) da empresa implantadora do sistema APS (Unidade Organizacional 2) realiza a modelagem do sistema (Recurso 3), gera a interface parametrizada com o ERP e outros sistemas de PCP (Recurso 4), realiza os testes do sistema na empresa (Recurso 5), realiza a parametrização do sistema (Recurso 6) e disponibiliza apostila para auxiliar no uso do sistema (Recurso 9). 


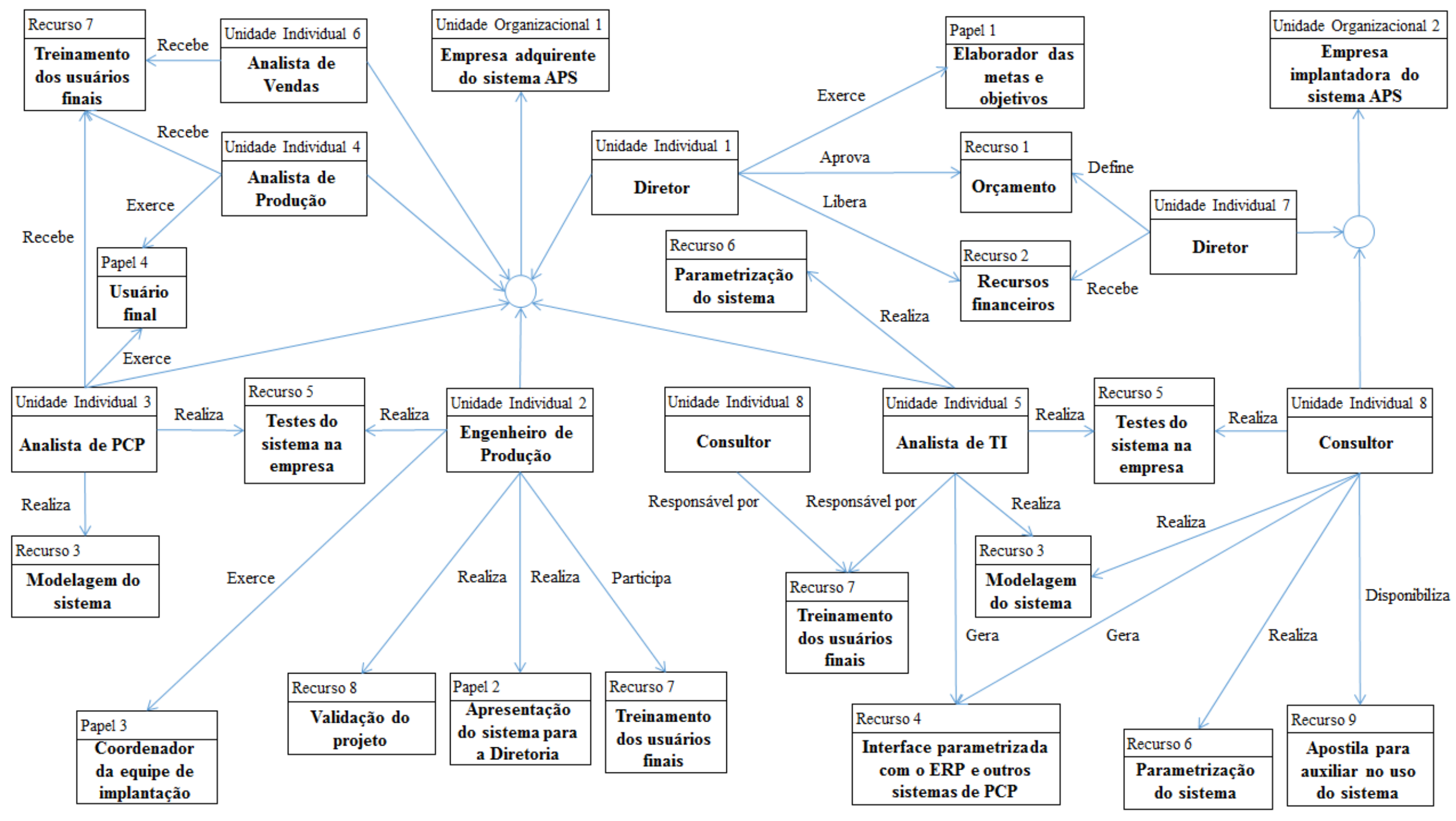

Figura 7 - Modelo de Atores e Recursos - Estado Atual 


\subsubsection{Modelo de Componentes e Requisitos Técnicos}

A Figura 8 apresenta o Modelo de Componentes e Requisitos Técnicos para apoio ao processo de implantação do sistema APS. Tal modelo foi desenvolvido a partir do conjunto de sistemas de informação utilizados pelas empresas que os possuíam para apoio ao processo de implantação e também com base em sistemas de apoio almejados por empresas que não os possuíam durante a execução de seu projeto.

Com base nas informações disponibilizadas, os objetivos do sistema de informação durante o processo de implantação do sistema APS nas empresas seriam gerar informações sobre os fluxos de processos (Objetivo SI 1) e permitir o envio e recebimento de informações pertinentes (Objetivo SI 2).

O sistema de informação para geração de informações sobre os fluxos de processos (Objetivo SI 1) e para envio e recebimento de informações pertinentes ao processo de implantação do sistema APS entre a empresa adquirente e a empresa implantadora (Objetivo SI 2) considera requisitos funcionais (que tangem a utilização do sistema de informação pretendido), bem como não funcionais (que tangem as medidas de segurança, usabilidade e acessibilidade, etc.). Tal sistema deve proporcionar interface amigável ao usuário (Requisito Não Funcional 1), possuir robustez (Requisito Não Funcional 2) e segurança (Requisito Não Funcional 3), restringindo o acesso apenas aos envolvidos nos processos, e também proporcionar o acesso remoto (Requisito Não Funcional 4) por meio da web aos profissionais envolvidos no projeto.

O objetivo "gerar informações sobre os fluxos de processos (Objetivo SI 1)" do sistema de informação, tem como requisitos funcionais relatar quais fluxos já foram testados (Requisito Funcional 1), informar quem testou os fluxos (Requisito Funcional 2), informar quando os fluxos foram testados (Requisito Funcional 3) e informar o resultado dos fluxos (Requisito Funcional 4). Para o cumprimento deste objetivo do sistema de informação o Consultor (Unidade Individual 8) e o Analista de Tecnologia da Informação (Unidade Individual 5) são os responsáveis pelo gerenciamento e o acesso é disponibilizado ao Consultor (Unidade Individual 8), Analista de Tecnologia da Informação (Unidade Individual 5), Analista de Vendas (Unidade Individual 6), Analista de Produção (Unidade Individual 4), Analista de PCP (Unidade Individual 3) e Engenheiro de Produção (Unidade Individual 2). Tal objetivo do sistema de informação apoia a garantia de maior integração entre as operações produtivas (Objetivo 4) por meio do forte relacionamento existente durante o processo de implantação, e apoia a eliminação de perdas por espera nos processos produtivos (Objetivo 6) ao poupar perdas de tempo com a desorganização do processo. 
O objetivo "permitir o envio e recebimento de informações pertinentes (Objetivo SI 2)" do sistema de informação, tem como requisitos funcionais relatar o andamento dos processos (Requisito Funcional 5) e gerenciar o tempo gasto em cada etapa do processo (Requisito Funcional 6). Para o cumprimento deste objetivo do sistema de informação o Consultor (Unidade Individual 8) e o Analista de Tecnologia da Informação (Unidade Individual 5) são os responsáveis pelo gerenciamento e o acesso ao sistema. Tal objetivo do sistema de informação apoia a eliminação de perdas por espera nos processos produtivos (Objetivo 6), apoia a ampliação do conhecimento da dinâmica do sistema (Regra 1), a realização de testes durante o processo de implantação (Regra 3) e a execução dos testes iniciais (Processo 6) e dos testes finais (Processo 8). 


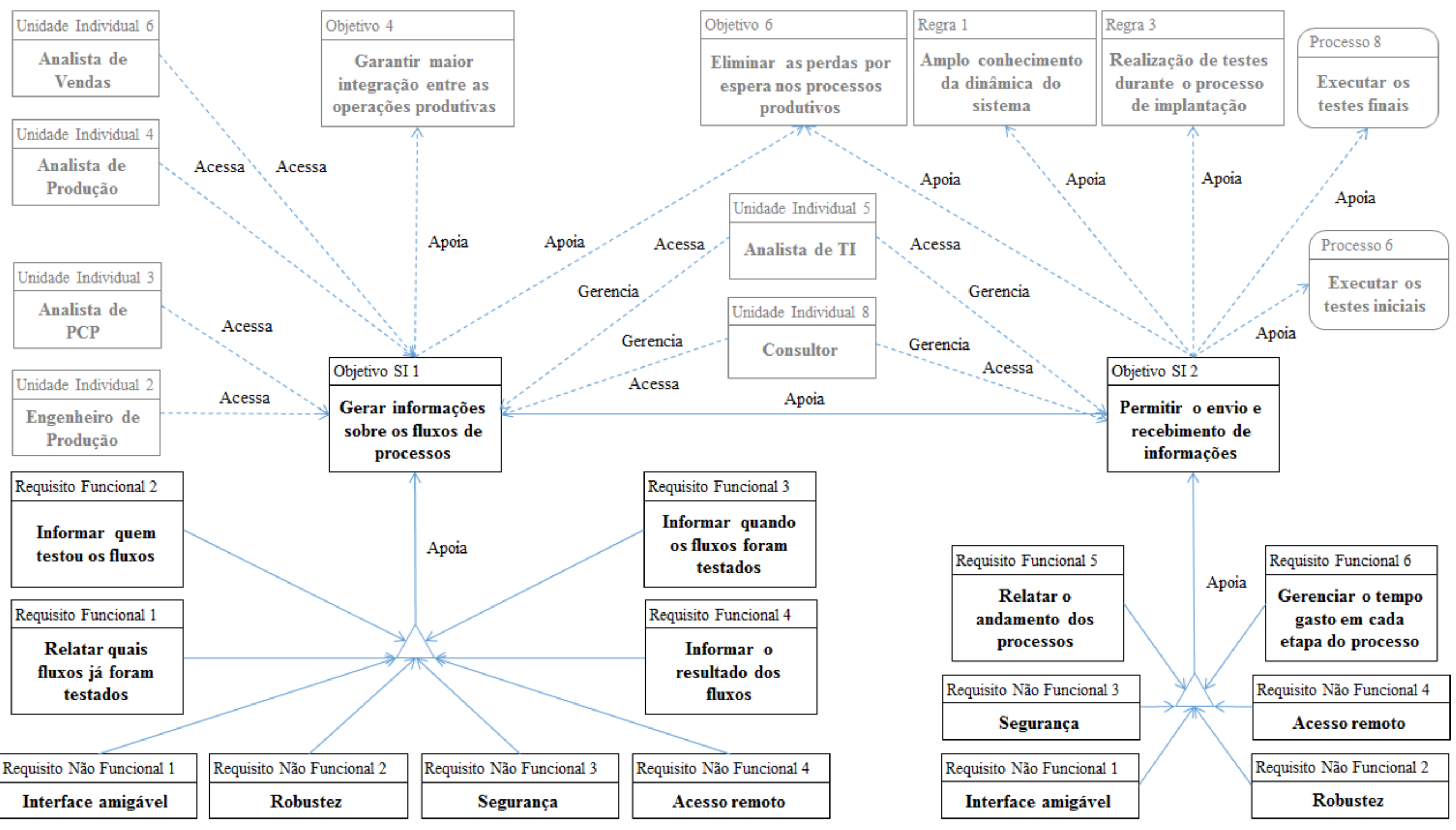

Figura 8 - Modelo de Componentes e Requisitos Técnicos - Estado Atual 


\subsection{Modelo de Necessidades de Mudanças}

Após analisar os modelos apresentados na seção anterior e com base na revisão da literatura, foi realizada uma comparação entre as características das redes de inovação autoorganizadas e as características inerentes aos processos de implantação de sistemas APS realizados atualmente. A realização dos estudos de caso demonstrou que o processo de implantação de sistemas APS nas empresas analisadas possuem diferenças significativas quanto às características de uma rede de inovação auto-organizada. A comparação resultou em um conjunto de mudanças necessárias para viabilizar a formação de uma rede auto-organizada nos processos de implantação.

O Quadro 5 apresenta as características das redes de inovação auto-organizadas encontradas na literatura, a presença ou ausência de cada característica em cada uma das empresas objeto de estudo, as evidências dos estudos de caso e as necessidades de mudanças para viabilizar a formação de uma rede auto-organizada no processo de implantação de sistemas APS. O Quadro 5 representa o Modelo de Necessidades de Mudanças (Modelo Need for Change) da metodologia EKD-CMM. As células preenchidas na coluna de ocorrência nas empresas, relatam a presença da característica, ainda que não totalmente desenvolvida, ao passo que as células não preenchidas relatam a ausência.

Conforme pode ser verificado no Quadro 5, a característica de adequação às mudanças impostas pelo ambiente foi encontrada em todas as empresas, pois o processo de implantação de sistemas APS por si só representa uma adequação, pois configura uma inovação organizacional nas empresas adquirentes. Portanto, pode-se afirmar que não existe necessidade de mudança para atendimento à esta característica.

A característica amplo conhecimento das competências dos atores envolvidos e acesso a essas competências apenas não foi encontrada na primeira empresa, embora nas outras empresas nem todos os funcionários participantes do processo de implantação compreendam isso claramente, pois geralmente apenas o Coordenador do Projeto em empresas adquirentes do sistema e os Consultores de empresas implantadoras conhecem as competências de cada envolvido. Como necessidade de mudança, propõe-se apresentar as competências de cada ator envolvido nas reuniões iniciais e disponibilizá-las a todos por meio de sistemas de informação.

A característica aprendizado e desenvolvimento conjunto da rede foi verificada apenas na sexta e na sétima empresa, porém, a geração de aprendizado ocorre primordialmente entre os principais atores envolvidos no projeto, o que pode centralizar o conhecimento. Como necessidade de mudança, propõe-se promover a geração de aprendizado por meio de maior 
interação entre os atores envolvidos nos encontros presenciais e utilização de sistemas de informação para envio e recebimento de informações pertinentes.

Quadro 5 - Necessidades de mudanças

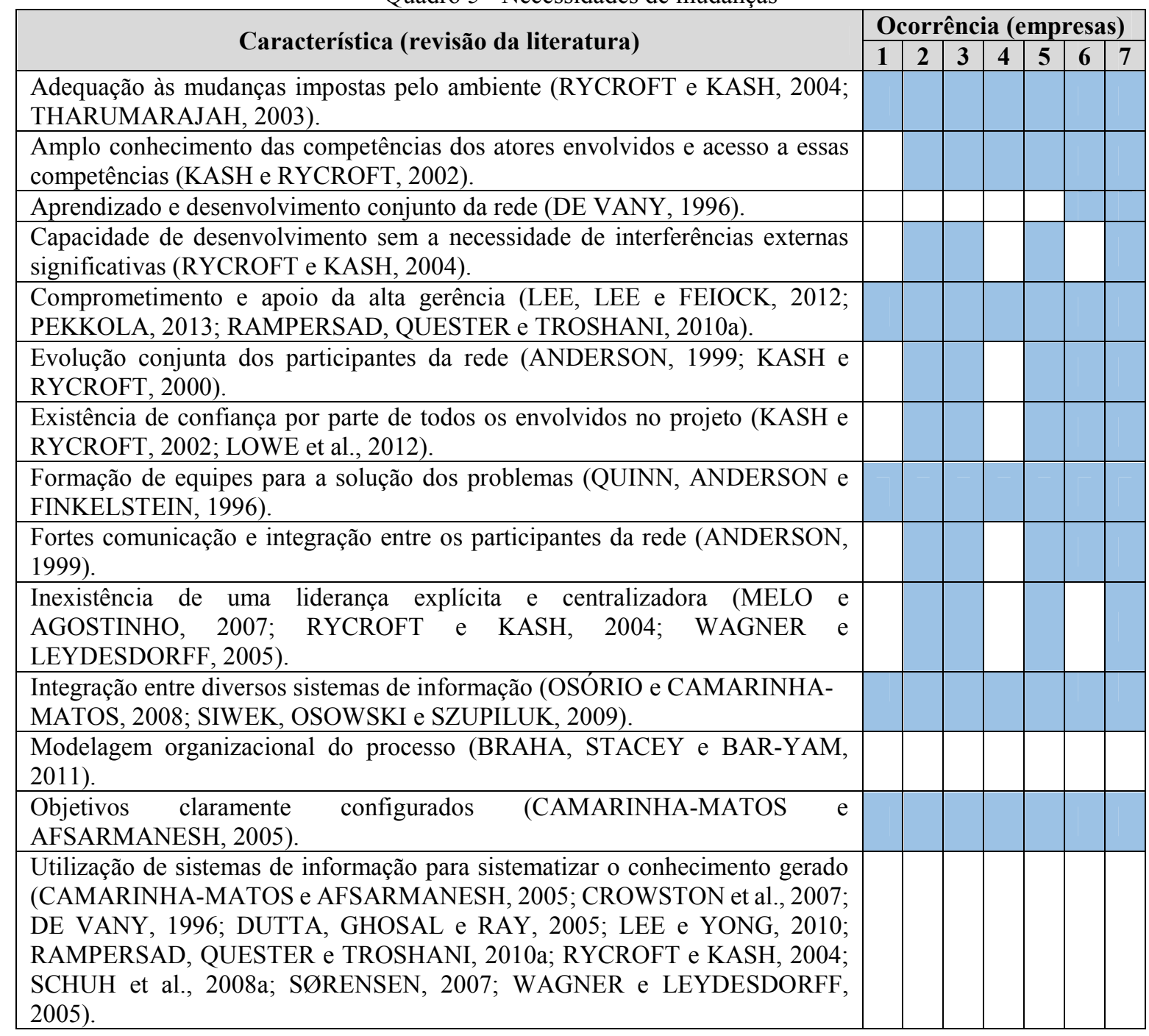

A característica capacidade de desenvolvimento sem a necessidade de interferências externas significativas foi encontrada na segunda, terceira, quinta e sétima empresa, e na primeira e na quarta, devido ao fato de as empresas não possuírem profissionais de Tecnologia da Informação atuando no projeto, existe muita dependência dos profissionais da empresa implantadora. Já a sexta empresa foi muito dependente das decisões tomadas na matriz estrangeira. Como necessidade de mudança, propõe-se disponibilizar treinamento intensivo de todos os atores envolvidos no projeto, selecionar funcionários com expressivas competências em Tecnologia da Informação e apresentar claramente os objetivos e possíveis benefícios aos diretores da matriz estrangeira.

A característica comprometimento e apoio da alta gerência foi contemplada por todas as empresas adquirentes do sistema, pois a Diretoria elaborou adequadamente as metas e 
objetivos e também disponibilizou todos os recursos necessários. Portanto, pode-se afirmar que não existe necessidade de mudança para atendimento à esta característica.

A característica evolução conjunta dos participantes da rede foi uma característica parcialmente encontrada nas segunda, terceira, quinta, sexta e sétima empresas, pois o processo de implantação destes casos foram os mais bem-sucedidos. É importante ressaltar que muitos atores envolvidos no projeto conhecem apenas as atividades inerentes a eles, sem uma visão ampla do projeto em si. Como necessidade de mudança, propõe-se a utilização de sistemas de informação para envio e recebimento de informações pertinentes e apresentação detalhada dos objetivos e principais processos necessários para o projeto.

A característica existência de confiança por parte de todos os envolvidos no projeto apenas não esteve presente na primeira e na quarta empresa, pois alguns funcionários destas empresas ainda mantêm uma certa resistência quanto ao uso e possíveis benefícios do sistema. Como necessidade de mudança, propõe-se apresentar claramente os principais benefícios que o sistema pode proporcionar e motivar os funcionários durante as reuniões iniciais do projeto.

A característica formação de equipes para a solução dos problemas foi encontrada em todas as empresas, pois as equipes são formadas apropriadamente, porém nem todos os participantes conhecem claramente todos os objetivos do projeto. Como necessidade de mudança, propõe-se avaliar as competências de cada ator envolvido e descrever claramente os objetivos do projeto a todos.

A característica fortes comunicação e integração entre os participantes da rede não existiu na primeira e quarta empresa, pois devido à inexistência de sistemas de informação de apoio ao projeto, estas características não são contempladas. Como necessidade de mudança, propõe-se a utilização de sistemas de informação para envio e recebimento de informações pertinentes.

A característica inexistência de uma liderança explícita e centralizadora foi contemplada parcialmente em algumas empresas, pois foi verificada a centralização das informações no Coordenador do Projeto de empresas adquirentes do sistema e nos Consultores de empresas implantadoras, bem como a dependência das decisões dos diretores da matriz estrangeira em uma empresa. Como necessidade de mudança, propõe-se delegar maior participação aos outros atores envolvidos no processo de implantação do sistema.

A característica integração entre diversos sistemas de informação foi contemplada por todas as empresas, pois para a utilização de sistemas APS é primordial a integração entre estes e outros sistemas de PCP. Portanto, pode-se afirmar que não existe necessidade de mudança para atendimento à esta característica. 
A característica modelagem organizacional do processo de implantação não foi contemplada por nenhuma das empresas. Como necessidade de mudança, propõe-se gerar consiste e correta modelagem organizacional do processo para compreender a ligação entre as empresas, dinâmica, robustez e fragilidade das atividades desenvolvidas e o papel de cada ator envolvido.

A característica objetivos claramente configurados foi contemplada por todas as empresas, porém não é de conhecimento de todos os envolvidos no projeto. Como necessidade de mudança, propõe-se apresentar claramente os principais benefícios que o sistema pode proporcionar e o que a empresa almeja com sua implantação.

A característica utilização de sistemas de informação para sistematizar o conhecimento gerado não foi contemplada por nenhuma empresa, pois nem todas as empresas possuem sistemas de informação de apoio aos processos de implantação, e as que possuem não contemplam esse objetivo em seu sistema. Como necessidade de mudança, propõe-se utilizar sistemas de informação para troca de experiência e informações entre os atores envolvidos, depósito de arquivos e documentação do projeto.

\subsection{Considerações finais}

A competitividade das empresas no cenário econômico atual é um importante fator para sua sobrevivência e as constantes buscas por inovação representam um dos mecanismos mais relevantes para sua manutenção e/ou aumento. A implantação de sistemas APS representa uma das mais relevantes inovações organizacionais na área de PCP, e de acordo com dados coletados nos estudos de caso realizados na pesquisa de campo deste trabalho e na revisão da literatura; as empresas que os implantam podem se tornar mais competitivas por meio da redução dos lead times industriais, com consequentes redução de prazos de entrega e aumento e antecipação do faturamento; melhoria de sua reputação junto aos clientes; maior produtividade no trabalho; melhor gerenciamento da cadeia de suprimentos; dentre outros benefícios.

$\mathrm{Na}$ literatura é destacado que apesar de todos benefícios que os sistemas APS proporcionam, para que os mesmos sejam obtidos, é necessário que o processo de implantação seja realizado de maneira bem-sucedida. Fatores como apoio e comprometimento da alta gerência da empresa, autonomia, confiança no sistema, motivação e treinamento dos funcionários, consistente e correta modelagem organizacional do processo, integração com outros sistemas de PCP e cooperação entre os profissionais envolvidos no projeto são de grande importância para a realização bem-sucedida do processo de implantação. 
Por meio de revisão da literatura, foi verificado que a formação de redes de inovação auto-organizadas mostra-se relevante para a condução de processos de geração de inovação organizacional semelhantes a projetos de implantação de sistemas APS, pois esta formação além de permitir o alcance dos fatores necessários para realização bem-sucedida, ajuda a explorar as competências dos membros envolvidos, facilitando a transferência de conhecimento entre eles. Nesse sentido, foi proposta a seguinte questão de pesquisa: "analisando o processo de implantação de sistemas APS sob a perspectiva do recorte analítico de redes de inovação auto-organizadas, quais elementos dessas redes podem apoiar o processo?’. Para responder esta questão, foram realizados sete estudos de caso para analisar a presença ou ausência desses elementos no processo de implantação.

Por meio de informações obtidas em sete estudos de caso foi verificado que apesar de alguns funcionários de empresas adquirentes de sistemas APS terem conhecimento da importância de fatores inerentes à redes de inovação auto-organizadas tais como autonomia, colaboração, confiança, transferência de conhecimento, configuração clara dos objetivos e participação ativa dos envolvidos no projeto de implantação do sistema, eles dispendem pouca atenção à essas práticas.

Esta pesquisa apresenta contribuições tanto para a literatura de sistemas APS, ao propor uma nova abordagem analítica para o processo de implantação; quanto para a literatura de redes de inovação auto-organizadas, ao apresentar a formação dessas redes para condução de processos de geração de inovação organizacional.

Com relação às limitações inerentes deve ser destacada o não atendimento a todas as sugestões propostas pela metodologia EKD. Na metodologia é indicado reunir um grupo de pessoas para realizar a modelagem organizacional do processo de implantação em cada empresa. Nas entrevistas, devido às restrições impostas pela Diretoria, participaram apenas os principais funcionários que participaram do projeto de implantação.

No próximo capítulo do trabalho, é apresentado o Modelo To-Be da metodologia EKDCMM, constituído pelas informações obtidas no Modelo $A s-I s$ e que incorpora as recomendações do Modelo de Necessidades de Mudanças. O atendimento a esta proposta, seguindo todas as etapas sinalizadas por Ahlemann e Gastl (2007), permitiu a geração de um modelo de referência para implantação sob a perspectiva de redes de inovação autoorganizadas, já que por meio da aplicação do conhecimento disponibilizado por eles, modelos de referência são eficientes para apoiar projetos semelhantes em outras organizações (REINHARTZ-BERGER, SOFFER e STURM, 2010). 


\section{MODELO DE REFERÊNCIA}

No âmbito interno de uma empresa industrial, a área de planejamento e controle da produção é uma das mais importantes, pois é intimamente relacionada com o alcance dos objetivos estratégicos definidos pela alta gerência para sua sobrevivência, competitividade e crescimento no mercado em que atua. Dentre os sistemas computadorizados desenvolvidos desde a década de 1970 para gestão dos processos e atividades inerentes à esta área, os sistemas APS são considerados como os mais eficazes para o planejamento e programação da produção e demais atividades relacionadas. A implantação de sistemas complexos tais como o APS representa uma inovação organizacional na empresa, pois eles são métodos organizacionais que visam a melhoria de desempenho. Contudo, para que os possíveis benefícios destes sistemas sejam alcançados, é necessário implantá-los de maneira bem-sucedida. Por meio de uma revisão da literatura, verifica-se que as implantações de sistemas APS são muito limitadas à características particulares de determinada empresa, as instruções para o processo de implantação não são muito detalhadas, após a conclusão do projeto existe muita dependência da empresa implantadora, o conhecimento gerado pode não ser muito adequado a outros processos de implantação, e os relacionamentos entre a empresa adquirente e implantadora do sistema ainda são pouco compreendidos. Tendo em vista que a formação de redes auto-organizadas representa um mecanismo adequado para conduzir processos de geração de inovação em empresas, já que a abordagem analítica de redes de inovação permite a verificação das ligações e relacionamentos entre empresas e entre áreas funcionais dentro de uma empresa, que modelos de referência permitem coordenar o processo de mudança associado à implantação de uma inovação, esta pesquisa apresenta um modelo de referência para a implantação de sistemas APS sob a perspectiva de redes de inovação auto-organizadas. O modelo de referência apresentado foi desenvolvido por meio da metodologia de modelagem organizacional Enterprise Knowledge Development (EKD), a qual engloba os objetivos, regras do negócio, processos, atores e recursos, componentes e requisitos técnicos, e conceitos envolvidos no projeto.

Nesta etapa, enfatizou-se a modelagem do estado futuro (Modelo $T o-B e$ ) do processo de implantação de sistemas APS, desenvolvida por meio das informações obtidos em campo por meio dos sete estudos de caso realizados; e também das diretrizes para a implantação de 
sistemas APS e dos elementos das redes de inovação auto-organizadas, ambos apresentados pela literatura.

Os seis submodelos do Modelo To-Be desenvolvido compõem o modelo de referência apresentado nesta pesquisa. Este modelo pode ser considerado um modelo de referência porque permite visualizar os estados atual e futuro (BUBENKO, PERSSON e STIRNA, 2001) do processo de implantação de sistemas APS, foi desenvolvido a partir de situações práticas e de teorias formuladas (VERNADAT, 1996), e captou processos e informações comuns em sete empresas (MATOOK e INDULSKA, 2009; REINHARTZ-BERGER, SOFFER e STURM, 2010), visando auxiliar na compreensão de todos os possíveis sistemas de informação de apoio, relacionamentos, entidades, processos, objetivos, regras e conceitos significativos do projeto (ROMERO e MOLINA, 2010).

Para que este modelo de referência fosse desenvolvido foram ser seguidas as fases de planejamento, construção, validação, teste e documentação, recomendadas por Ahlemann e Gastl (2007) para o desenvolvimento de modelos de referência. É importante ressaltar que para validar o modelo de referência desenvolvido nesta pesquisa, foi enviado um questionário para especialistas na área, profissionais das sete empresas dos estudos de caso que participaram do processo de implantação e profissionais de duas empresas implantadoras destes sistemas, para que os mesmos verificassem sua consistência. Para testar o modelo, o mesmo foi disponibilizado a duas empresas implantadoras de sistemas APS para que ele possa ser replicado em futuros processos de implantação e posteriormente documentado.

\subsection{Modelos de referência: caracterização e conceituação}

Camarinha-Matos e Afsarmanesh (2007) afirmam que no contexto de um sistema complexo como uma rede colaborativa, a modelagem é fundamental para compreender, gerenciar, simular ou prever o comportamento da rede e para o desenvolvimento de softwares. $\mathrm{O}$ alcance de interoperabilidade em um ambiente de redes colaborativas requer modelos adequados, plataformas de tecnologia de informação e comunicação para apoiar operações interorganizacionais e troca de informações em tempo real, adequado alinhamento tecnológico e gerencial, bem como ferramentas e modelos adequados para monitoramento e avaliação do desempenho (CHITUC, AZEVEDO e TOSCANO, 2009).

De acordo com Bubenko, Persson e Stirna (2001), uma maneira de coordenar o processo de mudança associado à implantação de uma inovação é utilizar um modelo de referência que permita visualizar os estados presente e futuro, os recursos necessários para a transição, os caminhos disponíveis e as justificativas necessárias para a tomada de decisão e obtenção do 
apoio da alta administração. Modelos de referência industriais geralmente envolvem práticas de negócio comprovadas e podem ser usados como um ponto de partida para processos de geração de inovação (SCHUH et al., 2008b).

Um modelo de referência é um modelo que pode ser usado para o desenvolvimento ou avaliação de um modelo particular e que pode ser desenvolvido a partir de situações do mundo real (melhores práticas) ou de teorias (VERNADAT, 1996). De acordo com Ahlemann (2009), pode ser definido como um modelo de informação usado para apoiar a construção de outros modelos. Auxiliam na compreensão de todos os possíveis relacionamentos, entidades e conceitos significativos de algum domínio, visando fornecer diretrizes e facilitar a criação de modelos específicos (ROMERO e MOLINA, 2010). Espera-se deles a aceleração do desenvolvimento de sistemas de informação, redução dos custos associados, apoio à comunicação de ideias inovadoras e melhores práticas e redução dos riscos de fracasso (AHLEMANN, 2009). Projetistas e analistas usam modelos de referência para orientar modelos de processos que satisfazem seus requisitos particulares, pois eles podem reduzir o tempo e esforço necessários para a modelagem (HADDAR, MAKNI e ABDALLAH, 2014).

De acordo com Haddar, Makni e Abdallah (2014) modelos de referência podem ser distinguidos por meio de critérios tais como escopo coberto pelas suas funcionalidades, suas granularidades, as visões que eles descrevem (processo, informações, objetos, organização), grau de integração entre as visões, propósitos apoiados, grupos de usuários discutidos, disponibilidade de maior explicação textual, inclusão explícita de cenários alternativos de negócios e a existência de diretrizes sobre como reusá-los.

Modelos de referência são recomendados na modelagem empresarial para aumentar a eficiência do processo de modelagem, permitindo o reuso desses modelos em uma maneira sistemática e não apenas improvisada (GOEPP, ROSE e CAILLAUD, 2014). De acordo com Haddar, Makni e Abdallah (2014), dependendo do tipo e nível de abstração de um modelo de referência, existem quatro técnicas de reuso propostas na literatura: reuso por adoção, montagem, especialização e customização. O reuso por adoção é aplicável quando os modelos são muito detalhados e podem ser usados na totalidade para a empresa sob consideração. $\mathrm{O}$ reuso por montagem sustém-se em reusar partes úteis do processo de construção do modelo de referência. O reuso por especialização é permitido por modelos que fornecem conhecimento em um alto nível de abstração. O reuso por customização lida com modelos configuráveis que são criados para serem usados em um domínio específico e serem customizados em projetos diferentes. 
Ahlemann e Gastl (2007), afirmam que para que modelos de referência sejam desenvolvidos devem ser seguidas, sequencialmente, as seguintes etapas:

1) Planejamento: esta etapa engloba atividades como identificação do modelo, métodos usados para criá-lo, as ferramentas computacionais implantadas, a organização da modelagem de referência e o planejamento do projeto;

2) Construção: esta etapa abrange atividades como captura do domínio de conhecimento, construção de um quadro de referência, preparação da primeira investigação empírica, execução da primeira investigação empírica e construção do modelo inicial;

3) Validação: esta etapa compreende atividades como planejamento e execução da segunda investigação empírica e refinamento do modelo;

4) Teste: esta etapa abrange as atividades de aplicação e refinamento do modelo de referência; e

5) Documentação do modelo de referência.

De acordo com Camarinha-Matos e Afsarmanesh (2008), modelos de referência são necessários para a consolidação e desenvolvimento sustentável da área de redes colaborativas e, no processo de definição e estabelecimento de um modelo de referência, é fundamental considerar as entradas e contribuições parciais de trabalhos anteriores.

\subsection{Modelo de referência para a implantação de sistemas APS sob a perspectiva de redes de inovação auto-organizadas}

Nesta seção é apresentado o modelo de referência para o processo de implantação de sistemas APS em empresas sob a perspectiva de redes de inovação auto-organizadas, o qual foi desenvolvido com base nos dados coletados nos sete estudos de caso, nas recomendações da literatura para a implantação de sistemas APS e nos construtos das redes de inovação autoorganizadas que podem funcionar como elementos de apoio ao projeto. Este modelo apresenta a sistematização do processo de implantação de sistemas APS em empresas por meio da modelagem organizacional realizada com a metodologia EKD-CMM, compreendendo o estado futuro ou Modelo To-Be da metodologia.

O modelo apresentado contempla os seis submodelos da metodologia EKD, sendo eles o Modelo de Objetivos, Modelo de Regras do Negócio, Modelo de Processos, Modelo de Atores e Recursos, Modelo de Componentes e Requisitos Técnicos, e Modelo de Conceitos. É importante ressaltar que nas figuras que representam os seis submodelos, as caixas destacadas com a cor branca representam informações provenientes dos estudos de caso e as caixas 
preenchidas com a cor cinza representam informações provenientes da literatura sobre processos de implantação de sistemas APS e redes de inovação auto-organizadas.

\subsubsection{Modelo de Objetivos}

A Figura 9 apresenta o Modelo de Objetivos do processo de implantação de sistemas APS sob a perspectiva de redes de inovação auto-organizadas. Como pode ser visto na Figura 9, com a implantação de sistemas APS as empresas visam garantir maior produtividade e excelência no ambiente de trabalho (Objetivo 5), o que é possível com a garantia de maior eficácia (Objetivo 5.1) e maior eficiência (Objetivo 5.2), e gera redução de custos na empresa (Oportunidade 5) e resulta em melhor organização industrial (Oportunidade 4). Porém, para que isso seja alcançado, é necessário enfrentar a resistência cultural dos funcionários (Restrição 1) no que se refere ao receio à mudanças nos processos produtivos (Restrição 1.1) e receio à informática (Restrição 1.2) e também explicar detalhadamente os objetivos do projeto e os benefícios oriundos da implantação, para que não haja incompreensão do sistema (Restrição 2).

A garantia de maior produtividade e excelência no ambiente de trabalho (Objetivo 5) apoia a eliminação das perdas por espera nos processos produtivos (Objetivo 6), o que apoia a redução da ociosidade de recursos (Oportunidade 6), redução de lead times (Oportunidade 7) e redução de estoques (Oportunidade 8).

A eliminação das perdas por espera nos processos produtivos (Objetivo 6) apoia a garantia de balanceamento da cadeia de suprimentos (Objetivo 7), a qual, por sua vez, possibilita a otimização da capacidade produtiva (Oportunidade 12).

A integração entre os sistemas APS, ERP e outros sistemas de PCP visa garantir maior integração entre as operações produtivas (Objetivo 4), especialmente as realizadas nas unidades de Produção (Objetivo 4.1), Aquisições (Objetivo 4.2), Comercial (Objetivo 4.3) e Distribuição (Objetivo 4.4). Tal integração apoia a garantia de balanceamento da cadeia de suprimentos (Objetivo 7) e possibilita melhor visualização do status dos pedidos (Oportunidade 11).

Com a utilização dos sistemas APS é possível garantir melhor programação da produção (Objetivo 3), o que é o resultado da garantia de melhor sequenciamento (Objetivo 3.1), garantia de melhor alocação de carga (Objetivo 3.2), garantia de coleta rápida de informações (Objetivo 3.3), garantia de melhor planejamento das aquisições (Objetivo 3.4), garantia de atualização instantânea das ordens de produção (Objetivo 3.5) e garantia de ajuste automático (Objetivo 3.6). Uma melhor programação da produção (Objetivo 3) resulta em apoio ao processo de tomada de decisão (Oportunidade 10) e inovação organizacional na empresa (Oportunidade 13). O uso parcial do sistema (Ameaça 1) devido a inconsistentes modelagens e falta de 
conhecimento dos funcionários, bem como a falta de atualização do mesmo (Ameaça 2) prejudicam a garantia de melhor programação da produção (Objetivo 3).

A garantia de melhor programação da produção (Objetivo 3) e a garantia de balanceamento da cadeia de suprimentos (Objetivo 7) apoiam a garantia de prazos de entrega mais curtos (Objetivo 2), o que gera melhoria do atendimento aos clientes (Oportunidade 2), e aumento e antecipação do faturamento (Oportunidade 3).

A garantia de prazos de entrega mais curtos (Objetivo 2) apoia a garantia de confiabilidade no planejamento estratégico (Objetivo 1), o que gera aumento da satisfação dos clientes (Oportunidade 1), consequentemente, melhorando a imagem da empresa no mercado, e apoia a obtenção de novos clientes (Oportunidade 9). 


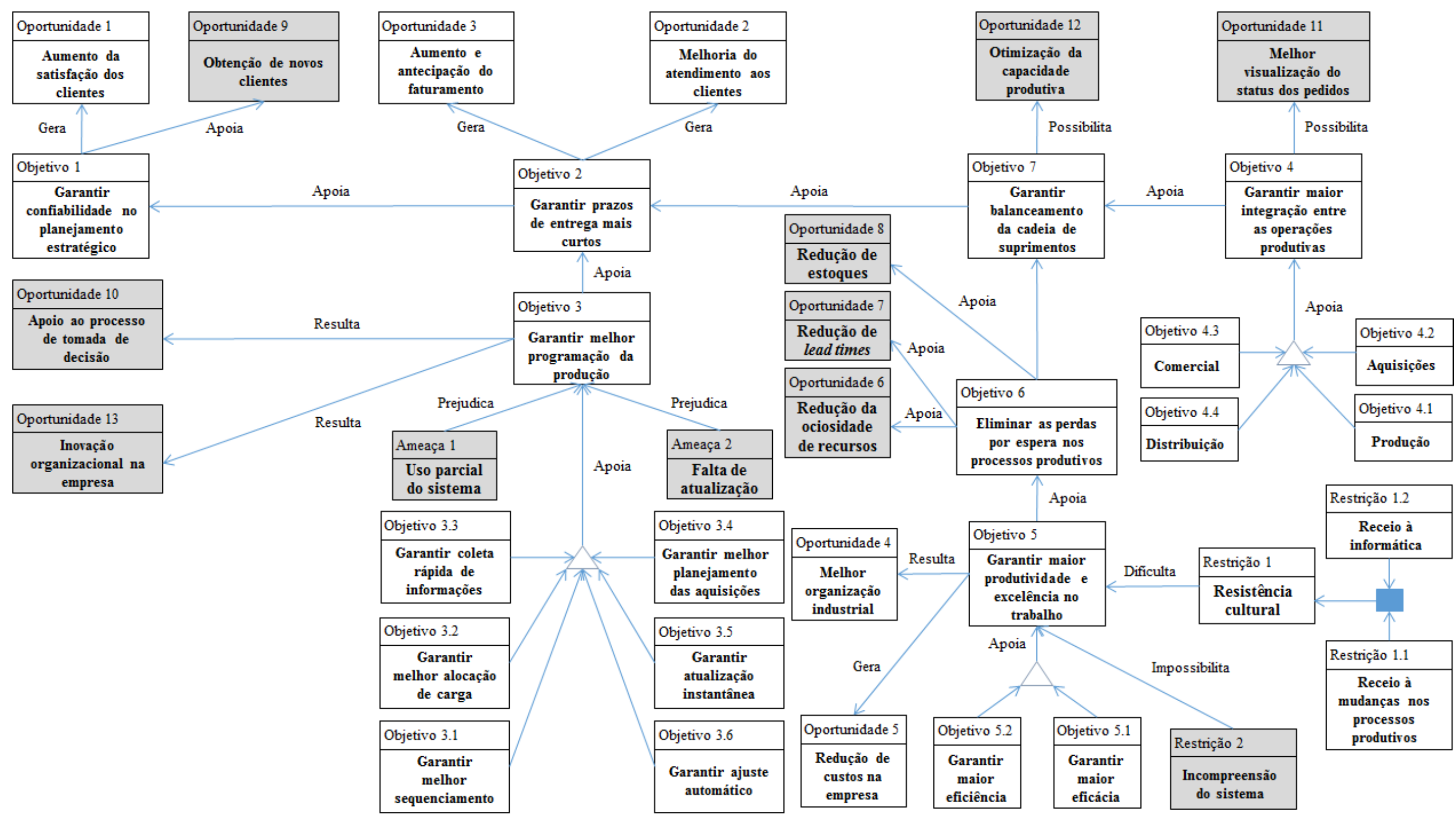

Figura 9 - Modelo de Objetivos - Estado Futuro 


\subsubsection{Modelo de Regras do Negócio}

O Modelo de Regras do Negócio mostra a influência das regras do processo de implantação do sistema APS sobre os objetivos do processo. Tal modelo está representado na Figura 10.

O treinamento dos usuários finais para o uso do sistema (Regra 1.1) apoia a ampliação do conhecimento do sistema (Regra 1), o que é necessário para garantir maior produtividade e excelência no trabalho (Objetivo 5), apoiar a eliminação das perdas por espera nos processos produtivos (Objetivo 6), apoiar a garantia de balanceamento da cadeia de suprimentos (Objetivo 7) e apoiar a garantia de confiabilidade no planejamento estratégico (Objetivo 1).

A adaptação da solução do sistema às necessidades da empresa (Regra 2.1) e o fornecimento de diversas informações (Regra 2.2) apoiam o amplo conhecimento dos processos produtivos (Regra 2), o que apoia a garantia de maior integração entre as operações produtivas (Objetivo 4) e é necessário para garantir melhor programação da produção (Objetivo 3).

A realização de testes durante o processo de implantação do sistema (Regra 3) verifica se com sua utilização é possível garantir melhor programação da produção (Objetivo 3).

A integração com o ERP e outros sistemas de PCP (Regra 4) e a parametrização do sistema (Regra 5) são condições necessárias para garantir melhor programação da produção (Objetivo 3) e garantir maior integração entre as operações produtivas (Objetivo 4).

O cumprimento dos prazos de entrega (Regra 6) é uma condição necessária para garantir prazos de entrega mais curtos (Objetivo 2).

O comprometimento da alta gerência (Regra 7) apoia a garantia de maior integração entre as operações produtivas (Objetivo 4) e a garantia de confiabilidade no planejamento estratégico (Objetivo 1).

A manutenção da parceria com a empresa implantadora do sistema APS (Regra 11.1) é necessária para realizar as constantes atualizações do sistema (Regra 11), o que é necessário para garantir melhor programação da produção (Objetivo 3).

A redução da dependência da empresa implantadora do APS (Regra 10.1) motiva a participação ativa dos membros e usuários finais (Regra 10) no processo de implantação do sistema, o que, em conjunto com a motivação dos usuários finais (Regra 9), apresentação dos objetivos do projeto a todos os envolvidos (Regra 8), cooperação entre os envolvidos no projeto (Regra 13) e autonomia (Regra 12) apoia a garantia de maior produtividade e excelência no trabalho (Objetivo 5). 


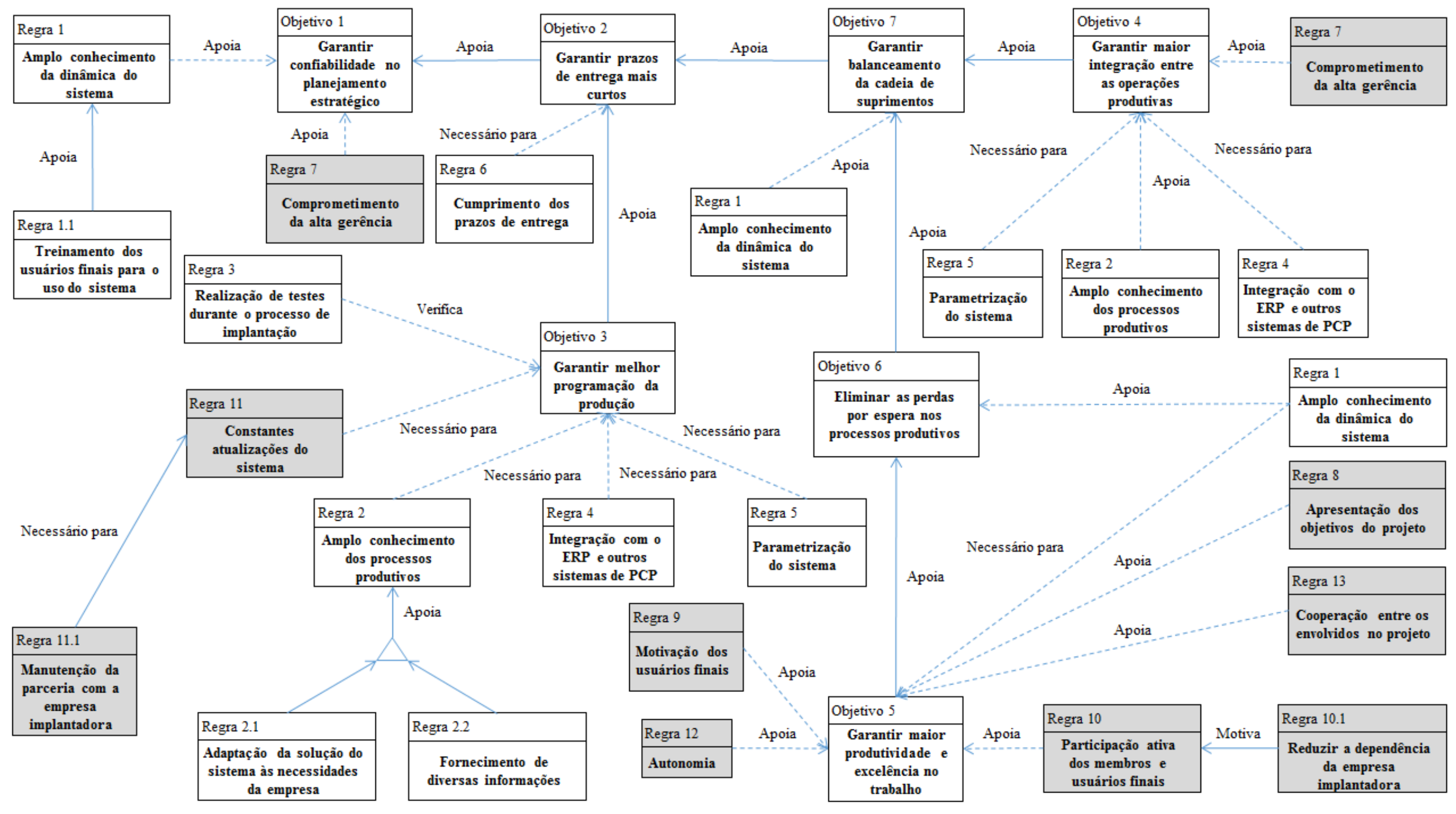

Figura 10 - Modelo de Regras do Negócio - Estado Futuro 


\subsubsection{Modelo de Processos}

De modo geral, com base nas informações obtidas em campo nas sete empresas e na literatura, durante o processo de implantação de sistemas APS, a equipe de implantação deve realizar 22 principais processos, os quais estão representados na Figura 11.

Após analisarem o estado atual da área de PCP da empresa (Processo 1), os funcionários envolvidos geram uma lista com a definição dos indicadores de desempenho almejados pelo sistema a ser adquirido (InfoSet 1). Após estarem cientes da necessidade de aquisição de um sistema de PCP mais eficiente e eficaz, funcionários da área pertinente avaliam os principais sistemas disponíveis no mercado (Processo 2), etapa que, após concluída, define o sistema mais adequado à empresa (InfoSet 2).

Com o sistema devidamente selecionado (InfoSet 2), profissionais envolvidos com projetos de melhoria nas empresas negociam a aprovação da aquisição do sistema APS com a Diretoria da empresa (Processo 3), com posterior apresentação do sistema (InfoSet 3).

Após a apresentação do sistema (InfoSet 3), os funcionários da área pertinente levantam e posteriormente apresentam todos os custos do projeto para a Diretoria (Processo 4). Com a autorização da aquisição do sistema por parte da Diretoria (InfoSet 4), inicia-se a negociação da aquisição do sistema com a empresa implantadora selecionada (Processo 5), o que resulta no contrato de aquisição do sistema (InfoSet 5).

Após a conclusão de todos os acordos legais, os coordenadores do processo iniciam a identificação de profissionais competentes e comprometidos para o projeto de implantação (Processo 6) resultando em uma equipe devidamente designada (InfoSet 6).

Com a equipe do projeto de implantação designada (InfoSet 6) são definidos os papéis, recursos e atividades a serem realizadas por cada membro do projeto (Processo 7), os quais serão apresentados na reunião com todos os membros do projeto (InfoSet 7). Nessa reunião, os coordenadores devem buscar promover maior autonomia e interação entre os membros do projeto (Processo 8), e com a equipe motivada (InfoSet 8), apresentar os sistemas de informação de apoio ao processo de implantação (Processo 9), disponibilizando a permissão de acesso aos sistemas de apoio aos membros (InfoSet 9).

Após a apresentação dos papéis e responsabilidades de cada membro envolvido e dos sistemas de informação de apoio ao projeto os funcionários representantes de cada área impactada pelo sistema e os coordenadores do projeto especificam e avaliam as necessidades da empresa quanto aos requisitos do sistema (Processo 10), o que resulta em um relatório com a organização de informações e parâmetros (InfoSet 10). 
Com as informações e parâmetros definidos (InfoSet 10), é desenvolvido um modelo inicial com limitadas complexidade e funcionalidade (Processo 11), o que resulta na modelagem do sistema (InfoSet 11). Com o sistema modelado (InfoSet 11), são selecionados os produtos e/ou processos que serão utilizados nos testes (Processo 12), o que resulta na parametrização inicial do sistema (InfoSet 12). Com o sistema inicialmente parametrizado (InfoSet 12), são executados os testes iniciais (Processo 13), sendo que após sua conclusão, com o sistema aprovado (InfoSet 13), toda a equipe do projeto de implantação do sistema discute os resultados (Processo 14), sendo gerado um relatório sobre as funcionalidades do sistema (InfoSet 14). Tal relatório (InfoSet 14) deve ser disponibilizado por meio dos sistemas de informação de apoio ao projeto (Processo 15). Em seguida, deve ser realizada uma reunião com todos os membros do projeto (InfoSet 15) para que todos possam avaliar as funcionalidades para corrigir prováveis erros e acrescentar as possíveis melhorias ao modelo (Processo 16).

Caso necessário, esta avaliação resulta na remodelagem do sistema (InfoSet 16). Subsequentemente, é iniciado o treinamento dos usuários finais do sistema (Processo 17), e com os funcionários devidamente treinados (InfoSet 17), é gerada a interface parametrizada entre o APS e o ERP e/ou o APS e outros sistemas de PCP (Processo 18). Esta integração resulta na parametrização final do sistema (InfoSet 18) e, após isso são executados os testes finais (Processo 19).

Após a realização dos testes finais (Processo 19) e com o sistema devidamente parametrizado (InfoSet 19) é fornecido um treinamento adicional aos usuários finais do sistema (Processo 20).

Com os usuários finais devidamente capacitados (InfoSet 20), os profissionais da empresa adquirente membros do projeto devem firmar parceria com a empresa implantadora, para futuras atualizações do sistema (Processo 21). A conclusão bem-sucedida dessas atividades possibilita a validação do projeto pela Diretoria (InfoSet 21). Os profissionais da empresa adquirente envolvidos no processo, junto com os Consultores da empresa implantadora, devem documentar os resultados do projeto (Processo 22), e por fim, disponibilizar uma apostila para auxiliar os futuros usuários do sistema (InfoSet 22). 


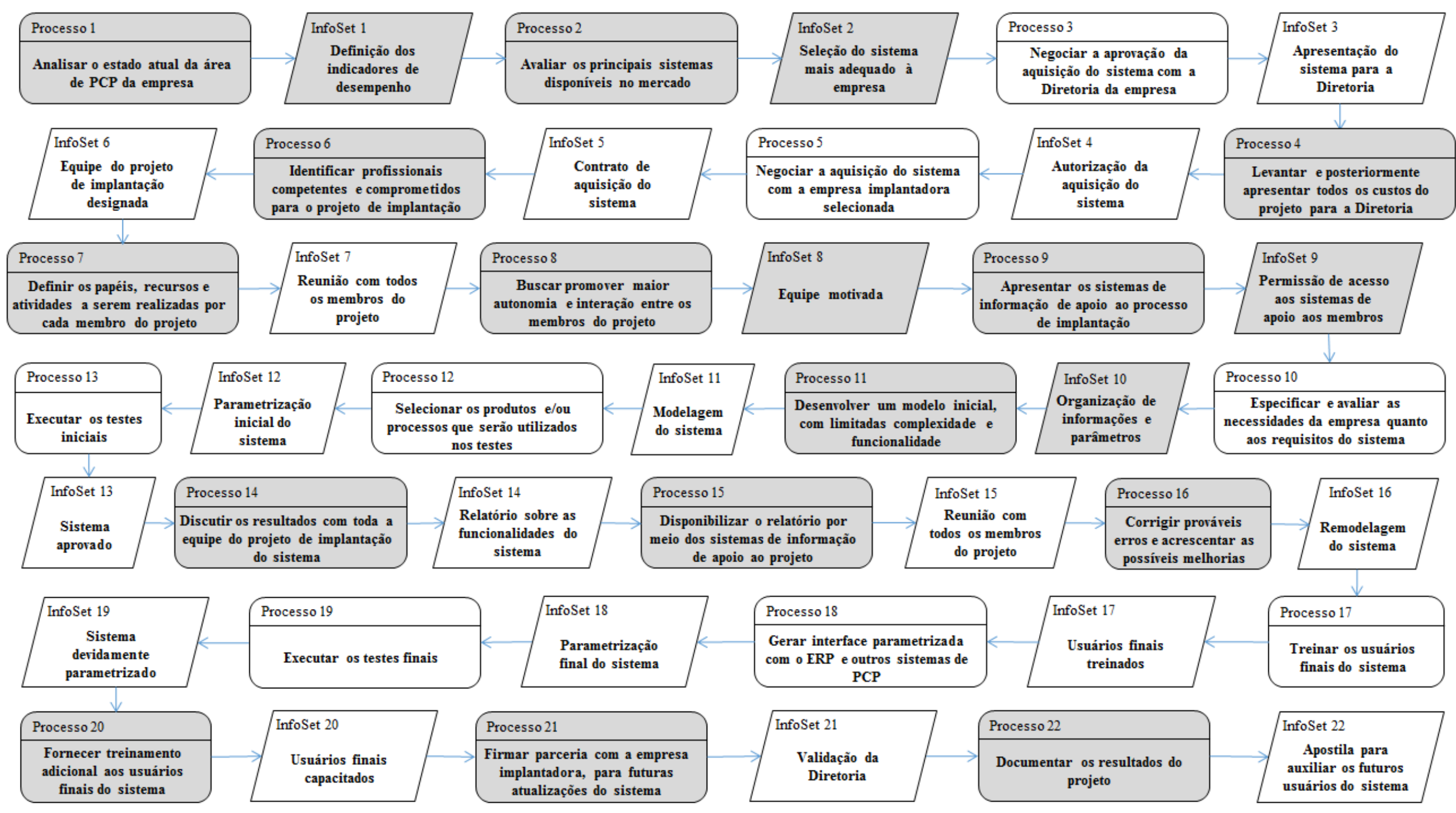

Figura 11 - Modelo de Processos - Estado Futuro 


\subsubsection{Modelo de Atores e Recursos}

Neste modelo está descrito o papel dos principais envolvidos nas etapas do processo de implantação de sistemas APS, tomando como base os profissionais das empresas dos estudos de caso e profissionais que participaram em processos de implantação apresentados pela literatura. A Figura 12 apresenta a visão geral do modelo.

O Diretor (Unidade Individual 1) da empresa adquirente do sistema APS (Unidade Organizacional 1) exerce o papel de elaborador das metas e objetivos do processo de implantação do sistema (Papel 1) e motivador da equipe interna do projeto (Papel 2), a qual é composta por Engenheiro de Produção (Unidade Individual 2), Analista de PCP (Unidade Individual 3), Analista de Produção (Unidade Individual 4), Analista de TI (Unidade Individual 5), Analista de Vendas (Unidade Individual 6), Gestor de Compras (Unidade Individual 7) e Gestor de Operações (Unidade Individual 8). O Diretor (Unidade Individual 1) da empresa adquirente do sistema APS (Unidade Organizacional 1) também aprova o orçamento (Recurso 1), libera os recursos financeiros necessários para a aquisição do sistema (Recurso 2) e define o cronograma do projeto (Recurso 3).

O Engenheiro de Produção (Unidade Individual 2) realiza a avaliação da área de PCP da empresa (Processo 1), realiza a avaliação dos sistemas APS disponíveis no mercado (Processo 2), seleciona o sistema APS (Recurso 4) mais adequado para a empresa, realiza a validação do projeto (Recurso 11), apresenta o sistema para a Diretoria (Papel 3) e exerce a função de coordenador da equipe interna do projeto de implantação do sistema (Papel 4).

Junto com o Analista de PCP (Unidade Individual 3), o Engenheiro de Produção (Unidade Individual 2) participa da modelagem do sistema (Recurso 6), fornecendo informações necessárias.

O Analista de PCP (Unidade Individual 3), o Analista de Produção (Unidade Individual 4) e o Gestor de Compras (Unidade Individual 7) exercem a função de usuários finais do sistema (Papel 5).

O Engenheiro de Produção (Unidade Individual 2) e o Analista de TI (Unidade Individual 5), junto com o Consultor (Unidade Individual 10) da empresa implantadora do sistema APS (Unidade Organizacional 2) firmam a parceria entre as duas empresas (Processo 21) e são responsáveis pelo treinamento dos usuários finais do sistema (Recurso 10), o qual é destinado ao Analista de Produção (Unidade Individual 4), Analista de Vendas (Unidade Individual 6), Gestor de Compras (Unidade Individual 7) e Gestor de Operações (Unidade Individual 8). 
O Analista de TI (Unidade Individual 5) é responsável pelos sistemas de informação de apoio ao projeto (Recurso 5), realiza a modelagem do sistema (Recurso 6), realiza os testes do sistema na empresa (Recurso 7), gera a interface parametrizada com o ERP e outros sistemas de PCP (Recurso 8), realiza a parametrização do sistema (Recurso 9) e realiza as atualizações técnicas do sistema (Processo 23).

O Diretor (Unidade Individual 9) da empresa implantadora do sistema APS (Unidade Organizacional 2) define o orçamento (Recurso 1) e recebe os recursos financeiros (Recurso 2) da empresa adquirente do sistema APS (Unidade Organizacional 1).

O Consultor (Unidade Individual 10) é responsável pelos sistemas de informação de apoio ao projeto (Recurso 5), realiza a modelagem do sistema (Recurso 6), realiza os testes do sistema na empresa (Recurso 7), gera a interface parametrizada com o ERP e outros sistemas de PCP (Recurso 8), realiza a parametrização do sistema (Recurso 9), disponibiliza uma apostila para auxiliar futuros usuários no uso do sistema (Recurso 12) e auxilia nas atualizações técnicas do sistema (Processo 23). 


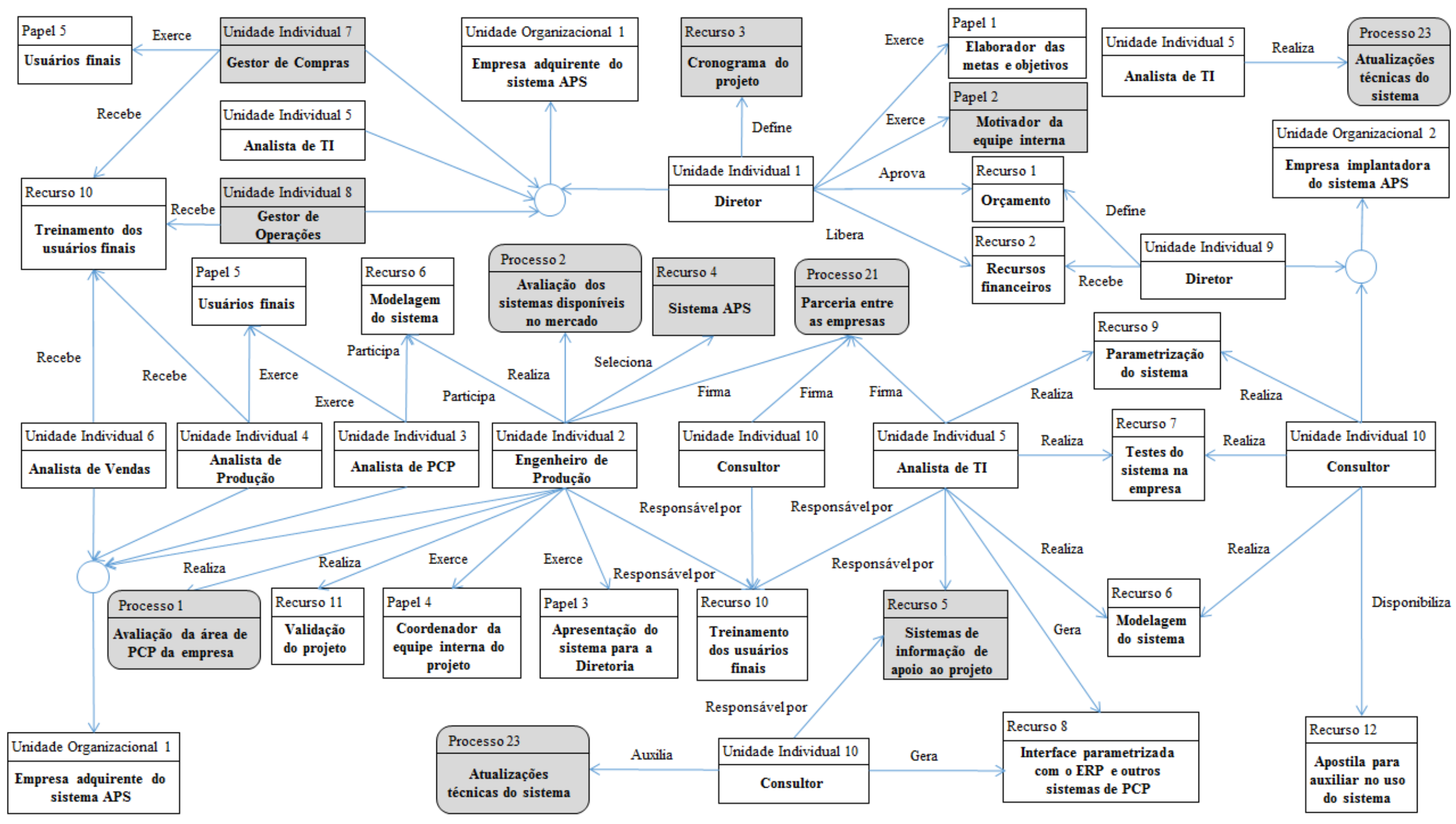

Figura 12 - Modelo de Atores e Recursos - Estado Futuro 


\subsubsection{Modelo de Componentes e Requisitos Técnicos}

A Figura 13 apresenta a visão geral do Modelo de Componentes e Requisitos Técnicos do processo de implantação do sistema APS. Tal modelo foi desenvolvido com base nos sistemas de informação de apoio das empresas que os possuíam, em sistemas de apoio almejados das empresas da pesquisa de campo que não os possuíam na época do processo de implantação; e também por requisitos apresentados pela literatura.

O sistema de informação para apoio ao projeto de implantação de sistemas APS deve considerar requisitos funcionais (que tangem a utilização do sistema), bem como não funcionais (que tangem as medidas de segurança, usabilidade e acessibilidade, etc.). Os objetivos do sistema de informação desenvolvido nesta pesquisa, para auxiliar o processo de implantação do sistema APS nas empresas são gerar informações sobre os fluxos de processos (Objetivo SI 1) e permitir o envio e recebimento de informações pertinentes (Objetivo SI 2). Como pode ser visto nas Figuras 14 e 15, este sistema deve proporcionar interface amigável ao usuário (Requisito Não Funcional 1), possuir robustez (Requisito Não Funcional 2), segurança (Requisito Não Funcional 3), restringindo o acesso apenas aos envolvidos no projeto, e possibilitar acesso remoto (Requisito Não Funcional 4) por meio da web.

Como pode ser visto na Figura 14, o objetivo "gerar informações sobre os fluxos de processos (Objetivo SI 1)" do sistema de informação, tem como requisitos funcionais relatar quais fluxos já foram testados (Requisito Funcional 1), informar quem testou os fluxos (Requisito Funcional 2), informar quando os fluxos foram testados (Requisito Funcional 3) e informar o resultado dos fluxos (Requisito Funcional 4). Como pode ser visualizado na Figura 13, para o cumprimento deste objetivo do sistema de informação o Consultor (Unidade Individual 10) e o Analista de TI (Unidade Individual 5) são os responsáveis pelo gerenciamento e o acesso é disponibilizado ao Consultor (Unidade Individual 10), Analista de TI (Unidade Individual 5), Analista de Vendas (Unidade Individual 6), Analista de Produção (Unidade Individual 4), Analista de PCP (Unidade Individual 3) e Engenheiro de Produção (Unidade Individual 2). Na figura 14 pode ser verificado que tal objetivo do sistema de informação apoia a garantia de maior integração entre as operações produtivas (Objetivo 4) por meio do forte relacionamento existente durante o processo de implantação, e apoia a autonomia dos funcionários (Regra 12), ao proporcionar o compartilhamento de informações sobre atividades realizadas no projeto.

Como pode ser visto na Figura 15, o objetivo "permitir o envio e recebimento de informações pertinentes (Objetivo SI 2)" do sistema de informação, tem como requisitos funcionais relatar o andamento dos processos (Requisito Funcional 5), gerenciar o tempo gasto 
em cada etapa do processo (Requisito Funcional 6), permitir o depósito de arquivos (Requisito Funcional 7), gerar documentação do projeto (Requisito Funcional 8), apresentar as competências de cada membro (Requisito Funcional 9), facilitar a troca de informações com o sistema ERP (Requisito Funcional 10) durante o projeto de implantação, e registrar lições aprendidas durante o projeto (Requisito Funcional 11), atuando como uma ferramenta para externalização do conhecimento, transformando o conhecimento tácito baseado na experiência dos funcionários em conhecimento explícito disponível no sistema de informação (NONAKA, TOYAMA e KONNO, 2000).

Como pode ser visualizado na Figura 13, para o cumprimento do objetivo "permitir o envio e recebimento de informações pertinentes (Objetivo SI 2)" do sistema de informação o Consultor (Unidade Individual 10) e o Analista de TI (Unidade Individual 5) são os responsáveis pelo gerenciamento e o acesso é disponibilizado ao Consultor (Unidade Individual 10), Analista de TI (Unidade Individual 5), Analista de PCP (Unidade Individual 3) e Engenheiro de Produção (Unidade Individual 2). Na Figura 15 pode ser verificado que tal objetivo do sistema de informação apoia a ampliação do conhecimento da dinâmica do sistema (Regra 1), a realização de testes durante o processo de implantação (Regra 3), a apresentação dos objetivos do projeto (Regra 8), as constantes atualizações do sistema (Regra 11), o firmamento de parceria com a empresa implantadora (Processo 21), a documentação dos resultados do projeto (Processo 22), e a execução dos testes iniciais (Processo 13) e dos testes finais (Processo 19). 


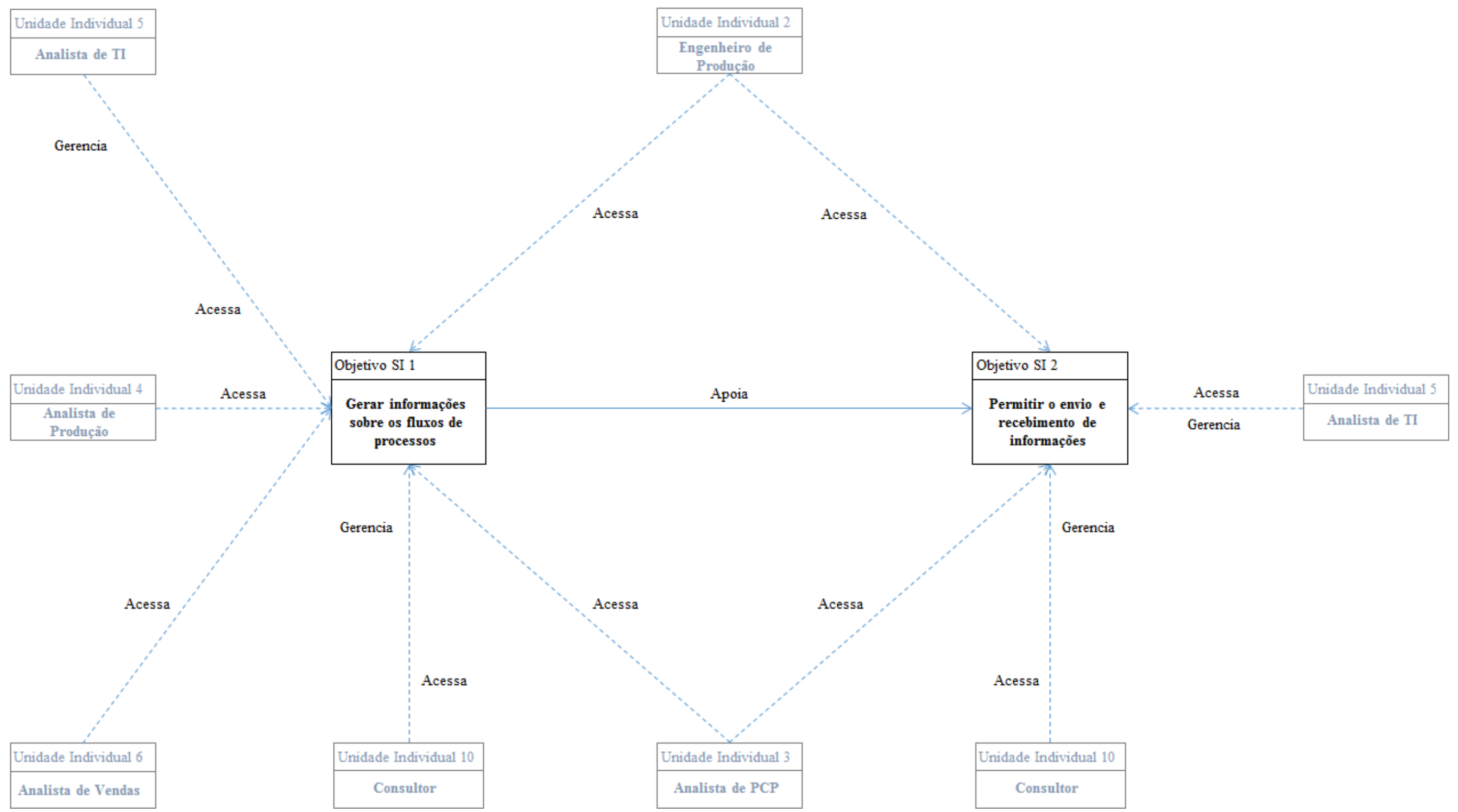

Figura 13 - Visão geral do Modelo de Componentes e Requisitos Técnicos - Estado Futuro 


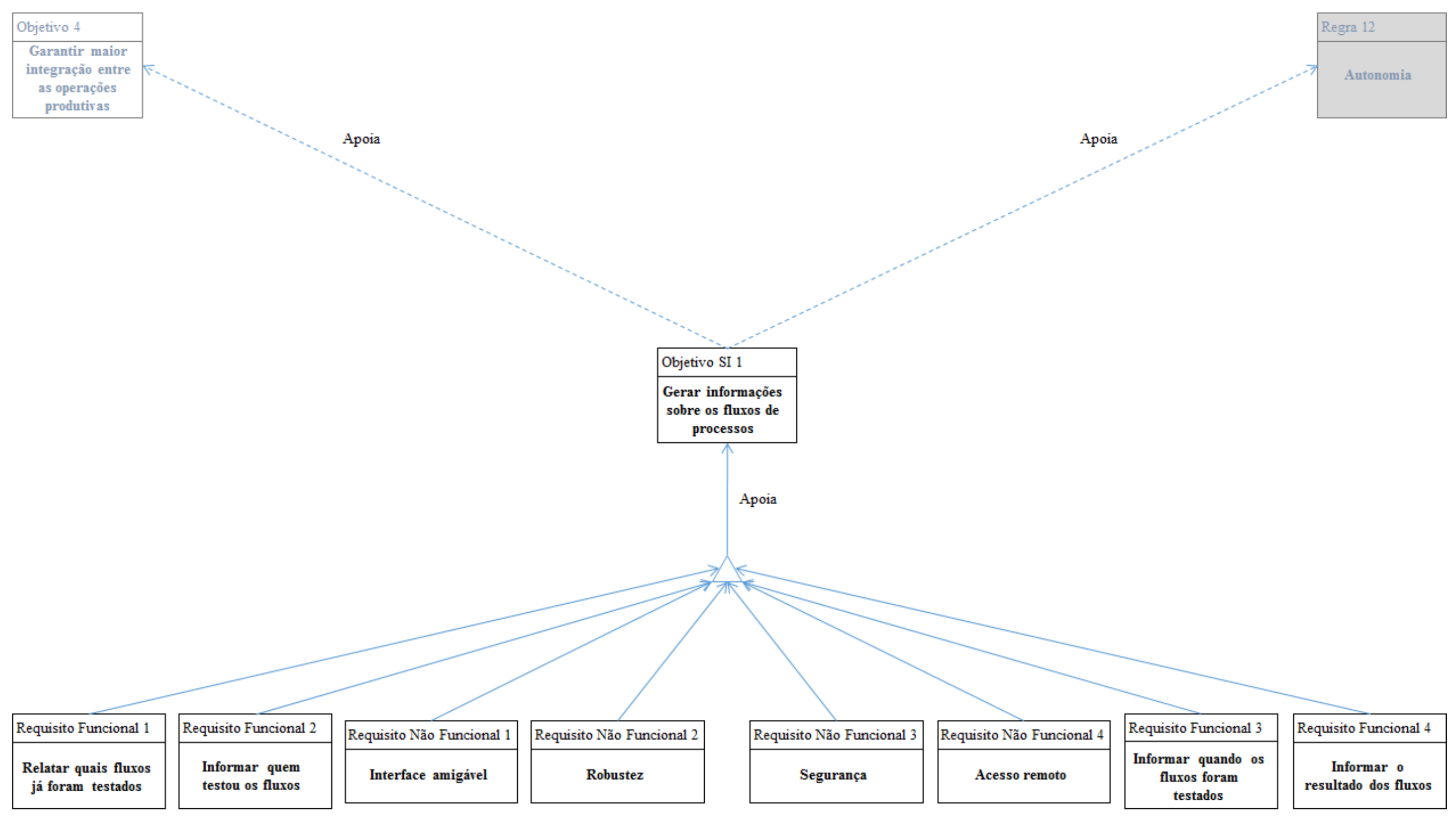

Figura 14 - Submodelo do Objetivo SI 1 


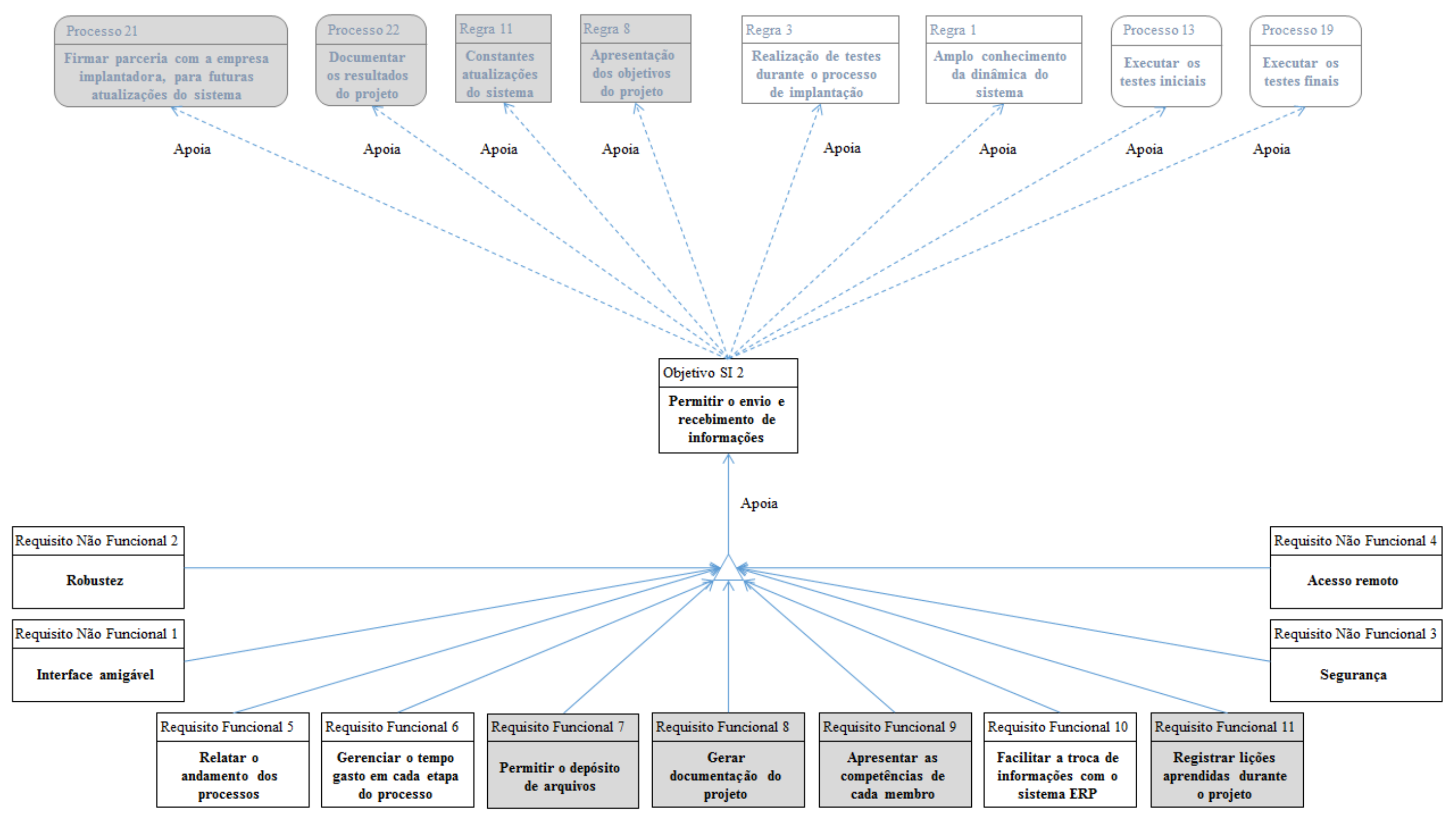

Figura 15 - Submodelo do Objetivo SI 2 


\subsubsection{Modelo de Conceitos}

A Figura 16 apresenta o Modelo de Conceitos do processo de implantação de sistemas APS sob a perspectiva de redes de inovação auto-organizadas. Este modelo retrata os termos mais importantes que os profissionais envolvidos em projetos de implantação de sistemas APS em empresas devem conhecer.

Os funcionários da empresa adquirente que fazem parte da equipe do projeto de implantação e os Consultores da empresa implantadora devem ter profundo conhecimento sobre sistemas Advanced Planning and Scheduling (Conceito 1) e sobre os conceitos fundamentais que fazem parte de sua estrutura, tais como Material Requirements Planning (Conceito 2), Master Production Scheduling (Conceito 3), Gráfico de Gantt (Conceito 4), Work In Process (Conceito 5), Bill Of Materials (Conceito 6), Available-To-Promise (Conceito 7), Capacity Requirement Planning (Conceito 8), Profitable-To-Promise (Conceito 9), Hierarchical Production Planning (Conceito 10) e Capable-To-Promise (Conceito 11).

É interessante também que os membros do projeto tenham conhecimento dos outros sistemas de PCP que a empresa possivelmente possui, tais como Manufacturing Resources Planning (Conceito 12), Enterprise Resources Planning (Conceito 13), Sales \& Operations Planning (Conceito 14) e Manufacturing Execution Systems (Conceito 15), qual a interface deles com o APS, e de que maneira um impacta nos resultados gerados pelo outro.

Para aumentar a motivação dos membros para a realização bem-sucedida do projeto de implantação, é muito importante que os mesmos tenham consciência que os sistemas APS (Conceito 1) proporcionam competitividade (Conceito 16) e melhoria contínua (Conceito 18) e representam uma inovação organizacional (Conceito 17) na área de PCP da empresa.

Para que os sistemas APS (Conceito 1) gerem os benefícios que eles são capazes de proporcionar é necessário haver um projeto de implantação bem-sucedido (Conceito 19), o que necessita de experiência (Conceito 22) dos Consultores, cooperação (Conceito 23) e liderança (Conceito 24) dos membros envolvidos. A modelagem organizacional (Conceito 20) e a autoorganização (Conceito 21) auxiliam no alcance de um projeto de implantação bem-sucedido (Conceito 19). 


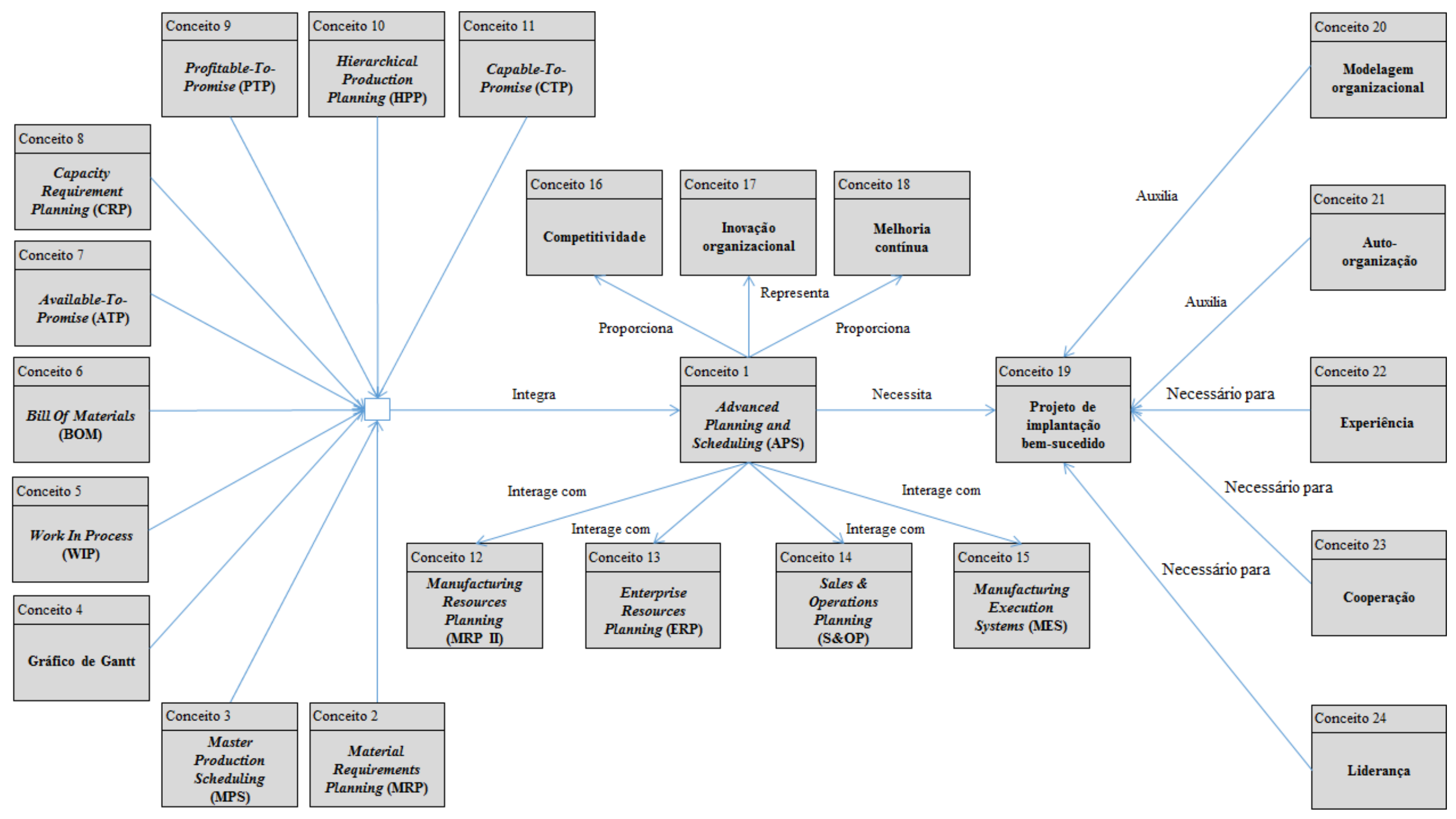

Figura 16 - Modelo de Conceitos - Estado Futuro 


\subsection{Discussão dos resultados}

Nesta seção, são discutidos os resultados da modelagem organizacional do processo de implantação de sistemas APS, apresentando as contribuições de cada modelo e como os elementos de redes de inovação auto-organizadas auxiliam no projeto; e as etapas do desenvolvimento do modelo de referência proposto.

\subsubsection{Da modelagem organizacional}

A metodologia EKD foi escolhida para a modelagem organizacional do processo de implantação de sistemas APS devido ao fato de que a mesma propicia uma forma sistemática de analisar e documentar os componentes de uma empresa (BUBENKO, PERSSON e STIRNA, 2001).

O Modelo de Objetivos desenvolvido facilitou a compreensão das estratégias e oportunidades advindas com a implantação e posterior uso dos sistemas APS, restrições que impedem a conclusão bem-sucedida do projeto e ameaças ao uso eficaz do sistema, provenientes de um projeto malsucedido. Pode-se afirmar que os objetivos de maior importância para o projeto são a garantia de melhor programação da produção, garantia de maior integração entre as operações produtivas e garantia de confiabilidade no planejamento estratégico, pois estão intimamente ligados à competitividade da empresa.

As diretrizes do Modelo de Regras do Negócio além de possuírem estreita relação com os objetivos, conforme orientação dada por Bubenko, Persson e Stirna (2001), sinalizaram também as principais considerações a serem feitas durante a realização das atividades do projeto. A atenção a elementos das redes de inovação auto-organizadas auxilia bastante na conclusão do projeto, pois apresenta características apontadas na literatura que auxiliam grandemente a realização bem-sucedida de atividades colaborativas entre indivíduos e organizações.

O Modelo de Processos desenvolvido mapeou os fluxos físico (de pessoas) e lógico (de informações) realizados durante o projeto de implantação. O detalhamento dos processos a serem executados em cada etapa permite à organização atuar de forma eficiente e com boa velocidade de resposta ao cronograma definido. A atenção à competências essenciais que os membros da equipe do projeto devem possuir, tais como experiência prévia em projetos anteriores, motivação, comprometimento, trabalho em equipe e bom conhecimento de informática auxiliam na condução eficaz do projeto.

Conforme afirmam Freel e Harrison (2006) e Zeng, Xie e Tamc (2010), a inovação não representa o produto de uma iniciativa isolada, mas da interação entre diferentes atores e assim 
sendo, é importante configurar a rede de relacionamentos criada para estruturar os processos necessários para atingi-la. O Modelo de Atores e Recursos permitiu visualizar o vínculo existente entre as organizações, apresentou os papéis que os profissionais envolvidos no projeto exercem, e também mostrou os processos e recursos pelos quais eles são responsáveis no auxílio, firmamento, geração, gerenciamento, participação e realização.

O Modelo de Componentes e Requisitos Técnicos assume considerável importância ao listar objetivos de sistemas de informação de apoio para o processo de implantação de sistemas APS. Este modelo evidencia a necessidade de atenção aos requisitos não funcionais que garantem a boa usabilidade do sistema de informação tais como interface amigável, robustez, segurança da informação compartilhada pela rede de inovação formada entre os profissionais das empresas adquirente e implantadora do sistema e acesso remoto por meio da web. O modelo desenvolvido possibilita conhecer o andamento de cada processo, o armazenamento do conhecimento gerado durante o projeto e por meio desse armazenamento, a transformação do conhecimento tácito de consultores e demais profissionais envolvidos em conhecimento explícito disponibilizado por meio dele.

O Modelo de Conceitos visa facilitar uma compreensão dos principais termos e conceitos que os profissionais envolvidos no projeto de implantação, e especialmente os usuários finais do sistema devem conhecer. Neste modelo também estão contidos os principais conceitos que o sistema APS representa e proporciona para a empresa, e os conceitos intrínsecos e necessários a um projeto de implantação bem-sucedido.

\subsubsection{Do modelo de referência}

O modelo de referência para processos de implantação de sistemas APS sob a perspectiva de redes de inovação auto-organizadas foi desenvolvido por meio da atenção aos estágios recomendados por Ahlemann e Gastl (2007) para a construção de modelos de referência.

É importante ressaltar que as etapas de planejamento, construção e validação do modelo foram integralmente concluídas. Para validar o modelo desenvolvido, o mesmo (junto com um questionário) foi enviado a especialistas da área de sistemas APS, consultores de empresas implantadoras e profissionais das sete empresas adquirentes do sistema que participaram das entrevistas para a realização dos estudos de caso desta pesquisa. O questionário utilizado para validação do modelo de referência desenvolvido nesta pesquisa é apresentado no Apêndice C.

O modelo de referência foi analisado por um grupo de 11 especialistas em sistemas APS, sendo este grupo composto por 4 docentes pesquisadores, 4 profissionais de empresas 
implantadoras de sistemas APS, 2 pesquisadores acadêmicos e 1 profissional de empresa adquirente de sistemas APS que participou no processo de implantação. Ao analisar o modelo de referência, os avaliadores informavam se em sua opinião o objetivo, regra, processo ou conceito era pouco relevante, relevante ou muito relevante. Além disso, caso os avaliadores encontrassem inconsistências no modelo, os mesmos apontavam sugestões de melhoria para aumentar sua confiabilidade. A avaliação do Modelo de Atores e Recursos e do Modelo de Componentes e Requisitos Técnicos diferiu da avaliação dos outros modelos pelo fato de não serem desdobrados minuciosamente como os outros, pois sua complexidade dificultaria o processo de avaliação.

Os Gráficos 1, 2, 3, 4, 5 e 6 apresentam, respectivamente, os resultados da avaliação do Modelo de Objetivos, Regras do Negócio, Processos, Atores e Recursos, Componentes e Requisitos Técnicos e Conceitos.

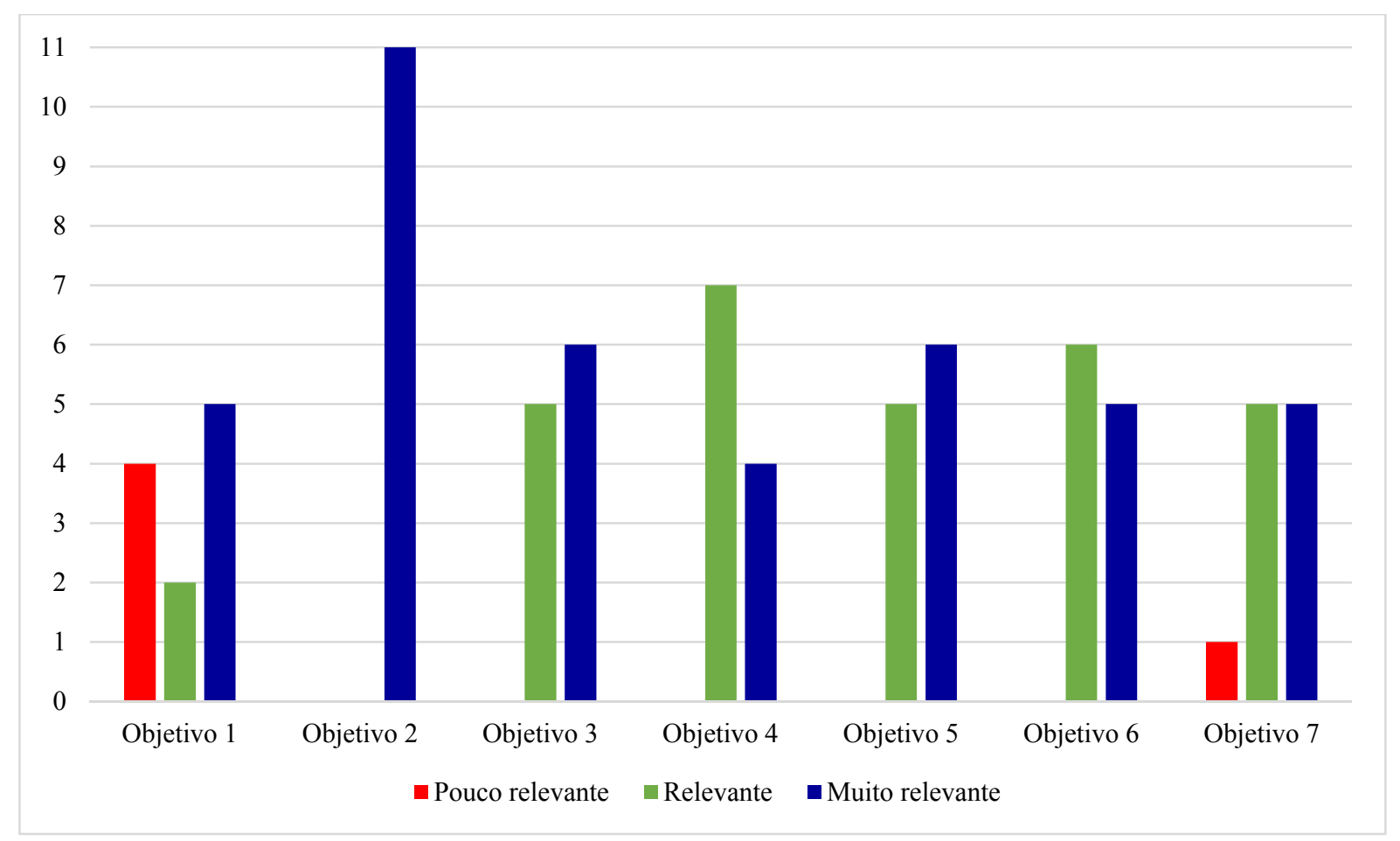

Gráfico 1 - Avaliação do Modelo de Objetivos 


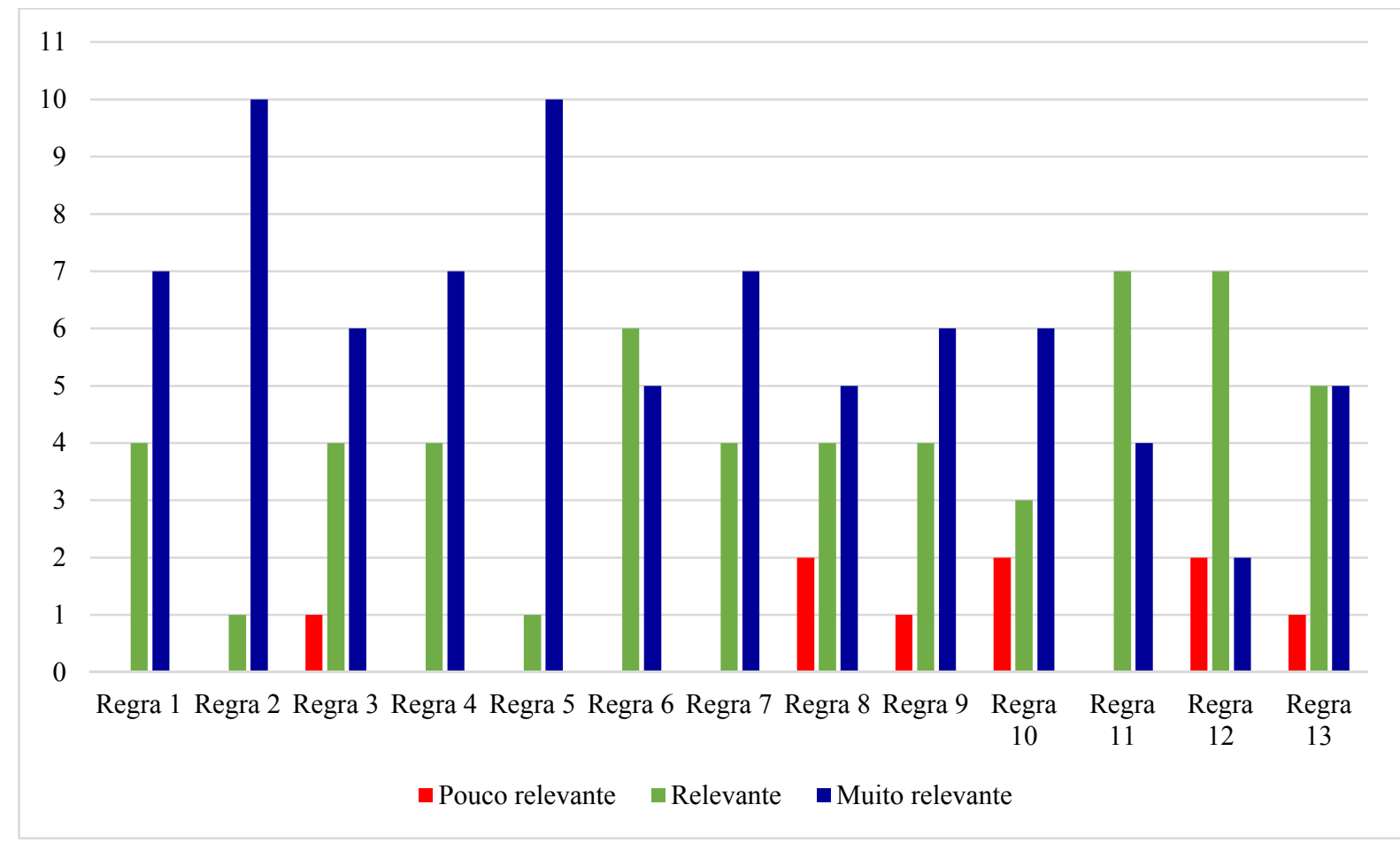

Gráfico 2 - Avaliação do Modelo de Regras do Negócio

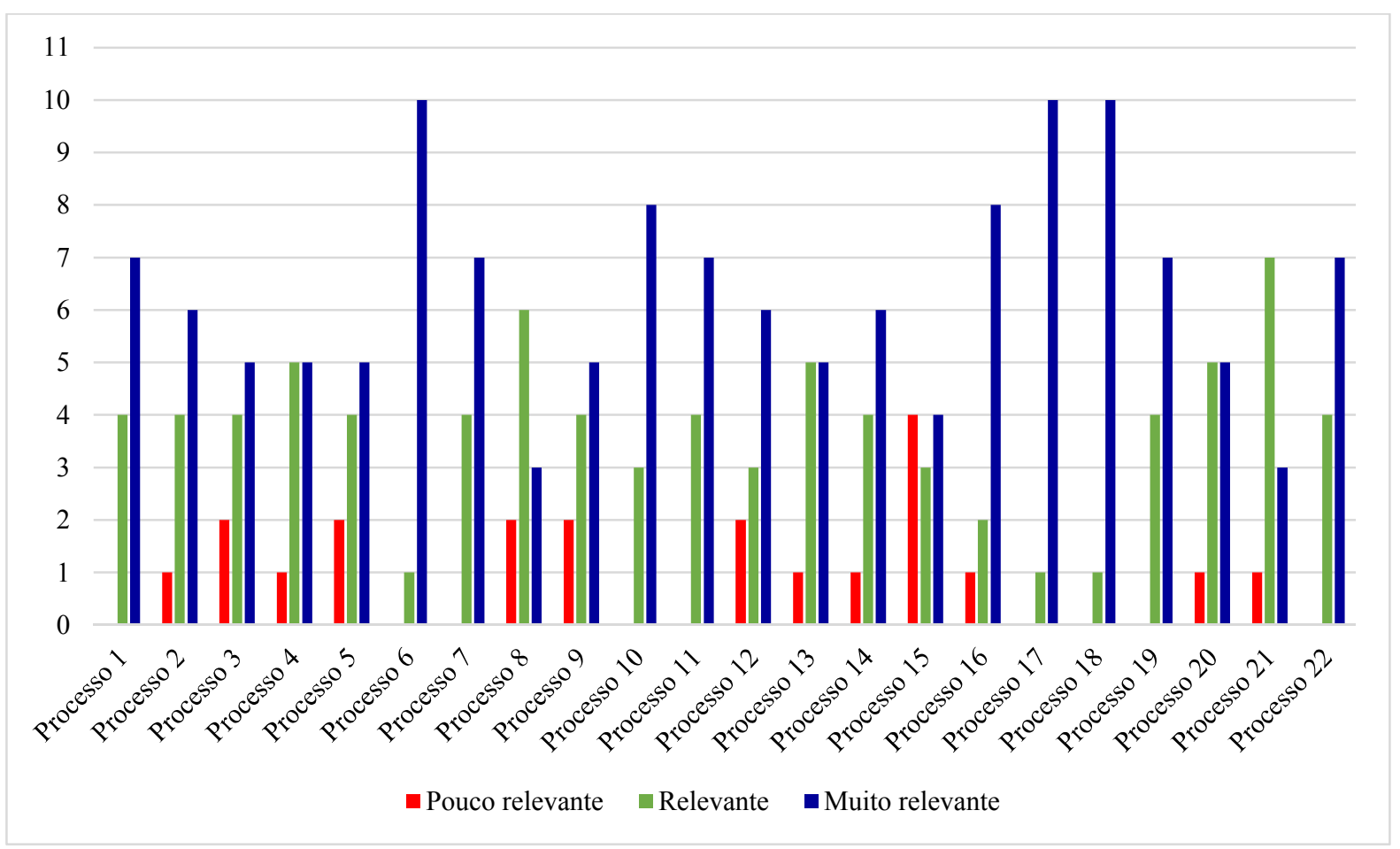

Gráfico 3 - Avaliação do Modelo de Processos 


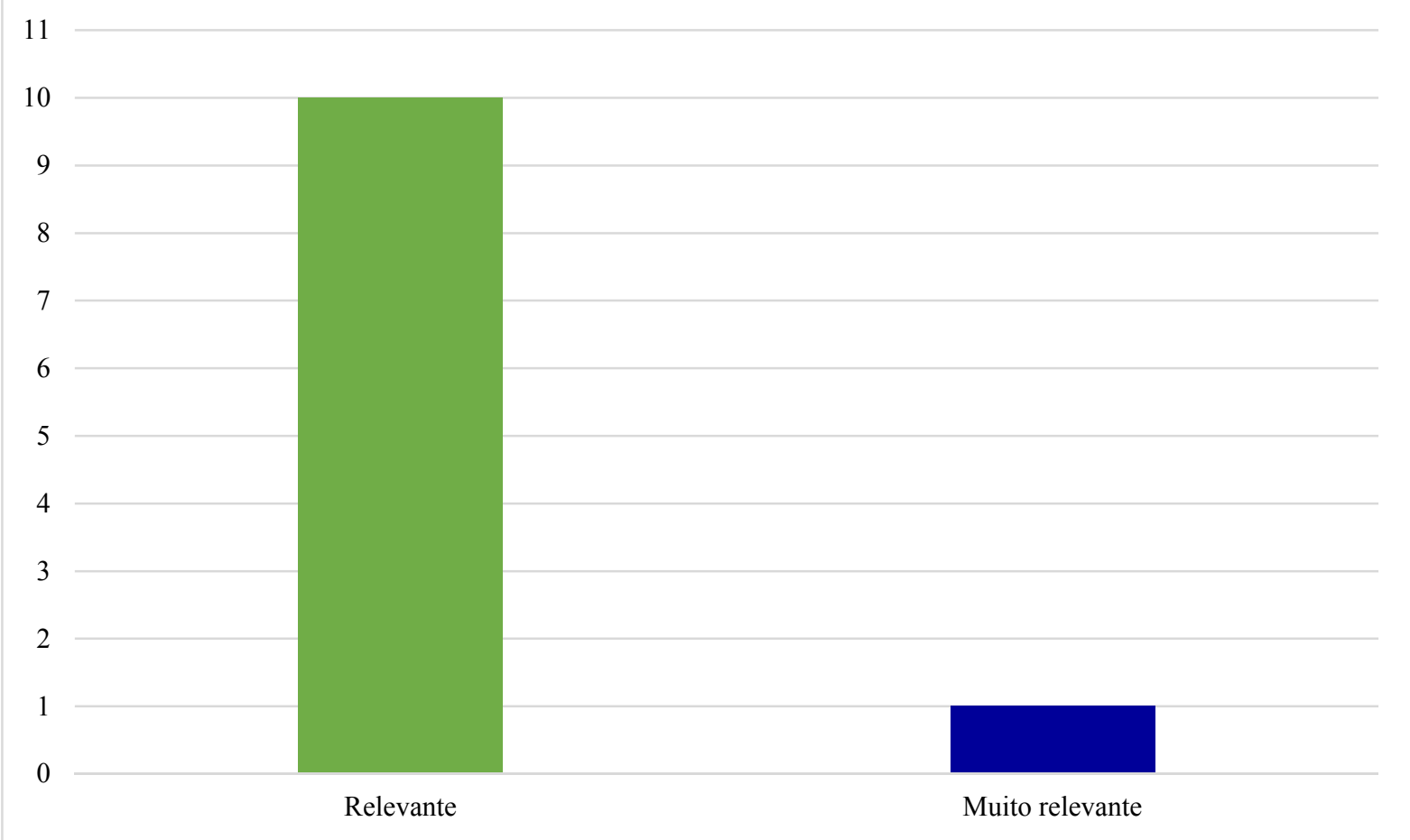

Gráfico 4 - Avaliação do Modelo de Atores e Recursos

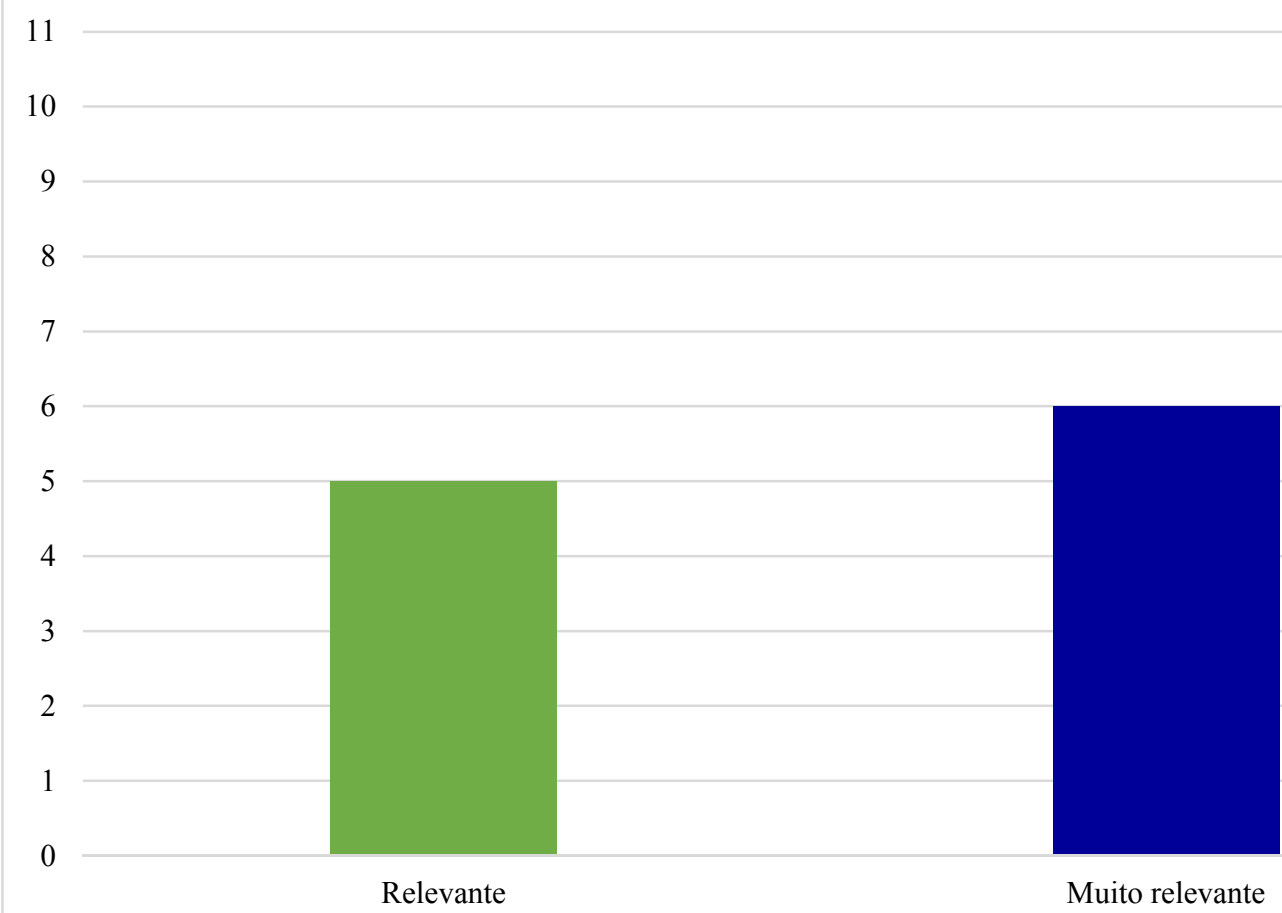

Gráfico 5 - Avaliação do Modelo de Componentes e Requisitos Técnicos 


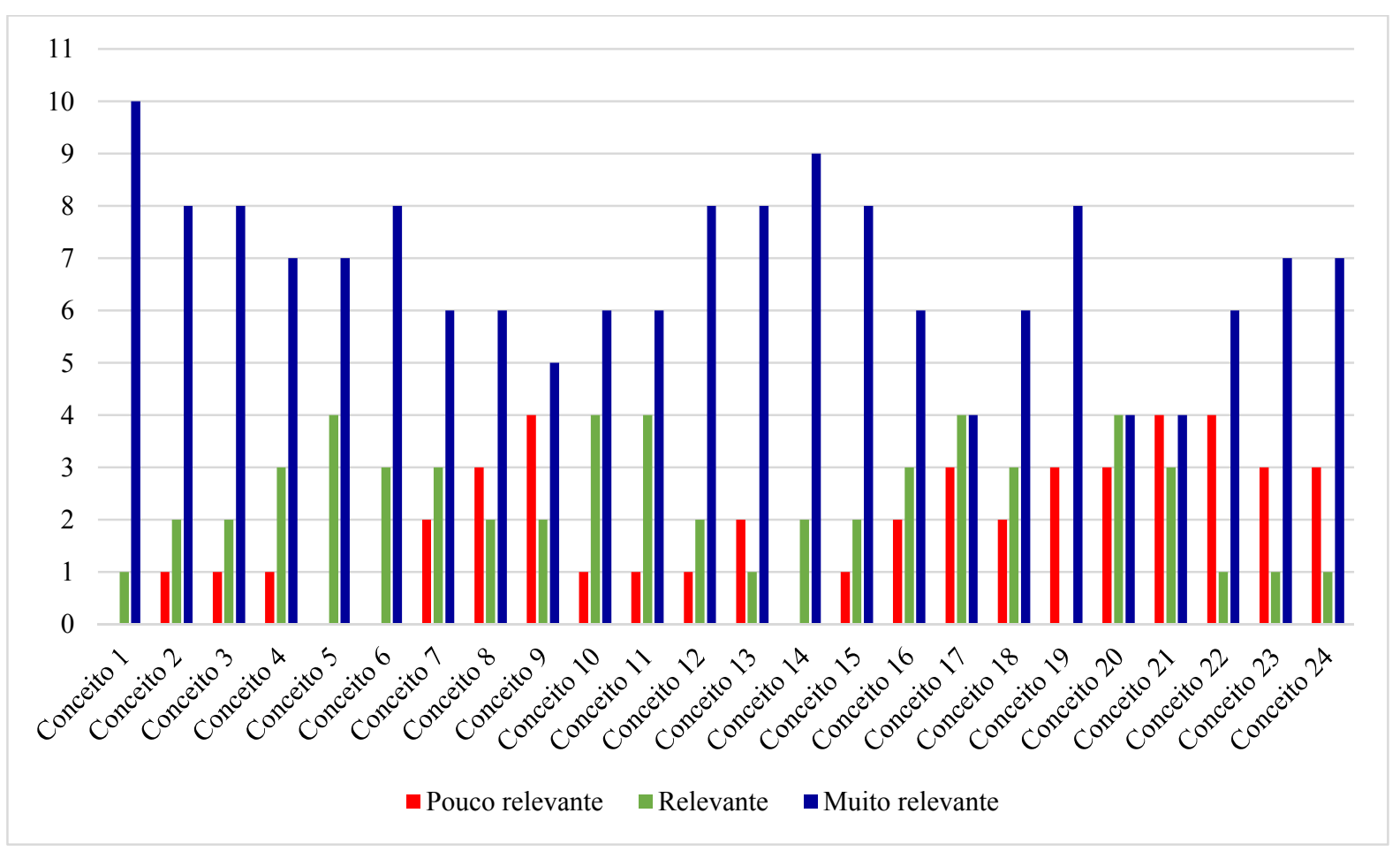

Gráfico 6 - Avaliação do Modelo de Conceitos

A Tabela 1 apresenta o resultado geral da avaliação do modelo e referência e de cada modelo que o compõe. Para a composição desta tabela, com relação aos Modelos de Objetivos, Regras do Negócio, Processos e Conceitos foram analisadas as respostas dadas a cada um de seus componentes e atribuídos os seguintes pesos aos critérios: 33,33\% a pouco relevante, $66,66 \%$ a relevante e 100\% a muito relevante. O Modelo de Atores e Recursos e o Modelo de Componentes e Requisitos Técnicos foram analisados da mesma forma que os anteriores, porém sem serem desdobrados.

Em cada modelo, a pontuação dada a cada componente foi obtida por meio de média aritmética ponderada, e a média aritmética de todos os componentes resultou na consistência (em porcentagem) de cada um destes modelos. A consistência do modelo de referência representa o resultado da média aritmética dos seis modelos que o compõem.

Tabela 1 - Resultados da avaliação dos modelos

\begin{tabular}{|l|c|}
\hline \multicolumn{1}{|c|}{ Modelo } & Consistência (\%) \\
\hline Modelo de Objetivos & 82,79 \\
\hline Modelo de Regras do Negócio & 83,32 \\
\hline Modelo de Processos & 83 \\
\hline Modelo de Atores e Recursos & 70 \\
\hline Modelo de Componentes e Requisitos Técnicos & 85 \\
\hline Modelo de Conceitos & 81,45 \\
\hline Modelo de Referência (índice geral) & 80,93 \\
\hline
\end{tabular}

Com base nas respostas obtidas no questionário e no índice de consistência alcançado $(80,93 \%)$ é possível afirmar que o modelo de referência sob a perspectiva de redes de inovação 
auto-organizadas mostra-se adequado para orientar processos de implantação de sistemas APS. Poucas sugestões de melhoria foram sinalizadas, e de modo geral, os avaliadores acreditam que como a abordagem apresentada no modelo é ampla (ao considerar outros aspectos além dos objetivos do projeto e focar em elementos de redes de inovação auto-organizadas que podem trazer benefícios substanciais), o mesmo pode ser utilizado como uma referência a futuros processos.

Seguindo as orientações de Ahlemann e Gastl (2007), o modelo de referência foi disponibilizado a duas empresas implantadoras de sistemas APS para que possa ser testado em projetos futuros e posteriormente documentado por essas empresas.

\subsection{Considerações finais}

A implantação de sistemas APS representa uma das mais relevantes inovações organizacionais na área de PCP, pois de acordo com a revisão da literatura e dados coletados nos estudos de caso realizados para o desenvolvimento deste trabalho; utilizando eles as empresas que os implantam podem se tornar mais competitivas por meio da redução de custos, estoques, lead times industriais, ociosidade de recursos e prazos de entrega dos produtos; melhor organização industrial; apoio ao processo de tomada de decisão; melhor visualização do status dos pedidos; otimização da capacidade produtiva; aumento e antecipação do faturamento; melhor atendimento aos clientes; melhoria de sua reputação junto aos clientes; obtenção de novos clientes; maior produtividade no trabalho; melhor gerenciamento da cadeia de suprimentos; dentre outros benefícios.

Este capítulo do trabalho apresenta relevantes contribuições para a literatura de sistemas APS, pois apresenta uma abordagem nova para análise e condução de processos de implantação destes sistemas, preenchendo lacunas de pesquisa levantadas em pesquisas anteriores, tais como necessidade de pesquisas que apresentem projetos de implantação bem-sucedidos do sistema, análise das relações entre a empresa adquirente e implantadora do sistema, atenção aos aspectos de implantação e compreensão do processo em si.

Para o desenvolvimento do modelo de referência, buscou-se coletar informações a respeito de projetos de implantação de sistemas APS em um número considerável de empresas e artigos, para maior confiabilidade e embasamento de sua estrutura. A inserção dos elementos das redes de inovação auto-organizadas em projetos de implantação de sistemas APS apresentou diversos benefícios tanto para a empresa adquirente, quanto para implantadora do sistema, ao apresentar os principais objetivos, oportunidades, restrições, ameaças, regras, processos, membros, papéis, recursos, sistemas de informação e conceitos envolvidos no 
projeto. Dentre os benefícios merecem destaque a transformação do conhecimento tácito dos consultores e demais profissionais envolvidos no projeto de implantação em conhecimento explícito disponibilizado pelos sistemas de informação de apoio, definição de uma equipe capacitada, motivada e comprometida, estabelecimento de fortes vínculos cooperativos entre os membros da equipe, armazenamento do conhecimento obtido no projeto e manutenção da parceria entre as empresas após sua conclusão.

A compreensão dos principais objetivos e oportunidades que os sistemas APS podem proporcionar é bastante relevante para motivar os funcionários da empresa adquirente do sistema a participarem ativamente do projeto de implantação, pois isto o torna mais eficaz, ajuda a superar as prováveis restrições de alguns membros e mostra as principais ameaças que podem surgir após a sua conclusão.

A incorporação de elementos de redes de inovação auto-organizadas entre as principais regras inerentes ao alcance dos objetivos da implantação de sistemas APS, além de auxiliar na sua obtenção, é essencial para visualizar as principais características necessárias aos membros da empresa adquirente e implantadora do sistema durante e após a conclusão do projeto. A consideração a elementos de redes de inovação auto-organizadas tais como comprometimento da alta gerência, apresentação dos objetivos do projeto, motivação dos usuários finais do sistema, participação ativa dos membros e usuários finais no projeto, manutenção da parceria entre as empresas após a conclusão do projeto, autonomia e cooperação entre os envolvidos aumentam fortemente a conclusão bem-sucedida do projeto de implantação de sistemas APS e uso eficaz do sistema após a conclusão.

A apresentação dos principais processos necessários, dos papéis e recursos que cada membro é responsável, dos sistemas de informação de apoio e dos conceitos que cada membro envolvido deve conhecer auxilia na redução do tempo de conclusão, ajuda a transformar o conhecimento tácito dos membros em conhecimento explícito amplamente disponível, mostra a importância da criação de fortes vínculos entre os membros das empresas envolvidas; e aumenta o conhecimento dos membros do projeto e usuários finais do sistema, o que auxilia na redução da dependência da empresa implantadora e uso eficaz do sistema após a conclusão do processo de implantação.

Espera-se que o modelo de referência para processos de implantação de sistemas APS sob a perspectiva de redes de inovação auto-organizadas apresentado neste capítulo do trabalho possa ser aperfeiçoado e utilizado e por consultores e gestores em futuros projetos similares em empresas; e também por pesquisadores, como referência para o desenvolvimento de novas pesquisas acadêmicas envolvendo a temática. 


\section{CONSIDERAÇÕES FINAIS}

Com as grandes transformações impostas, as empresas lidam com mercados cada vez mais exigentes em relação a custos, prazos, qualidade, confiabilidade e tudo mais que represente competitividade. Em vista disso, seus diretores, gestores e demais funcionários são constantemente pressionados a obter ganhos progressivos.

O PCP e seus sistemas associados têm o objetivo de planejar e controlar a produção de maneira que a empresa satisfaça os requisitos de produção do modo mais eficiente possível. A área de planejamento e controle da produção é uma das áreas funcionais mais relevantes para a empresa, pois além de ser integrada com diversas outras, é responsável pelo gerenciamento do fluxo de materiais do sistema de produção por meio do fluxo de informações e processos, e faz o elo entre as decisões tomadas pelos profissionais do nível estratégico da empresa e as atividades desenvolvidas por profissionais, máquinas e equipamentos no nível operacional.

Os tradicionais sistemas de PCP computadorizados implantados em empresas desde a segunda metade do século XX, representados pelos sistemas MRP, MRP II e ERP apresentam falhas na operação, pois desconsideram os limites de capacidade de produção, restrições de mão de obra, matérias-primas e demais recursos produtivos, além dos custos inerentes aos processos. Na década de 1990, motivada pelos constantes desenvolvimentos, uma nova geração de softwares conhecidos como sistemas APS emergiu, sendo estes softwares baseados nos princípios de planejamento hierárquico, fazendo uso extensivo de abordagens de solução conhecidas como programação matemática e meta-heurísticas. Os sistemas APS representam um avanço para o planejamento e controle da produção das empresas que os implantam e os utilizam plena e eficazmente, pois consideram as diversas restrições presentes nos processos de produção e são poderosos softwares de planejamento e programação da produção que foram desenvolvidos para trabalhar de maneira integrada com seus predecessores, suprindo suas deficiências.

Desde o seu desenvolvimento nos anos 1990, as pesquisas acadêmicas acerca de sistemas APS têm aumentado grandemente, devido à importância destes sistemas para a área de planejamento e controle da produção das empresas, e também pelo fato de os mesmos representarem uma importante inovação organizacional, já que são bastante avançados em 
relação a seus predecessores e representam métodos organizacionais relacionados a práticas de negócios, organização do local de trabalho e relações externas.

Durante a realização desta pesquisa, consultando a literatura, foi destacado que existe a necessidade de descrever processos bem-sucedidos de implantação de sistemas complexos tais como sistemas APS; que muitos processos de implantação de sistemas APS não satisfazem as expectativas iniciais, devido a projetos mal conduzidos; que a formação de uma rede de empresas na qual as pessoas participam ativamente do processo de implantação é essencial para o seu sucesso nas indústrias; e que os aspectos de implantação destes sistemas são largamente ignorados pela academia. Essas lacunas de pesquisa motivaram o desenvolvimento deste projeto.

Durante a realização desta pesquisa pôde-se verificar que assim como a literatura sinaliza, os aspectos de implantação de sistemas APS ainda são bastante ignorados, tendo em vista que muitos membros do projeto não compreendem claramente os objetivos da aquisição do sistema e as regras inerentes ao alcance destes objetivos, existe muita variação na forma em que os processos de implantação são dirigidos nas empresas, os papéis, recursos e responsabilidades dos membros não são claramente definidos, e poucos membros compreendem claramente os conceitos necessários para a implantação do sistema e seu futuro uso. Além destes fatores internos à empresa adquirente do sistema, a falta de compreensão clara das atividades, responsabilidades e papéis dos membros da empresa implantadora participantes do projeto, em alguns casos traz impactos negativos na utilização do sistema após o fim do projeto, pois a troca de conhecimento entre as duas empresas é bastante fraca.

Por meio da revisão da literatura, foi verificado que a formação de uma rede autoorganizada para o projeto de implantação de sistemas APS pode mostrar-se bastante eficiente para a condução do processo, tendo em vista que ambos possuem características semelhantes tais como integração entre diversos sistemas; necessidade de correta e consistente modelagem organizacional dos processos desenvolvidos; comprometimento e apoio da alta gerência para a condução do projeto; motivação dos membros da rede que serão os usuários finais do sistema; configuração clara dos objetivos do projeto; uso das telecomunicações; treinamento dos membros do projeto e usuários finais do sistema; troca de experiência e compartilhamento de conhecimento entre os membros; procedimentos padronizados; autonomia entre os envolvidos; avaliação dos processos atuais da empresa, para adequação às mudanças impostas pelo ambiente; dentre outros aspectos.

Com a incorporação de elementos das redes de inovação auto-organizadas, tais como cooperação entre os envolvidos, comprometimento da alta gerência, apresentação dos objetivos 
do projeto, motivação dos usuários finais do sistema, participação ativa dos membros e usuários finais no projeto, manutenção da parceria entre as empresas após a conclusão do projeto, autonomia e cooperação entre os envolvidos; a conclusão bem-sucedida do projeto de implantação de sistemas APS aumenta consistentemente, pois isso além de reduzir o tempo de conclusão, apresenta as fragilidades do projeto quando não é dada atenção à necessidade de cooperação entre membros das empresas para troca de conhecimento entre eles, e também permite transformar o conhecimento tácito dos membros em conhecimento explícito, disponibilizado por meio da utilização de sistemas de informação. Com a conclusão bemsucedida do projeto e manutenção da cooperação entre as empresas, certamente o uso do sistema será mais eficaz.

Esta pesquisa apresenta contribuições para a literatura de sistemas APS, ao preencher lacunas de pesquisa sinalizadas em trabalhos anteriores, descrever processos de implantação em sete organizações, propor uma nova abordagem para projetos de implantação, e apresentar um modelo de referência para implantação de sistemas APS sob a perspectiva de redes de inovação auto-organizadas. A pesquisa também apresenta contribuições para a literatura de redes de inovação auto-organizadas, ao apresentar a formação de uma destas redes para condução de processos de geração de inovação organizacional em empresas.

O modelo de referência para processos de implantação de sistemas APS sob a perspectiva de redes de inovação auto-organizadas foi desenvolvido por meio da modelagem organizacional com a metodologia EKD, pois a mesma proporciona uma maneira sistemática de analisar e documentar os componentes de uma empresa. $\mathrm{O}$ referido modelo compreende o modelo de objetivos, modelo de regras do negócio, modelo de processos, modelo de atores e recursos, modelo de componentes e requisitos técnicos, e modelo de conceitos.

Em relação às contribuições que o modelo de objetivos apresenta a futuros projetos de implantação de sistemas APS destacam-se a apresentação de algumas oportunidades que tais sistemas podem proporcionar e que com base nos sete estudos de caso não são claramente consideradas na apresentação do projeto aos membros e usuários finais. O conhecimento de oportunidades como redução da ociosidade de recursos, lead times industriais e estoques, obtenção de novos clientes, apoio ao processo de tomada de decisão, melhor visualização do status dos pedidos, otimização da capacidade produtiva e inovação organizacional na área de planejamento e controle da produção aumentam consideravelmente a motivação dos membros e usuários finais para a participação ativa no projeto de implantação e reduz a ocorrência de incompreensão, uso parcial e falta de atualização técnica do sistema. 
No modelo de regras do negócio, a incorporação de elementos de redes auto-organizadas tais como comprometimento da alta gerência, apresentação dos objetivos do projeto, motivação dos usuários finais, participação ativa dos membros e usuários finais, manutenção da parceria com a empresa implantadora, autonomia e cooperação entre os envolvidos no projeto entre as regras necessárias para o alcance dos objetivos do projeto de implantação de sistemas APS aumenta consideravelmente o sucesso do projeto.

Entre contribuições que o modelo de processos proporciona, merecem destaque a análise do estado atual da área de planejamento e controle da produção da empresa, a avaliação dos principais sistemas APS disponíveis no mercado, a identificação de profissionais competentes e comprometidos para o projeto de implantação, a definição dos papéis, recursos e atividades a serem realizadas por cada membro do projeto, a busca pela promoção de maior autonomia e interação entre os membros do projeto, a inserção e apresentação dos sistemas de informação de apoio ao processo de implantação, a discussão dos resultados dos testes com toda a equipe do projeto de implantação do sistema, a disponibilização de relatórios por meio dos sistemas de informação de apoio ao projeto, o fornecimento de treinamento adicional aos usuários finais do sistema, o firmamento de parceria com a empresa implantadora para futuras atualizações do sistema e a documentação dos resultados do projeto.

Como principais contribuições que o modelo de atores e recursos propicia à definição da equipe em futuros projetos de implantação de sistemas APS têm-se a inserção de atores de áreas importantes da empresa entre os usuários finais, tais como Gestor de Compras e Gestor de Operações e a consideração a outros papéis e recursos no projeto, sendo o sistema de informação de apoio ao projeto o principal recurso adicional.

A inserção de requisitos funcionais como permitir o depósito de arquivos, gerar documentação do projeto, apresentar as competências de cada membro e registrar lições aprendidas durante o projeto no objetivo "permitir o envio e recebimento de informações", e a apresentação das regras, processos e objetivos que o sistema apoia foram as principais contribuições obtidas do modelo de componentes e requisitos técnicos.

O modelo de conceitos representou uma novidade para a condução do projeto de implantação ao propor a apresentação de diversos conceitos importantes para o conhecimento dos membros do projeto e usuários finais do sistema. Durante o processo, com base nas informações relatadas nos estudos de caso, verificou-se que os membros não têm ampla noção dos principais fundamentos dos sistemas APS (MRP, MPS, gráfico de Gantt, WIP, BOM, ATP, CRP, PTP, HPP e CTP), o potencial de integração que este possui com outros sistemas como MRP II, ERP, S\&OP e MES, o que ele representa (competitividade, inovação organizacional, 
melhoria contínua), e alguns fatores necessários para a conclusão bem-sucedida de seu projeto de implantação (modelagem organizacional, auto-organização, experiência, cooperação e liderança).

Conclui-se que as questões levantadas no protocolo de pesquisa do projeto foram devidamente respondidas, pois no Modelo $A s-I s$ foram apresentados os principais obstáculos para a implantação de sistemas APS, por meio da revisão da literatura para a construção do Modelo Need for Change foram obtidos os principais elementos das redes de inovação autoorganizadas que podem funcionar como apoio ao projeto de implantação e a aprovação do Modelo To-Be ou modelo de referência proposto comprovou as vantagens que a propriedade de auto-organização em redes de inovação pode apresentar para a implantação de sistemas APS.

É importante ressaltar que para que o modelo de referência proposto nesta pesquisa seja útil a futuros processos de implantação de sistemas APS é necessário desenvolver a cultura organizacional colaborativa entre os membros envolvidos no projeto, pois do contrário, nenhum dos benefícios proporcionados pelos elementos de redes de inovação auto-organizadas serão alcançados. Esta cultura organizacional colaborativa é mais evidente na necessidade de compartilhamento de conhecimento e experiências entre os membros, motivação dos membros e usuários finais, confiança, participação ativa, comprometimento, evolução e autonomia.

Esta pesquisa apresenta como limitação o fato de que poucos membros do projeto de implantação de sistemas APS nas empresas foram entrevistados, pois além da indisponibilidade de participação de todos, em alguns casos, muitos funcionários que foram membros do projeto já não fazem mais parte do quadro de funcionários da organização. Muitas características do projeto podem ter sido negligenciadas nas entrevistas, porém, para reduzir a probabilidade dessa ocorrência, foram realizados estudos de caso em sete empresas, a fim de tornar os dados mais confiáveis, consistentes e generalizáveis. É importante ressaltar ainda que devido à duração da pesquisa, não foram acompanhados os testes, nem tampouco obtidos os resultados da utilização do modelo de referência para processos de implantação de sistemas APS sob a perspectiva de redes de inovação auto-organizadas por parte das empresas implantadoras que obtiveram o modelo, o que impossibilitou a documentação do mesmo.

É importante destacar que para que o modelo de referência desenvolvido mostre-se adequado, foi necessário que o mesmo obtivesse alta aprovação por parte dos membros da equipe interna do projeto de implantação das empresas, consultores e especialistas da área. $\mathrm{O}$ modelo de referência foi enviado junto com um questionário a estes profissionais para validálo, e os retornos obtidos evidenciam alta confiabilidade do modelo, visto que o mesmo obteve índices significativos de consistência. 
Espera-se que o modelo de referência para processos de implantação de sistemas APS sob a perspectiva de redes de inovação auto-organizadas apresentado nesta pesquisa, possa ser aperfeiçoado e utilizado por consultores e gestores em futuros projetos similares em empresas para que possa ser documentado; bem como por pesquisadores, como referência para o desenvolvimento de novas pesquisas acadêmicas envolvendo a temática. 


\section{REFERÊNCIAS}

ABREU, A.; MACEDO, P.; CAMARINHA-MATOS, L. M. Elements of a methodology to assess the alignment of core-values in collaborative networks. International Journal of Production Research, London, v. 47, n. 17, p. 4907-4934, 2009.

AGERON, B.; LAVASTRE, O.; SPALANZANI, A. Innovative supply chain practices: the state of French companies. Supply Chain Management: An International Journal, Bingley, v. 18, n. 3, p. 265-276, 2013.

AHLEMANN, F. Towards a conceptual reference model for project management information systems. International Journal of Project Management, Philadelphia, v. 27, n. 1, p. 19-30, 2009.

AHLEMANN, F.; GASTL, H. Process model for an empirically grounded reference model construction. In: FETTKE, P.; LOOS, P. (Eds.). Reference modeling for business systems analysis. Hershey: Idea Group Publishing, 2007.

AL-TAHAT, M. D.; BATAINEH, K. M. Statistical analyses and modeling of the implementation of agile manufacturing tactics in industrial firms. Mathematical Problems in Engineering, New York, v. 2012, p. 1-23, 2012.

AMARA, N.; LANDRY, R. Sources of information as determinants of novelty of innovation in manufacturing firms: evidence from the 1999 statistics Canada innovation survey. Technovation, Philadelphia, v. 25, n. 3, p. 245-259, 2005.

AMATO NETO, J. Redes de cooperação produtiva e clusters regionais: oportunidades para as pequenas e médias empresas. São Paulo: Atlas: Fundação Vanzolini, 2000.

ANDERSON, P. Comply theory and organization science. Organization Science, Catonsville, v. 10, n. 3, p. 216-232, 1999.

ARSOVSKI, S.; ARSOVSKI, Z.; MIROVIC, Z. The integrating role of simulation in modern manufacturing planning and scheduling. Journal of Mechanical Engineering, Ljubljana, v. 55 , n. 1, p. 33-44, 2009.

AZEVEDO, A. L.; SOUSA, J. P. A component-based approach to support order planning in a distributed manufacturing enterprise. Journal of Materials Processing Technology, Philadelphia, v. 107, n. 1/3, p. 431-438, 2000. 
BAJEC, M.; KRISPER, M. A methodology and tool support for managing business rules in organizations. Information Systems, Philadelphia, v. 30, n. 6, p. 423-443, 2005.

BARCO, R.; LÁZARO, P.; MUÑOZ, P. A unified framework for self-healing in wireless networks. IEEE Communications Magazine, Piscataway, v. 50, n. 12, p. 134-142, 2012.

BERIO, G.; VERNADAT, F. Enterprise modelling with CIMOSA: functional and organizational aspects. Production Planning \& Control: The Management of Operations, London, v. 12, n. 2, p. 128-136, 2001.

BOCCA, F. F.; RODRIGUES, L. H. A.; ARRAES, N. A. M. When do I want to know and why? Different demands on sugarcane yield predictions. Agricultural Systems, Philadelphia, v. 135, p. 48-56, 2015.

BONAZZI, F. L. Z.; ZILBER, M. A. Innovation and business model: a case study about integration of Innovation Funnel and Business Model Canvas. Revista Brasileira de Gestão de Negócios, São Paulo, v. 16, n. 53, p. 616-637, 2014.

BORTOLLOSSI, L. N.; SAMPAIO, M. A produção acadêmica publicada na revista Gestão \& Produção de 1999 a 2010: tendências e direções para pesquisas futuras. Gestão \& Produção, São Carlos, v. 19, n. 1, p. 189-201, 2012.

BOULAKSIL, Y., FRANSOO, J. C.; HALM, E. N. G. V. Setting safety stocks in multi-stage inventory systems under rolling horizon mathematical programming models. OR Spectrum, Heidelberg, v. 31, n. 1, p. 121-140, 2009.

BRAHA, D.; STACEY, B.; BAR-YAM, Y. Corporate competition: a self-organized network. Social Networks, Philadelphia, v. 33, n. 3, p. 219-230, 2011.

BRANDENBURG, M.; TÖLLE, F-J. MILP-based campaign scheduling in a specialty chemicals plant: a case study. OR Spectrum, Heidelberg, v. 31, n. 1, p. 141-166, 2009.

BRITTO, J. Cooperação interindustrial e redes de empresas. In: KUPFER, D.; HASENCLEVER, L. (Orgs.). Economia industrial: fundamentos teóricos e práticos no Brasil. Rio de Janeiro: Campus, 2002.

BRUN, A. et al. Value and risk assessment of Supply Chain Management improvement projects. International Journal of Production Economics, Philadelphia, v. 99, n. 1/2, p. 186201, 2006.

BRUZZONE, A. A. G. et al. Energy-aware scheduling for improving manufacturing process sustainability: a mathematical model for flexible flow shops. CIRP Annals - Manufacturing Technology, Philadelphia, v. 61, n. 1, p. 459-462, 2012.

BUBENKO, J.; BRASH, D.; STIRNA, J. EKD user guide. ELEKTRA: Electrical Enterprise Knowledge for Transforming Applications: Project n. 22927, 1998. 
BUBENKO, J.; PERSSON, A.; STIRNA, J. EKD D3: User guide of the knowledge management approach using enterprise knowledge patterns. Hyperknowledge IST-200028401, 2001.

CAMARINHA-MATOS, L. M.; AFSARMANESH, H. Elements of a base VE infrastructure. Computers in Industry, Philadelphia, v. 51, n. 2, p. 139-163, 2003.

CAMARINHA-MATOS, L. M.; AFSARMANESH, H. Collaborative networks: a new scientific discipline. Journal of Intelligent Manufacturing, New York, v. 16, n. 4/5, p. 439$452,2005$.

CAMARINHA-MATOS, L. M.; AFSARMANESH, H. A comprehensive modeling framework for collaborative networked organizations. Journal of Intelligent Manufacturing, New York, v. 18, n. 5, p. 529-542, 2007.

CAMARINHA-MATOS, L. M.; AFSARMANESH, H. On reference models for Collaborative Networked Organizations. International Journal of Production Research, London, v. 46, n. 9, p. 2453-2469, 2008.

CAMARINHA-MATOS, L. M. et al. Collaborative Networked Organizations: concepts and practice in enterprise manufacturing. Computers \& Industrial Engineering, Philadelphia, v. 57, n. 1, p. 46-60, 2009.

CAPLINSKAS, A. et al. Processing of undesirable business events in advanced production planning systems. INFORMATICA, Vilnius, v. 23, n. 4, p. 563-579, 2012.

CAPUTO, G.; GALLO, M.; GUIZZI, G. Optimization of production plan through simulation techniques. WSEAS Transactions on Information Science and Applications, Kanagawa, v. 6, n. 3, p. 352-362, 2009.

CARNEVALLI, J. A.; MIGUEL, P. A. C. Review, analysis and classification of the literature on QFD - types of research, difficulties and benefits. International Journal of Production Economics, Philadelphia, v. 114, n. 2, p. 737-754, 2008.

CASSI, L. et al. Research networks as infrastructure for knowledge diffusion in European regions. Economics of Innovation and New Technology, London, v. 17, n. 7/8, p. 663-676, 2008.

CHAMBERS, N. Beyond MRPII: a new approach to manufacturing planning and simulation. Industrial Management \& Data Systems, Bingley, v. 96, n. 4, p. 3-5, 1996.

CHEIKHROUHOU, N.; POULY, M.; MADINABEITIA, G. Trust categories and their impacts on information exchange processes in vertical collaborative networked organisations. International Journal of Computer Integrated Manufacturing, London, v. 26, n. 1/2, p. 87100, 2013. 
CHEN, C. J. et al. Advanced planning and scheduling for TFT-LCD color filter fab with multiple lines. The International Journal of Advanced Manufacturing Technology, Berlin, v. 67, n. $1 / 4$, p. $101-110,2013$.

CHEN, K.; JI, P. A mixed integer programming model for Advanced Planning and Scheduling (APS). European Journal of Operational Research, Philadelphia, v. 181, n. 1, p. 515-522, 2007.

CHEN, W-L.; HUANG, C-Y.; LAI, Y-C. Multi-tier and multi-site collaborative production: illustrated by a case example of TFT-LCD manufacturing. Computers \& Industrial Engineering, Philadelphia, v. 57, n. 1, p. 61-72, 2009.

CHERN, C-C.; YANG, I-C. A heuristic master planning algorithm for supply chains that consider substitutions and commonalities. Expert Systems with Applications, Philadelphia, v. 38, n. 12, p. 14918-14934, 2011.

CHITUC, C-M.; AZEVEDO, A.; TOSCANO, C. Collaborative business frameworks comparison, analysis and selection: an analytic perspective. International Journal of Production Research, London, v. 47, n. 17, p. 4855-4883, 2009.

CHITUC, C-M.; NOF, S. Y. The Join/Leave/Remain (JLR) decision in Collaborative Networked Organizations. Computers \& Industrial Engineering, Philadelphia, v. 53, n. 1, p. 173-195, 2007.

CORSARO, D.; CANTÙ, C.; TUNISINI, A. Actors' heterogeneity in innovation networks. Industrial Marketing Management, Philadelphia, v. 41, n. 5, p. 780-789, 2012.

CROWSTON, K. et al. Self-organization of teams for free/libre open source software development. Information and Software Technology, Philadelphia, v. 49, n. 6, p. 564-575, 2007.

CROXTON, K. L. et al. The demand management process. International Journal of Logistics Management, Bingley, v. 13, n. 2, p. 51-66, 2002.

DANGELICO, R. M.; PONTRANDOLFO, P.; PUJARI, D. Developing sustainable new products in the textile and upholstered furniture industries: role of external integrative capabilities. Journal of Product Innovation Management, New Jersey, v. 30, n. 4, p. 642$658,2013$.

DAVID, F.; PIERREVAL, H.; CAUX, C. Advanced Planning and Scheduling systems in aluminium conversion industry. International Journal of Computer Integrated Manufacturing, London, v. 19, n. 7, p. 705-715, 2006.

DAYOU, L.; PU, Y.; JI, Y. Development of a multiobjective GA for Advanced Planning and Scheduling problem. The International Journal of Advanced Manufacturing Technology, Berlin, v. 42, n. 9/10, p. 974-992, 2009. 
DE VANY, A. Information, chance, and evolution: alchian and the economics of selforganization. Economic Inquiry, Hoboken, v. 34, n. 3, p. 427-443, 1996.

DUTRA, F. A. F.; ERDMANN, R. H. Análise do Planejamento e Controle da Produção sob a ótica da teoria da complexidade. Produção, São Paulo, v. 17, n. 2, p. 407-419, 2007.

DUTTA, B.; GHOSAL, S.; RAY, D. Farsighted network formation. Journal of Economic Theory, Philadelphia, v. 122, n. 2, p. 143-164, 2005.

EBECKEN, N. F. F. A process for innovation in a collaborative network. Journal of Information \& Knowledge Management, New Jersey, v. 10, n. 2, p. 183-192, 2011.

EISENHARDT, K. M. Building theories from case study research. Academy of Management Review, New York, v. 14, n. 4, p. 532-550, 1989.

ESCHENBÄCHER, J.; SEIFERT, M.; THOBEN, K-D. Improving distributed innovation processes in virtual organisations through the evaluation of collaboration intensities. Production Planning \& Control: The Management of Operations, London, v. 22, n. 5/6, p. 473-487, 2011.

ESPINOSA, A.; PORTER, T. Sustainability, complexity and learning: insights from complex systems approaches. The Learning Organization, Bingley, v. 18, n. 1, p. 54-72, 2011.

FERNANDES, F. C. F. et al. Identificação dos principais autores em Planejamento e Controle da Produção por meio de um survey mundial com pesquisadores da área. Gestão \& Produção, São Carlos, v. 14, n. 1, p. 83-95, 2007.

FERNANDES, F. C. F.; SANTORO, M. C. Avaliação do grau de prioridade e do foco do Planejamento e Controle da Produção (PCP): modelos e estudos de casos. Gestão \& Produção, São Carlos, v. 12, n. 1, p. 25-38, 2005.

FRAYET, J-M. et al. Agent-based supply-chain planning in the forest products industry. International Journal of Flexible Manufacturing Systems, New York, v. 19, n. 4, p. 358391, 2007.

FREEL, M. S.; HARRISON, R. T. Innovation and cooperation in the small firm sector: evidence from 'Northern Britain'. Regional Studies, London, v. 40, n. 4, p. 289-305, 2006.

FREEMAN, C. Technological infrastructure and international competitiveness. Industrial and Corporate Change, Oxford, v. 13, n. 3, p. 541-569, 2004.

GARCIA-SABATER, J. P.; MAHEUT, J.; GARCIA-SABATER, J. J. A two-stage sequential planning scheme for integrated operations planning and scheduling system using MILP: the case of an engine assembler. Flexible Services and Manufacturing Journal, New York, v. 24, n. 2, p. 171-209, 2012. 
GAYIALIS, S. P.; TATSIOPOULOS, I. P. Design of an IT-driven decision support system for vehicle routing and scheduling. European Journal of Operational Research, Philadelphia, v. 152, n. 2, p. 382-398, 2004.

GEN, M.; LIN, L. Multiobjective evolutionary algorithm for manufacturing scheduling problems: state-of-the-art survey. Journal of Intelligent Manufacturing, New York, v. 25, n. 5, p. 849-866, 2014.

GEN, M.; LIN, L.; ZHANG, H. Evolutionary techniques for optimization problems in integrated manufacturing system: state-of-the-art-survey. Computers \& Industrial Engineering, Philadelphia, v. 56, n. 3, p. 779-808, 2009.

GENIN, P.; THOMAS, A.; LAMOURI, S. How to manage robust tactical planning with an APS (Advanced Planning Systems). Journal of Intelligent Manufacturing, New York, v. 18, n. 2, p. 209-221, 2007.

GIACON, E.; MESQUITA, M. A. Levantamento das práticas de programação detalhada da produção: um survey na indústria paulista. Gestão \& Produção, São Carlos, v. 18, n. 3, p. 487 498, 2011.

GIL, A. C. Como elaborar projetos de pesquisa. 5a ed. São Paulo: Atlas, 2010.

GOEPP, V.; ROSE, B.; CAILLAUD, E. Coupling reference modelling and performance evaluation for the effective integration of eco-design tools into the design process. International Journal of Computer Integrated Manufacturing, London, v. 27, n. 3, p. 242$265,2014$.

GREGORIADES, A.; SUTCLIFFE, A. A socio-technical approach to business process simulation. Decision Support Systems, Philadelphia, v. 45, n. 4, p. 1017-1030, 2008.

GÜNTHER, H-O.; MEYR, H. Supply chain planning and Advanced Planning Systems. OR Spectrum, Heidelberg, v. 31, n. 1, p. 1-3, 2009.

HADDAR, N. Z.; MAKNI, L.; ABDALLAH, H. B. Literature review of reuse in business process modeling. Software \& Systems Modeling, Heidelberg, v. 13, n. 3, p. 975-989, 2014.

HALLIKAS, J.; KARKKAINEN, H.; LAMPELA, H. Learning in networks: an exploration from innovation perspective. International Journal of Technology Management, Geneva, v. 45, n. 3/4, p. 229-243, 2009.

HENDRY, L.; HUANG, Y.; STEVENSON, M. Workload control: successful implementation taking a contingency-based view of Production Planning and Control. International Journal of Operations \& Production Management, Bingley, v. 33, n. 1, p. 69-103, 2013.

$\mathrm{HOCH}$, J. E. Shared leadership and innovation: the role of vertical leadership and employee integrity. Journal of Business and Psychology, New York, v. 28, n. 2, p. 159-174, 2013. 
HVOLBY, H-H.; STEGER-JENSEN, K. Technical and industrial issues of Advanced Planning and Scheduling (APS) systems. Computers in Industry, Philadelphia, v. 61, n. 9, p. 845-851, 2010 .

ICHIMURA, T.; AOKI, T.; SONG, G. F. The Effectiveness of System Integration in CIMS of Japanese companies. Computers \& Industrial Engineering, Philadelphia, v. 27, n. 1-4, p. 139-142, 1994.

IVERT, L. K. Shop floor characteristics influencing the use of Advanced Planning and Scheduling systems. Production Planning \& Control: The Management of Operations, London, v. 23, n. 6, p. 452-467, 2012.

IVERT, L. K.; JONSSON, P. The potential benefits of Advanced Planning and Scheduling systems in Sales and Operations Planning. Industrial Management \& Data Systems, Bingley, v. 110, n. 5, p. $659-681,2010$.

IVERT, L. K.; JONSSON, P. Problems in the onward and upward phase of APS system implementation: why do they occur? International Journal of Physical Distribution \& Logistics Management, Bingley, v. 41, n. 4, p. 343-363, 2011.

IVERT, L. K.; JONSSON, P. When should Advanced Planning and Scheduling systems be used in Sales and Operations Planning? International Journal of Operations \& Production Management, Bingley, v. 34, n. 10, p. 1338-1362, 2014.

JIMÉNEZ-JIMÉNEZ， D.; MARTÍNEZ-COSTA， M.; SANZ-VALLE， R. Knowledge management practices for innovation: a multinational corporation's perspective. Journal of Knowledge Management, Bingley, v. 18, n. 5, p. 905-918, 2014.

JONSSON, P.; KJELLSDOTTER, L.; RUDBERG, M. Applying Advanced Planning Systems for supply chain planning: three case studies. International Journal of Physical Distribution \& Logistics Management, Bingley, v. 37, n. 10, p. 816-834, 2007.

JUNG, H. An available-to-promise process considering production and transportation uncertainties and multiple performance measures. International Journal of Production Research, London, v. 50, n. 7, p. 1780-1798, 2012.

KALLESTRUP, K. B. et al. Decision support in hierarchical planning systems: The case of procurement planning in oil refining industries. Decision Support Systems, Philadelphia, v. 68, p. 49-63, 2014.

KARLSSON, C.; TAYLOR, M.; TAYLOR, A. Integrating new technology in established organizations: a mapping of integration mechanisms. International Journal of Operations \& Production Management, Bingley, v. 30, n. 7, p. 672-699, 2010.

KASH, D. E.; RYCROFT, R. W. Patterns of innovating complex technologies: a framework for adaptive network strategies. Research Policy, Philadelphia, v. 29, n. 7/8, p. 819-831, 2000. 
KASH, D. E.; RYCROFT, R. W. Emerging patterns of complex technological innovation. Technological Forecasting and Social Change, Philadelphia, v. 69, n. 6, p. 581-606, 2002.

KAVAKLI, E. et al. Incorporating privacy requirements into the system design process: the PriS conceptual framework. Internet Research, Bingley, v. 16, n. 2, p. 140-158, 2006.

KIRIKOVA, M. Explanatory capability of enterprise models. Data \& Knowledge Engineering, Philadelphia, v. 33, n. 2, p. 119-136, 2000.

KRISTIANTO, Y.; AJMAL, M. M.; HELO, P. Advanced Planning and Scheduling with collaboration processes in agile supply and demand networks. Business Process Management Journal, Bingley, v. 17, n. 1, p. 107-126, 2011.

KRUSE, G. The customer is always right. Manufacturing Engineer, Stevenage, v. 79, n. 5, p. 206-209, 2000.

KUNG, L-C.; CHERN, C-C. Heuristic factory planning algorithm for Advanced Planning and Scheduling. Computers \& Operations Research, Philadelphia, v. 36, n. 9, 2513-2530, 2009.

KURODA, M.; SHIN, H.; ZINNOHARA, A. Robust scheduling in an Advanced Planning and Scheduling environment. International Journal of Production Research, London, v. 40, n. 15, p. 3655-3668, 2002.

LAI, I. K. W.; TAM, S. K. T.; CHAN, M. F. S. Knowledge cloud system for network collaboration: A case study in medical service industry in China. Expert Systems with Applications, Philadelphia, v. 39, n. 15, p. 12205-12212, 2012.

LEE, S.; YONG, H-S. Distributed agile: project management in a global environment. Empirical Software Engineering, New York, v. 15, n. 2, p. 204-217, 2010.

LEE, Y.; LEE, I. W.; FEIOCK, R. C. Interorganizational collaboration networks in economic development policy: an exponential random graph model analysis. Policy Studies Journal, Hoboken, v. 40, n. 3, p. 547-573, 2012.

LEE, Y. H.; JEONG, C. S.; MOON, C. Advanced Planning and Scheduling with outsourcing in manufacturing supply chain. Computers \& Industrial Engineering, Philadelphia, v. 43, n. 1/2, p.351-374, 2002.

LIN, C-H.; HWANG, S-L.; WANG, E. M-Y. A reappraisal on Advanced Planning and Scheduling systems. Industrial Management \& Data Systems, Bingley, v. 107, n. 8, p. 1212 1226, 2007.

LIN, L. et al. Network modeling and evolutionary optimization for scheduling in manufacturing. Journal of Intelligent Manufacturing, New York, v. 23, n. 6, p. 2237-2253, 2012. 
LOWE, M. S. et al. Self-organizing innovation networks, mobile knowledge carriers and diasporas: insights from a pioneering boutique hotel chain. Journal of Economic Geography, Oxford, v. 12, n. 5, p. 1113-1138, 2012.

LUCZAK, H.; NICOLAI, H.; KEES, A. PPC-systems: re-engineering or replacement? Venus: a fuzzy-decision-tool helps to evaluate outdated Production Planning and Control systems. Production Planning \& Control: The Management of Operations, London, v. 9, n. 5, p. 448456, 1998.

LUPEIKIENE, A. et al. Advanced Planning and Scheduling systems: modeling and implementation challenges. INFORMATICA, Vilnius, v. 25, n. 4, p. 581-616, 2014.

MACCARTHY, B. L.; FERNANDES, F. C. F. A multi-dimensional classification of production systems for the design and selection of Production Planning and Control systems, Production Planning \& Control: The Management of Operations, London, v. 11, n. 5, p. 481496, 2000.

MARQUES, D. M. N.; GUERRINI, F. M. Reference model for implementing an MRP system in a highly diverse component and seasonal lean production environment. Production Planning \& Control: The Management of Operations, London, v. 23, n. 8, p. 609-623, 2012.

MARTINS, R. A. Abordagens quantitativa e qualitativa. In: MIGUEL, P. A. C. (Org.). Metodologia de pesquisa em engenharia de produção e gestão de operações. $2^{\mathrm{a}}$ ed. Rio de Janeiro: Elsevier: ABEPRO, 2012.

MATOOK, S.; INDULSKA, M. Improving the quality of process reference models: a quality function deployment-based approach. Decision Support Systems, Philadelphia, v. 47, n. 1, p. 60-71, 2009.

MAYMAND, M. M.; FARSIJANI, H.; MOOSAVI, S. S. T. Investigation of the key success factors in virtual tourism. Indian Journal of Science and Technology, Adyar, v. 5, n. 7, p. 3073-3080, 2012.

MCKAY, K. N.; WIERS, V. C. S. Integrated decision support for planning, scheduling, and dispatching tasks in a focused factory. Computers in Industry, Philadelphia, v. 50, n. 1, p. 5$14,2003$.

MEIXELL, M. J.; WU, D. Demand propagation in the extended enterprise: a comparative analysis of product and process design policies. International Journal of Production Research, London, v. 43, n. 20, p. 4169-4189, 2005.

MElO, M. A. C.; AGOSTINHO, M. C. E. 'Gestão Adaptativa': uma proposta para o gerenciamento de redes de inovação. Revista de Administração Contemporânea, Curitiba, v. 11, n. 2, p. 93-111, 2007. 
MESQUITA, M. A.; CASTRO, R. L. Análise das práticas de planejamento e controle da produção em fornecedores da cadeia automotiva brasileira. Gestão \& Produção, São Carlos, v. 15, n. 1, p. $33-42,2008$.

MEYR, H.; WAGNER, M.; ROHDE, J. Structure of Advanced Planning Systems. In: STADTLER, H.; KILGER, C. (Eds.). Supply Chain Management and Advanced Planning: concepts, models software and case studies. Third Edition. Heidelberg: Springer Berlin Heidelberg New York, 2005.

MIGUEL, P. A. C. Estudo de caso na engenharia de produção: estruturação e recomendações para sua condução. Produção, São Paulo, v. 17, n. 1, p. 216-229, 2007.

MIGUEL, P. A. C.; SOUSA, R. O método do estudo de caso na engenharia de produção. In: MIGUEL, P. A. C. (Org.). Metodologia de pesquisa em engenharia de produção e gestão de operações. $2^{\mathrm{a}}$ ed. Rio de Janeiro: Elsevier: ABEPRO, 2012.

MOSCOSO, P. G.; WÄFLER, T.; WINDISCHER, A. A modelling framework for complementary design of production planning and control systems. Ergonomics, London, v. 42, n. 11, p. 1492-1506, 1999.

MUKHOPADHYAY, S. K.; DWIVEDY, J. KUMAR, A. Design and implementation of an integrated production planning system for a pharmaceutical manufacturing concern in India. Production Planning \& Control: The Management of Operations, London, v. 9, n. 4, p. 391402, 1998.

NEUBAUER, T. An empirical study about the status of business process management. Business Process Management Journal, Bingley, v. 15, n. 2, p. 166-183, 2009.

NEUMANN, K.; SCHWINDT, C.; TRAUTMANN, N. Advanced production scheduling for batch plants in process industries. OR Spectrum, Heidelberg, v. 24, n. 3, p. 251-279, 2002.

NEVES, F. V. F.; GUERRINI, F. M. Modelo de requisitos e componentes técnicos para a formação e gerência de redes de cooperação entre empresas da construção civil. Gestão \& Produção, São Carlos, v. 17, n. 1, p. 195-206, 2010.

NGAI, E. W. T. et al. RFID research: an academic literature review (1995-2005) and future research directions. International Journal of Production Economics, Philadelphia, v. 112, n. 1, p. 510-520, 2008.

NONAKA, I.; TOYAMA, R.; KONNO, N. SECI, Ba and leadership: a unified model of dynamic knowledge creation. Long Range Planning, Philadelphia, v. 33, n. 1, p. 5-34, 2000.

NOTEBOOM, B. Governance and competence: how can they be combined? Cambridge Journal of Economics, Oxford, v. 28, n. 4, p. 505-525, 2004.

NURCAN, S. Analysis and design of co-operative work process a framework. Information and Software Technology, Philadelphia, v. 40, n. 3, p. 143-156, 1998. 
NURCAN, S.; ROLLAND, C. Using EKD-CMM electronic guide book for managing change in organisations. In: EUROPEAN-JAPANESE CONFERENCE ON INFORMATION MODELLING AND KNOWLEDGE BASES, 9, 1999, Iwate, Japão. Book XI, p. 105-123. Tampere, Finland, TUT, 1999.

NURCAN, S.; ROLLAND, C. A multi-method for defining organizational change. Information and Software Technology, Philadelphia, v. 41, n. 2, p. 61-82, 2003.

NYHUIS, P.; WIENDAHL, H-P. 3-Sigma PPC - a holistic approach for managing the logistic performance of production systems. CIRP Annals - Manufacturing Technology, Philadelphia, v. 53, n. 1, p. 371-376, 2004.

OLLUS, M. et al. Supporting collaborative project management. Production Planning \& Control: The Management of Operations, London, v. 22, n. 5/6, p. 538-553, 2011.

OMAR, M. K.; BENNELL, J. A. Revising the máster production schedule in a HPP framework context. International Journal of Production Research, London, v. 47, n. 20, p. 5857-5878, 2009.

ORGANISATION FOR ECONOMIC CO-OPERATION AND DEVELOPMENT - OECD. Oslo Manual: guidelines for collecting and interpreting innovation data. Third edition. Paris: OECD: Eurostat, 2005.

OSÓRIO, A. L.; CAMARINHA-MATOS, L. M. Distributed process execution in collaborative networks. Robotics and Computer-Integrated Manufacturing, Philadelphia, v. 24, n. 5, p. 647-655, 2008.

OU-YANG, C.; HON, S. J. Developing an agent-based APS and ERP collaboration framework. The International Journal of Advanced Manufacturing Technology, Berlin, v. 35, n. 9/10, p. 943-967, 2008.

ÖZTÜRK, C.; ORNEK, A. M. Operational extended model formulations for Advanced Planning and Scheduling systems. Applied Mathematical Modelling, Philadelphia, v. 38, n. 1, p. 181-195, 2014.

PÁDUA, S. I. D. Estudo sobre a aplicação do método de avaliação do modelo de processos de negócio do EKD. Produção, São Paulo, v. 22, n. 1, p. 155-172, 2012.

PÁDUA, S. I. D.; CAZARINI, E. W.; INAMASU, R. Y. Modelagem organizacional: captura dos requisitos organizacionais no desenvolvimento de sistemas de informação. Gestão \& Produção, São Carlos, v. 11, n. 2, p. 197-209, 2004.

PALMBERG, C. The sources and success of innovations - determinants of commercialisation and break-even times. Technovation, Philadelphia, v. 26, n. 11, p. 1253-1267, 2006.

PARUNG, J.; BITITCI, U. S. A metric for collaborative networks. Business Process Management Journal, Bingley, v. 14, n. 5, p. 654-674, 2008. 
PATRAKOSOL, B.; OLSON, D. L. How interfirm collaboration benefits IT innovation. Information \& Management, Philadelphia, v. 44, n. 1, p. 53-62, 2007.

PEDROSO, M. C.; CORREAA, H. L. Sistemas de programação da produção com capacidade finita: uma decisão estratégica? Revista de Administração de Empresas, São Paulo, v. 36, n. 4, p. 60-73, 1996.

PEKKOLA, S. Managing a network by utilizing performance measurement information. Measuring Business Excellence, Bingley, v. 17, n. 1, p. 72-79, 2013.

PENG, Y.; LU, D.; CHEN, Y. A constraint programming method for Advanced Planning and Scheduling system with multilevel structured products. Discrete Dynamics in Nature and Society, New York, v. 2014, p. 1-7, 2014.

PESSOA, M. A. O. et al. Time windows and constraint programming to deal with strong restriction in the due date of productive systems. Annual Reviews in Control, Philadelphia, v. 38, n. 1, p. 134-146, 2014.

PICARD, W.; RABELO, R. J. Engagement in collaborative networks. Production Planning \& Control: The Management of Operations, London, v. 21, n. 2, p. 101-102, 2010.

PROTEGEROU, A.; CALOGHIROU, Y.; SIOKAS, E. Research networking and technology fusion through EU-funded collaborative projects. Science and Public Policy, Oxford, v. 40, n. 5, p. 576-590, 2013.

QUANTE, R.; MEYR, H.; FLEISCHMANN, M. Revenue management and demand fulfillment: matching applications, models, and software. OR Spectrum, Heidelberg, v. 31, n. 1, p. 31-62, 2009.

QUETTI, C.; PIGNI, F.; CLERICI, A. Factors affecting RFId adoption in a vertical supply chain: the case of the silk industry in Italy. Production Planning \& Control: The Management of Operations, London, v. 23, n. 4, p. 315-331, 2012.

QUINN, J. B.; ANDERSON, P.; FINKELSTEIN, S. Managing professional intellect: making the most of the best. Harvard Business Review, Boston, v. 74, n. 2, p. 71-80, 1996.

RAMPERSAD, G.; QUESTER, P.; TROSHANI, I. Examining network factors: commitment, trust, coordination and harmony. Journal of Business \& Industrial Marketing, Bingley, v. 25, n. 7, p. 487-500, 2010a.

RAMPERSAD, G.; QUESTER, P.; TROSHANI, I. Managing innovation networks: Exploratory evidence from ICT, biotechnology and nanotechnology networks. Industrial Marketing Management, Philadelphia, v. 39, n. 5, p. 793-805, 2010 b.

REINHARTZ-BERGER, I.; SOFFER, P.; STURM, A. Extending the adaptability of reference models. IEEE Transactions on Systems, Man, and Cybernetics - Part A: Systems and Humans, Edmonton, v. 40, n. 5, p. 1045-1056, 2010. 
RODRIGUEZ, D. S. S.; COSTA, H. G.; DO CARMO, L. F. R. R. S. Métodos de auxílio multicritério à decisão aplicados a problemas de PCP: mapeamento da produção em periódicos publicados no Brasil. Gestão \& Produção, São Carlos, v. 20, n. 1, p. 134-146, 2013.

ROLLAND, C.; NURCAN, S.; GROSZ, G. A decision making pattern for guiding the Enterprise Knowledge Development process. Information and Software Technology, Philadelphia, v. 42, n. 5, p. 313-331, 2000.

ROMERO, D.; MOLINA, A. Virtual organisation breeding environments toolkit: reference model, management framework and instantiation methodology. Production Planning \& Control: The Management of Operations, London, v. 21, n. 2, p. 181-217, 2010.

ROMERO, D.; RABELO, R. J.; MOLINA, A. Collaborative networks as modern industrial organisations: real case studies. International Journal of Computer Integrated Manufacturing, London, v. 26, n. 1/2, p. 1-2, 2013.

RUDBERG, M.; CEDERBORG, O. APS for tactical planning in a steel processing company. Industrial Management \& Data Systems, Bingley, v. 111, n. 4, p. 608-628, 2011.

RUDBERG, M.; THULIN, J. Centralised supply chain master planning employing Advanced Planning Systems. Production Planning \& Control: The Management of Operations, London, v. 20, n. 2, p. 158-167, 2009.

RYCROFT, R. W.; KASH, D. E. Self-organizing innovation networks: implications for globalization. Technovation, Philadelphia, v. 24, n. 3, p. 187-197, 2004.

SACOMANO NETO, M.; TRUZZI, O. M. S. Configurações estruturais e relacionais da rede de fornecedores: uma resenha compreensiva. Revista de Administração, São Paulo, v. 39, n. 3, p. 255-263, 2004.

SAFAEI, A. S. et al. Integrated multi-site production-distribution planning in supply chain by hybrid modelling. International Journal of Production Research, London, v. 48, n. 14, p. 4043-4069, 2010.

SÁNCHEZ-GONZÁLEZ, J. et al. A multi-cell multi-objective self-optimisation methodology based on genetic algorithms for wireless cellular networks. International Journal of Network Management, New Jersey, v. 23, n. 4, p. 287-307, 2013.

SANTA-EULALIA, L. A. et al. Advanced Supply Chain Planning Systems (APS) today and tomorrow. In: ÖNKAL, D.; AKTAS, E. (Eds.). Supply Chain Management: pathways for research and practice. Rijeka: InTech, 2011a.

SANTA-EULALIA, L. A. et al. Agent-based experimental investigations of the robustness of tactical planning and control policies in a softwood lumber supply chain. Production Planning \& Control: The Management of Operations, London, v. 22, n. 8, p. 782-799, 2011 b. 
SANTA-EULALIA, L. A.; FRAYRET, J-M.; D’AMOURS, S. Essay on conceptual modeling, analysis and illustration of agent-based simulations for distributed supply chain planning. INFOR: Information Systems and Operational Research, Toronto, v. 46, n. 2, p. 97-116, 2008.

SCHUH, G. et al. Complexity-based modeling of reconfigurable collaborations in production industry. CIRP Annals - Manufacturing Technology, Philadelphia, v. 57, n. 1, p. 445-450, 2008a.

SCHUH, G. et al. Process oriented framework to support PLM implementation. Computers in Industry, Philadelphia, v. 59, n. 2/3, p. 210-218, 2008 b.

SERRANO, V.; FISCHER, T. Collaborative innovation in ubiquitous systems. Journal of Intelligent Manufacturing, New York, v. 18, n. 5, p. 599-615, 2007.

SETIA, P.; SAMBAMURTHY, V.; CLOSS, D. J. Realizing business value of agile IT applications: antecedents in the supply chain networks. Information Technology and Management, New York, v. 9, n. 1, p. 5-19, 2008.

SHAMSUZZOHA, A.; KYLLÖNEN, S.; HELO, P. Collaborative customized product development framework. Industrial Management \& Data Systems, Bingley, v. 109, n. 5, p. 718-735, 2009.

SIWEK, K.; OSOWSKI, S.; SZUPILUK, R. Ensemble neural network approach for accurate load forecasting in a power system. International Journal of Applied Mathematics and Computer Science, Zielona Góra, v. 19, n. 2, p. 303-315, 2009.

STADTLER, H. Supply Chain Management and advanced planning - basics, overview and challenges. European Journal of Operational Research, Philadelphia, v. 163, n. 3, p. 575 $588,2005$.

STEGER-JENSEN, K. et al. Advanced Planning and Scheduling technology. Production Planning \& Control: The Management of Operations, London, v. 22, n. 8, p. 800-808, 2011.

STEGER-JENSEN, K.; SVENSSON, C. Issues of mass customisation and supporting ITsolutions. Computers in Industry, Philadelphia, v. 54, n. 1, p. 83-103, 2004.

SØRENSEN, F. The geographies of social networks and innovation in tourism. Tourism Geographies, London, v. 9, n. 1, p. 22-48, 2007.

TENHIÄLÄ, A. Contingency theory of capacity planning: the link between process types and planning methods. Journal of Operations Management, Philadelphia, v. 29, n. 1/2, p. 65-77, 2011.

THARUMARAJAH, A. A self-organising view of manufacturing enterprises. Computers in Industry, Philadelphia, v. 51, n. 2, p. 185-196, 2003. 
THORGREN, S.; WINCENT, J.; ÖRTQVIST, D. Designing interorganizational networks for innovation: an empirical examination of network configuration, formation and governance. Journal of Engineering and Technology Management, Philadelphia, v. 26, n. 3, p. 148-166, 2009.

TONELLI, F. et al. Production planning of mixed-model assembly lines: a heuristic mixed integer programming based approach. Production Planning \& Control: The Management of Operations, London, v. 24, n. 1, p. 110-127, 2013.

TSAI, K-H. Collaborative networks and product innovation performance: toward a contingency perspective. Research Policy, Philadelphia, v. 38, n. 5, p. 765-778, 2009.

UPHAM, S. P.; ROSENKOPF, L.; UNGAR, L. H. Innovating knowledge communities: An analysis of group collaboration and competition in science and technology. Scientometrics, Dordrecht, v. 83, n. 2, p. 525-554, 2010.

TURRIONI, J. B.; MELLO, C. H. P. Metodologia de pesquisa em engenharia de produção: estratégias, métodos e técnicas para condução de pesquisas quantitativas e qualitativas. Apostila do curso de Especialização em Qualidade e Produtividade. Universidade Federal de Itajubá, Itajubá, MG, 2012.

VERNADAT, F. B. Enterprise modeling and integration: principles and applications. London: Chapman \& Hall, 1996.

VIANA, A. C. et al. Self-organization in spontaneous networks: the approach of DHT-based routing protocols. Ad Hoc Networks, Philadelphia, v. 3, n. 5, p. 589-606, 2005.

VILLEGAS, F. A.; SMITH, N. R. Supply chain dynamics: analysis of inventory vs. order oscillations trade-off. International Journal of Production Research, London, v. 44, n. 6, p. 1037-1054, 2006.

VOSS, C.; TSIKRIKTSIS, N.; FROHLICH, M. Case research in operations management. International Journal of Operations \& Production Management, Bingley, v. 22, n. 2, p. 195-219, 2002.

WAGNER, C. S.; LEYDESDORFF, L. Network structure, self-organization, and the growth of international collaboration in science. Research Policy, Philadelphia, v. 34, n. 10, p. 1608$1618,2005$.

WANG, X.; CHENG, H.; HUANG, M. Multi-robot navigation based QoS routing in selforganizing networks. Engineering Applications of Artificial Intelligence, Philadelphia, v. 26, n. 1, p. 262-272, 2013.

WEZEL, W. V.; DONK, D. P. V. GAALMAN, G. The planning flexibility bottleneck in food processing industries. Journal of Operations Management, Philadelphia, v. 24, n. 3, p. 287 300, 2006. 
WIENDAHL, H-H.; VON CIEMINSKI, G; WIENDAHL, H-P. Stumbling blocks of PPC: towards the holistic configuration of PPC systems. Production Planning \& Control: The Management of Operations, London, v. 16, n. 7, p. 634-651, 2005.

WIERS, V. C. S. A case study on the integration of APS and ERP in a steel processing plant. Production Planning \& Control: The Management of Operations, London, v. 13, n. 6, p. 552$560,2002$.

WIERS, V. C. S. The relationship between shop floor autonomy and APS implementation success: evidence from two cases. Production Planning \& Control: The Management of Operations, London, v. 20, n. 7, p. 576-585, 2009.

YIN, R. K. Estudo de caso: planejamento e métodos. Tradução Daniel Grassi. $4^{\text {a }}$ ed. Porto Alegre: Bookman, 2010.

YUSUF, Y.; GUNASEKARAN, A.; ABTHORPE, M. S. Enterprise information systems project implementation: a case study of ERP in Rolls-Royce. International Journal of Production Economics, Philadelphia, v. 87, n. 3, p. 251-266, 2004.

ZAIDAT, A.; BOUCHER, X.; VINCENT, L. A. Framework for organization network engineering and integration. Robotics and Computer-Integrated Manufacturing, Philadelphia, v. 21, n. 3, p. 259-271, 2005.

ZENG, S.X.; XIE, X.M.; TAMC, C.M. Relationship between cooperation networks and innovation performance of SMEs. Technovation, Philadelphia, v. 30, n. 3, p. 181-194, 2010.

ZHONG, R. Y. et al. RFID-enabled real-time Advanced Planning and Scheduling shell for production decision making. International Journal of Computer Integrated Manufacturing, London, v. 26, n. 7, p. 649-662, 2013.

ZORYK-SCHALLA, A. J., FRANSOO, J. C.; DE KOK, T. G. Modeling the planning process in Advanced Planning Systems. Information \& Management, Philadelphia, v. 42, n. 1, p. 7587, 2004. 


\section{APÊNDICES}

\section{APÊNDICE A - MODELAGEM ORGANIZACIONAL DO PROCESSO DE IMPLANTAÇÃO DE SISTEMAS APS NAS EMPRESAS OBJETO DE ESTUDO}

\section{Estudo de caso - Empresa 1}

Este estudo de caso foi realizado em uma empresa brasileira que iniciou suas atividades em janeiro de 2006, e que fabrica diversos segmentos de fios e cabos. A empresa possui uma unidade no Brasil, localizada na cidade de Guarulhos e conta atualmente com 66 funcionários. Em termos de faturamento, é classificada como empresa de médio porte. Possui uma ampla gama de produtos, os quais fabrica na ordem make-to-order.

De acordo com o funcionário da empresa que participou da entrevista para este estudo de caso, apesar de a empresa ter implantado o sistema APS desde 2010, a mesma ainda não o utiliza plenamente, pois sua linha de produtos é bastante diversificada, e seus produtos possuem grande diversidade de matérias-primas, o que dificulta a programação. De acordo com o funcionário, o sistema é adequado para quem produz sempre produtos padronizados, e por essa razão a produção de apenas uma parte dos produtos da empresa é programada pelo APS.

\section{Modelo de Objetivos}

De acordo com as informações obtidas na entrevista, a falta de pontualidade na entrega dos produtos foi um dos principais motivos que levaram a empresa a implantar o sistema APS, pois o sistema de PCP utilizado anteriormente não possuía todas as funcionalidades que o APS possui, inviabilizando a geração de diversos cenários. Como pode ser visto na Figura 17, a utilização do sistema APS na área de Planejamento e Controle da Produção da empresa permite o encaixe de mais pedidos (Objetivo 1.1), garante maior faturamento (Objetivo 1.2), maior pontualidade nas entregas (Objetivo 1.3) e mais espaço adicional na carteira de pedidos (Objetivo 1.4), o que apoia a garantia de um horizonte maior de visualização dos prazos de entregas (Objetivo 1). Um melhor planejamento da produção, compras e entregas (Objetivo 2) apoia a garantia de um maior horizonte de visualização dos prazos de entrega (Objetivo 1), auxilia a tomada de decisões operacionais (Oportunidade 1), gera a redução de custos na 
empresa (Oportunidade 2) e é influenciado pela busca da empresa em atender à norma ISO 9001/2008.

A grande diversidade de produtos e materiais da empresa (Restrição 1) e a grande quantidade de alternativas de produção (Restrição 2) dificultam a garantia de um melhor planejamento da produção, compras e entregas (Objetivo 2), pois dificultam a tomada de decisão sobre a melhor alternativa. 


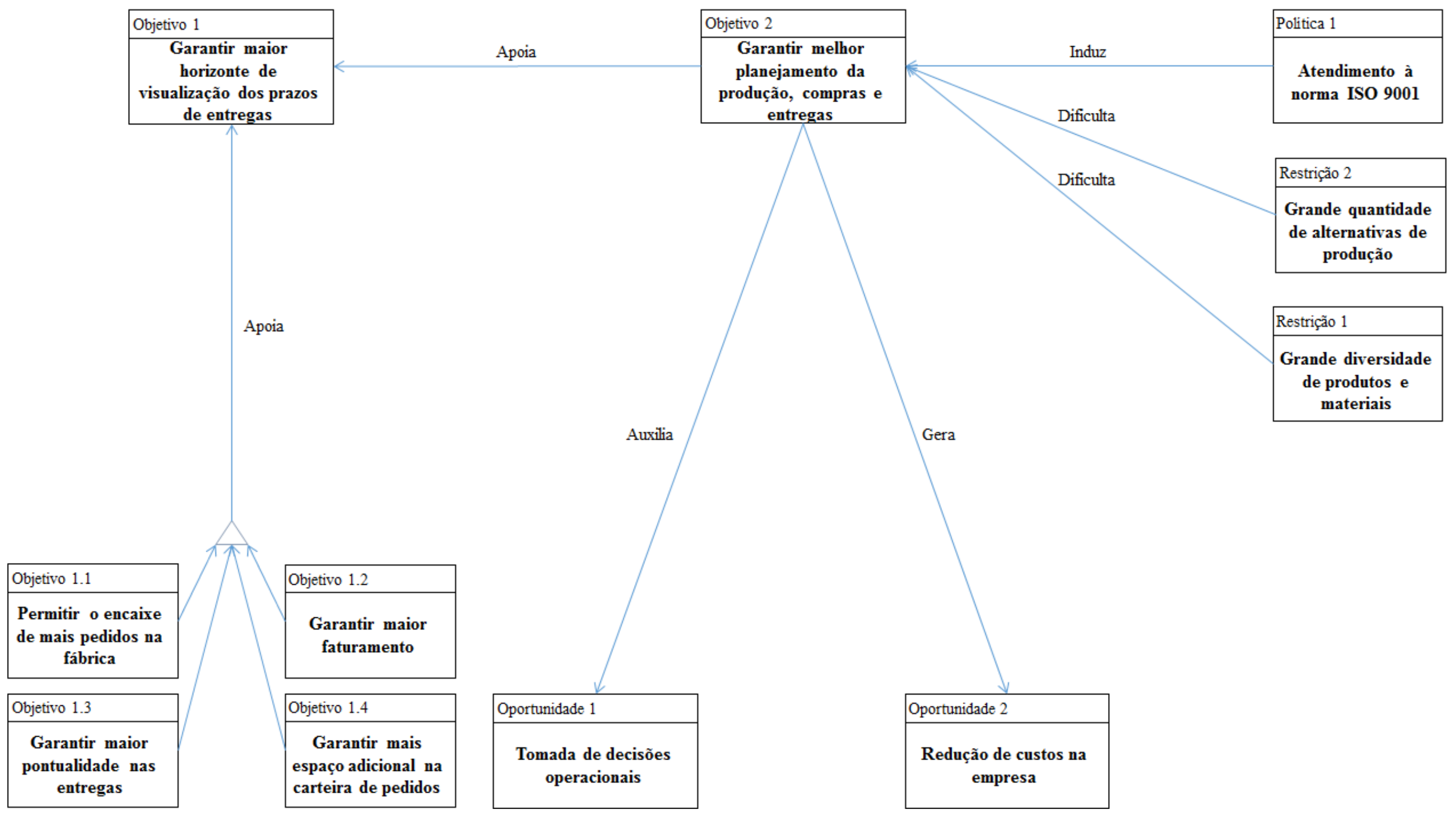

Figura 17 - Modelo de Objetivos - Empresa 1 


\section{Modelo de Regras do Negócio}

O Modelo de Regras do Negócio mostra a influência das regras do processo de implantação do sistema APS sobre os objetivos do processo. Tal modelo está representado na Figura 18.

A geração de poucas soluções de programação (Regra 1) agiliza a garantia de um melhor planejamento da produção, compras e entregas (Objetivo 2), o qual, para que ocorra, necessita da integração com os sistemas ERP e EGA (Regra 6) e é dificultado pela grande diversidade de produtos e materiais da empresa (Regra 2).

A adaptação da solução do sistema às necessidades da empresa (Regra 4.1), bem como o fornecimento de diversas informações (Regra 4.2) apoiam a amplificação do conhecimento dos funcionários sobre os processos produtivos (Regra 4), o que facilita a garantia de um melhor planejamento da produção, compras e entregas (Objetivo 2).

O treinamento dos usuários finais quanto ao uso do sistema (Regra 3.1) aumenta o conhecimento da dinâmica do sistema (Regra 3), o que facilita a garantia de um melhor planejamento da produção, compras e entregas (Objetivo 2).

A realização de testes no sistema após a etapa de modelagem (Regra 5) aumenta o conhecimento da dinâmica do sistema (Regra 3), bem como verifica se com as soluções geradas realmente é possível garantir um melhor planejamento da produção, compras e entregas (Objetivo 2), e, consequentemente, um maior horizonte de visualização dos prazos de entregas (Objetivo 1). 


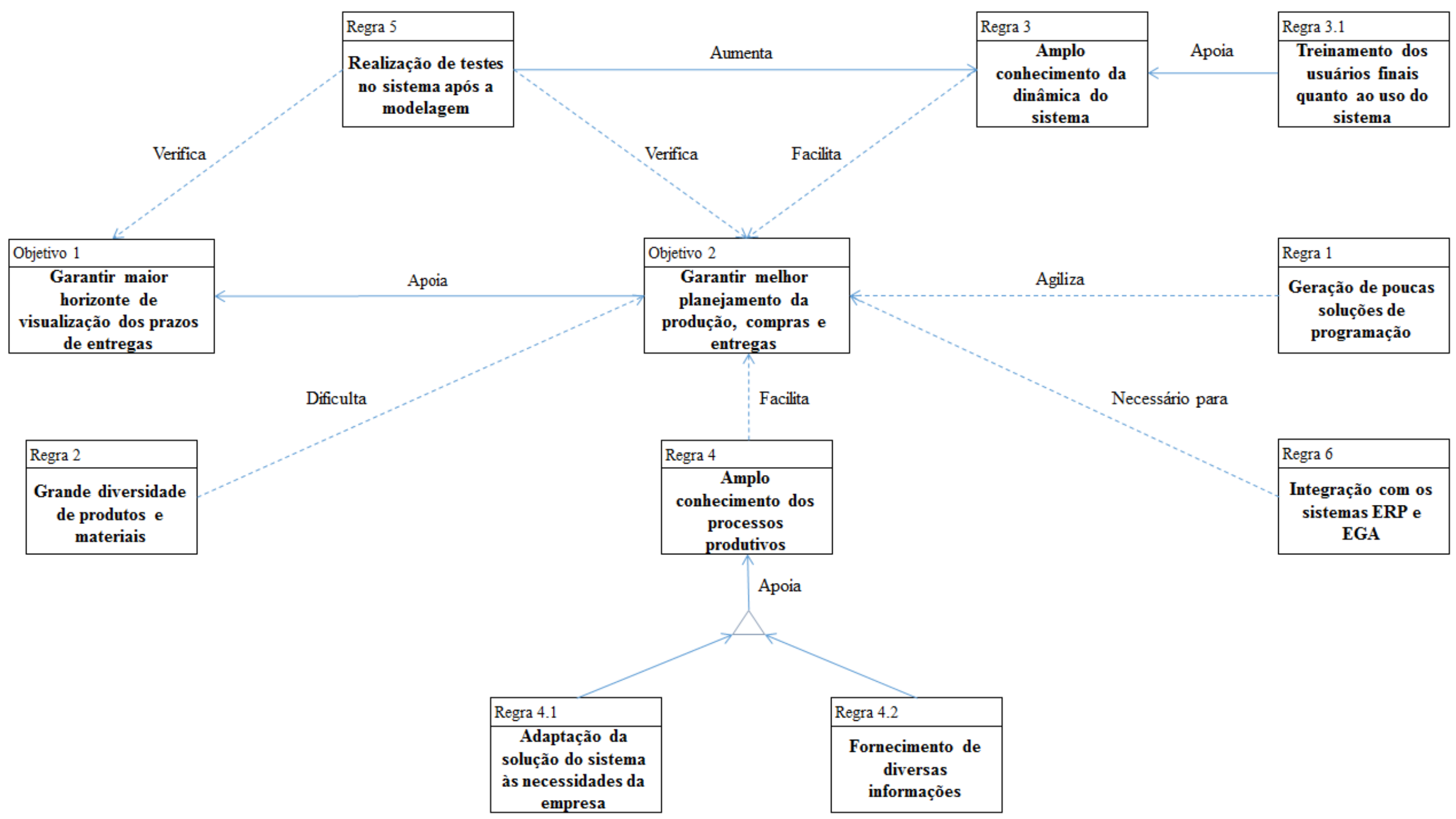

Figura 18 - Modelo de Regras do Negócio - Empresa 1 


\section{Modelo de Processos}

Durante o processo de implantação do sistema APS na empresa, a equipe de implantação realizou 7 principais processos, os quais estão representados na Figura 19.

Após estar ciente da necessidade de adquirir um sistema de planejamento e controle da produção mais eficiente e eficaz, o Conselho Administrativo da empresa adquirente do software autorizou a aquisição do sistema (InfoSet 1), e a área pertinente da empresa negociou a transação com a empresa de consultoria que fará a sua implantação (Processo 1), resultando em sua aquisição (InfoSet 2).

Após a aquisição do sistema (InfoSet 2), os profissionais da empresa implantadora do software participantes do processo de implantação realizaram visitas técnicas na empresa adquirente para avaliar suas necessidades quanto às funcionalidades do sistema (Processo 2), resultando em sua modelagem (InfoSet 3 ).

Com o sistema modelado (InfoSet 3), os funcionários da área de Planejamento e Controle da Produção realizaram vários testes (Processo 3), gerando um relatório detalhado contendo a análise das funcionalidades do sistema (InfoSet 4), o qual, após analisado pelos profissionais da empresa implantadora, auxiliou na definição das melhorias do sistema (Processo 4), o que resultou na remodelagem do mesmo (InfoSet 5).

Com o sistema remodelado (InfoSet 5), os funcionários da área de Planejamento e Controle da Produção entraram em contato com os profissionais da empresa implantadora do sistema ERP que participaram de seu processo de implantação, visando criar a integração entre este e o sistema APS (Processo 5), resultando na interface parametrizada entre sistemas (InfoSet $6)$.

Com a interface entre o APS e o ERP parametrizada (InfoSet 6), o APS foi implantado definitivamente na empresa (Processo 6), sendo então parametrizado (InfoSet 7). Com o sistema parametrizado, os funcionários pertinentes foram treinados para o seu uso (Processo 7), e alguns deles geraram uma apostila para auxílio a futuros usuários (InfoSet 8). 

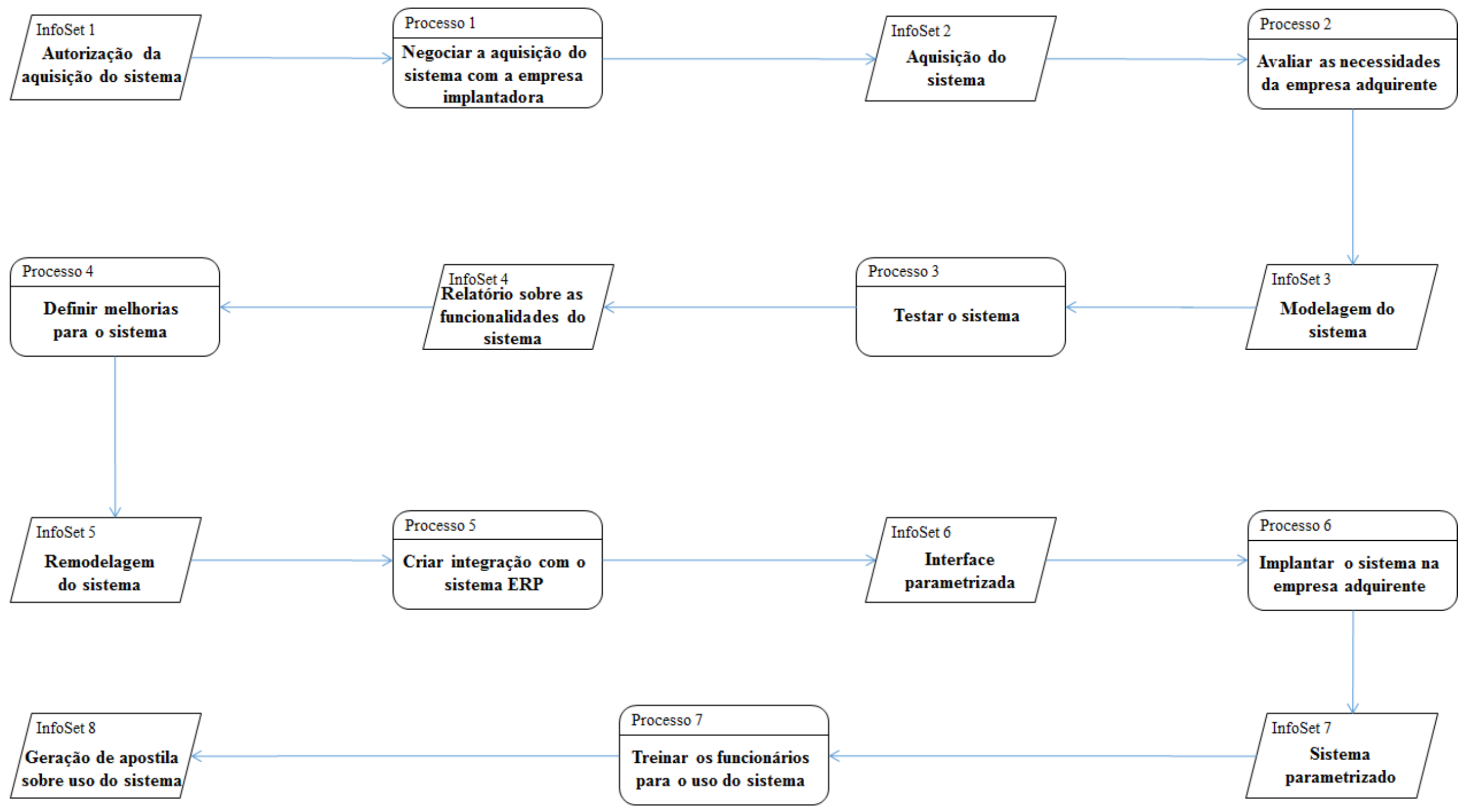

Figura 19 - Modelo de Processos - Empresa 1 


\section{Modelo de Atores e Recursos}

Neste modelo está descrito o papel de cada envolvido nas etapas do processo de implantação do sistema APS na empresa. A Figura 20 apresenta a visão geral do modelo.

O Diretor (Unidade Individual 1) da empresa adquirente do sistema APS (Unidade Organizacional 1) elabora as metas e objetivos do processo de implantação do sistema APS (Papel 1), aprova o orçamento (Recurso 1) e libera os recursos financeiros necessários para a sua aquisição (Recurso 2).

O Analista de Planejamento e Controle da Produção (Unidade Individual 2) da empresa adquirente do sistema APS (Unidade Organizacional 1), com base nas necessidades de melhoria das atividades pertinentes a ele, realiza a apresentação do sistema para o Conselho Administrativo da empresa (Papel 2); em conjunto com o Consultor (Unidade Individual 7) da empresa implantadora do APS (Unidade Organizacional 2) realiza a modelagem do sistema (Recurso 3); em conjunto com o Consultor (Unidade Individual 9) da empresa implantadora do ERP (Unidade Organizacional 3), gera a interface parametrizada entre o APS e o ERP (Recurso 5); participa da parametrização do sistema (Recurso 6); e em conjunto com o Consultor (Unidade Individual 7) da empresa implantadora do APS (Unidade Organizacional 2) é responsável pelo treinamento dos usuários finais quanto ao uso do sistema (Recurso 7), o qual é ministrado para o Analista de Produção (Unidade Individual 3), Engenheiro (Unidade Individual 5) e Representante Comercial (Unidade Individual 4).

O Diretor (Unidade Individual 6) da empresa implantadora do sistema APS (Unidade Organizacional 2) define o orçamento (Recurso 1) e recebe os recursos financeiros (Recurso 2) da empresa adquirente do sistema APS (Unidade Organizacional 1), designando o Consultor (Unidade Individual 7) e Desenvolvedor (Unidade Individual 8) para realizar as atividades do processo de implantação do sistema.

O Desenvolvedor (Unidade Individual 8) da empresa implantadora do sistema APS (Unidade Organizacional 2) com base no levantamento das necessidades de melhoria apontadas pelo Analista de PCP (Unidade Individual 1) realiza a remodelagem do sistema (Recurso 4).

O Consultor (Unidade Individual 7), com base na análise das necessidades da empresa adquirente quanto às funcionalidades do sistema APS, em conjunto com o Analista de PCP (Unidade Individual 2) realiza a modelagem do sistema (Recurso 3), é responsável pela sua parametrização (Recurso 6) e pelo treinamento dos usuários finais (Recurso 7). 


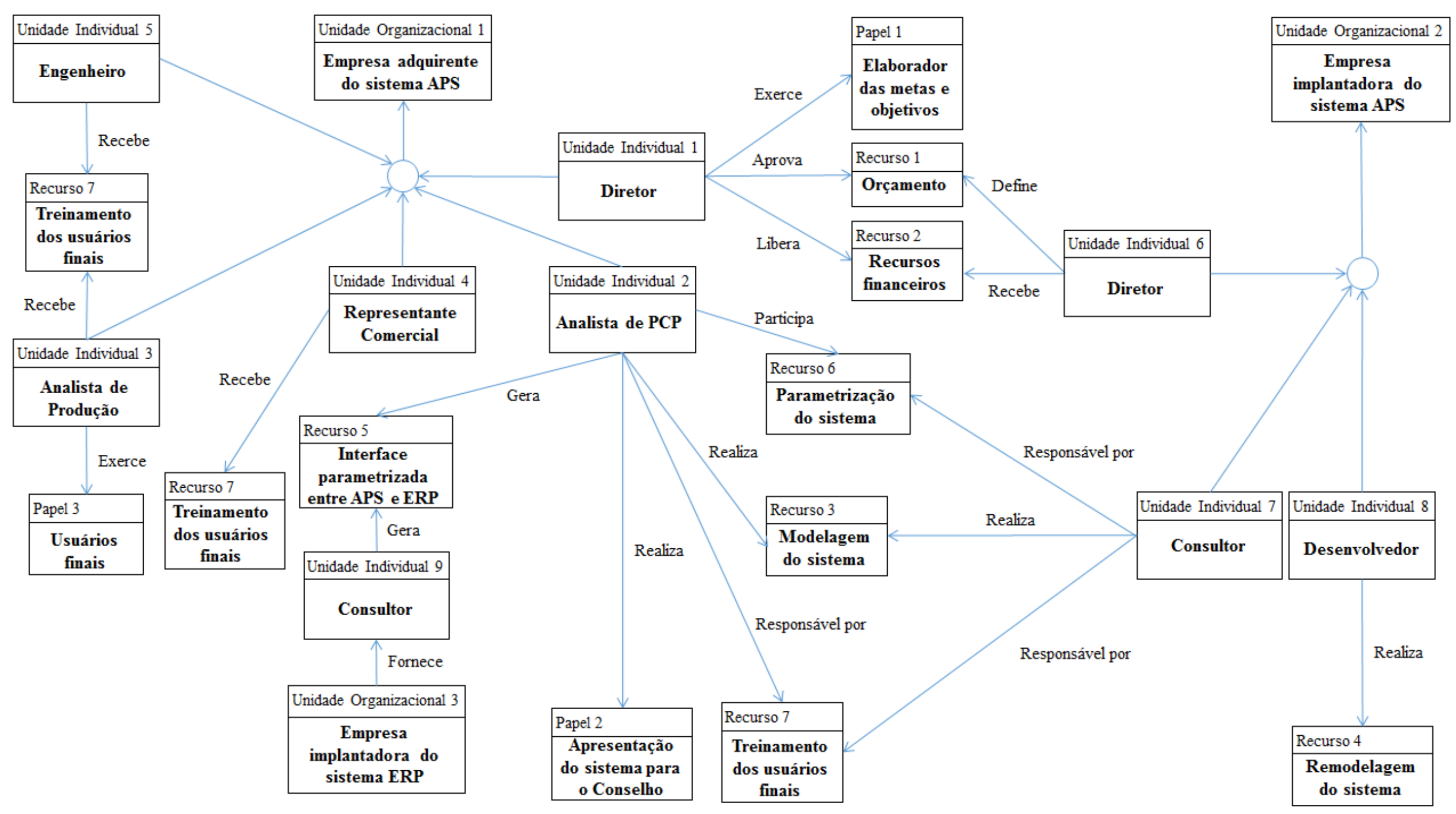

Figura 20 - Modelo de Atores e Recursos - Empresa 1 


\section{Modelo de Componentes e Requisitos Técnicos}

A Figura 21 apresenta o Modelo de Componentes e Requisitos Técnicos do processo de implantação do sistema APS. Este modelo foi desenvolvido a partir da expectativa do funcionário entrevistado quanto aos requisitos que poderiam auxiliar o processo de implantação, uma vez que a organização não possuía nenhum sistema de informação que pudesse auxiliá-la.

De acordo com as informações obtidas, o funcionário da organização acredita que o único objetivo de um sistema de informação que poderia auxiliar o processo de implantação do sistema APS na empresa é permitir a integração entre os sistemas APS, ERP e EGA (Objetivo SI). Com essa integração, o EGA torna-se responsável pelo controle da produção; o ERP pela emissão de ordens de explosão de matérias-primas, montagem de produtos; e o APS pelo planejamento das atividades produtivas. A integração gerada por meio deste sistema apoia a garantia de melhor planejamento da produção, compras e entregas (Objetivo 2).

O sistema para integração entre os sistemas APS, ERP e EGA (Objetivo SI) considera requisitos funcionais (que tangem a utilização do sistema de informação pretendido), bem como não funcionais (que tangem as medidas de segurança, usabilidade e acessibilidade, etc.). Ele visa realizar a integração entre o APS e o ERP (Requisito Funcional 1), coletar os dados do sistema EGA relacionados ao apontamento da produção (Requisito Funcional 2), enviar estes dados para o sistema APS (Requisito Funcional 3), agilizando assim a implantação efetiva do sistema APS (Requisito Funcional 4). Tal sistema deve proporcionar interface amigável ao usuário (Requisito Não Funcional 1), possuir robustez (Requisito Não Funcional 2) e segurança (Requisito Não Funcional 3), restringindo o acesso apenas aos envolvidos nos processos.

Este sistema é definido e acessado pelo Analista de PCP (Unidade Individual 2) e Consultor (Unidade Individual 7) e facilita a integração com os sistemas ERP e EGA (Regra 6) e o fornecimento de diversas informações (Regra 4.2), bem como agiliza o processo de criação de integração com o sistema ERP (Processo 5). 


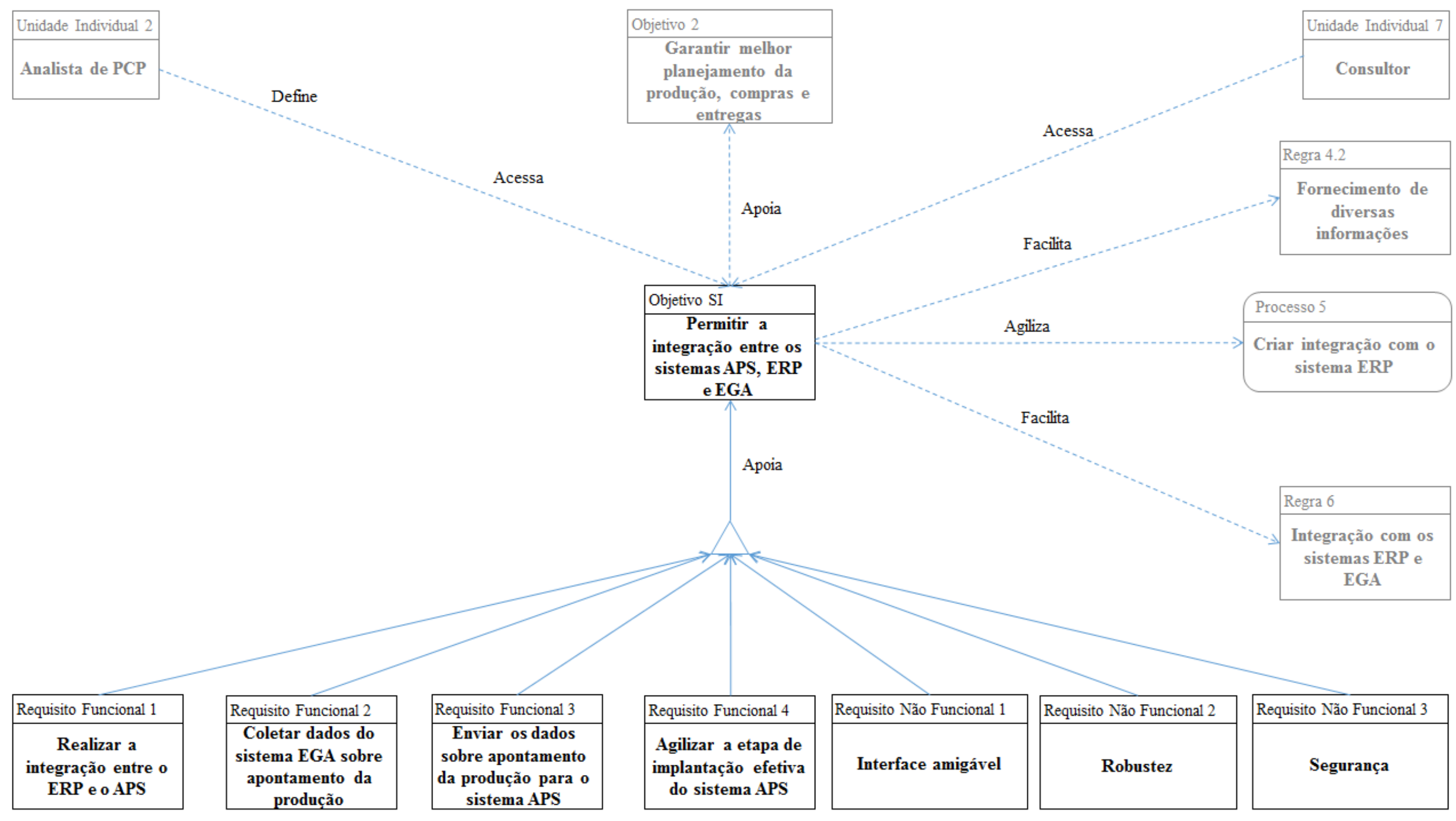

Figura 21 - Modelo de Componentes e Requisitos Técnicos - Empresa 1 


\section{Estudo de caso - Empresa 2}

Este estudo de caso foi realizado em uma empresa multinacional de origem americana, produtora de máquinas e equipamentos para a indústria alimentícia. A empresa iniciou suas atividades no final do século XIX e possui unidades industriais no Brasil, Canadá, Chile, Estados Unidos e México nas Américas; África do Sul e Egito na África; Arábia Saudita, Catar, Cazaquistão, China, Cingapura, Emirados Árabes Unidos, Filipinas, Honk Kong, Índia, Israel, Japão, Kuwait, Malásia, Rússia, Tailândia, Turcomenistão, Turquia, Ucrânia, Uzbequistão e Vietnã na Ásia; Alemanha, Bélgica, Bielorússia, Bulgária, Croácia, Dinamarca, Espanha, Estônia, Finlândia, França, Grécia, Hungria, Irlanda, Islândia, Itália, Lituânia, Polônia, Portugal, Suécia, Suíça, Reino Unido e República Tcheca na Europa. A empresa emprega em torno de 270 funcionários no Brasil, sendo 200 na unidade industrial localizada em Araraquara e 70 em um escritório localizado em São Paulo. Em termos de número de funcionários a empresa é classificada como empresa de médio porte. A empresa disponibiliza diversos produtos, respondendo por aproximadamente $75 \%$ do mercado de máquinas para a indústria cítrica. Nos anos de 2005 a 2013 foi eleita pelo Great Place Work uma das melhores empresas de porte médio para se trabalhar no Brasil.

De acordo com o funcionário da empresa que participou da entrevista para este estudo de caso, a empresa foi uma das pioneiras a implantar sistemas APS no Brasil.

Como a empresa enfrentava os problemas de alto estoque em processo, diversidade de produtos, muitas ordens de produção abertas ao mesmo tempo e dependência da especialização do programador, os funcionários propuseram para a Diretoria da empresa a implantação do sistema, processo que ocorreu em 2001.

Diversos benefícios foram alcançados com a implantação do sistema APS na empresa, tais como redução do lead time de fabricação, diminuição do estoque em processo, aumento da produtividade, maior organização e facilidade para a gestão do processo de produção, maior flexibilidade com relação ao mercado, simulação de cenários, antecipação de possíveis problemas e imprevistos, redução do inventário em processo, melhor programação da aquisição de matérias-primas, priorização automática dos lotes, relevância atribuída ao produto, horizonte maior de programação, melhor visualização das restrições de produção e criação de vínculos entre as ordens de produção de cada componente da lista de materiais de cada produto. 


\section{Modelo de Objetivos}

De acordo com as informações obtidas pelo funcionário que participou da entrevista, a agilidade na entrega dos produtos e a redução da dependência de determinados funcionários em relação ao controle do processo foram os principais motivos que levaram a empresa a implantar o sistema APS. Além disso, a facilidade de integração com os softwares existentes na empresa também influenciou de forma significativa.

Como pode ser visto na Figura 22, a utilização do sistema APS no Planejamento e Controle da Produção da empresa, visa garantir maior excelência no ambiente de trabalho (Objetivo 6), pois seu uso garante maior eficácia (Objetivo 6.1) e maior eficiência (Objetivo 6.2) ao trabalho dos funcionários, o que resulta em melhor organização industrial (Oportunidade $3)$.

O alcance de maior excelência no ambiente de trabalho (Objetivo 6) apoia a eliminação das perdas por espera nos processos produtivos (Objetivo 5), o que assim como a maior integração entre as ordens de produção (Objetivo 3), proporciona a diminuição de estoques em processo (Objetivo 4).

A maior integração entre as ordens de produção (Objetivo 3) garante melhor programação da produção (Objetivo 2), a qual, quando alcançada, garante melhor sequenciamento (Objetivo 2.1), melhor alocação de carga (Objetivo 2.2), coleta rápida de informações (Objetivo 2.3), melhor planejamento das aquisições (Objetivo 2.4), atualização instantânea (Objetivo 2.5) e ajuste automático (Objetivo 2.6) das ordens de produção.

O alcance de uma melhor programação da produção (Objetivo 2) apoia a agilidade na entrega dos produtos (Objetivo 1), a qual gera aumento e antecipação do faturamento (Oportunidade 1) e aumento da satisfação do cliente (Oportunidade 2). 


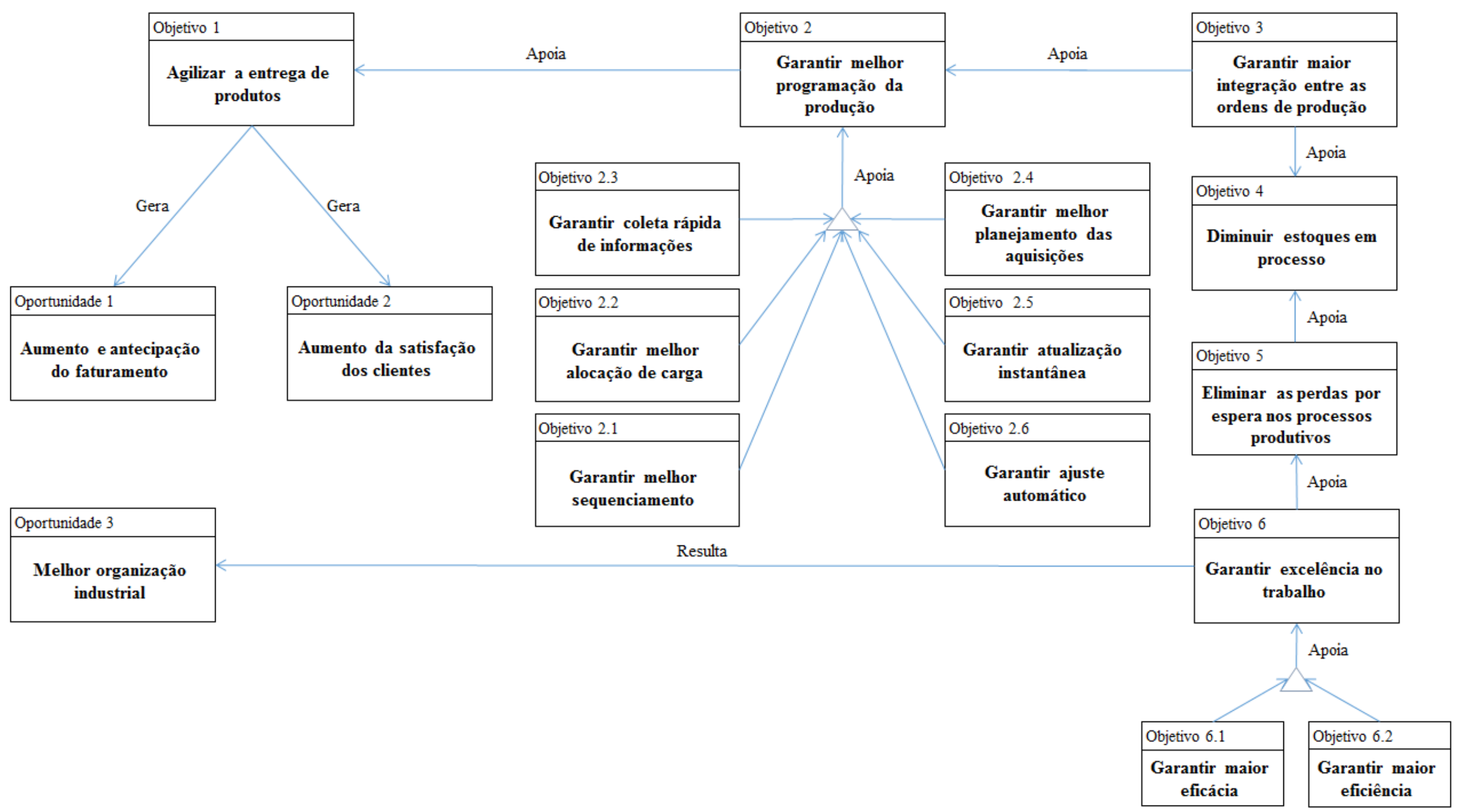

Figura 22 - Modelo de Objetivos - Empresa 2 


\section{Modelo de Regras do Negócio}

O Modelo de Regras do Negócio mostra a influência das regras do processo de implantação do sistema APS sobre os objetivos do processo. Tal modelo está representado na Figura 23.

O treinamento dos usuários finais para o uso do sistema (Regra 3.1) apoia a amplificação do conhecimento da sua dinâmica (Regra 3), o que é necessário para garantir excelência no trabalho (Objetivo 6) e apoiar a eliminação das perdas por espera nos processos produtivos (Objetivo 5).

A realização de testes no sistema após a modelagem (Regra 5) verifica se com seu uso é possível diminuir estoques em processo (Objetivo 4), garantir maior integração entre as ordens de produção (Objetivo 3) e garantir melhor programação da produção (Objetivo 2).

A adaptação da solução do sistema às necessidades da empresa (Regra 4.1) e o fornecimento de diversas informações relacionadas ao chão de fábrica (Regra 4.2) apoiam a amplificação do conhecimento dos processos produtivos (Regra 4), o que é necessário para garantir maior integração entre as ordens de produção (Objetivo 3) e garantir melhor programação da produção (Objetivo 2).

A integração com o sistema de apontamento da produção e o ERP (Regra 2) é necessária para garantir melhor programação da produção (Objetivo 2), o que apoia a agilidade na entrega de produtos (Objetivo 1), a qual é forçada pelo cumprimento dos prazos de entrega (Regra 1). 


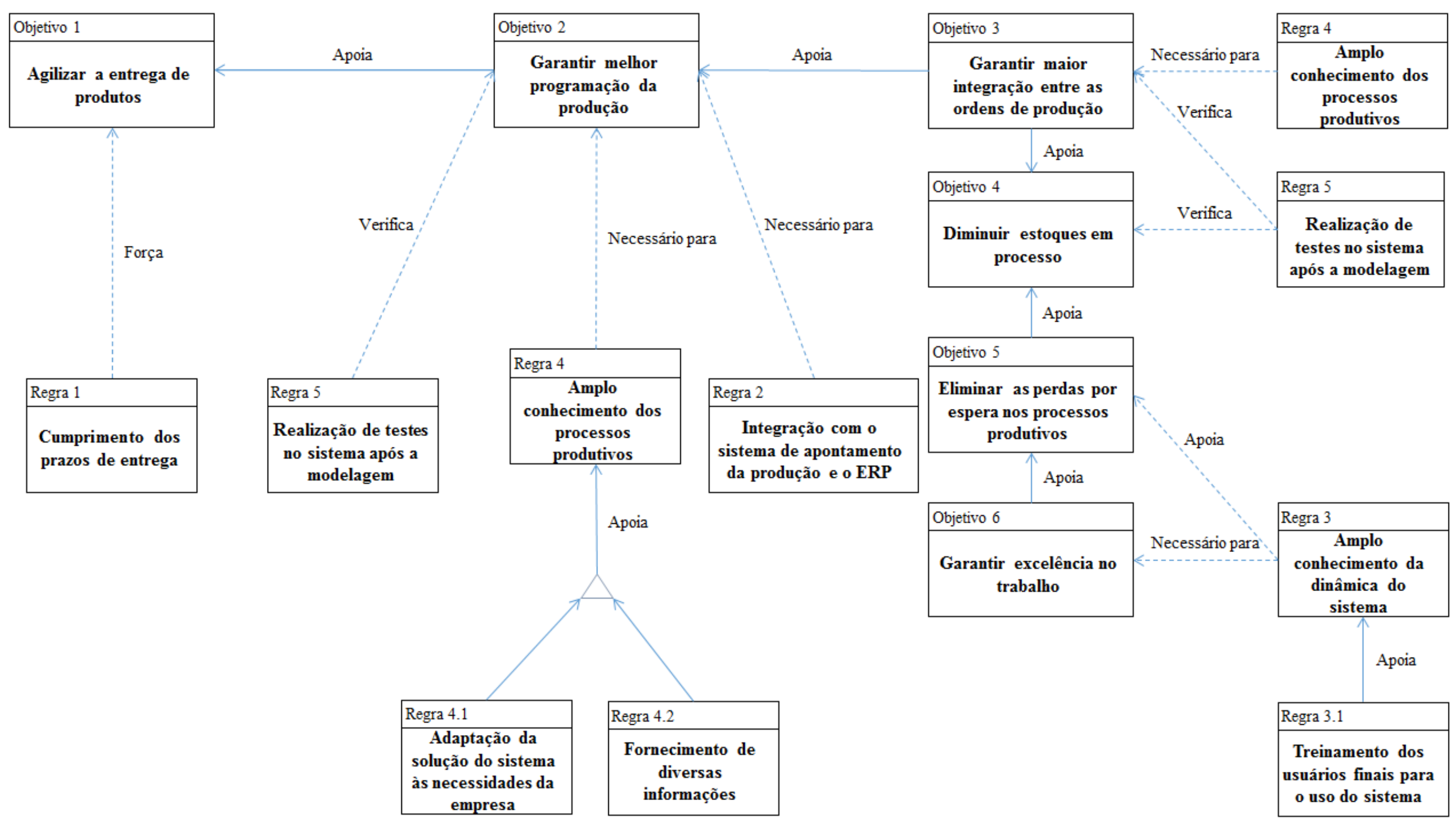

Figura 23 - Modelo de Regras do Negócio - Empresa 2 


\section{Modelo de Processos}

Durante o processo de implantação do sistema APS na empresa, a equipe de implantação realizou 8 principais processos, os quais estão representados na Figura 24.

Após estar ciente da necessidade de adquirir um sistema de Planejamento e Controle da Produção mais eficiente e eficaz, a Diretoria da empresa adquirente do software autorizou a aquisição do sistema (InfoSet 1), e a área pertinente da empresa negociou a transação com a empresa de consultoria, a qual fará a sua implantação (Processo 1), resultando em sua aquisição (InfoSet 2).

Após a aquisição do sistema (InfoSet 2), os profissionais da empresa implantadora do software participantes do processo de implantação realizaram visitas técnicas na empresa adquirente para avaliar suas necessidades quanto às funcionalidades do sistema (Processo 2), resultando na modelagem do sistema (InfoSet 3).

Com o sistema modelado (InfoSet 3), os profissionais participantes do processo de implantação executaram as especificações do sistema (Processo 3), o que resultou na seleção dos produtos a serem testados (InfoSet 4). Com a realização dos testes iniciais (Processo 4) e o sistema aprovado (InfoSet 5), foi criada a integração entre o APS, o sistema de apontamento da produção e o ERP (Processo 5). Com a interface entre estes sistemas parametrizada (InfoSet 6), o sistema foi configurado na empresa (Processo 6), tendo por fim o sistema parametrizado (InfoSet 7).

Com o sistema parametrizado (InfoSet 7), os profissionais executaram os testes finais (Processo 7), tendo como resultado um relatório sobre as funcionalidades do sistema (InfoSet 8). Ao final do processo os funcionários que seriam os usuários finais do sistema foram treinados para o seu uso (Processo 8). 


\begin{tabular}{|c|c|c|c|}
\hline \multirow{2}{*}{\begin{tabular}{|l} 
InfoSet 1 \\
Autorização da \\
aquisição do sistema
\end{tabular}} & Processo 1 & \multirow{2}{*}{$\sqrt{\begin{array}{c}\text { InfoSet } 2 \\
\text { Aquisição do } \\
\text { sistema }\end{array}}$} & \multirow{2}{*}{$\begin{array}{l}\text { Processo } 2 \\
\text { Avaliar as necessidades } \\
\text { da empresa adquirente }\end{array}$} \\
\hline & $\begin{array}{c}\begin{array}{c}\text { Negociar a aquisição do } \\
\text { sistema com a empresa } \\
\text { implantadora }\end{array} \\
\end{array}$ & & \\
\hline Processo 4 & \multirow{2}{*}{\begin{tabular}{|l} 
InfoSet 4 \\
Seleção dos \\
produtos a serem \\
testados \\
\end{tabular}} & Processo 3 & \multirow{2}{*}{$\begin{array}{l}\text { InfoSet } 3 \\
\begin{array}{c}\text { Modelagem do } \\
\text { sistema }\end{array}\end{array}$} \\
\hline $\begin{array}{c}\text { Executar os testes } \\
\text { iniciais }\end{array}$ & & $\begin{array}{c}\text { Executar as } \\
\text { especificações }\end{array}$ & \\
\hline
\end{tabular}

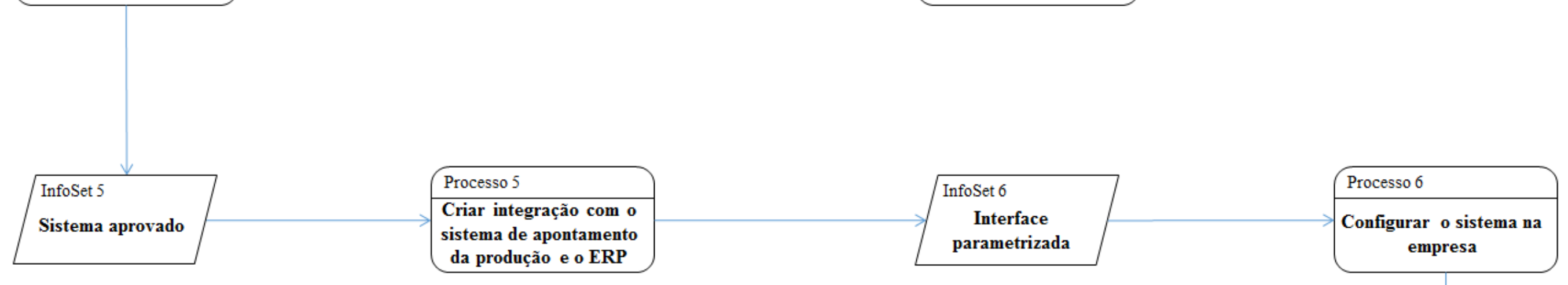

\begin{tabular}{|c|c|c|c|}
\hline Processo 8 & InfoSet 8 & Processo 7 & InfoSet 7 \\
\hline $\begin{array}{l}\text { Treinar os funcionários } \\
\text { para o uso do sistema }\end{array}$ & $\begin{array}{l}\text { Relatório sobre as } \\
\text { funcionalidades do } \\
\text { sistema }\end{array}$ & Executar os testes finais & $\begin{array}{c}\text { Sistema } \\
\text { parametrizado }\end{array}$ \\
\hline
\end{tabular}

Figura 24 - Modelo de Processos - Empresa 2 


\section{Modelo de Atores e Recursos}

Neste modelo está descrito o papel de cada envolvido nas etapas do processo de implantação do sistema APS na empresa. A Figura 25 apresenta a visão geral do modelo.

O Diretor (Unidade Individual 1) da empresa adquirente do sistema APS (Unidade Organizacional 1) elabora as metas e objetivos do processo de implantação do sistema APS (Papel 1), aprova o orçamento (Recurso 1) e libera os recursos financeiros necessários para a sua aquisição (Recurso 2).

O Analista de Planejamento e Controle da Produção da empresa adquirente (Unidade Individual 2), com base nas necessidades de melhoria das atividades pertinentes a ele, realiza a apresentação do sistema para a Diretoria (Papel 2); em conjunto com o Consultor (Unidade Individual 7) da empresa implantadora do sistema APS (Unidade Organizacional 2) realiza a modelagem do sistema (Recurso 4); em conjunto com o Analista de Tecnologia da Informação (Unidade Individual 3), gera a interface parametrizada entre o APS, o sistema de apontamento da produção e o ERP (Recurso 5); e em conjunto com o Gerente de Projeto (Unidade Individual 6) da empresa implantadora do sistema APS (Unidade Organizacional 2) gera a parametrização do sistema (Recurso 6) e é responsável pelo treinamento dos usuários finais quanto ao uso do sistema (Recurso 7).

O Diretor (Unidade Individual 5) da empresa implantadora do sistema APS (Unidade Organizacional 2) define o orçamento (Recurso 1) e recebe os recursos financeiros (Recurso 2) da Diretoria da empresa adquirente do sistema APS (Unidade Organizacional 1), designando um Consultor (Unidade Individual 7) e um Gerente de Projeto (Unidade Individual 6) para realizar as atividades do processo de implantação do sistema.

O Consultor (Unidade Individual 7) da empresa implantadora do sistema APS (Unidade Organizacional 2) com base na avaliação das necessidades da empresa adquirente do sistema (Unidade Organizacional 1) e em conjunto com o Analista de Produção (Unidade Individual 4) realiza a modelagem do sistema (Recurso 4).

O Gerente de Projeto (Unidade Individual 6) da empresa implantadora do sistema APS (Unidade Organizacional 2) em conjunto com o Analista de Tecnologia da Informação (Unidade Individual 3) realiza os testes do sistema (Recurso 3), e em conjunto com o Analista de PCP (Unidade Individual 2) gera a parametrização do sistema (Recurso 6) e é responsável pelo treinamento dos usuários finais (Recurso 7), que é representado pelo Analista de Produção (Unidade Individual 4). 


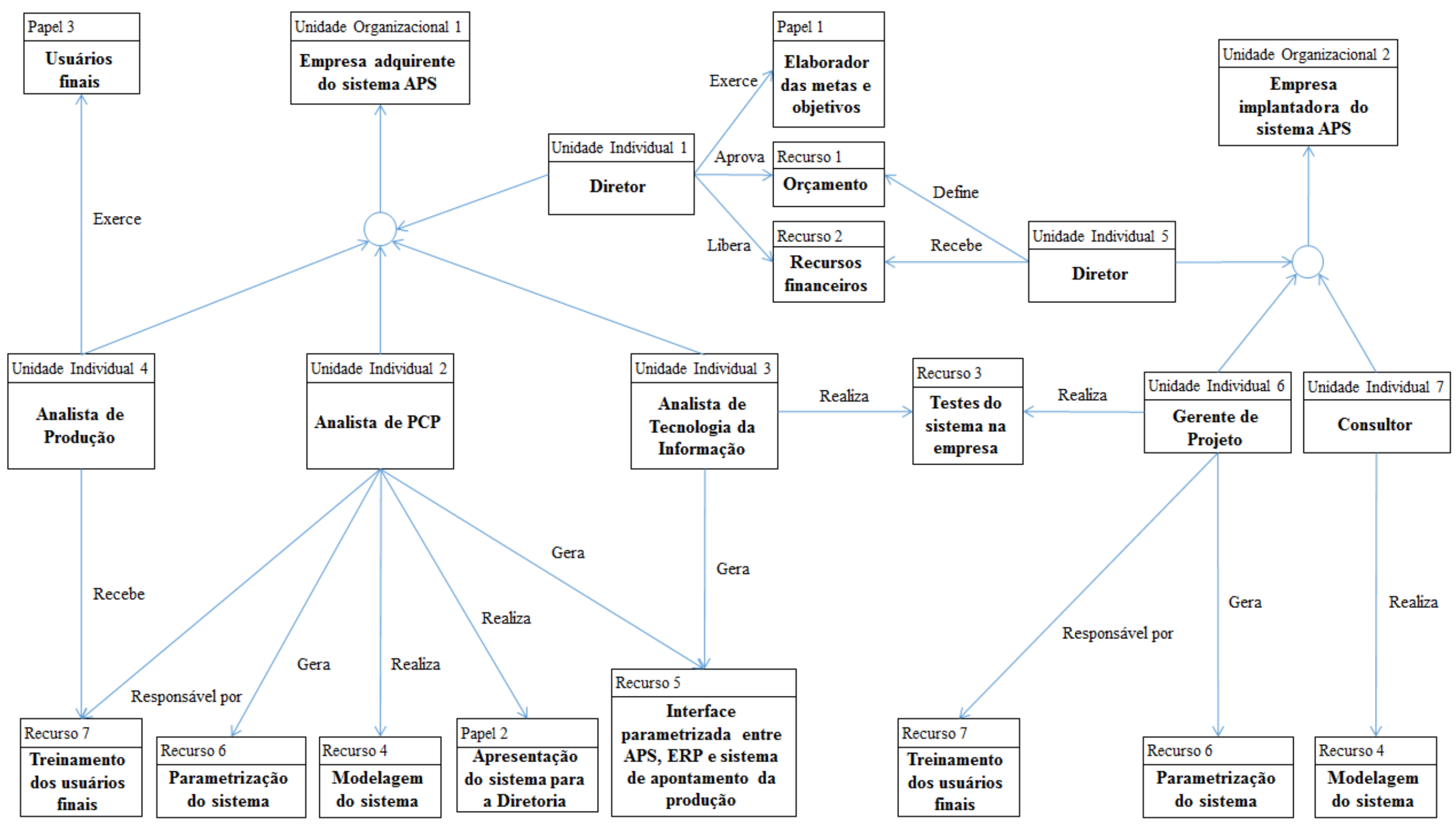

Figura 25 - Modelo de Atores e Recursos - Empresa 2 


\section{Modelo de Componentes e Requisitos Técnicos}

A Figura 26 apresenta o Modelo de Componentes e Requisitos Técnicos do processo de implantação do sistema APS. Este modelo foi desenvolvido a partir da expectativa do funcionário entrevistado quanto aos requisitos que poderiam auxiliar o processo de implantação, uma vez que a organização não possuía nenhum sistema de informação que pudesse auxiliá-la.

De acordo com as informações obtidas, o funcionário da organização acredita que um sistema de informação que poderia auxiliar o processo de implantação do sistema APS na empresa tem como objetivo controlar o escopo do projeto (Objetivo SI). Com este sistema, o processo de implantação se torna mais ágil, o que antecipa o uso do sistema na empresa, e auxilia a meta de agilizar a entrega de produtos (Objetivo 1).

O sistema para controlar o escopo do projeto (Objetivo SI) deve considerar requisitos funcionais (que tangem a utilização do sistema de informação pretendido), bem como não funcionais (que tangem as medidas de segurança, usabilidade e acessibilidade, etc.). Ele visa possibilitar a integração entre os atores envolvidos (Requisito Funcional 1), gerenciar o cronograma (Requisito Funcional 2), a qualidade (Requisito Funcional 3) e os custos do projeto (Requisito Funcional 4). Tal sistema deve proporcionar interface amigável ao usuário (Requisito Não Funcional 1), possuir robustez (Requisito Não Funcional 2) e segurança (Requisito Não Funcional 3), restringindo o acesso apenas aos envolvidos nos processos.

Este sistema é definido e acessado por Analistas de Tecnologia da Informação (Unidade Individual 2), acessado por Analistas de PCP (Unidade Individual 1), Consultor (Unidade Individual 4) e Gerente de Projeto (Unidade Individual 5).

O sistema de informação pretendido, controlando o escopo do projeto, induz a busca pela melhoria contínua no processo (Oportunidade 1), apoia o cumprimento dos prazos de entrega (Regra 1) e o acompanhamento e avaliação dos resultados (Processo 8). 


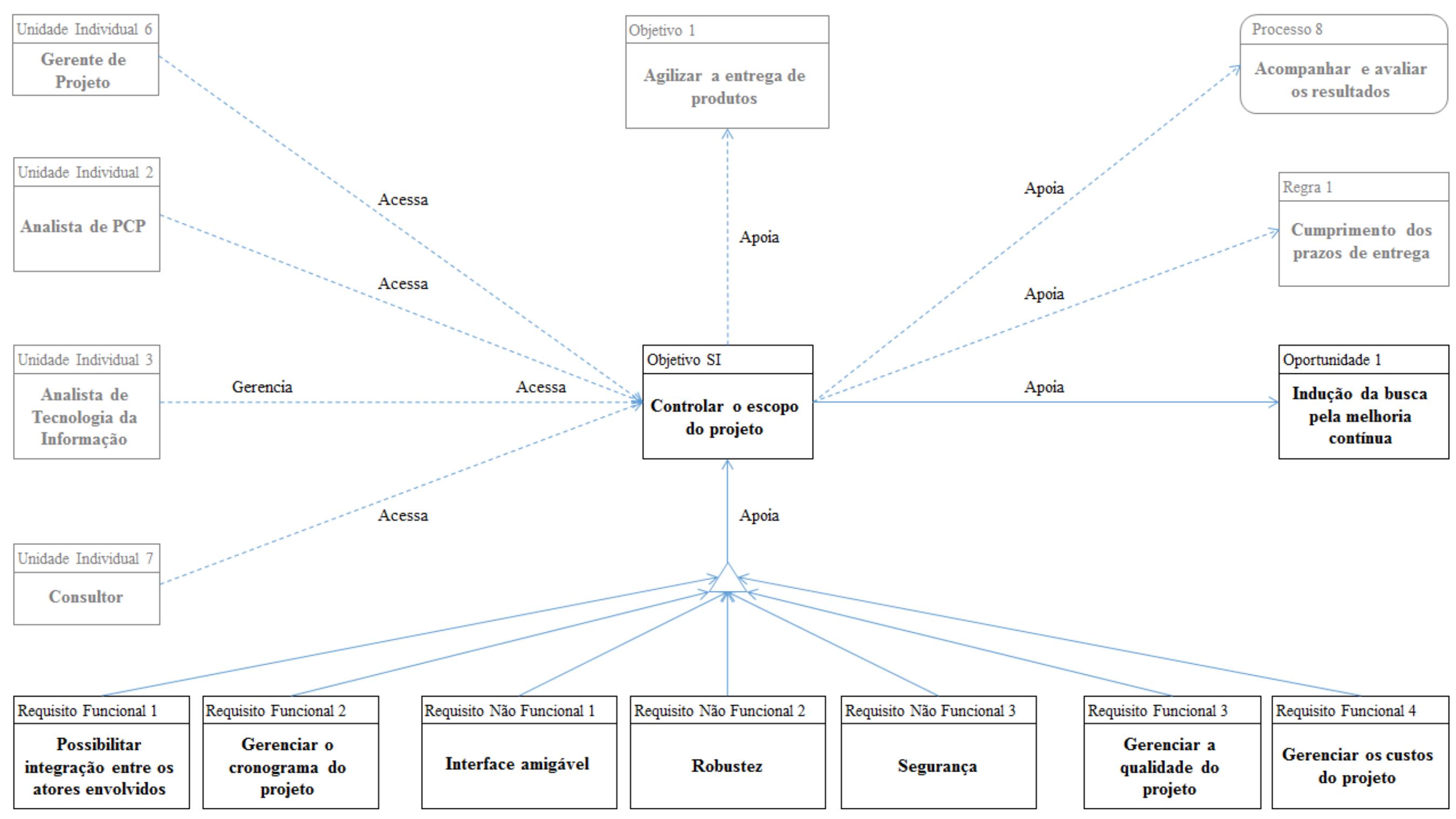

Figura 26 - Modelo de Componentes e Requisitos Técnicos - Empresa 2 


\section{Estudo de caso - Empresa 3}

Este estudo de caso foi realizado em uma empresa brasileira que iniciou suas atividades em 1949, e que atualmente é uma das maiores fabricantes nacionais de controles elétricos e eletrônicos. A empresa está localizada na cidade de Porto Ferreira, possui uma unidade produtiva e uma unidade de montagem e conta atualmente com 1.350 funcionários, sendo 1.150 na unidade produtiva. Em termos de número de funcionários a empresa é classificada como empresa de médio porte. A empresa disponibiliza mais de 15 mil produtos, produzindo anualmente mais de 70 milhões de itens na ordem make-to-stock, os quais são distribuídos para os mais de 13 mil clientes presentes no Brasil e em outros países da América Latina.

De acordo com o funcionário da empresa que participou da entrevista para este estudo de caso, a empresa obteve conhecimento a respeito do sistema APS em um congresso ministrado pela empresa de consultoria em São Paulo, no ano de 2005. Os funcionários ficaram empolgados com os casos bem-sucedidos apresentados no congresso, e como a empresa enfrentava os problemas de pobre visibilidade do progresso da produção, inabilidade para determinar a capacidade de atendimento à demanda de produção, altos níveis de estoque e trabalho em processo e pobre sincronização entre as células de produção, os funcionários propuseram para a Diretoria da empresa a implantação do sistema. A Diretoria decidiu realizar testes com o sistema na empresa, e caso os testes fossem bem-sucedidos, aprovaria sua implantação. Como os testes foram bastante satisfatórios, a empresa implantou o sistema, processo este que durou 6 meses, no ano de 2006.

Diversos benefícios foram alcançados com a implantação do sistema APS na empresa, tais como agilidade na entrega (o prazo médio de entrega dos produtos caiu de 40 para 4 dias), redução dos custos, aumento de faturamento, excelência no trabalho, alocação de mão de obra a outras áreas e atividades, significativa melhoria no controle de estoques e trabalho em processo, melhor coordenação da produção e simulação de diversas estratégias para o planejamento de médio prazo.

\section{Modelo de Objetivos}

De acordo com as informações obtidas na entrevista, a agilidade na entrega dos produtos foi um dos principais motivos que levaram a empresa a implantar o sistema APS, pois a concorrência com os produtos ofertados por empresas chinesas é muito acirrada, pois seus preços são mais atrativos. Tendo em vista que o prazo de entrega das empresas chinesas é bastante elevado, a empresa buscou meios de agilizar o prazo de entrega de seus produtos, lacuna esta que pode ser preenchida com a utilização dos sistemas APS. 
Como pode ser visto na Figura 27, a utilização do sistema APS na área de Planejamento e Controle da Produção da empresa garante melhores informações da produção (Objetivo 2), pois cria uma melhor integração entre a área de manufatura e a de montagem (Objetivo 2.1), permitindo um melhor rastreamento das ordens de produção (Objetivo 2.2).

A garantia de melhores informações sobre a produção (Objetivo 2), apoia a garantia de excelência no trabalho (Objetivo 5), pois a maior organização do chão de fábrica garante maior produtividade (Objetivo 5.1) e maior eficácia (Objetivo 5.2), o que resulta na redução de custos na empresa (Oportunidade 4).

A garantia de melhores informações da produção (Objetivo 2) apoia a garantia de melhor planejamento das atividades produtivas (Objetivo 3), o que por sua vez é alcançado pelo melhor planejamento da produção (Objetivo 3.1) e melhor planejamento das aquisições (Objetivo 3.2).

Um dos pontos fortes dos sistemas APS é a geração de melhor sequenciamento da produção (Objetivo 4), o que facilita a tomada de decisões operacionais (Oportunidade 3), e apoia a agilidade na entrega dos produtos (Objetivo 1), o que gera o aumento e antecipação do faturamento (Oportunidade 2) e permite o aumento da competitividade da empresa em relação às concorrentes chinesas (Oportunidade 1). 


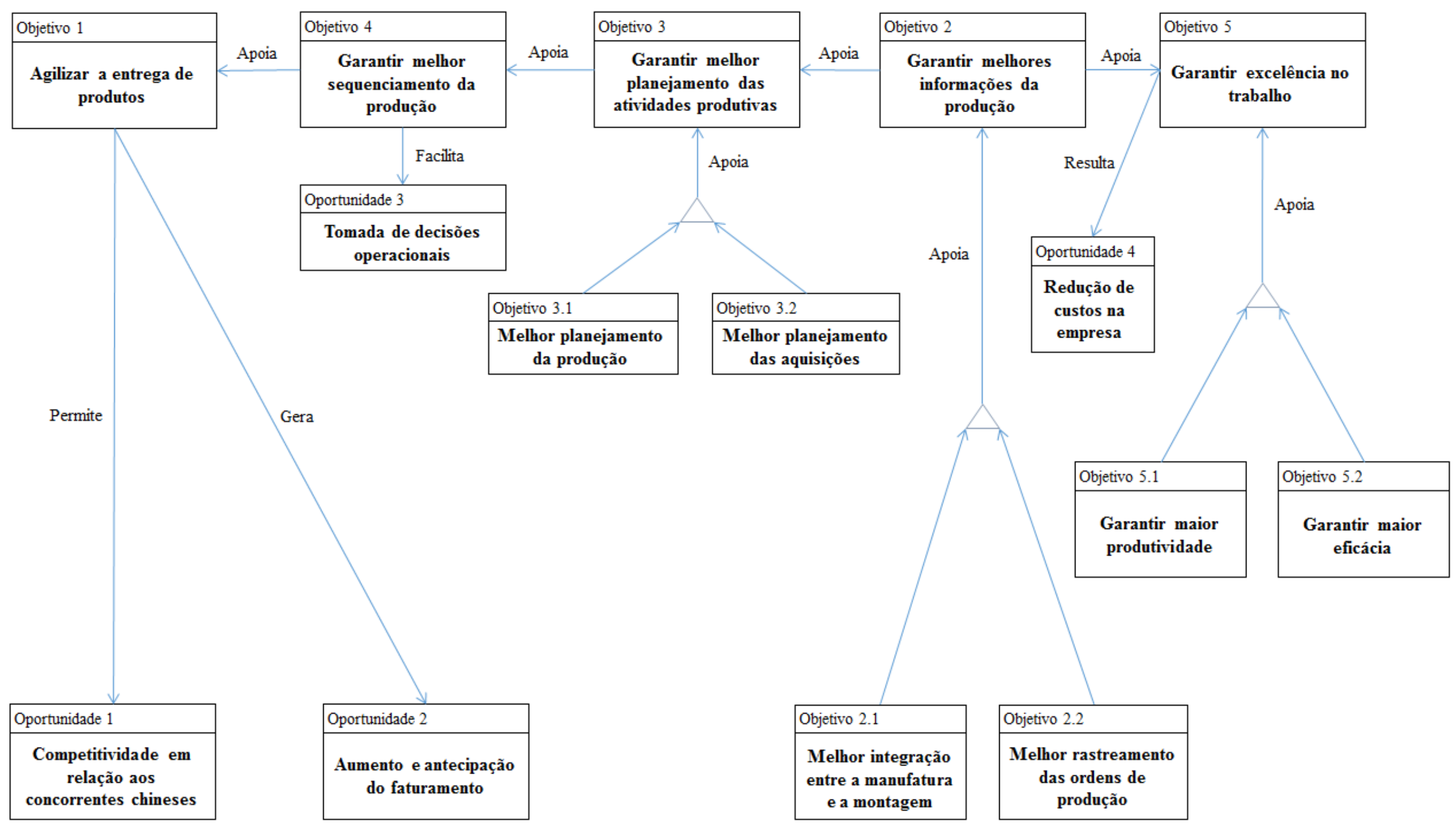

Figura 27 - Modelo de Objetivos - Empresa 3 


\section{Modelo de Regras do Negócio}

O Modelo de Regras do Negócio mostra a influência das regras do processo de implantação do sistema APS sobre os objetivos do processo. Tal modelo está representado na Figura 28.

A realização de testes em alguns produtos antes da implantação efetiva do sistema na empresa (Regra 2) visa verificar se é possível garantir um melhor planejamento das atividades produtivas (Objetivo 3), e também garantir melhores informações da produção (Objetivo 2), comparando o desempenho da empresa antes e após o uso do sistema.

A adaptação da solução do sistema às necessidades da empresa (Regra 3), bem como a integração com o sistema ERP (Regra 4) são necessárias para a obtenção de um melhor planejamento das atividades produtivas (Objetivo 3).

O amplo conhecimento dos processos produtivos da empresa por parte dos funcionários (Regra 5) facilita a escolha do melhor sequenciamento da produção gerado pelo sistema (Objetivo 4), o que também é possibilitado pela integração com o sistema ERP (Regra 4), permitindo assim dar maior prioridade aos produtos mais relevantes.

O treinamento dos usuários finais em relação ao uso do sistema (Regra 6.1) apoia a difusão do conhecimento de sua dinâmica (Regra 6), o que apoia a obtenção de excelência no trabalho (Objetivo 5).

A redução do tempo médio de entrega dos produtos (Regra 1) é necessária para agilizar a entrega de produtos (Objetivo 1), visando tornar a empresa mais competitiva em relação às concorrentes chinesas. 


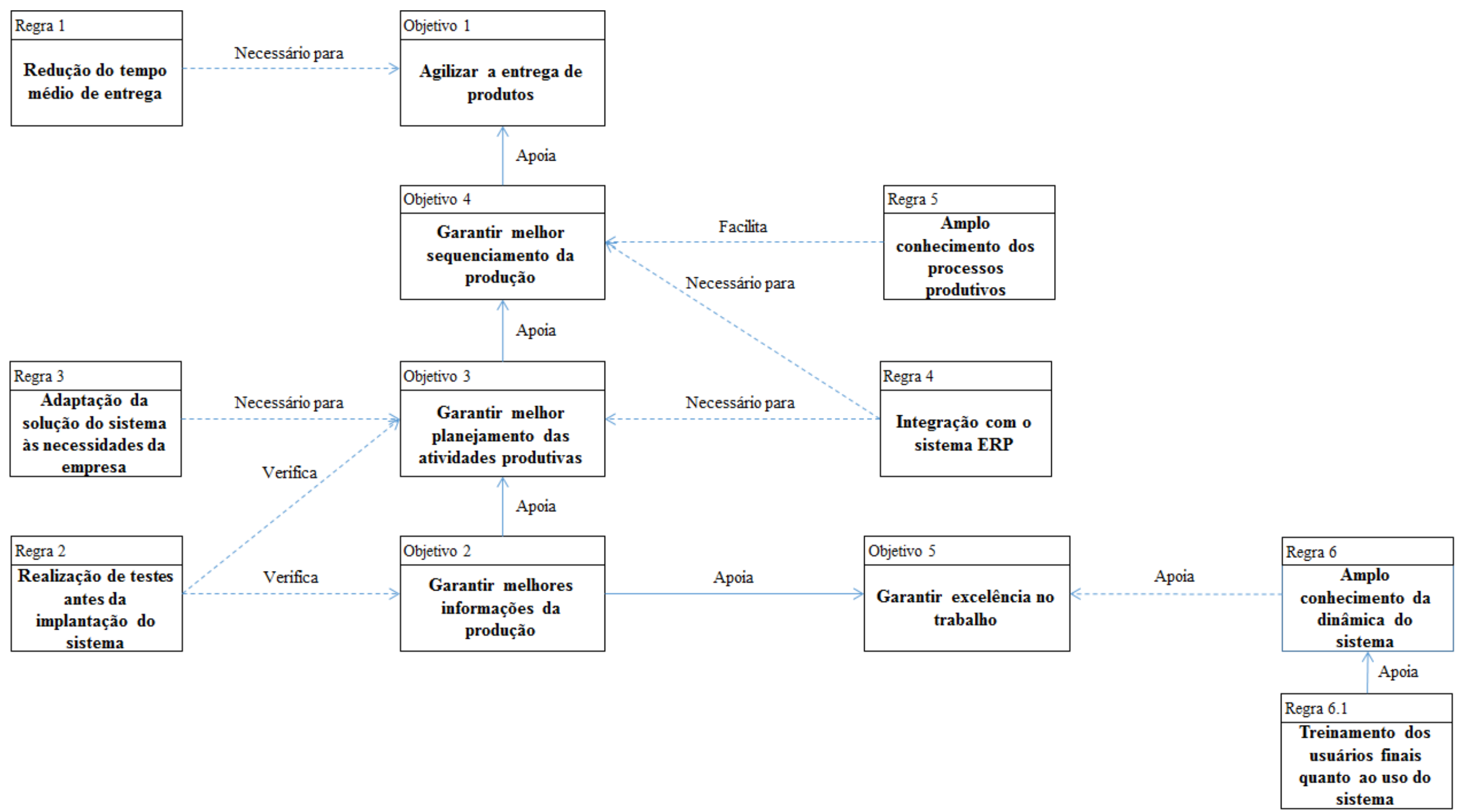

Figura 28 - Modelo de Regras do Negócio - Empresa 3 


\section{Modelo de Processos}

Durante o processo de implantação do sistema APS na empresa, a equipe de implantação realizou 7 principais processos, os quais estão representados na Figura 29.

Alguns funcionários da empresa participaram de um congresso ministrado por profissionais da empresa implantadora de sistemas APS realizado em São Paulo, no ano de 2005 (Infoset Externo 1). Neste congresso foi apresentado o sistema, bem como vários casos bem-sucedidos de sua implantação em diversas empresas. Após estar ciente da necessidade de adquirir um sistema de Planejamento e Controle da Produção mais eficiente e eficaz, estes funcionários negociaram a aprovação da Diretoria da empresa adquirente do software para a realização de testes com alguns produtos (Processo 1), visando verificar a eficiência e eficácia do sistema. A Diretoria autorizou a aquisição do sistema (InfoSet 2), e a área pertinente da empresa elaborou o contrato de risco (Processo 2), no qual ficou determinado que caso os testes fossem satisfatórios a empresa adquiriria o sistema, caso contrário pagaria as horas dispendidas nos testes.

Após a formalização das negociações, os funcionários da empresa adquirente do sistema fizeram a seleção dos produtos a serem testados (InfoSet 3). Em seguida, no período de 3 meses os funcionários da empresa implantadora testaram o uso do sistema na empresa (Processo 3).

Após a realização dos testes, caso o sistema fosse reprovado, o processo de implantação seria encerrado e a empresa adquirente do sistema pagaria as horas dispendidas nos testes para a empresa implantadora. Como o sistema foi aprovado (InfoSet 4), os profissionais da empresa implantadora participantes do processo de implantação integraram as funcionalidades do sistema em relação à realidade da empresa adquirente, realizando sua modelagem (Processo 4).

Com o sistema modelado (InfoSet 5), os funcionários da área de TI criaram a integração entre o APS e o sistema ERP da empresa (Processo 5), de forma a possibilitar o intercâmbio de informações entre os dois sistemas.

Com a interface entre o APS e o ERP parametrizada (InfoSet 6), o APS é implantado efetivamente na empresa (Processo 6), dando início a seu uso, após o mesmo estar devidamente parametrizado (InfoSet 7). Com o sistema implantado, os funcionários pertinentes são treinados para o seu uso (Processo 7), finalizando o processo de implantação. 


\section{InfoSet Externo 1
Participação de funcionários em um congresso}

Novos conhecimentos

sobre sistemas APS

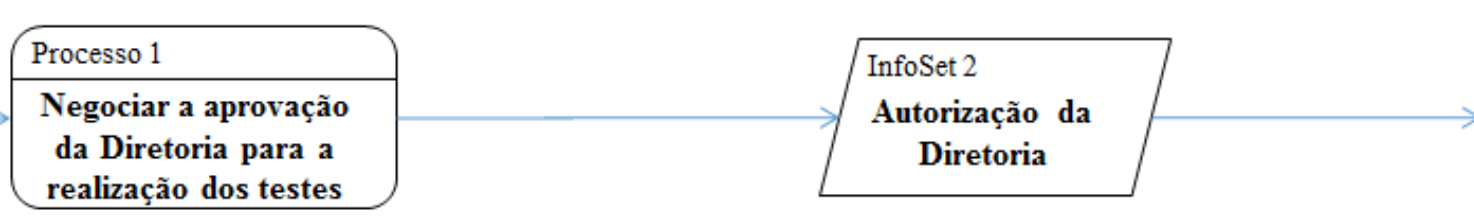

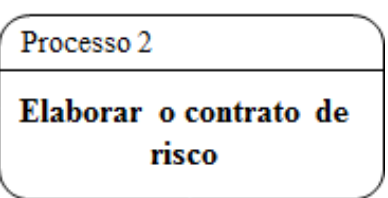

risco

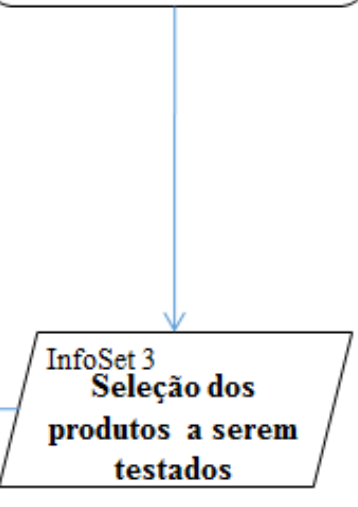

\begin{tabular}{|c|c|c|c|}
\hline Processo 4 & InfoSet 4 & Processo 3 & InfoSet 3 \\
\hline $\begin{array}{c}\text { Modelar o sistema de } \\
\text { acordo com a realidade } \\
\text { da empresa }\end{array}$ & Sistema aprovado & $\begin{array}{c}\text { Testar o uso do sistema } \\
\text { na empresa }\end{array}$ & $\begin{array}{c}\text { Seleção dos } \\
\text { produtos a serem } \\
\text { testados }\end{array}$ \\
\hline
\end{tabular}

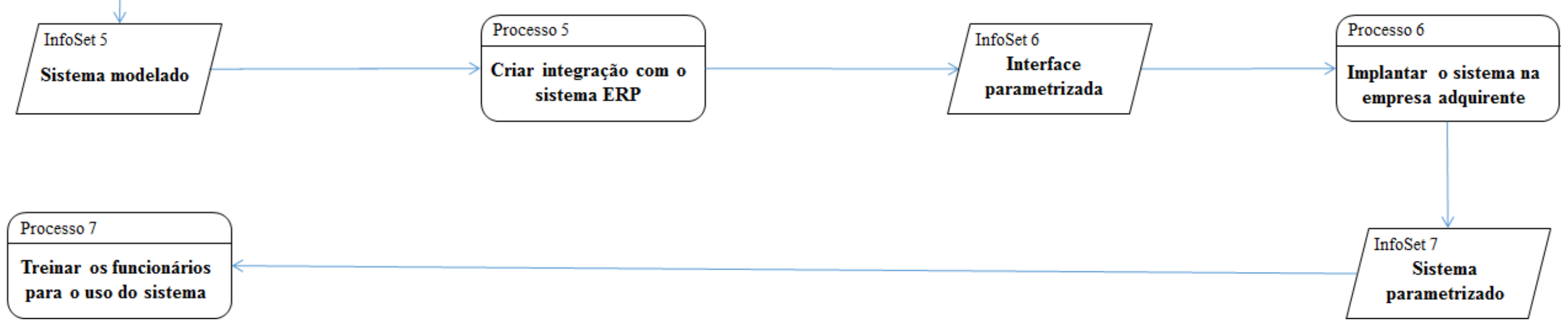

Figura 29 - Modelo de Processos - Empresa 3 


\section{Modelo de Atores e Recursos}

Neste modelo está descrito o papel de cada envolvido nas etapas do processo de implantação do sistema APS na empresa. A Figura 30 apresenta a visão geral do modelo. Um ponto essencial para a implantação do sistema é a constituição de uma equipe forte de trabalho, formada por profissionais da empresa adquirente e implantadora do software, trabalhando conjuntamente.

O Diretor (Unidade Individual 1) da empresa adquirente (Unidade Organizacional 1) elabora as metas e objetivos do processo de implantação do sistema APS (Papel 1), aprova o orçamento necessário (Recurso 1) e libera os recursos financeiros (Recurso 2) para a empresa implantadora do sistema APS (Unidade Organizacional 2).

O Analista de Compras (Unidade Individual 2) realiza a apresentação do sistema para a Diretoria (Papel 2), realiza os testes do sistema em alguns produtos da empresa (Recurso 3), participa da modelagem do sistema (Recurso 5); em conjunto com o Analista de Tecnologia da Informação (Unidade Individual 3) gera a interface parametrizada entre os sistemas APS e ERP (Recurso 4); e é responsável pelo treinamento dos usuários finais quanto ao uso do sistema (Recurso 7), os quais são representados pelo Analista de Produção (Unidade Individual 4).

O Analista de Tecnologia da Informação (Unidade Individual 2) em conjunto com o Consultor (Unidade Individual 6) da empresa implantadora do sistema APS (Unidade Organizacional 2) é responsável pela modelagem do sistema na empresa (Recurso 5); e em conjunto com o Analista de Compras (Unidade Individual 2) gera a interface parametrizada entre os sistemas APS e ERP (Recurso 4).

O Consultor (Unidade Individual 6), com base nas diretrizes elaboradas no contrato de risco, realiza os testes do sistema na empresa adquirente (Recurso 3), é responsável pela sua modelagem (Recurso 5) e parametrização (Recurso 6), bem como pelo treinamento dos usuários finais (Recurso 7). 


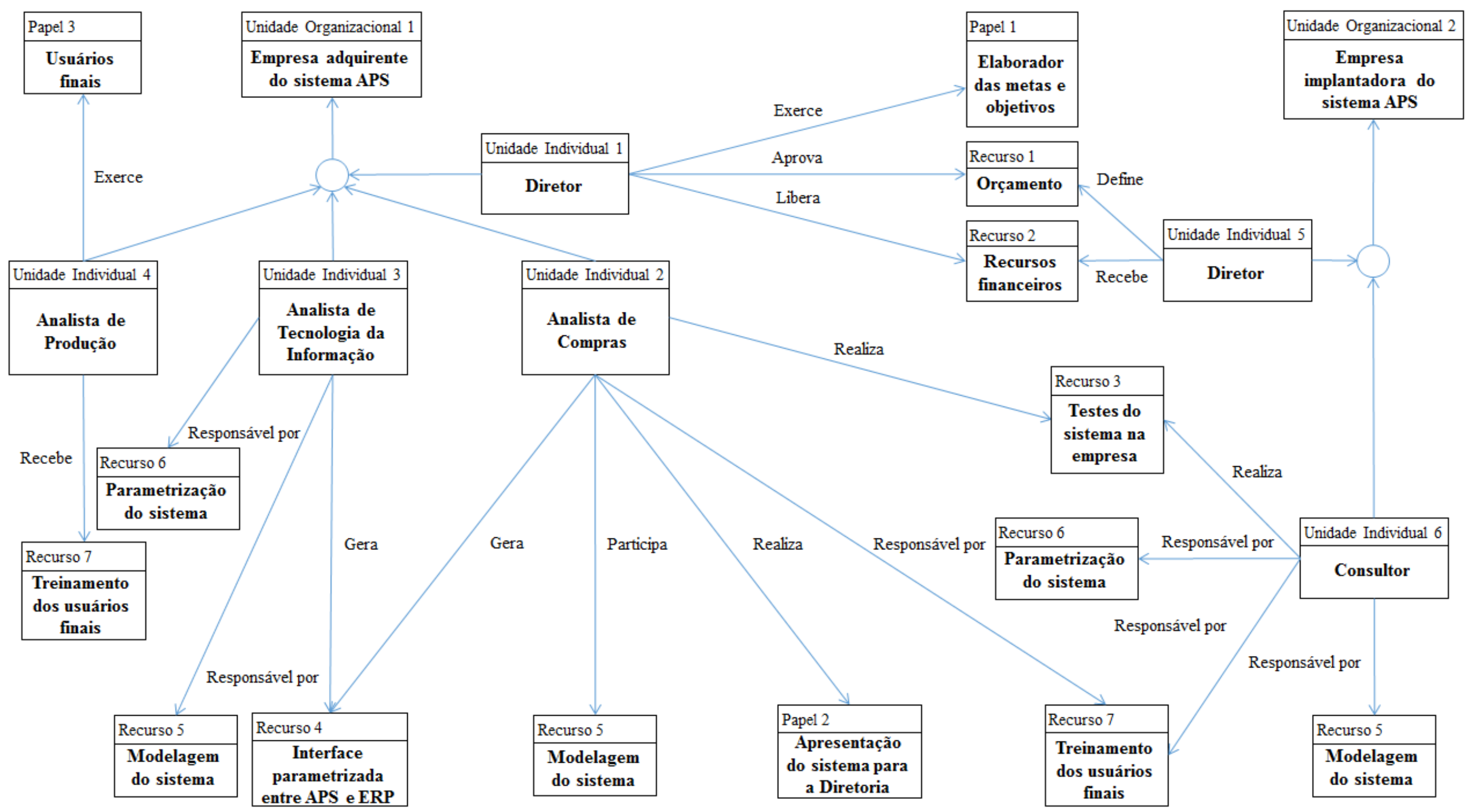

Figura 30 - Modelo de Atores e Recursos - Empresa 3 


\section{Modelo de Componentes e Requisitos Técnicos}

A Figura 31 apresenta o Modelo de Componentes e Requisitos Técnicos do processo de implantação do sistema APS. A empresa possui um sistema de informação que permite o envio e recebimento de informações relacionadas a transações que ocorrem entre ela e seus parceiros.

De acordo com as informações obtidas, o único objetivo deste sistema de informação durante o processo de implantação do sistema APS na empresa é permitir o envio e recebimento de informações pertinentes (Objetivo SI).

O sistema para envio e recebimento de informações pertinentes ao processo de implantação do sistema APS entre a empresa adquirente e a empresa implantadora (Objetivo SI) considera requisitos funcionais (que tangem a utilização do sistema de informação pretendido), bem como não funcionais (que tangem as medidas de segurança, usabilidade e acessibilidade, etc.). Ele visa relatar o andamento dos processos (Requisito Funcional 1), e agilizar a etapa de implantação efetiva do sistema na empresa (Requisito Funcional 2). Tal sistema deve proporcionar interface amigável ao usuário (Requisito Não Funcional 1), possuir robustez (Requisito Não Funcional 2) e segurança (Requisito Não Funcional 3), restringindo o acesso apenas aos envolvidos nos processos, e possibilitar acesso remoto por meio da web (Requisito Não Funcional 4).

O sistema para envio e recebimento de informações pertinentes ao processo de implantação do sistema APS entre a empresa adquirente e a empresa implantadora (Objetivo SI) por meio da troca de conhecimento entre os atores envolvidos no processo facilita o aumento do conhecimento da dinâmica do sistema (Regra 6), e, consequentemente apoia a obtenção de melhor planejamento das atividades produtivas (Objetivo 3).

Tal sistema é gerenciado pelo Analista de Tecnologia da Informação (Unidade Individual 3) e acessado pelo Analista de Compras (Unidade Individual 2) e pelo Consultor (Unidade Individual 6). 


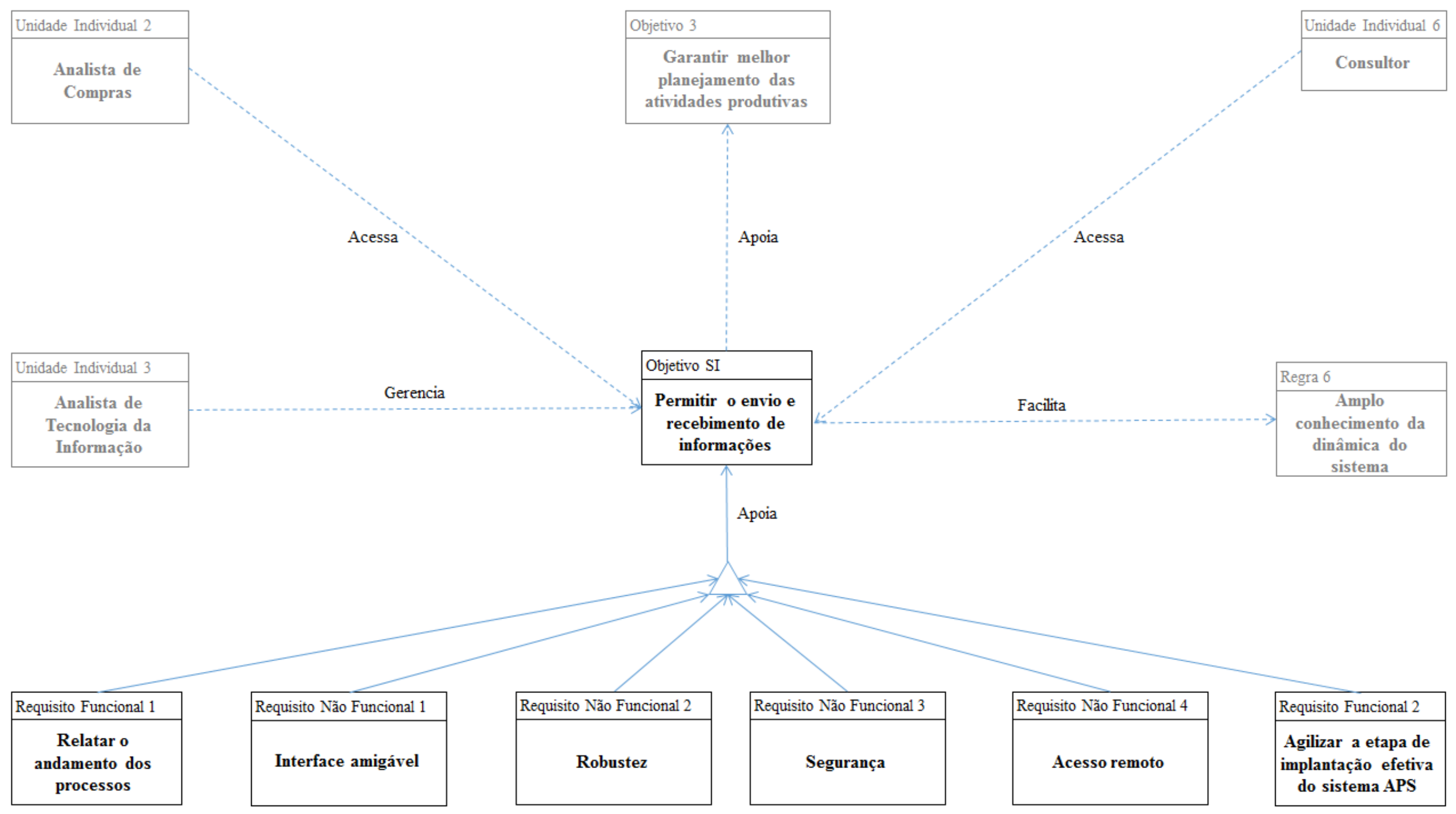

Figura 31 - Modelo de Componentes e Requisitos Técnicos - Empresa 3 


\section{Estudo de caso - Empresa 4}

Este estudo de caso foi realizado em uma empresa brasileira que foi fundada em 1969, a qual produz uma ampla gama de embalagens flexíveis industriais e comerciais, banners, bobinas de forração, envoltórios e serigrafia para diversos usos e mercados, os quais fabrica na ordem make-to-order. É uma das líderes nacionais na produção de embalagens flexíveis e também uma das maiores e mais tradicionais convertedoras em flexografia. Em seu segmento, é a empresa nacional que mais recebeu prêmios de qualidade. A matriz da empresa está localizada na cidade de Jaguariúna - SP, possuindo 140 funcionários; e sua filial, localizada na cidade de Ouro Fino - MG, possui 70 funcionários. Em termos de faturamento, a empresa é classificada como empresa de médio porte.

De acordo com o funcionário da empresa que participou da entrevista para este estudo de caso, a empresa sentiu a necessidade de adquirir um sistema que fosse ideal para coordenar produtos fabricados na base make-to-order e contemplasse a complexidade da indústria gráfica, pois cada tipo de impressão exige uma configuração diferente da máquina e cada substrato e item do cliente tem um processo diferente. A empresa tinha um sistema que não era satisfatório na parte de planejamento.

Por meio de pesquisas, os funcionários obtiveram conhecimento a respeito dos sistemas APS e a fim de verificar sua eficiência e eficácia, estes funcionários visitaram outras empresas para conhecimento do uso do sistema no chão de fábrica. A empresa esperava que o sistema fornecesse maior velocidade de informação, controle e apontamento automático das máquinas. O sistema foi implantado na empresa no final de 2010.

Diversos benefícios foram alcançados com a implantação do sistema APS na empresa, tais como melhoria da produtividade, melhor planejamento, melhor coordenação do set-up, rapidez no atendimento, apontamento automático e antecipação de eventos imprevistos.

\section{Modelo de Objetivos}

De acordo com as informações obtidas na entrevista, a velocidade de informação, melhor controle dos processos produtivos e apontamento automático das máquinas foram os principais motivos que levaram a empresa a implantar o sistema APS.

Como pode ser visto na Figura 32, a utilização do sistema APS na área de Planejamento e Controle da Produção da empresa garante maior eficiência (Objetivo 2.1) e maior eficácia (Objetivo 2.2), auxiliando na garantia de maior produtividade no trabalho (Objetivo 2), o que também é influenciado pelo atendimento à norma ISO 9001/2008, e que por sua vez gera redução de custos na empresa (Oportunidade 2). 
Para garantir maior produtividade no trabalho por meio da familiarização com o sistema APS (Objetivo 2) é necessário vencer a resistência cultural dos funcionários (Restrição 1) no que diz respeito ao receio à mudanças na gestão dos processos produtivos (Restrição 1.1) e receio à informática (Restrição 1.2).

A utilização do sistema APS garante maior controle dos processos produtivos (Objetivo 3), o que possibilita a avaliação do histórico das estratégias de produção (Oportunidade 3) e garante maior produtividade no trabalho (Objetivo 2).

Por meio do sistema APS é possível garantir melhor planejamento das atividades produtivas (Objetivo 4), especialmente as relacionadas às Aquisições (Objetivo 4.1) e à Produção (Objetivo 4.2). Esse melhor planejamento apoia a garantia de prazos de entrega mais curtos (Objetivo 1).

O sistema APS garante um melhor sequenciamento da produção (Objetivo 5), o que apoia a tomada de decisões operacionais (Oportunidade 4) e a garantia de prazos de entrega mais curtos (Objetivo 1).

A garantia de maior produtividade no trabalho (Objetivo 2), melhor planejamento das atividades produtivas (Objetivo 4) e melhor sequenciamento da produção (Objetivo 5) apoiam a garantia de prazos de entrega mais curtos (Objetivo 1), o que gera aumento e antecipação do faturamento (Oportunidade 1). 


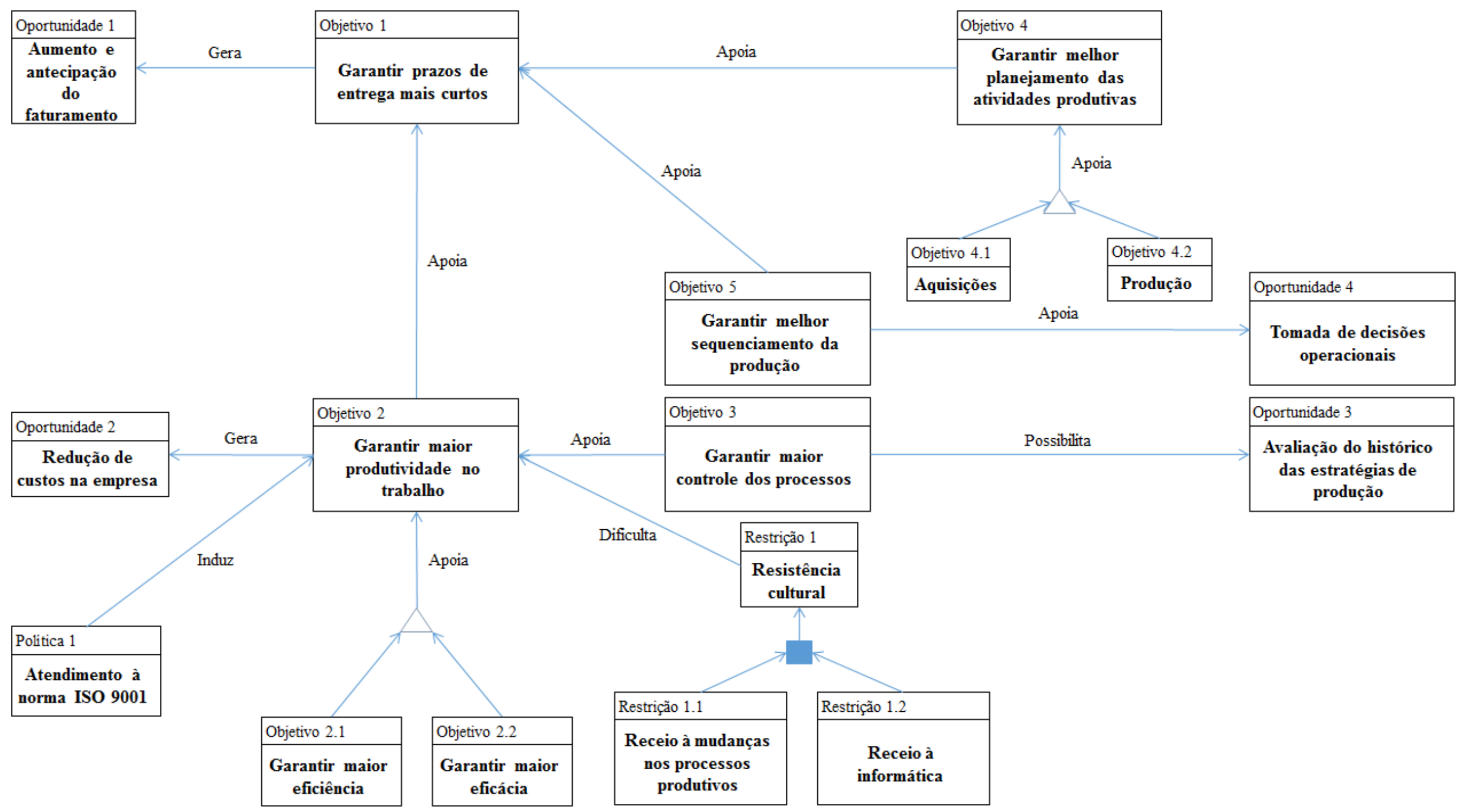

Figura 32 - Modelo de Objetivos - Empresa 4 


\section{Modelo de Regras do Negócio}

O Modelo de Regras do Negócio mostra a influência das regras do processo de implantação do sistema APS sobre os objetivos do processo. Tal modelo está representado na Figura 33.

A realização de testes no sistema após a modelagem (Regra 1) apoia a garantia de prazos de entrega mais curtos (Objetivo 1), verificando se o sistema atende aos requisitos necessários.

O treinamento dos usuários finais para o uso do sistema (Regra 2.1) apoia a ampliação do conhecimento da dinâmica do sistema (Regra 2), o que apoia a garantia de maior produtividade no trabalho (Objetivo 2).

A adaptação da solução do sistema às necessidades da empresa (Regra 3) apoia a garantia de maior controle dos processos produtivos (Objetivo 3), e também é necessária para garantir melhor planejamento das atividades produtivas (Objetivo 4).

A integração com o sistema ERP (Regra 4) é necessária para garantir melhor planejamento das atividades produtivas (Objetivo 4) e garantir melhor sequenciamento da produção (Objetivo 5). 


\begin{tabular}{|c|}
\hline Regra 1 \\
\hline $\begin{array}{c}\text { Realização de testes } \\
\text { no sistema após a } \\
\text { modelagem }\end{array}$ \\
\hline
\end{tabular}

Apoi

Apoia

\begin{tabular}{|l|}
\hline Objetivo 1 \\
\hline $\begin{array}{l}\text { Garantir prazos de } \\
\text { entrega mais curtos }\end{array}$
\end{tabular}

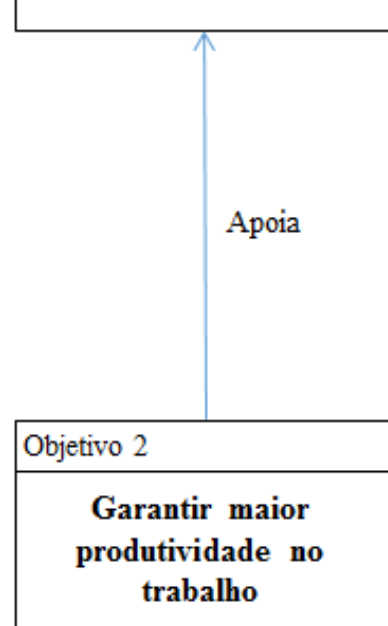

trabalho

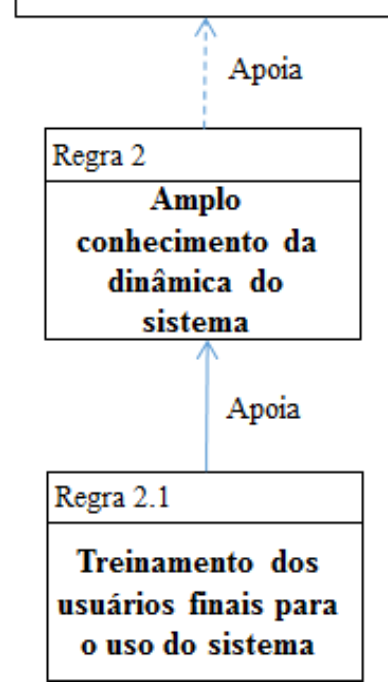

Figura 33 - Modelo de Regras do Negócio - Empresa 4

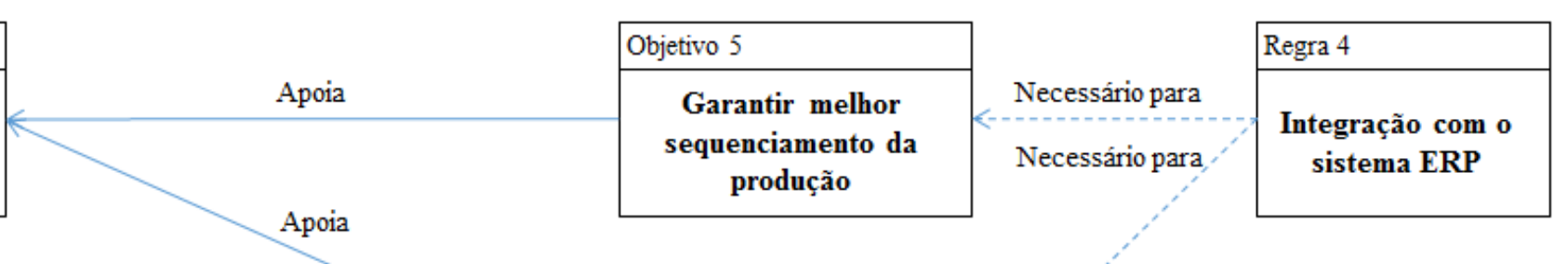

Apoia

Objetivo 3

Garantir maio controle dos processos

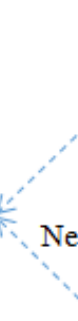

sistema ERP 


\section{Modelo de Processos}

Durante o processo de implantação do sistema APS na empresa, a equipe de implantação realizou 10 principais processos, os quais estão representados na Figura 34.

Após estar ciente da necessidade de adquirir um sistema de Planejamento e Controle da Produção mais eficiente e eficaz o Gerente e o Analista de PCP obtiveram conhecimento do sistema por meio de outras empresas, sendo o funcionamento do sistema em outra empresa apresentado a eles (InfoSet 1). Empolgados com sua excelência, os referidos funcionários apresentaram o sistema para a Diretoria da empresa adquirente e posteriormente foi negociada a sua aquisição (Processo 1). Após a Diretoria ter autorizado a aquisição do sistema (InfoSet 2), a área pertinente da empresa negociou a transação com a empresa de consultoria, a qual faria a sua implantação (Processo 2).

Após o sistema ser adquirido, foi formada a equipe do projeto de implantação (InfoSet 3), e após isso, foram avaliadas as necessidades da empresa adquirente (Processo 3). Esta avaliação e a execução das atividades necessárias resultou na modelagem do sistema (InfoSet 4). Com o sistema modelado, foram executadas as especificações (Processo 4). Após a execução das especificações (Processo 4), foi feita a seleção dos produtos a serem testados (InfoSet 5).

Após a realização dos testes iniciais (Processo 5) e com o sistema aprovado (InfoSet 6), foi criada a integração com o sistema ERP (Processo 6), e com a interface entre os sistemas APS e ERP parametrizada (InfoSet 7), os funcionários foram treinados para o uso do sistema APS (Processo 7). Após o sistema ter sido configurado na empresa (Processo 8), e o mesmo ter sido parametrizado (InfoSet 8), foram executados os testes finais (Processo 9) e com o sistema aprovado (InfoSet 9), foram acompanhados os resultados (Processo 10). 

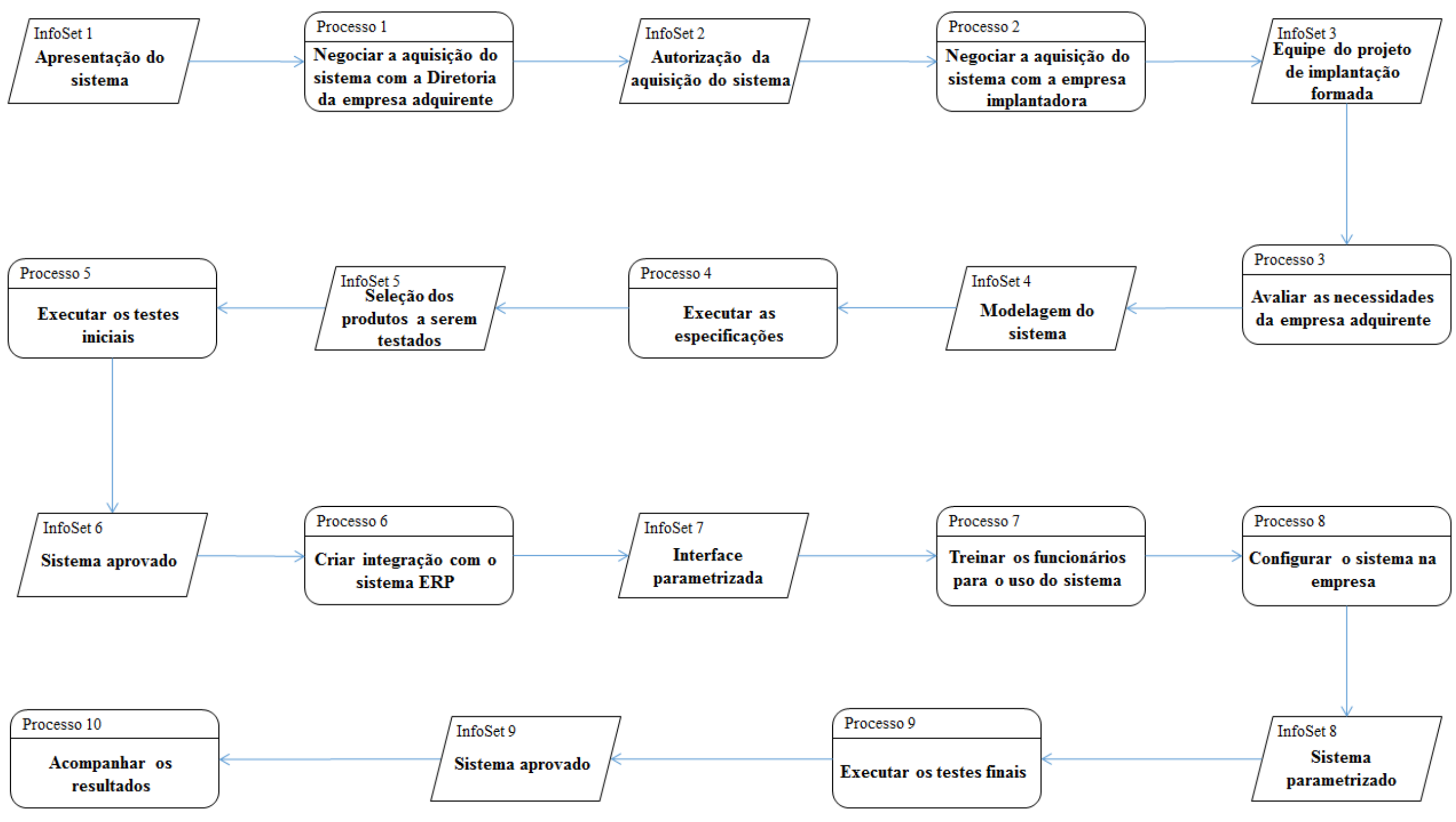

Figura 34 - Modelo de Processos - Empresa 4 


\section{Modelo de Atores e Recursos}

No Modelo de Atores e Recursos está descrito o papel de cada envolvido nas etapas do processo de implantação do sistema APS na empresa. A Figura 35 apresenta a visão geral do modelo.

O Diretor (Unidade Individual 1) da empresa adquirente do sistema APS (Unidade Organizacional 1) elabora as metas e objetivos do processo de implantação do sistema APS (Papel 1), aprova o orçamento (Recurso 1) e libera os recursos financeiros necessários para a sua aquisição (Recurso 2).

O Analista de Planejamento e Controle da Produção da empresa adquirente (Unidade Individual 4), com base nas necessidades de melhoria das atividades pertinentes a ele, realiza a apresentação do sistema para a Diretoria (Papel 2); participa da modelagem do sistema (Recurso 3); gera a interface parametrizada entre os sistemas APS e ERP (Recurso 5); e em conjunto com o Consultor (Unidade Individual 7) da empresa implantadora do sistema APS (Unidade Organizacional 2) realiza os testes necessários no sistema (Recurso 4) e são responsáveis pelo treinamento dos usuários finais quanto ao uso do sistema (Recurso 6).

O Gerente de PCP (Unidade Individual 3), em conjunto com o Analista de PCP (Unidade Individual 4) realiza a apresentação do sistema para a Diretoria (Papel 2) e participa da modelagem do sistema (Recurso 3).

O Auxiliar de PCP (Unidade Individual 2) é responsável pelo cadastro de materiais e processos (Papel 4) e após receber o treinamento (Recurso 6), em conjunto com o Supervisor de pré-impressão (Unidade Individual 5) exerce o papel de usuário final do sistema (Papel 3).

O Diretor (Unidade Individual 6) da empresa implantadora do sistema APS (Unidade Organizacional 2) define o orçamento (Recurso 1) e recebe os recursos financeiros (Recurso 2) da empresa adquirente do sistema APS (Unidade Organizacional 1).

O Consultor (Unidade Individual 7) realiza os testes necessários no sistema APS (Recurso 4) e é responsável pela sua modelagem (Recurso 3), parametrização (Recurso 7), interface parametrizada com o sistema ERP (Recurso 5) e pelo treinamento dos usuários finais quanto ao seu uso (Recurso 6). 


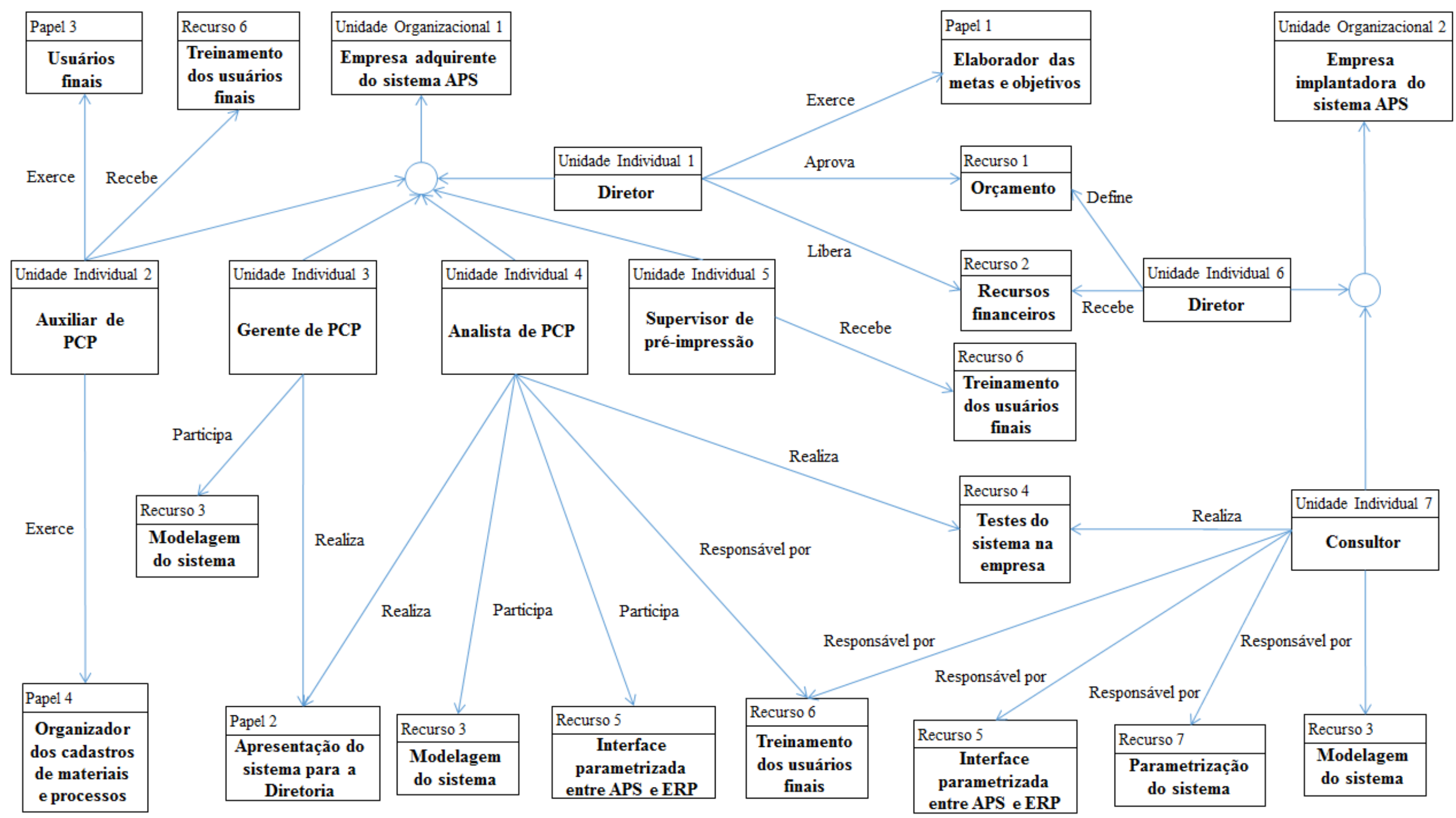

Figura 35 - Modelo de Atores e Recursos - Empresa 4 


\section{Modelo de Componentes e Requisitos Técnicos}

A Figura 36 apresenta o Modelo de Componentes e Requisitos Técnicos do processo de implantação do sistema APS. Este modelo foi desenvolvido a partir da expectativa do funcionário entrevistado quanto aos requisitos que poderiam auxiliar o processo de implantação, uma vez que a organização não possuía nenhum sistema de informação que pudesse auxiliá-la.

De acordo com as informações obtidas, o funcionário da organização acredita que um sistema de informação que poderia auxiliar o processo de implantação do sistema APS na empresa deve ter como objetivo permitir o envio e recebimento de informações (Objetivo SI). Com este sistema, o processo de implantação se torna mais eficiente, pois por meio dele os envolvidos no projeto têm visualização mais rápida dos testes de funcionamento do sistema APS, o que apoia garantir maior controle dos processos (Objetivo 3) e melhor planejamento das atividades produtivas (Objetivo 4).

O sistema de informação para envio e recebimento de informações (Objetivo SI) deve considerar requisitos funcionais (que tangem a utilização), bem como não funcionais (que tangem as medidas de segurança, usabilidade e acessibilidade, etc.). Ele visa possibilitar relatar o andamento dos processos (Requisito Funcional 1) e gerenciar o tempo gasto em cada etapa do processo (Requisito Funcional 2). Tal sistema deve proporcionar interface amigável ao usuário (Requisito Não Funcional 1), possuir robustez (Requisito Não Funcional 2) e segurança (Requisito Não Funcional 3), restringindo o acesso apenas aos envolvidos nos processos.

Este sistema é acessado pelo Analista de PCP (Unidade Individual 4) e pelo Consultor (Unidade Individual 7). Tal sistema gerencia a realização de testes no sistema APS após a modelagem (Regra 1) e dissemina o conhecimento da dinâmica do sistema APS (Regra 2). 


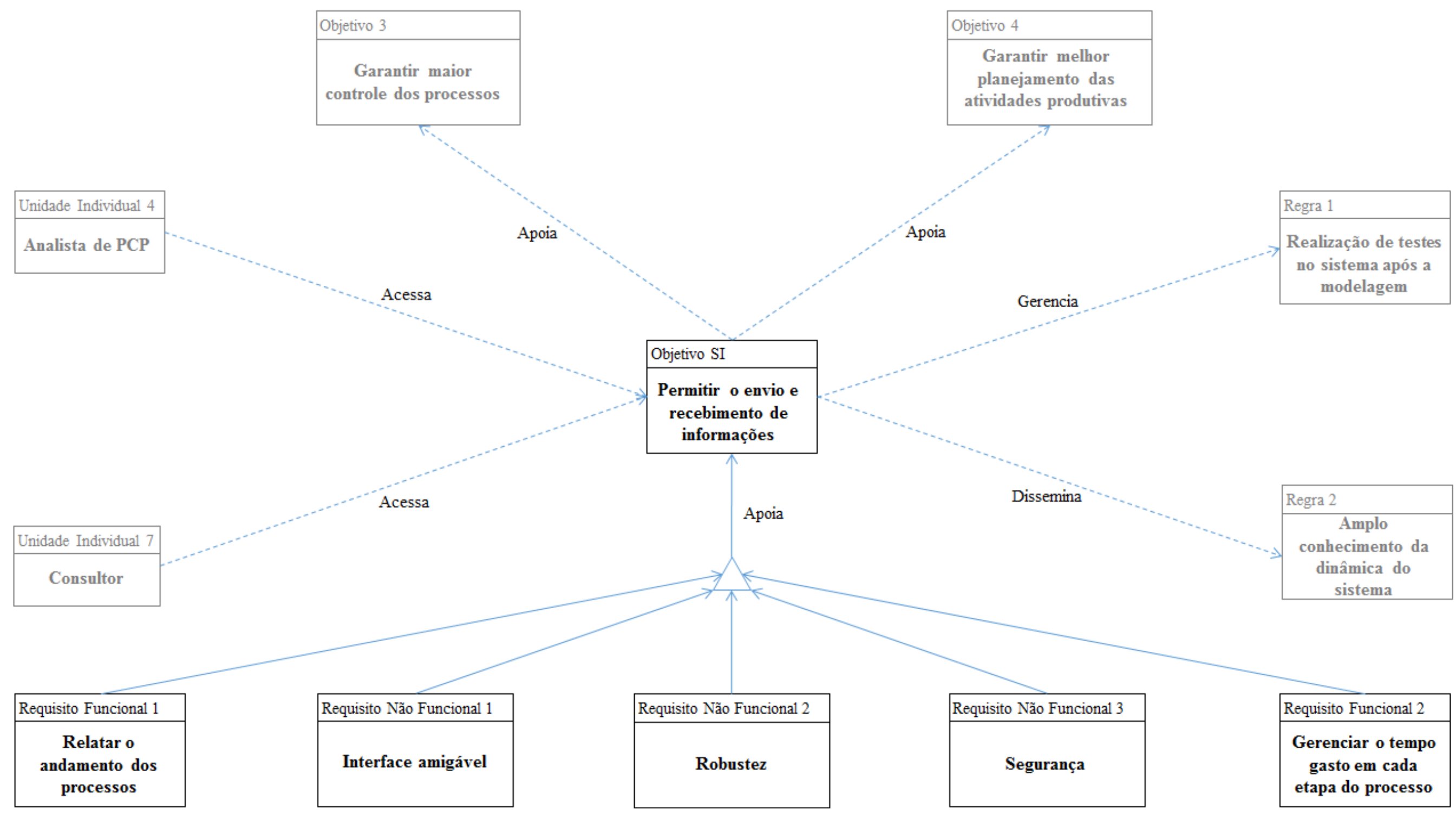

Figura 36 - Modelo de Componentes e Requisitos Técnicos - Empresa 4 


\section{Estudo de caso - Empresa 5}

Este estudo de caso foi realizado em uma empresa fabricante de bebidas, subsidiária de uma multinacional japonesa que possui 270 unidades industriais localizadas nas Américas, Ásia, Europa e Oceania, com mais de 46 mil funcionários. A organização é classificada como empresa de grande porte, tanto em termos de número de funcionários, quanto com relação ao faturamento. Ocupando a terceira posição em seu segmento no Brasil e com uma vasta gama de produtos incluindo cervejas, refrigerantes, sucos, energéticos e águas, a empresa iniciou suas atividades no país em 1939 e possui 13 unidades industriais localizadas nos estados do Amazonas, Bahia, Ceará, Goiás, Maranhão, Pará, Pernambuco, Rio de Janeiro, Rio Grande do Sul, Santa Catarina e São Paulo, empregando em torno de 11 mil funcionários. A unidade analisada neste estudo de caso está localizada na cidade de Itu, estado de São Paulo, a qual possui em torno de 2 mil funcionários.

De acordo com o funcionário da empresa que participou da entrevista para este estudo de caso, como a empresa visava atender adequadamente os prazos de entrega, garantir melhor gerenciamento de estoques e melhor balanceamento da cadeia de suprimentos, os funcionários propuseram para a Diretoria da empresa a implantação do sistema APS, processo que ocorreu em 2010. Benefícios como melhor planejamento da produção, melhor planejamento comercial e antecipação a eventos imprevistos foram alcançados pela empresa com a implantação do sistema.

\section{Modelo de Objetivos}

De acordo com as informações obtidas na entrevista, a redução no tempo dos prazos de entrega, melhor gerenciamento de estoques e balanceamento da cadeia de suprimentos foram os principais motivos que levaram a empresa a implantar o sistema APS.

Como pode ser visto na Figura 37, a utilização do sistema APS na área de Planejamento e Controle da Produção da empresa possibilita a redução dos estoques de produtos acabados (Objetivo 3), o que apoia o balanceamento da cadeia de suprimentos da empresa (Objetivo 4), garantindo assim maior integração entre as operações produtivas (Objetivo 5), especialmente aquelas desenvolvidas nas unidades de Produção (Objetivo 5.1), Aquisições (Objetivo 5.2) e Comercial (Objetivo 5.3). A maior integração entre as operações produtivas (Objetivo 5) apoia a garantia de melhor planejamento das atividades produtivas (Objetivo 6).

Por meio do sistema APS, é possível garantir maior eficiência (Objetivo 2.1) e maior eficácia (Objetivo 2.2), o que apoia o alcance de maior produtividade no trabalho (Objetivo 2) o que por sua vez gera a redução de custos na empresa (Oportunidade 3). 
Com a maior produtividade no trabalho (Objetivo 2) e melhor planejamento das atividades produtivas (Objetivo 6) é possível garantir prazos de entrega mais curtos (Objetivo 1), o que gera aumento e antecipação do faturamento (Oportunidade 1) e melhoria do atendimento aos clientes (Oportunidade 2). 


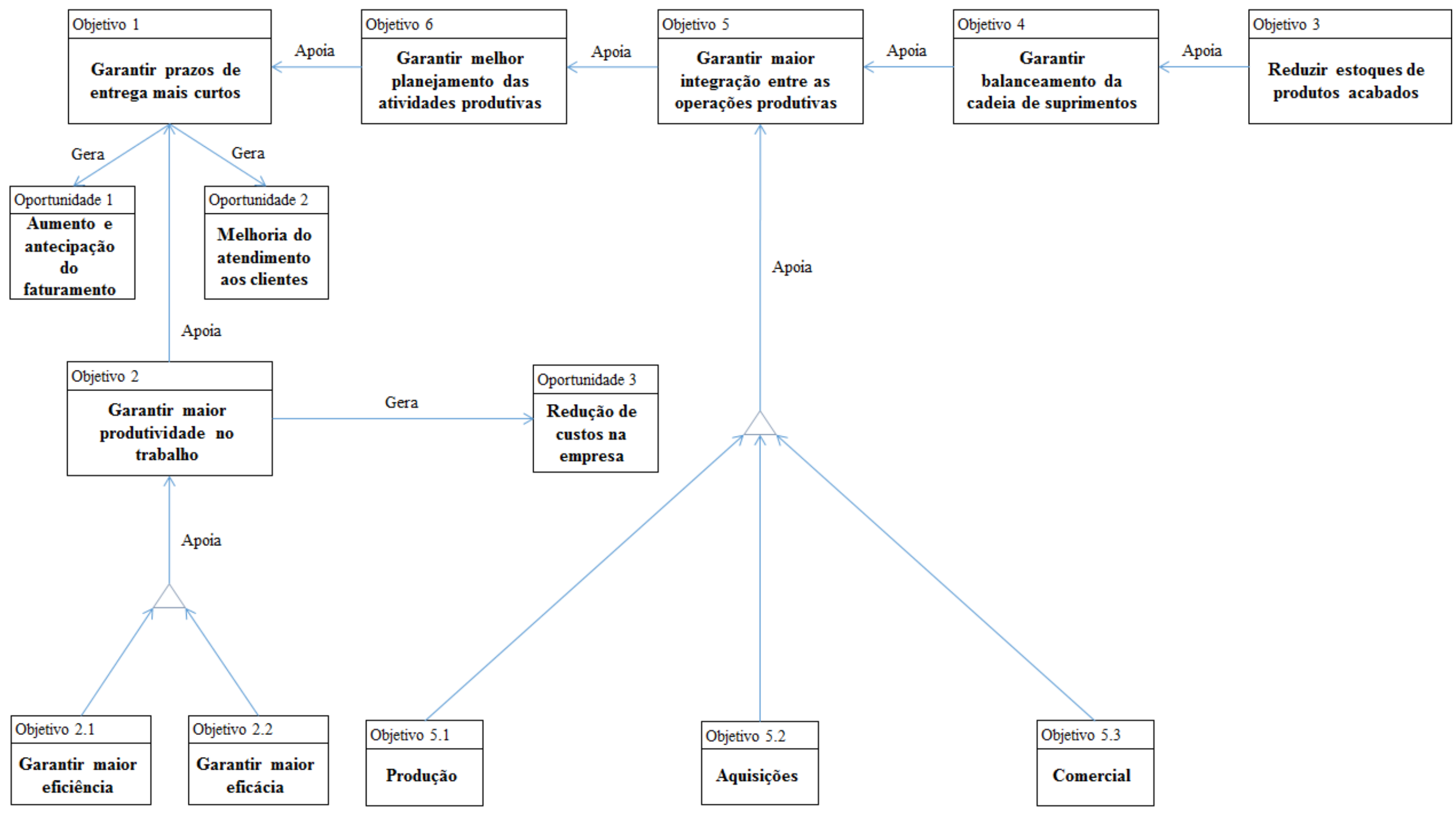

Figura 37 - Modelo de Objetivos - Empresa 5 


\section{Modelo de Regras do Negócio}

O Modelo de Regras do Negócio mostra a influência das regras do processo de implantação do sistema APS sobre os objetivos do processo. Tal modelo está representado na Figura 38.

Como a empresa disponibiliza produtos alimentícios, a perecibilidade dos produtos (Regra 3) determina a necessidade de redução dos estoques de produtos acabados (Objetivo 3).

O treinamento dos usuários finais para o uso do sistema (Regra 2.1) apoia a ampliação do conhecimento da dinâmica do sistema (Regra 2), o que apoia a garantia de maior produtividade no trabalho (Objetivo 2) e, por meio de programações adequadas, o balanceamento da cadeia de suprimentos (Objetivo 4).

A realização de testes no sistema após a modelagem (Regra 1) apoia a garantia de prazos de entrega mais curtos (Objetivo 1) e de melhor planejamento das atividades produtivas (Objetivo 6), verificando se o sistema realmente atende aos requisitos necessários.

A parametrização do sistema (Regra 4) e a integração com os sistemas ERP e SaS (Regra 5) são necessárias para garantir maior integração entre as operações produtivas (Objetivo 5) e garantir melhor planejamento das atividades produtivas (Objetivo 6). 


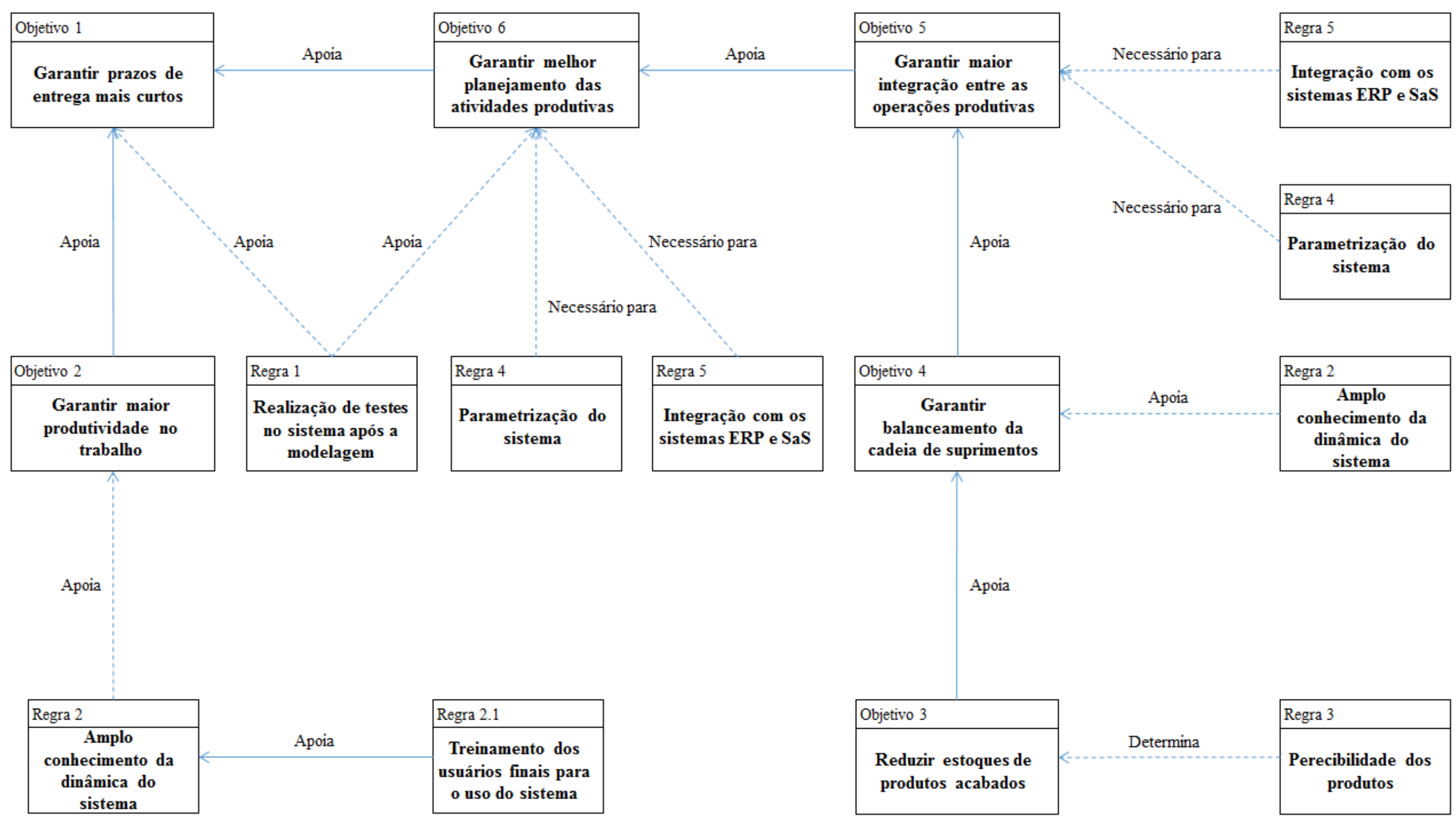

Figura 38 - Modelo de Regras do Negócio - Empresa 5 


\section{Modelo de Processos}

Durante o processo de implantação do sistema APS na empresa, a equipe de implantação realizou 7 principais processos, os quais estão representados na Figura 39.

Após estar ciente da necessidade de adquirir um sistema de Planejamento e Controle da Produção mais eficiente e eficaz, os funcionários da unidade da empresa adquirente contataram consultores da empresa implantadora do sistema para avaliar a cadeia de suprimentos (InfoSet 1) e sinalizar qual sistema seria o mais adequado para as melhorias pretendidas.

Após ser definido que o sistema APS seria o mais adequado à empresa, os funcionários pertinentes apresentaram o sistema para a Diretoria e posteriormente foi negociada a sua aquisição (Processo 1). Após a Diretoria ter autorizado a aquisição do sistema (InfoSet 2), a área pertinente da empresa negociou a transação com a empresa de consultoria, a qual fez a sua implantação (Processo 2).

Após a validação dos processos pela Diretoria (InfoSet 3) e as demais visitas técnicas, os Consultores configuraram o sistema na empresa (Processo 3), resultando em sua modelagem (InfoSet 4).

Com o sistema modelado, deu-se início à execução dos testes iniciais (Processo 4). Após a validação dos testes pela Diretoria (InfoSet 5), os funcionários pertinentes foram treinados para o uso do sistema (Processo 5).

Após a validação do treinamento pela Diretoria (InfoSet 6) foi criada a integração entre o APS e os sistemas ERP e o SaS, um software para modelagem estatística do planejamento de demanda (Processo 6).

Com o sistema parametrizado (InfoSet 7), foram executados os testes finais (Processo 7), os quais quando concluídos, foram validados pela Diretoria (InfoSet 8). 

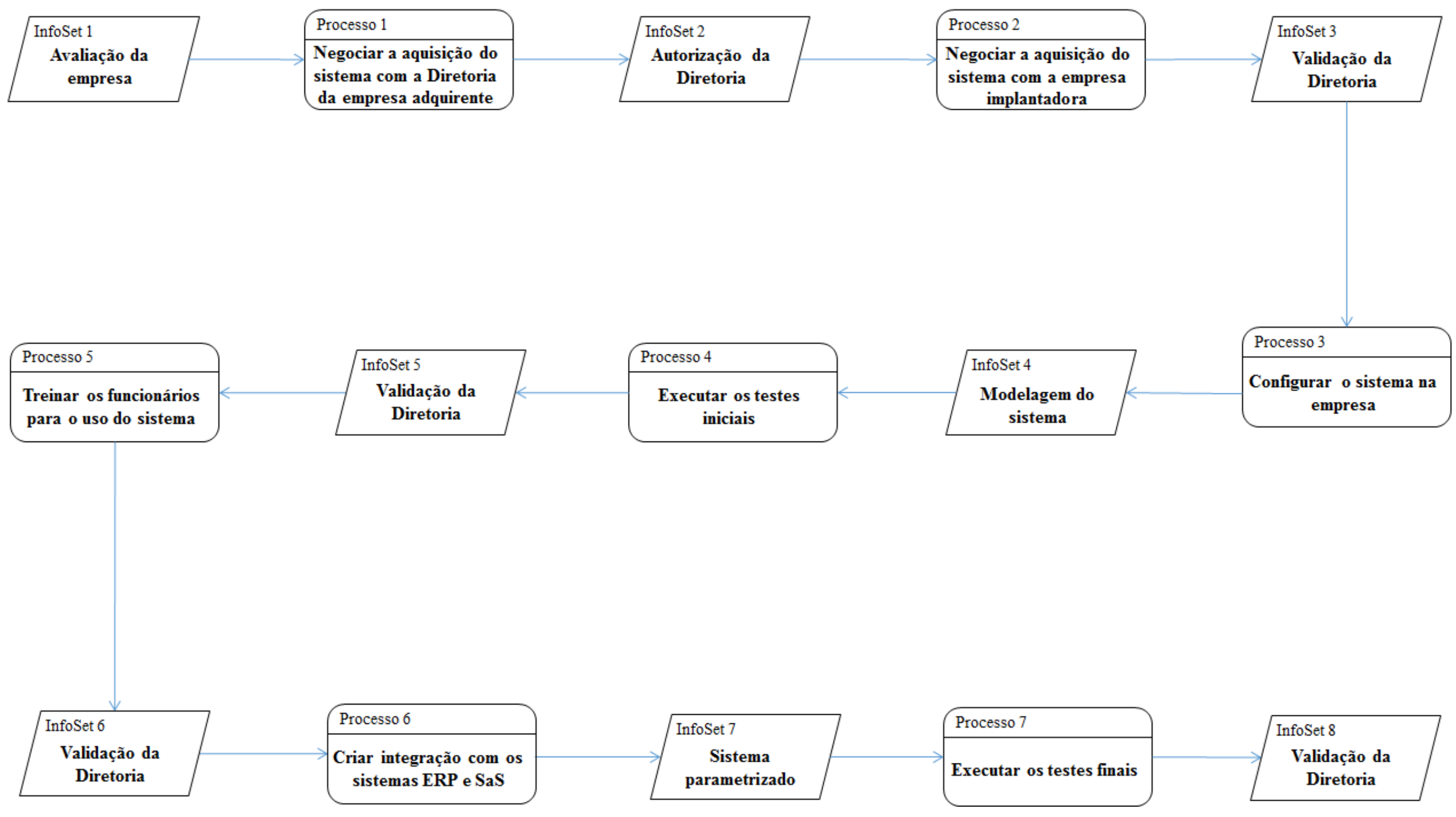

Figura 39 - Modelo de Processos - Empresa 5 


\section{Modelo de Atores e Recursos}

Neste modelo está descrito o papel de cada envolvido nas etapas do processo de implantação do sistema APS na empresa. A Figura 40 apresenta a visão geral do modelo.

O Vice-presidente de operações (Unidade Individual 1) da empresa adquirente do sistema APS (Unidade Organizacional 1), elabora as metas e objetivos do processo de implantação do sistema APS (Papel 1), aprova o orçamento (Recurso 1) e libera os recursos financeiros necessários para a sua aquisição (Recurso 2).

O Analista de Faturamento (Unidade Individual 7), o Analista de Carteira (Unidade Individual 8) e o Analista de Vendas (Unidade Individual 9) da empresa adquirente do sistema APS (Unidade Organizacional 1), apesar de não serem usuários assíduos do sistema, também recebem o treinamento destinado aos usuários finais (Recurso 7).

O Gerente de Projeto (Unidade Individual 2) e o Gerente de Planejamento (Unidade Individual 3) da empresa adquirente do sistema APS (Unidade Organizacional 1) são responsáveis pela validação dos processos (Recurso 8).

O Analista de PCP (Unidade Individual 4) da empresa adquirente do sistema APS (Unidade Organizacional 1) realiza os testes do sistema na empresa (Recurso 4) e participa do processo de geração de interface parametrizada do APS com os sistemas ERP e SaS (Recurso $5)$.

O Analista de Tecnologia da Informação (Unidade Individual 5) da empresa adquirente do sistema APS (Unidade Organizacional 1) é responsável pela interface parametrizada do APS com os sistemas ERP e SaS (Recurso 5), pela modelagem (Recurso 3) e pela parametrização do sistema (Recurso 6), e pelo treinamento dos usuários finais (Recurso 7).

O Analista de Planejamento e Demanda (Unidade Individual 6) da empresa adquirente do sistema APS (Unidade Organizacional 1) participa da parametrização do sistema (Recurso 6) e realiza os testes do sistema na empresa (Recurso 4).

O Diretor (Unidade Individual 10) da empresa implantadora do sistema APS (Unidade Organizacional 2) define o orçamento (Recurso 1) e recebe os recursos financeiros (Recurso 2) da empresa adquirente do sistema APS (Unidade Organizacional 1).

O Consultor (Unidade Individual 11) realiza os testes do sistema na empresa adquirente (Recurso 4) e é responsável pela modelagem (Recurso 3) e pela parametrização do sistema (Recurso 6), pela interface parametrizada do APS com os sistemas ERP e SaS (Recurso 5), e pelo treinamento dos usuários finais (Recurso 7). 


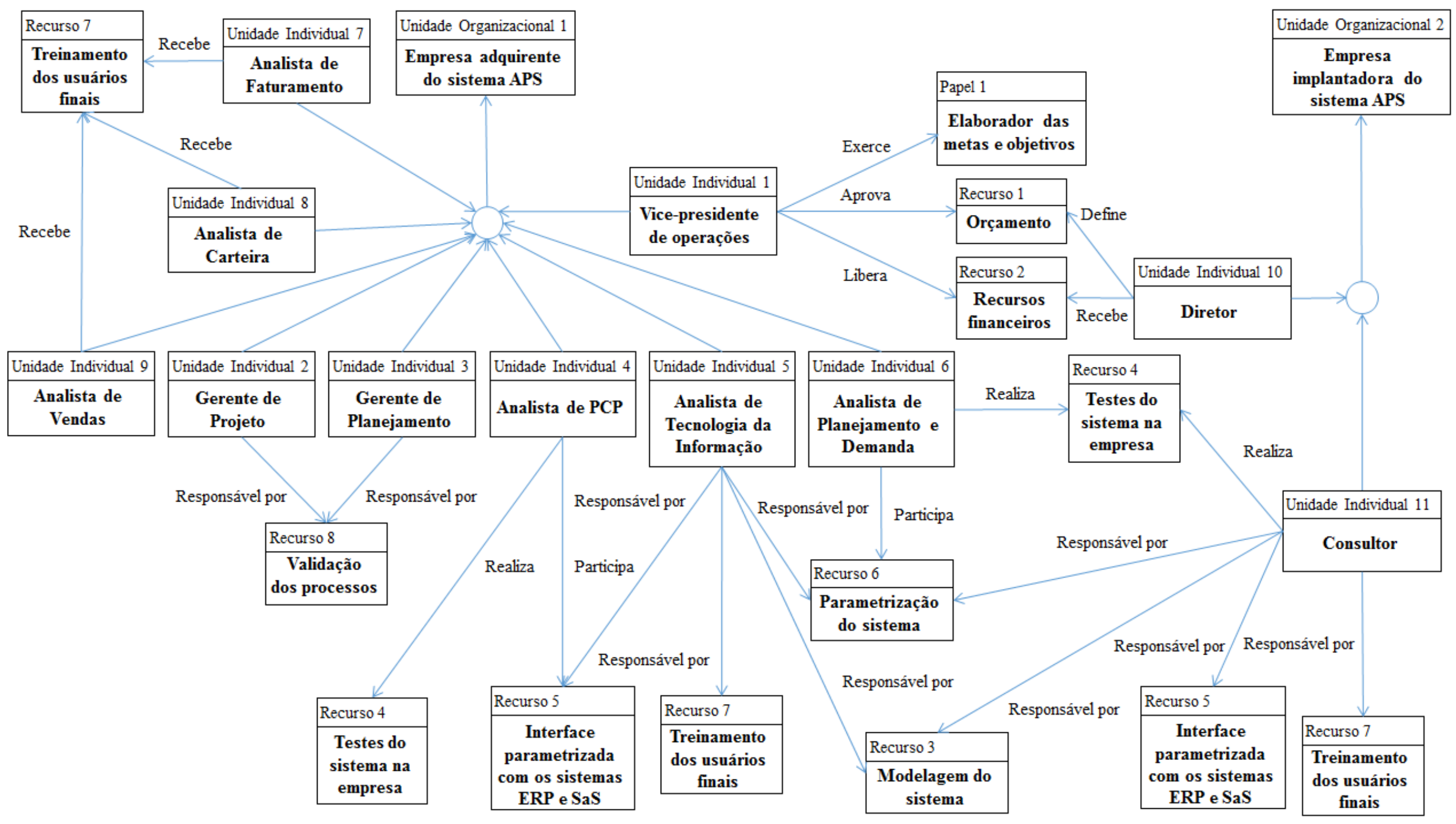

Figura 40 - Modelo de Atores e Recursos - Empresa 5 


\section{Modelo de Componentes e Requisitos Técnicos}

A Figura 41 apresenta o Modelo de Componentes e Requisitos Técnicos do processo de implantação do sistema APS. A empresa possui dois sistemas de informação, um para gerar informações sobre o fluxo de processos, o Solution Management; e outro para documentar os processos realizados, o ARIS.

O sistema para geração de informações sobre os fluxos de processos (Objetivo SI 1) e o sistema para documentação dos processos realizados (Objetivo SI 2) consideram requisitos funcionais (que tangem a utilização do sistema de informação pretendido), bem como não funcionais (que tangem as medidas de segurança, usabilidade e acessibilidade, etc.). O sistema para geração de informações sobre os fluxos de processos (Objetivo SI 1) visa relatar quais fluxos já foram realizados (Requisito Funcional 1), quem testou os fluxos (Requisito Funcional 2) e quando os fluxos foram testados (Requisito Funcional 3). O sistema para documentação dos processos realizados (Objetivo SI 2) visa relatar o andamento dos processos que ocorrem (Requisito Funcional 1). Ambos os sistemas devem proporcionar interface amigável ao usuário (Requisito Não Funcional 1), possuir robustez (Requisito Não Funcional 2) e segurança (Requisito Não Funcional 3), restringindo o acesso apenas aos envolvidos nos processos, e possibilitar acesso remoto (Requisito Não Funcional 4) por meio da web.

O sistema para geração de informações sobre os fluxos de processos (Objetivo SI 1) apoia o sistema para documentação dos processos realizados (Objetivo SI 2) e a garantia de maior integração entre as operações produtivas (Objetivo 5) e durante o processo de implantação este sistema é acessado pelo Consultor (Unidade Individual 11), Gerente de Projeto (Unidade Individual 2), Gerente de Planejamento (Unidade Individual 3), Analista de PCP (Unidade Individual 4), Analista de Tecnologia da Informação (Unidade Individual 5) e Analista de Planejamento e Demanda (Unidade Individual 6).

O sistema para documentação dos processos realizados (Objetivo SI 2) apoia a ampliação do conhecimento da dinâmica do sistema APS (Regra 2) por parte dos envolvidos no processo de implantação e é acessado pelo Consultor (Unidade Individual 11) e Analista de Tecnologia da Informação (Unidade Individual 5). 


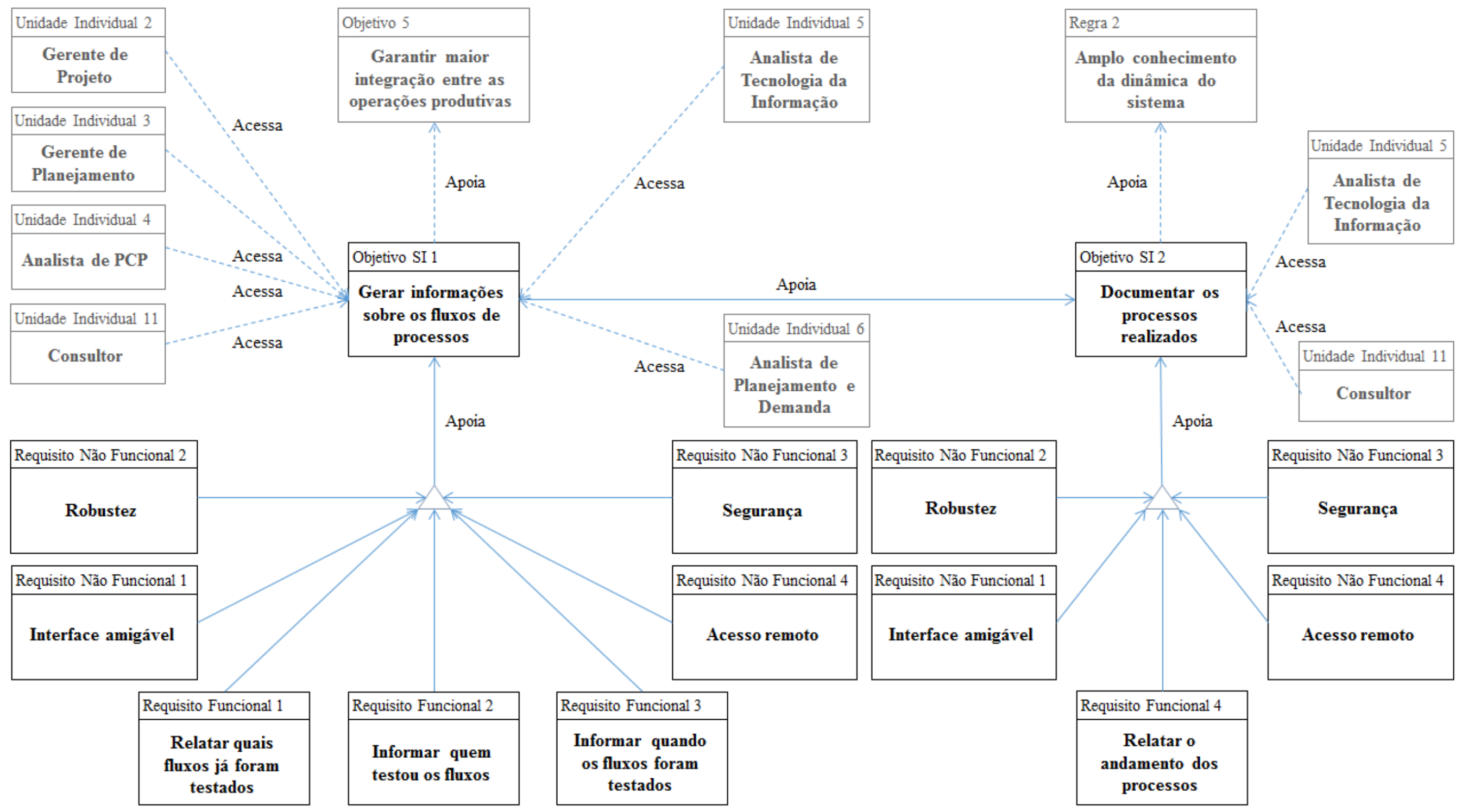

Figura 41 - Modelo de Componentes e Requisitos Técnicos - Empresa 5 


\section{Estudo de caso - Empresa 6}

Este estudo de caso foi realizado em uma empresa multinacional de origem francesa, produtora de tubos flexíveis e tubos umbilicais para a indústria petrolífera. A empresa possui unidades industriais na França, Brasil, Malásia, Estados Unidos, Inglaterra e Angola, bem como escritórios espalhados em mais de 40 países, empregando em torno de 30 mil funcionários. A organização é classificada como empresa de grande porte, tanto em termos de número de funcionários, quanto com relação ao faturamento. Ocupando a liderança mundial em seu segmento, a empresa possui 2 unidades industriais no Brasil, localizadas nas cidades de Vitória, estado do Espírito Santo; e Campos, estado do Rio de Janeiro. A unidade analisada neste estudo de caso está localizada na cidade de Vitória e possui em torno de 2 mil funcionários.

De acordo com o funcionário da empresa que participou da entrevista para este estudo de caso, como a empresa utilizava um sistema arcaico para gerenciar as atividades de planejamento e controle da produção e necessitava de maior confiabilidade nas informações relacionadas à produção, em 2006 o funcionário propôs para a Diretoria da empresa a implantação do sistema, processo este que se concretizou apenas em 2008.

Inicialmente, devido à divergências com a Diretoria, foi implantado um sistema similar ao APS na empresa, desenvolvido pelos próprios funcionários de uma unidade francesa, porém, como o desempenho do sistema não foi satisfatório, bem como foi implantado de maneira bemsucedida um sistema APS na unidade supracitada, a Diretoria aprovou a implantação do sistema na unidade de Vitória.

Diversos benefícios foram alcançados com a implantação do sistema APS na empresa, tais como maior confiabilidade das informações, melhor controle da produção, melhor capacidade de resposta e flexibilidade na geração da programação.

\section{Modelo de Objetivos}

De acordo com as informações obtidas na entrevista, a busca por maior confiabilidade das informações relacionadas à produção, melhor controle da produção, maior capacidade de resposta e flexibilidade na geração da programação foram os principais motivos que levaram a empresa a implantar o sistema APS.

Como pode ser visto na Figura 42, a utilização do sistema APS na área de Planejamento e Controle da Produção da empresa garante maior integração entre as operações produtivas (Objetivo 4), especialmente as desenvolvidas nas unidades de Produção (Objetivo 4.1), Aquisições (Objetivo 4.2) e Comercial (Objetivo 4.3). Essa maior integração entre as operações produtivas (Objetivo 4) apoia a garantia de melhor programação da produção (Objetivo 3), a 
qual, quando alcançada, garante melhor sequenciamento (Objetivo 3.1), melhor alocação de carga (Objetivo 3.2), coleta rápida de informações (Objetivo 3.3), melhor planejamento das aquisições (Objetivo 3.4), atualização instantânea das ordens de produção (Objetivo 3.5) e ajuste automático destas ordens (Objetivo 3.6).

A melhor programação da produção (Objetivo 3) apoia a garantia de balanceamento da cadeia de suprimentos da empresa (Objetivo 2), o que garante confiabilidade no planejamento de longo prazo (Objetivo 1).

Por meio do sistema APS, é possível garantir maior eficiência (Objetivo 5.1) e maior eficácia (Objetivo 5.2), o que apoia o alcance de maior produtividade e excelência no trabalho (Objetivo 5). O atendimento à norma ISO 9001/2008 (Política 1), no âmbito da qualidade nos processos; e à norma ISPS Code (Política 2), no âmbito da segurança e excelência no trabalho; induz a empresa a buscar garantir maior produtividade e excelência no trabalho (Objetivo 5), a qual, quando alcançada, gera redução de custos na empresa (Oportunidade 1).

A maior produtividade e excelência no trabalho (Objetivo 5) apoia a eliminação das perdas por espera nos processos produtivos (Objetivo 6), o que apoia a garantia de confiabilidade no planejamento de longo prazo (Objetivo 1). 


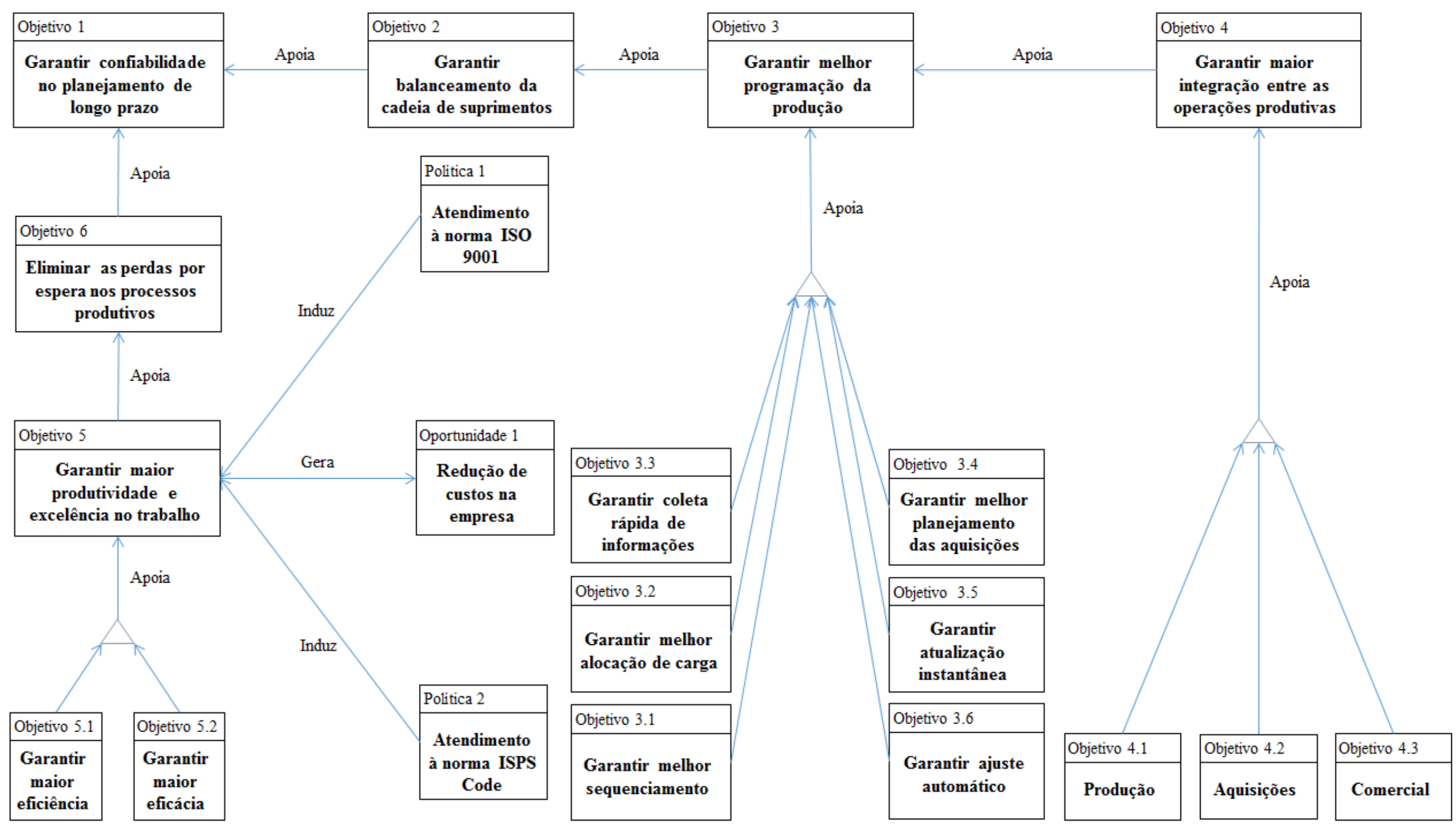

Figura 42 - Modelo de Objetivos - Empresa 6 


\section{Modelo de Regras do Negócio}

O Modelo de Regras do Negócio mostra a influência das regras do processo de implantação do sistema APS sobre os objetivos do processo. Tal modelo está representado na Figura 43.

O treinamento dos usuários finais para o uso do sistema (Regra 2.1) apoia a ampliação do conhecimento da dinâmica do sistema (Regra 2), o que garante balanceamento da cadeia de suprimentos da empresa (Objetivo 2) e, em conjunto com o amplo conhecimento dos processos produtivos (Regra 3) apoia a garantia de maior produtividade e excelência no trabalho (Objetivo $5)$.

A integração com o sistema PC Factory (Regra 5), um software de apontamento da produção; a integração com o sistema Cameleon (Regra 6), um software que lê os cenários de produção dos arquivos gerados pelo sistema ERP e os transforma em BOM (lista de materiais) e ordens de produção a serem enviadas e entendidas pelo APS; e a parametrização do sistema (Regra 7) foram condições necessárias para garantir melhor programação da produção (Objetivo 3). É importante destacar que na época da implantação do sistema APS o ERP não estava plenamente implantado na empresa, por isso houve a necessidade de integração entre os sistemas ERP, Cameleon e APS.

A integração com o sistema Cameleon (Regra 6) foi uma condição necessária para garantir maior integração entre as operações produtivas (Objetivo 4), especialmente às relacionadas às unidades de Produção e Comercial.

A adaptação da solução do sistema às necessidades da empresa (Regra 4) apoia a eliminação das perdas por espera nos processos produtivos (Objetivo 6). A realização de testes no sistema após a modelagem (Regra 1) apoia a garantia de confiabilidade no planejamento de longo prazo (Objetivo 1). 


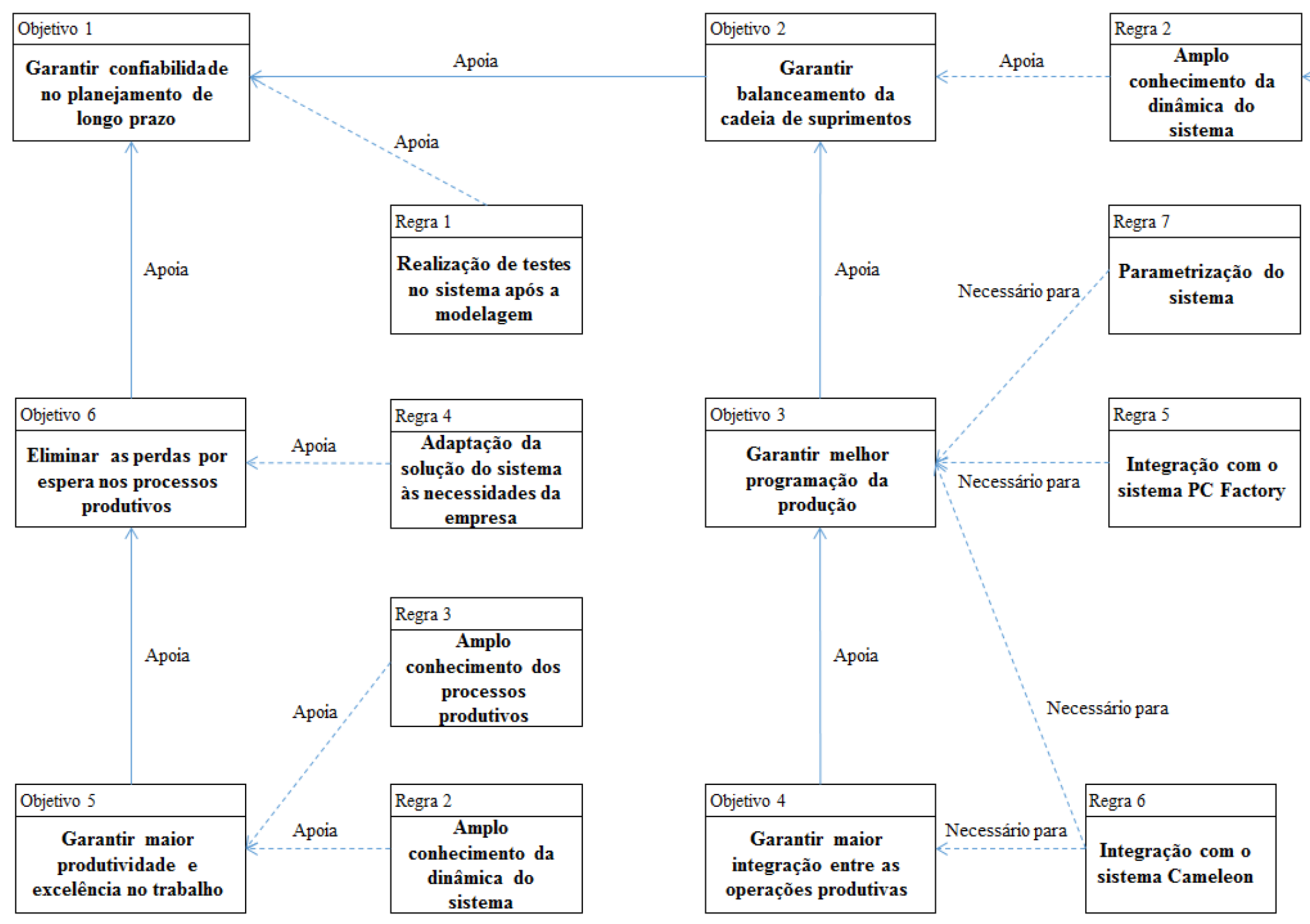

Figura 43 - Modelo de Regras do Negócio - Empresa 6 


\section{Modelo de Processos}

Durante o processo de implantação do sistema APS na empresa, a equipe de implantação realizou 9 principais processos, os quais estão representados na Figura 44.

Após o Supervisor de PCP da empresa obter conhecimento dos sistemas APS durante a realização de um curso de pós-graduação (InfoSet Externo 1) foram realizadas entrevistas com profissionais da empresa de consultoria (Processo 1), para verificar a adequação do sistema às necessidades da empresa.

Após ser definido que o sistema APS seria adequado à empresa, o Supervisor de PCP apresentou o sistema para a Diretoria (Processo 2). A Diretoria entrou em contato com profissionais da matriz da empresa, a qual fica localizada na França. Os profissionais de PCP e de Tecnologia da Informação da matriz, cientes da necessidade de melhoria na referida unidade industrial brasileira tentaram desenvolver um sistema similar ao APS (InfoSet 2), obtendo insucesso. Ciente de tal fato a Diretoria da unidade industrial brasileira autorizou a aquisição do sistema, dando início à negociação de sua aquisição com a empresa implantadora (Processo 3). Posteriormente, sua aquisição foi aprovada (InfoSet 3).

Antes do início do processo de implantação do sistema APS na unidade industrial brasileira, foi iniciado um processo similar na matriz (Processo 4). Diante desta similaridade, foi feita uma parceria entre as empresas de consultoria francesa e brasileira (InfoSet 4) para a parametrização do sistema na unidade industrial brasileira.

Após ser concretizada a parceria, os Consultores da empresa implantadora do sistema realizaram visitas técnicas na empresa adquirente para avaliar suas necessidades (Processo 5). A conclusão da avaliação resultou na configuração do sistema (InfoSet 5).

Com o sistema configurado (InfoSet 5), foram realizados os testes (Processo 6) e com o sistema aprovado (InfoSet 6), os funcionários pertinentes foram treinados para o seu uso (Processo 7). Após a conclusão dos testes, foi realizada a modelagem do sistema (InfoSet 7).

Após o sistema estar devidamente modelado (InfoSet 7), foi criada a integração com os sistemas PC Factory e Cameleon (Processo 8), tendo como resultado o sistema parametrizado (InfoSet 8).

Com o sistema parametrizado (InfoSet 8), foram executados os testes finais (Processo 9), tendo por fim a validação da Diretoria (InfoSet 9). 


InfoSet Externo 1
Conhecimento do
sistema em um curso $\rightarrow$\begin{tabular}{c}
$\begin{array}{c}\text { Processo } 1 \\
\text { Entrevistar profissionais } \\
\text { da empresa } \\
\text { implantadora }\end{array}$ \\
\hline
\end{tabular}

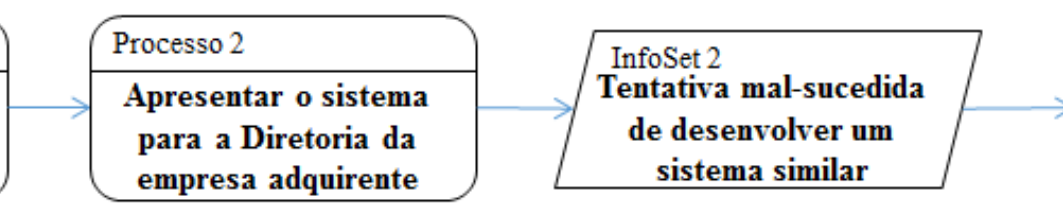

Processo 3
$\begin{gathered}\text { Negociar a aquisição do } \\ \text { sistema com a empresa } \\ \text { implantadora }\end{gathered}$

\begin{tabular}{|} 
InfoSet 3 \\
Aprovação da \\
Diretoria
\end{tabular}

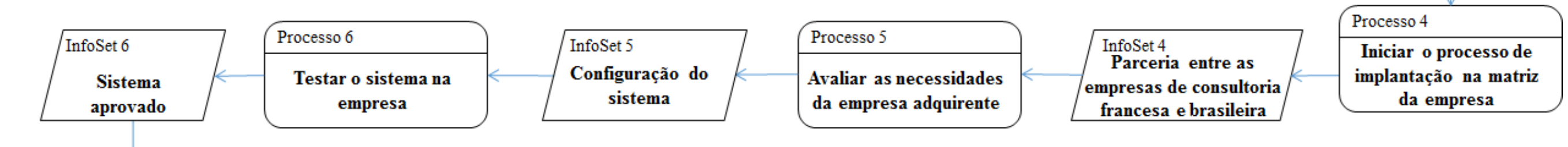

\begin{tabular}{|c|c|c|c|c|c|}
\hline Processo 7 & InfoSet 7 & Processo 8 & InfoSet 8 & Processo 9 & InfoSet 9 \\
\hline $\begin{array}{l}\text { Treinar os funcionários } \\
\text { para o uso do sistema }\end{array}$ & $\begin{array}{c}\text { Modelagem do } \\
\text { sistema }\end{array}$ & $\begin{array}{c}\text { Criar integração com o } \\
\text { sistemas PC Factory e } \\
\text { Cameleon }\end{array}$ & $\begin{array}{c}\text { Sistema } \\
\text { parametrizado }\end{array}$ & Executar os testes finais & $\begin{array}{l}\text { Validação da } \\
\text { Diretoria }\end{array}$ \\
\hline
\end{tabular}

Figura 44 - Modelo de Processos - Empresa 6 


\section{Modelo de Atores e Recursos}

Neste modelo está descrito o papel de cada envolvido nas etapas do processo de implantação do sistema APS na empresa. A Figura 45 apresenta a visão geral do modelo.

O Diretor (Unidade Individual 1) da empresa adquirente do sistema APS (Unidade Organizacional 1) elabora as metas e objetivos do processo de implantação do sistema APS (Papel 1), aprova o orçamento (Recurso 1) e libera os recursos financeiros necessários para a sua aquisição (Recurso 2).

O Engenheiro de Planejamento (Unidade Individual 2) e o Técnico de Planejamento (Unidade Individual 3) da empresa adquirente do sistema APS (Unidade Organizacional 1) recebem o treinamento destinado aos usuários finais (Recurso 7), exercendo a função designada (Papel 3).

O Supervisor de PCP (Unidade Individual 4) da empresa adquirente do sistema APS (Unidade Organizacional 1) realiza a apresentação do sistema para a Diretoria (Papel 2), participa da modelagem (Recurso 4) e parametrização do sistema (Recurso 6), realiza a interface parametrizada entre o APS e os sistemas PC Factory e Cameleon (Recurso 5), realiza os testes do sistema na empresa (Recurso 3) e é responsável pelo treinamento dos usuários finais (Recurso 7).

O Analista de Tecnologia da Informação (Unidade Individual 5) da empresa adquirente do sistema APS (Unidade Organizacional 1) realiza os testes do sistema na empresa (Recurso 3), é responsável pela interface parametrizada entre o APS e os sistemas PC Factory e Cameleon (Recurso 5), pela modelagem (Recurso 4) e parametrização do sistema (Recurso 6) e pelo treinamento dos usuários finais (Recurso 7).

O Diretor (Unidade Individual 6) da empresa implantadora do sistema APS (Unidade Organizacional 2) define o orçamento (Recurso 1) e recebe os recursos financeiros (Recurso 2) da empresa adquirente do sistema APS (Unidade Organizacional 1).

O Consultor (Unidade Individual 7) realiza os testes do sistema na empresa adquirente (Recurso 3), é responsável pela modelagem (Recurso 4) e parametrização do sistema (Recurso 6) e também pelo treinamento dos usuários finais (Recurso 7). 


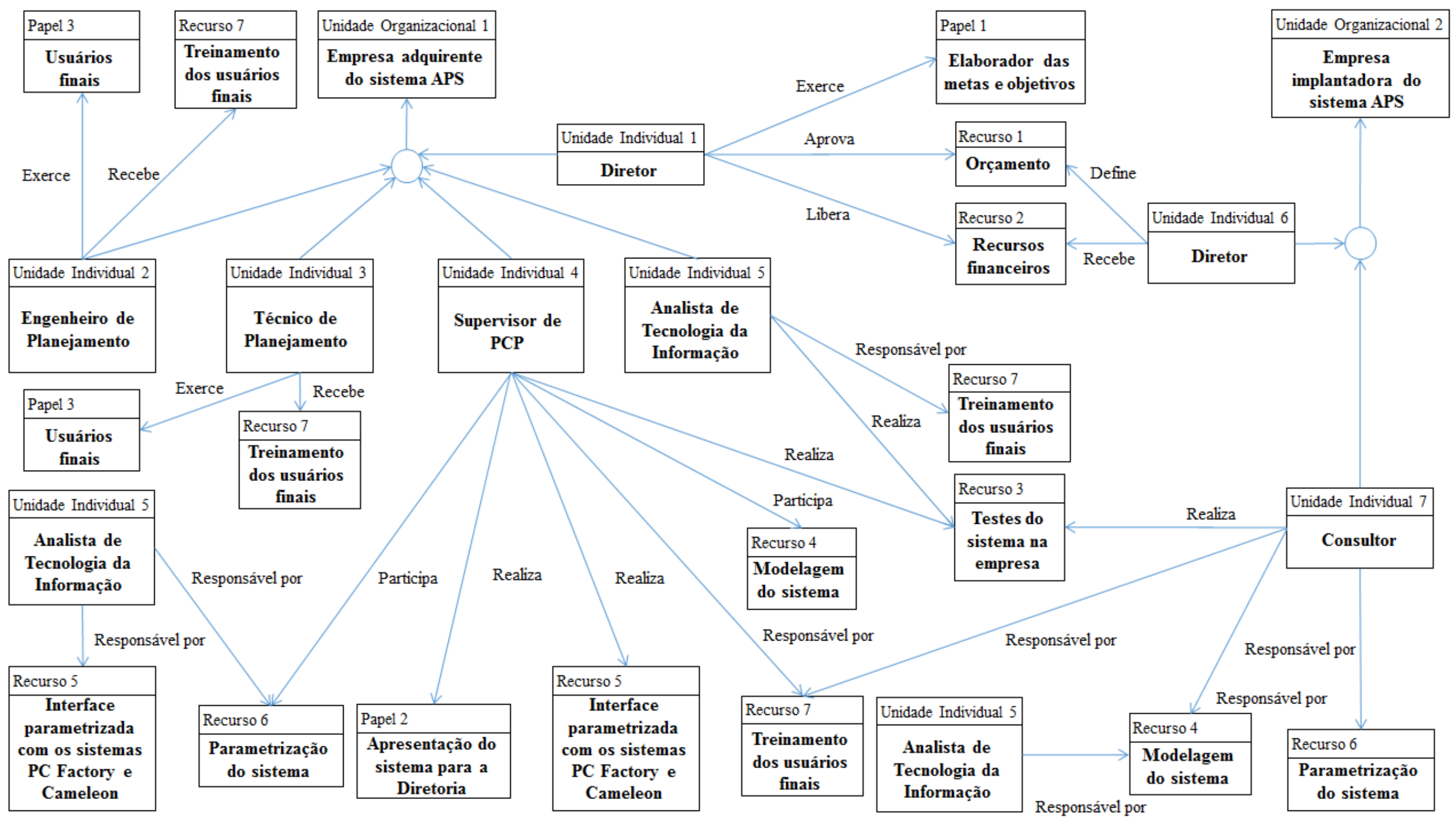

Figura 45 - Modelo de Atores e Recursos - Empresa 6 


\section{Modelo de Componentes e Requisitos Técnicos}

A Figura 46 apresenta o Modelo de Componentes e Requisitos Técnicos do processo de implantação do sistema APS. A empresa possui um sistema de informação que permite o envio e recebimento de informações relacionadas a transações que ocorrem entre ela e seus parceiros.

De acordo com as informações obtidas, o único objetivo deste sistema de informação durante o processo de implantação do sistema APS na empresa é permitir o envio e recebimento de informações pertinentes (Objetivo SI).

O sistema para envio e recebimento de informações pertinentes ao processo de implantação do sistema APS entre a empresa adquirente e a empresa implantadora (Objetivo SI) considera requisitos funcionais (que tangem a utilização do sistema de informação pretendido), bem como não funcionais (que tangem as medidas de segurança, usabilidade e acessibilidade, etc.). Ele visa relatar o andamento dos processos (Requisito Funcional 1) e gerenciar o tempo gasto em cada etapa do processo (Requisito Funcional 2). Tal sistema deve proporcionar interface amigável ao usuário (Requisito Não Funcional 1), possuir robustez (Requisito Não Funcional 2) e segurança (Requisito Não Funcional 3), restringindo o acesso apenas aos envolvidos nos processos, e possibilitar acesso remoto (Requisito Não Funcional 4) por meio da web.

Este sistema é acessado pelo Analista de Tecnologia da Informação (Unidade Individual 5), pelo Supervisor de PCP (Unidade Individual 4) e pelo Consultor da empresa implantadora do sistema (Unidade Individual 7).

O sistema para envio e recebimento de informações pertinentes ao processo de implantação do sistema APS entre a empresa adquirente e a empresa implantadora (Objetivo SI) por meio da troca de conhecimento entre os atores envolvidos no processo dissemina a ampliação do conhecimento da dinâmica do sistema (Regra 2), apoia a adaptação da solução do sistema às necessidades da empresa (Regra 4) e gerencia a realização de testes no sistema após a modelagem (Regra 1). Este sistema apoia a garantia de maior produtividade e excelência no trabalho (Objetivo 5). 


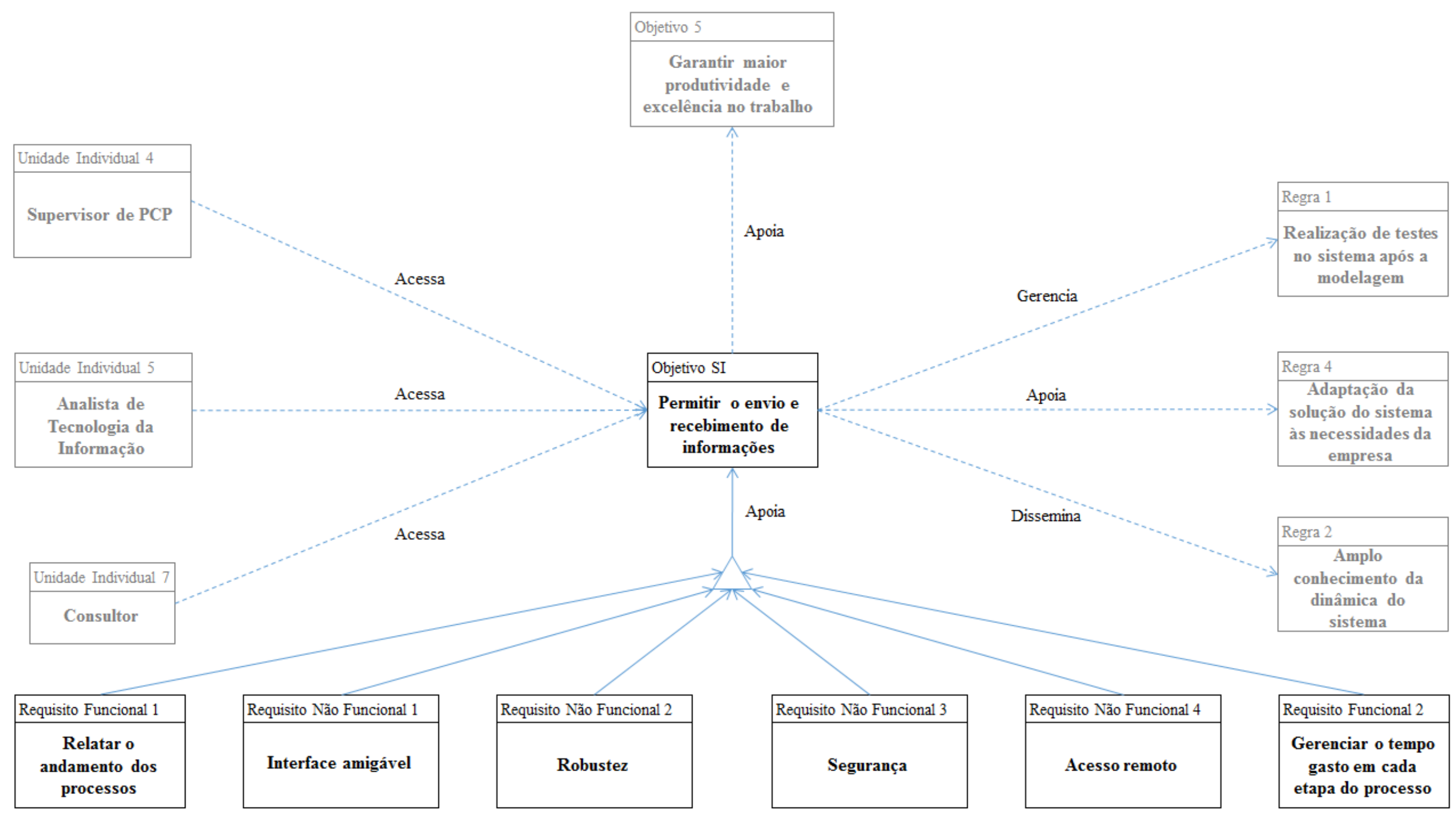

Figura 46 - Modelo de Componentes e Requisitos Técnicos - Empresa 6 


\section{Estudo de caso - Empresa 7}

Este estudo de caso foi realizado em uma empresa multinacional de origem francesa, produtora de tubos flexíveis e tubos umbilicais para a indústria petrolífera. A empresa possui unidades industriais na França, Brasil, Malásia, Estados Unidos, Inglaterra e Angola, bem como escritórios espalhados em mais de 40 países, empregando em torno de 30 mil funcionários. A organização é classificada como empresa de grande porte, tanto em termos de número de funcionários, quanto com relação ao faturamento. Ocupando a liderança mundial em seu segmento, a empresa possui 2 unidades industriais no Brasil, localizadas nas cidades de Vitória, estado do Espírito Santo; e Campos, estado do Rio de Janeiro. A unidade analisada neste estudo de caso está localizada na cidade de Campos e possui em torno de 300 funcionários.

De acordo com o funcionário da empresa que participou da entrevista para este estudo de caso, como a empresa estava iniciando suas atividades na unidade analisada na época da implantação e necessitava de um sistema de Planejamento e Controle da Produção eficiente, eficaz e que garantisse a integração com a unidade de Vitória; e tendo em vista o sucesso da utilização do sistema APS tanto na unidade francesa, quanto na unidade de Vitória, a Diretoria determinou sua implantação. Como os profissionais da unidade de Vitória participaram ativamente no processo de implantação, acompanhando todas as etapas, os mesmos implantaram o sistema na unidade de Campos, processo que ocorreu em 2014.

Diversos benefícios foram alcançados com a implantação do sistema APS na empresa, tais como maior confiabilidade das informações, melhor controle da produção, melhor capacidade de resposta, maior flexibilidade na geração da programação e integração com os módulos de planejamento de longo e curto prazo do sistema APS da unidade de Vitória.

\section{Modelo de Objetivos}

De acordo com as informações obtidas na entrevista, a busca por maior confiabilidade das informações relacionadas à produção, melhor controle da produção, maior capacidade de resposta, flexibilidade na geração da programação e integração com a unidade industrial de Vitória foram os principais motivos que levaram a empresa a implantar o sistema APS.

Como pode ser visto na Figura 47, a utilização do sistema APS na área de Planejamento e Controle da Produção da empresa garante maior integração entre as operações produtivas (Objetivo 4), especialmente as desenvolvidas nas unidades de Produção (Objetivo 4.1), Aquisições (Objetivo 4.2) e Comercial (Objetivo 4.3). Essa maior integração entre as operações produtivas (Objetivo 4) apoia a garantia de melhor programação da produção (Objetivo 3), a qual, quando alcançada, garante melhor sequenciamento (Objetivo 3.1), melhor alocação de 
carga (Objetivo 3.2), coleta rápida de informações (Objetivo 3.3), melhor planejamento das aquisições (Objetivo 3.4), atualização instantânea das ordens de produção (Objetivo 3.5) e ajuste automático destas ordens (Objetivo 3.6).

A garantia de melhor programação da produção (Objetivo 3) apoia a garantia de confiabilidade no planejamento de longo prazo (Objetivo 2), o que, para ser alcançada, requer integração com a outra unidade industrial brasileira (Objetivo 1).

Por meio do sistema APS, é possível garantir maior eficiência (Objetivo 5.1) e maior eficácia (Objetivo 5.2), o que apoia o alcance de maior produtividade e excelência no trabalho (Objetivo 5). O atendimento à norma ISO 9001/2008 (Política 1), no âmbito da qualidade nos processos; e à norma ISPS Code (Política 2), no âmbito da segurança e excelência no trabalho; induz a empresa a buscar garantir maior produtividade e excelência no trabalho (Objetivo 5), a qual, quando alcançada, gera redução de custos na empresa (Oportunidade 2).

A maior produtividade e excelência no trabalho (Objetivo 5) apoia a eliminação das perdas por espera nos processos produtivos (Objetivo 6), o que, devido ao compartilhamento de recursos e know-how entre as duas unidades, requer integração com a outra unidade industrial brasileira (Objetivo 1), o que auxilia a tomada de decisões operacionais (Oportunidade 1). 


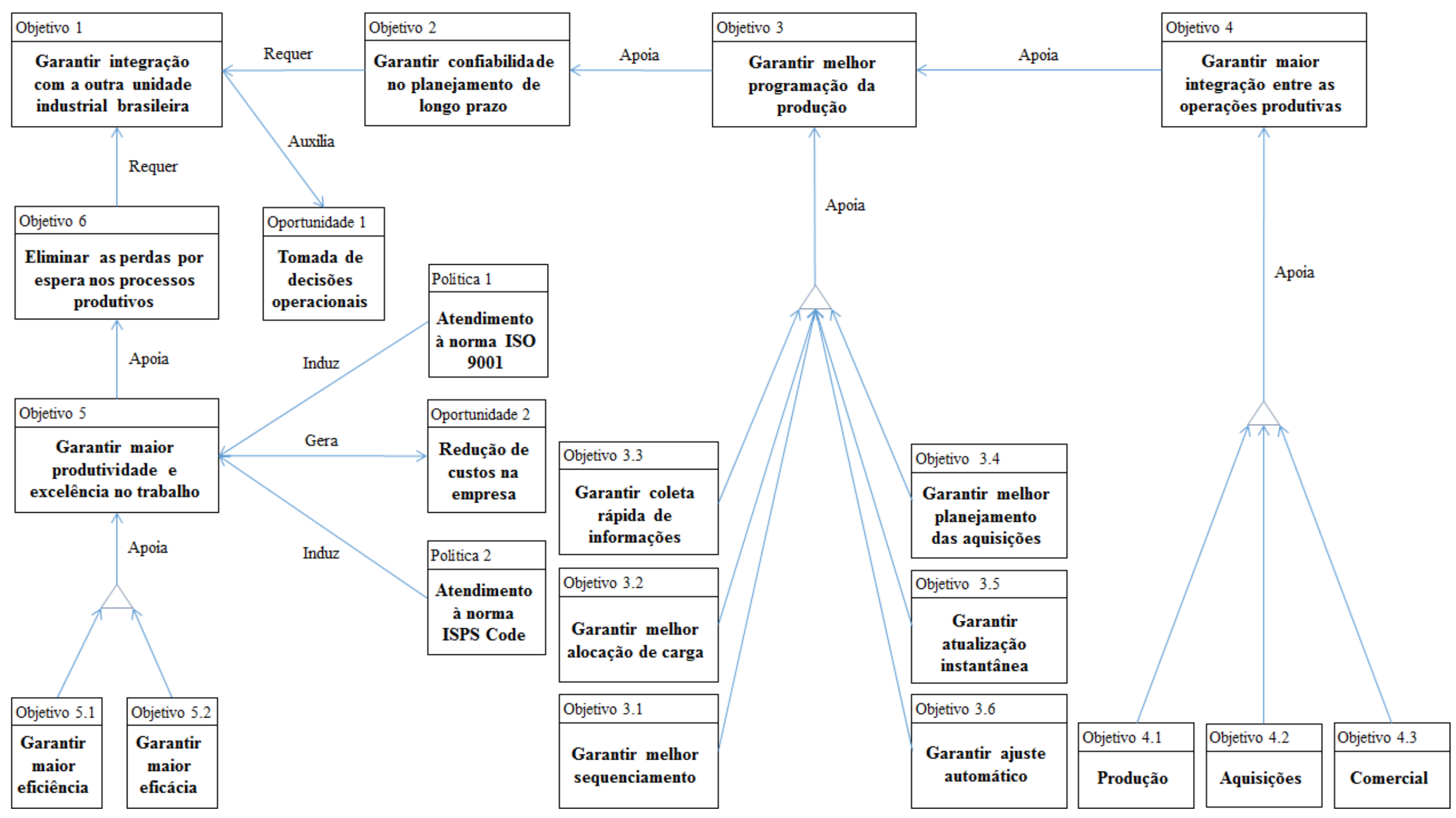

Figura 47 - Modelo de Objetivos - Empresa 7 


\section{Modelo de Regras do Negócio}

O Modelo de Regras do Negócio mostra a influência das regras do processo de implantação do sistema APS sobre os objetivos do processo. Tal modelo está representado na Figura 48 .

O treinamento dos usuários finais para o uso do sistema (Regra 2.1) apoia a ampliação do conhecimento da dinâmica do sistema (Regra 2), o que, em conjunto com a realização de testes no sistema após a modelagem (Regra 1) apoia a garantia de confiabilidade no planejamento de longo prazo (Objetivo 2).

O amplo conhecimento da dinâmica do sistema (Regra 2) e o amplo conhecimento dos processos produtivos (Regra 3) apoia a garantia de maior produtividade e excelência no trabalho (Objetivo 5).

A adaptação da solução do sistema APS às necessidades da empresa (Regra 4) apoia a eliminação das perdas por espera nos processos produtivos (Objetivo 6). A parametrização do sistema (Regra 6) é necessária para garantir maior integração entre as operações produtivas (Objetivo 4).

A integração do sistema APS com o ERP da outra unidade industrial (Regra 5) e a parametrização do sistema APS (Regra 6) são condições necessárias para garantir melhor programação da produção (Objetivo 3).

A integração do sistema APS com o ERP da outra unidade industrial (Regra 5) é necessária para garantir integração entre as duas unidades (Objetivo 1). 


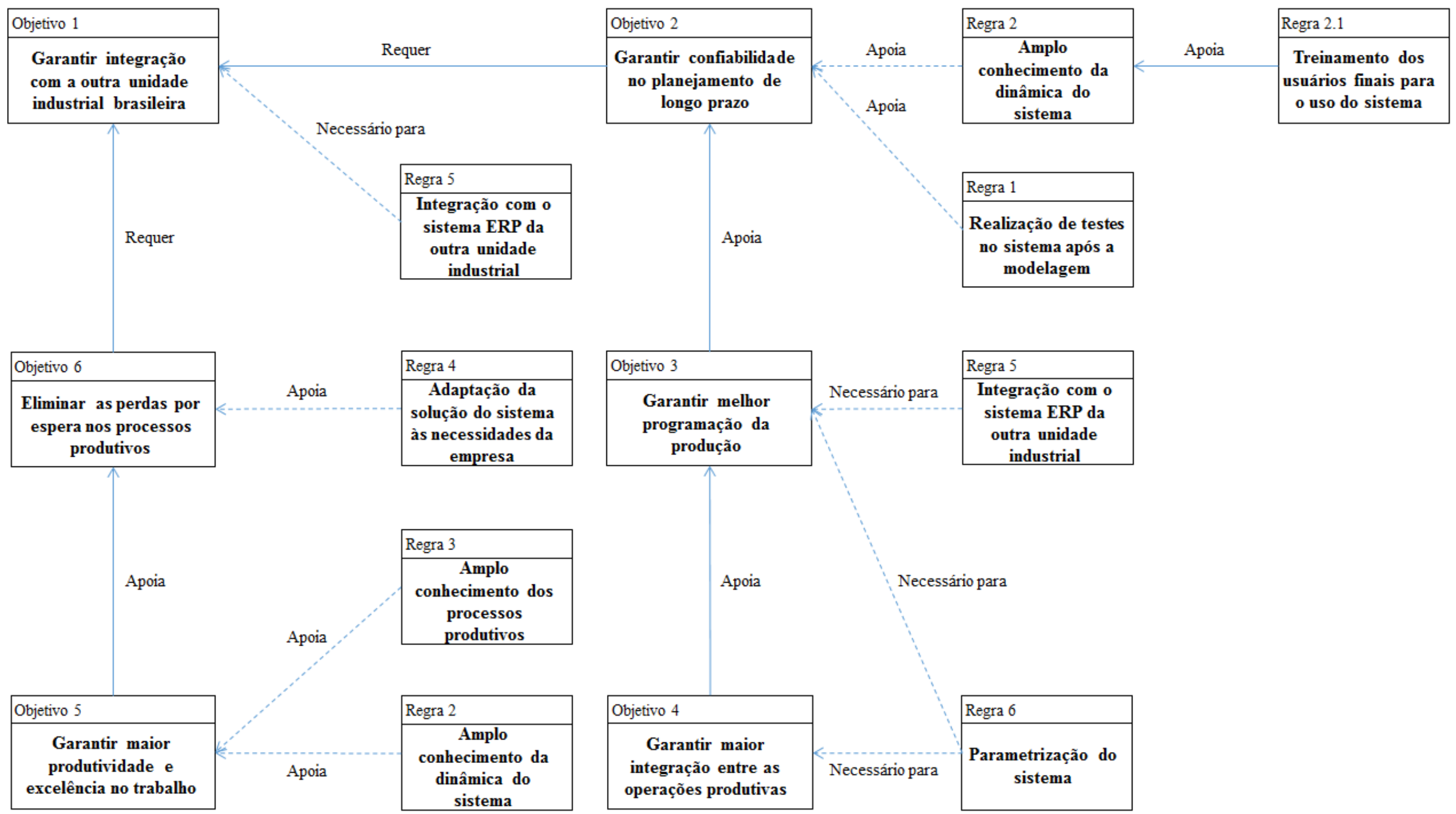

Figura 48 - Modelo de Regras do Negócio - Empresa 7 


\section{Modelo de Processos}

Durante o processo de implantação do sistema APS na empresa, a equipe de implantação realizou 6 principais processos, os quais estão representados na Figura 49.

Com a aprovação da Diretoria para a implantação do sistema APS na unidade de Campos (InfoSet 1) os funcionários envolvidos no projeto consultaram os relatórios gerados no processo de implantação da outra unidade industrial (Processo 1).

Como os funcionários da outra unidade industrial possuíam amplo conhecimento do processo de implantação realizado na unidade de Vitória, não houve necessidade de participação de empresas de consultoria no processo de implantação do sistema na unidade de Campos. Com a replicação do conhecimento gerado no processo de implantação da outra unidade industrial (InfoSet 2), os funcionários envolvidos, representados pelo Analista de Tecnologia da Informação e o Engenheiro de Planejamento, realizaram visitas técnicas na unidade de Campos para avaliar as necessidades da empresa (Processo 2).

Esta avaliação resultou na modelagem do sistema (InfoSet 3). Com a modelagem concluída, deu-se início aos testes do sistema na empresa (Processo 3), e com o sistema aprovado (InfoSet 4), foi iniciado o treinamento dos usuários finais para o seu uso (Processo $4)$.

Após a conclusão do treinamento, foi criada a integração entre o APS e o ERP da unidade industrial de Vitória (Processo 5). Após a conclusão da integração, com o sistema parametrizado (InfoSet 5), foi finalizado o processo de implantação, sendo geradas, por parte dos funcionários envolvidos, apostilas para auxiliar futuros funcionários para o uso do sistema (Processo 6). 


\begin{tabular}{|c|c|c|c|}
\hline InfoSet 1 & Processo 1 & InfoSet 2 & Processo 2 \\
\hline $\begin{array}{l}\text { Aprovação da Diretoria } \\
\text { para a implantação do } \\
\text { sistema na unidade }\end{array}$ & $\begin{array}{c}\text { Consultar os relatórios gerados } \\
\text { no processo de implantação da } \\
\text { unidade de Vitória }\end{array}$ & $\begin{array}{c}\text { Replicação do } \\
\text { conhecimento }\end{array}$ & $\begin{array}{l}\text { Avaliar as necessidades } \\
\text { da unidade de Campos }\end{array}$ \\
\hline
\end{tabular}

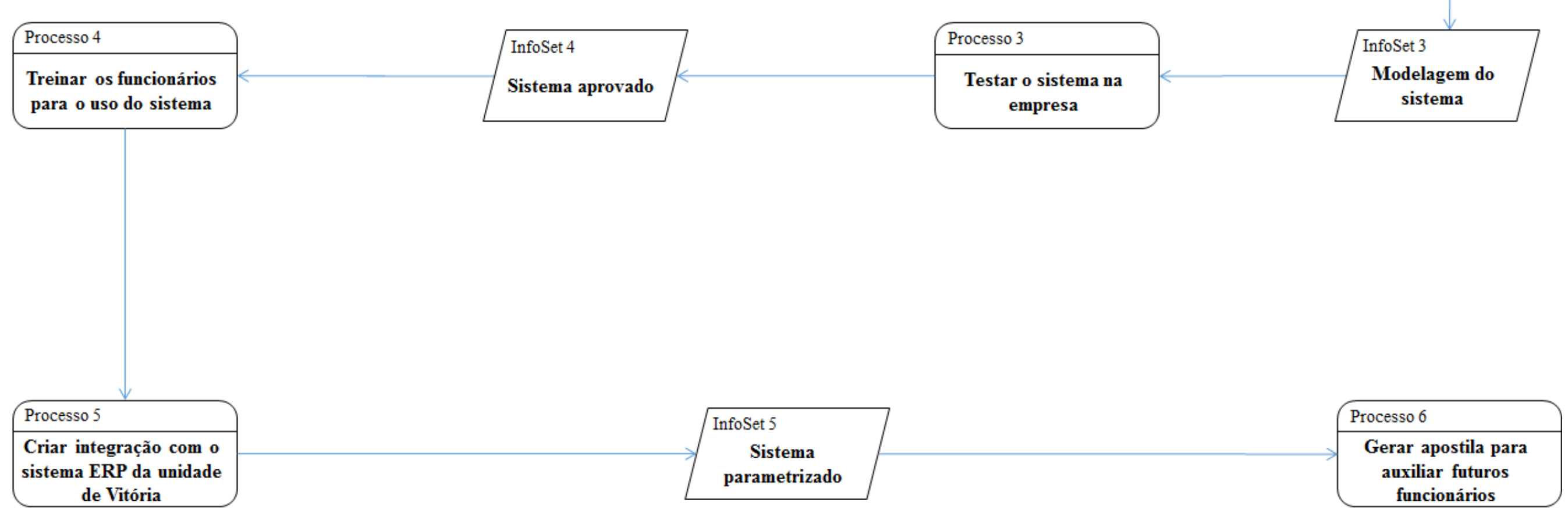

Figura 49 - Modelo de Processos - Empresa 7 


\section{Modelo de Atores e Recursos}

Neste modelo está descrito o papel de cada envolvido nas etapas do processo de implantação do sistema APS na empresa. A Figura 50 apresenta a visão geral do modelo.

O Diretor (Unidade Individual 1) da unidade industrial de Vitória (Unidade Organizacional 1) elabora as metas e objetivos do processo de implantação do sistema APS (Papel 1), aprova o orçamento (Recurso 1) e libera os recursos financeiros necessários para a sua aquisição (Recurso 2).

O Analista de PCP (Unidade Individual 4) da unidade industrial de Campos (Unidade Organizacional 2) recebe o treinamento destinado aos usuários finais (Recurso 5), exercendo a função designada (Papel 2).

O Engenheiro de Planejamento (Unidade Individual 2) e o Analista de Tecnologia da Informação (Unidade Individual 3) da unidade industrial de Vitória (Unidade Organizacional 1) realizam a modelagem do sistema (Recurso 3), os testes do sistema na empresa (Recurso 4) e a parametrização do sistema (Recurso 7); assim como são responsáveis pelo treinamento dos usuários finais (Recurso 5) e pela interface parametrizada com o sistema ERP da unidade industrial de Vitória (Recurso 6). 


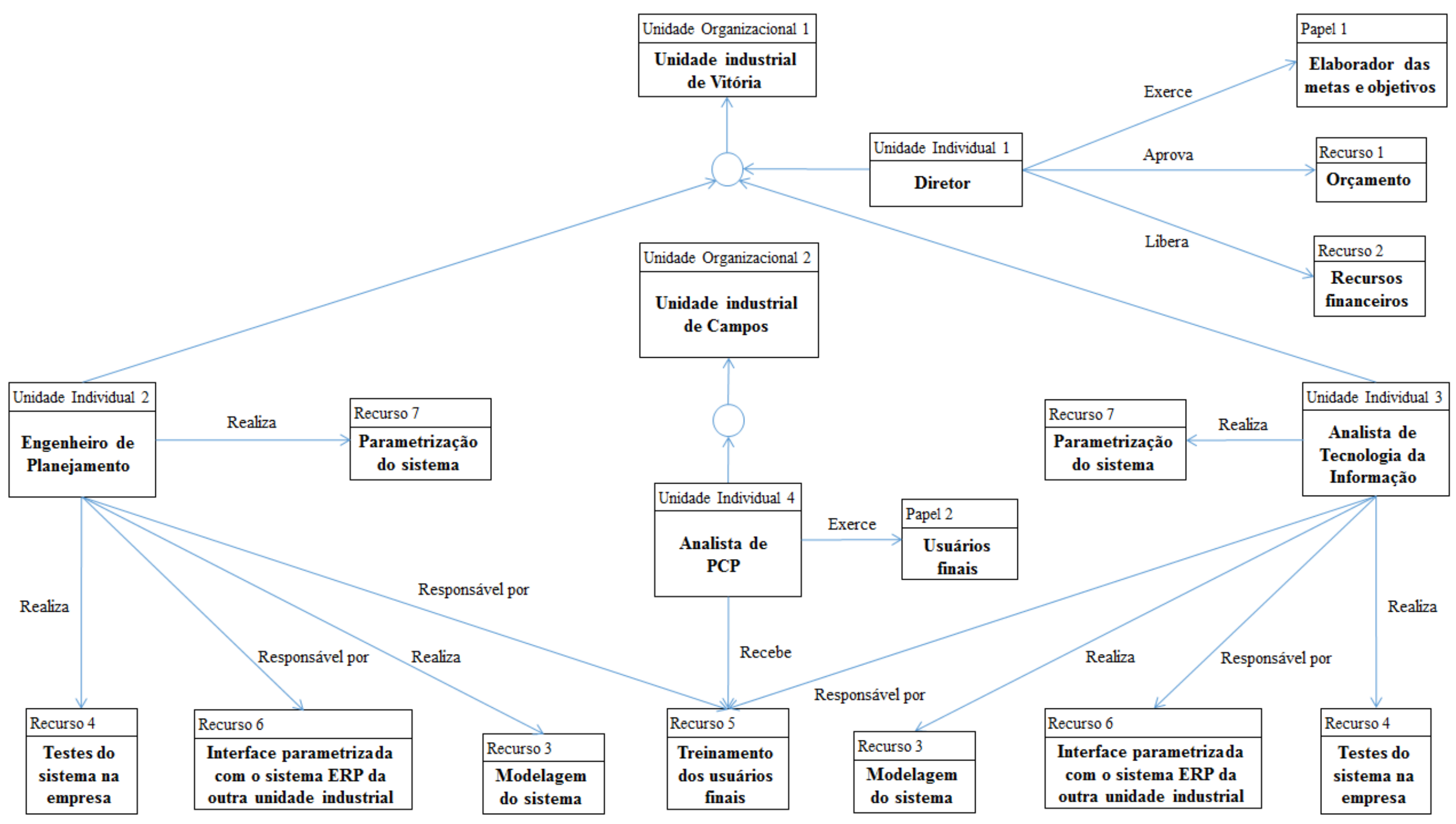

Figura 50 - Modelo de Atores e Recursos - Empresa 7 


\section{Modelo de Componentes e Requisitos Técnicos}

A Figura 51 apresenta o Modelo de Componentes e Requisitos Técnicos do processo de implantação do sistema APS. A empresa possui um sistema de informação que permite o envio e recebimento de informações relacionadas a transações que ocorrem entre ela e seus parceiros.

De acordo com as informações obtidas, o único objetivo deste sistema de informação durante o processo de implantação do sistema APS na empresa é permitir o envio e recebimento de informações pertinentes (Objetivo SI).

O sistema para envio e recebimento de informações pertinentes ao processo de implantação do sistema APS na unidade industrial de Campos (Objetivo SI) considera requisitos funcionais (que tangem a utilização do sistema de informação pretendido), bem como não funcionais (que tangem as medidas de segurança, usabilidade e acessibilidade, etc.). Ele visa relatar o andamento dos processos (Requisito Funcional 1) e gerenciar o tempo gasto em cada etapa do processo (Requisito Funcional 2). Tal sistema proporciona interface amigável ao usuário (Requisito Não Funcional 1), possui robustez (Requisito Não Funcional 2) e segurança (Requisito Não Funcional 3), restringindo o acesso apenas aos envolvidos nos processos, e possibilita acesso remoto (Requisito Não Funcional 4) por meio da web.

Este sistema é acessado pelo Engenheiro de Planejamento (Unidade Individual 2) e pelo Analista de Tecnologia da Informação (Unidade Individual 3) da unidade industrial de Vitória, e pelo Analista de PCP (Unidade Individual 4) da unidade industrial de Campos.

O sistema para envio e recebimento de informações pertinentes ao processo de implantação do sistema APS (Objetivo SI) por meio da troca de conhecimento entre os atores envolvidos no processo dissemina a ampliação do conhecimento da dinâmica do sistema (Regra 2), apoia a adaptação da solução do sistema às necessidades da empresa (Regra 4) e gerencia a realização de testes no sistema após a modelagem (Regra 1). Este sistema apoia a garantia de maior produtividade e excelência no trabalho (Objetivo 5) e a integração com a unidade industrial de Campos (Objetivo 1). 


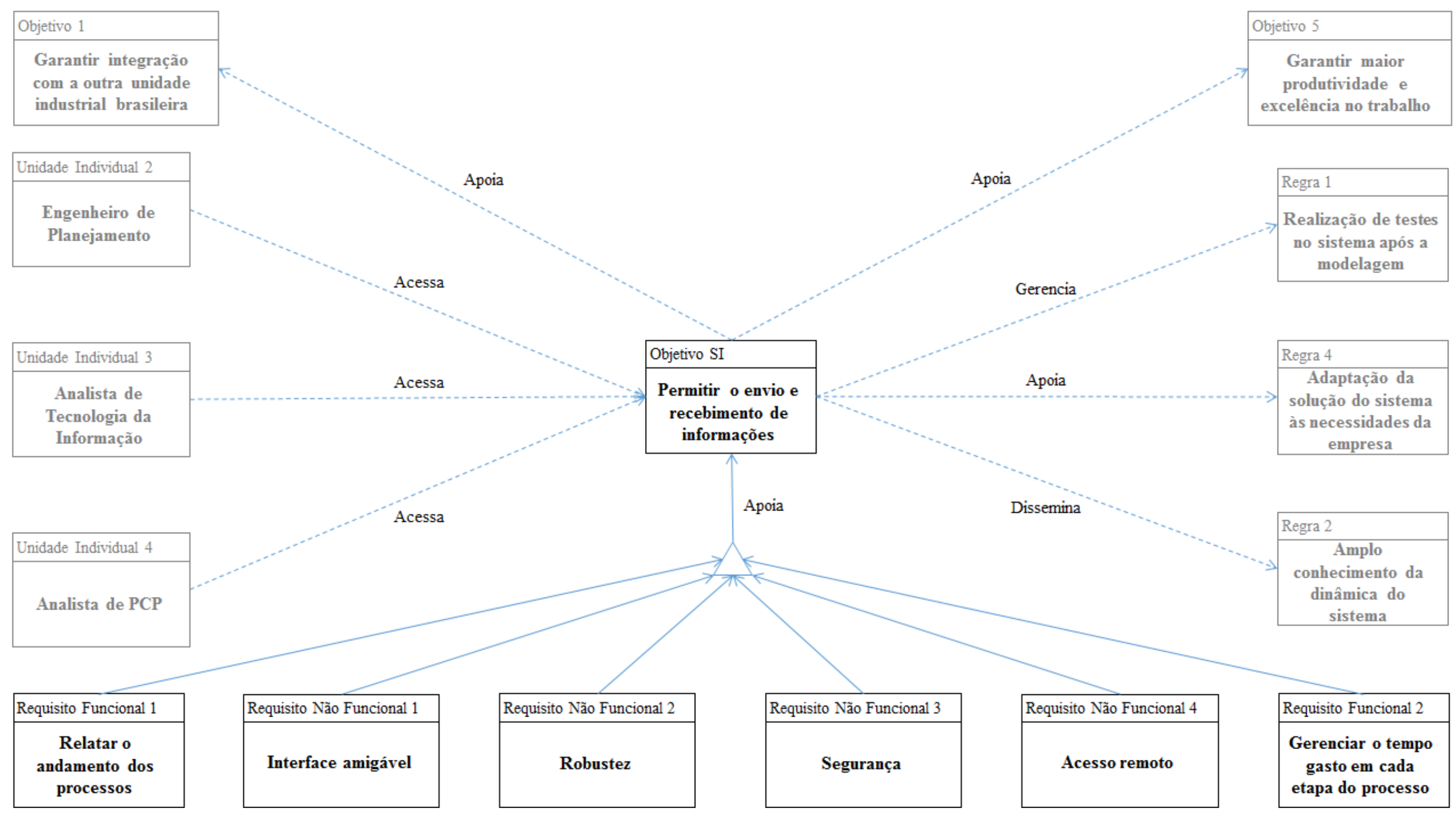

Figura 51 - Modelo de Componentes e Requisitos Técnicos - Empresa 7 


\section{APÊNDICE B - ROTEIRO DE ABORDAGEM PARA ENTREVISTA DE PROFISSIONAIS QUE PARTICIPARAM DO PROCESSO DE IMPLANTAÇÃO DE SISTEMAS APS NAS EMPRESAS DO ESTUDO DE CASOS MÚLTIPLOS}

\section{Caracterização geral da empresa}

1. Quantas unidades a empresa possui no Brasil?

2. A empresa está presente em outro(s) país(es)?

3. Quantos funcionários a empresa possui?

4. Quantos funcionários trabalham na unidade analisada?

5. Qual a posição da empresa no mercado em que atua?

6. Qual a classificação da empresa? Qual o órgão classificador?

\section{Fases da implantação do sistema APS}

7. Quais são as fases do processo de implantação do sistema APS na empresa?

8. Quais áreas da empresa foram afetadas pela implantação do sistema?

9. Quais atividades são desenvolvidas em cada fase do processo de implantação?

10. Quantos e quais as funções dos funcionários da empresa adquirente do sistema que participaram do processo de implantação?

11. Quais as funções dos funcionários da empresa implantadora e da empresa desenvolvedora do software?

12. Quais razões levaram a empresa a implantar o sistema?

13. Quais foram os principais benefícios alcançados e principais barreiras encontradas no processo de implantação do sistema?

14. Após o processo de implantação ser concluído e ser iniciada a utilização do sistema, existem algumas funcionalidades que podem ser melhor aproveitadas?

\section{EKD - Questões-guia}

\subsection{Modelo de Objetivos}

15. Quais são as estratégias da empresa para o processo de implantação de sistemas APS?

16. Existem políticas declaradas na empresa que podem influenciar o processo de implantação? 
17. Quais convenções, regras, regulamentos e leis são relevantes?

18. O que a empresa espera alcançar com a implantação do sistema APS?

19. Existe(m) algum(ns) problema(s) particular(es) que impede(m) o alcance de determinado(s) objetivo(s) almejado(s)?

20. Este(s) problema(s) está(ão) relacionado(s) a algum(ns) objetivo(s) específico(s)?

21. Qual(is) a(s) causa(s) deste(s) problema(s)?

22. Como este(s) problema(s) pode(m) ser minimizado(s) ou eliminado(s)?

23. Existem oportunidades específicas que podem ou poderiam ser usadas?

24. Na visão dos funcionários da empresa, quais ações podem ser tomadas para melhorar o processo de implantação?

25. Como estes objetivos podem ser alcançados?

26. Estes objetivos podem ser definidos em termos operacionais, dando um número de subobjetivos de apoio?

\subsection{Modelo de Regras do Negócio}

27. Dentro da empresa existem regras ou políticas declaradas que podem influenciar o processo de implantação?

28. Por quais regras os objetivos do processo de implantação podem ser alcançados?

29. Esta(s) regra(s) está(ão) relacionada(s) a algum objetivo específico?

30. Como esta regra pode ser decomposta?

31. Como validar o cumprimento da(s) regra(s)?

32. Quais processos disparam esta(s) regra(s)?

33. Esta(s) regra(s) pode(m) ser definida(s) em um aspecto operacional?

34. Esta(s) regra(s) pode(m) ser decomposta(s) em regras mais simples?

\subsection{Modelo de Processos de Negócio}

35. Quais são os principais processos existentes no processo de implantação?

36. Como estes processos são relacionados?

37. Por que estes processos são necessários?

38. Quais informações e fluxos de materiais o processo necessita?

39. Quais informações e fluxos de materiais o processo produz?

40. Quais regras disparam este processo?

41. Quais atores são responsáveis por realizar e apoiar este processo? 
42. O aprendizado gerado no processo de implantação é sistematizado de alguma forma?

\subsection{Modelo de Atores e Recursos}

43. Quais são os principais atores que participam no processo de implantação?

44. Como esses atores se relacionam?

45. Por quais processos este ator é responsável?

46. Quais processos este ator realiza?

47. Quais regras do negócio são definidas por este ator?

48. Por quais recursos este ator é responsável?

49. Quais recursos este ator possui?

\subsection{Modelo de Componentes e Requisitos Técnicos}

50. Quais sistemas de informação são ou poderiam ser utilizados para a gestão do processo de implantação?

51. Quais são os objetivos deste sistema?

52. Quais as funcionalidades deste sistema?

53. Quais requisitos este sistema precisa cumprir?

54. Quais atores acessam este sistema?

55. Quais objetivos do processo de implantação este sistema auxilia?

\subsection{Modelo de Conceitos}

56. Quais são as principais entidades do processo de implantação?

57. Como estas entidades são relacionadas?

58. Por que esta entidade é necessária?

59. Estas entidades apoiam alguma regra do negócio?

60. Os atributos da entidade são decompostos em sub-atributos? 


\section{APÊNDICE C - QUESTIONÁRIO ENVIADO A PROFISSIONAIS DAS EMPRESAS ADQUIRENTES, CONSULTORES DE EMPRESAS IMPLANTADORAS DE SISTEMAS APS E ESPECIALISTAS NA ÁREA, PARA VALIDAÇÃO DO MODELO DE REFERÊNCIA DESENVOLVIDO NA PESQUISA}

Nome:

Cargo:

Organização:

1. Após analisar o Modelo de Objetivos apresentado, qual sua conclusão?

\begin{tabular}{|c|c|c|c|}
\hline bjetivo 1: & Pouco relevante & Relevante & Muito relevante \\
\hline Objetivo 2: & Pouco relevante & Relevante & Muito relevante \\
\hline Objetivo 3: & Pouco relevante & Relevante & Muito relevante \\
\hline Objetivo 4: & Pouco relevante & Relevante & Muito relevante \\
\hline Objetivo 5: & Pouco relevante & Relevante & Muito relevante \\
\hline Objetivo 6: & Pouco relevante & Relevante & Muito relevante \\
\hline Objetivo 7: & Pouco relevante & Relevante & Muito relevante \\
\hline
\end{tabular}

2. Após analisar o Modelo de Regras do Negócio apresentado, qual sua conclusão?

\begin{tabular}{|c|c|c|c|}
\hline Regra 1 & Pouco relevante & Relevante & Muito relevante \\
\hline Regra & Pouco relevante & Relevante & Muito relevante \\
\hline Regra & Pouco relevante & Relevante & Muito relevante \\
\hline Regra & Pouco relevante & Relevante & Muito relevante \\
\hline Regra & Pouco relevante & Relevante & Muito relevante \\
\hline Regra & Pouco relevante & Relevante & Muito relevante \\
\hline
\end{tabular}




$\begin{array}{llllll}\text { Regra } & \text { 7: } \square & \text { Pouco relevante } \square & \text { Relevante } \square & \text { Muito relevante } \\ \text { Regra } & \text { 8: } \square & \text { Pouco relevante } \square & \text { Relevante } \square & \text { Muito relevante } \\ \text { Regra } & \text { 9: } \square & \text { Pouco relevante } \square & \text { Relevante } \square & \text { Muito relevante } \\ \text { Regra } & \text { 10: } \square & \text { Pouco relevante } \square & \text { Relevante } \square & \text { Muito relevante } \\ \text { Regra } & \text { 11: } \square & \text { Pouco relevante } \square & \text { Relevante } \square & \text { Muito relevante } \\ \text { Regra } & \text { 12: } \square & \text { Pouco relevante } \square & \text { Relevante } \square & \text { Muito relevante } \\ \text { Regra } & \text { 13: } \square\end{array}$

\section{Após analisar o Modelo de Processos apresentado, qual sua conclusão?}

\begin{tabular}{|c|c|c|c|}
\hline Processo 1: & Pouco relevante & Relevante & Muito relevante \\
\hline Processo 2: & Pouco relevante & Relevante & Muito relevante \\
\hline Processo 3: & Pouco relevante & Relevante & Muito relevante \\
\hline Processo 4: & Pouco relevante & Relevante & Muito relevante \\
\hline Processo 5: & Pouco relevante & Relevante & Muito relevante \\
\hline Processo 6: & Pouco relevante & Relevante & Muito relevante \\
\hline Processo 7: & Pouco relevante & Relevante & Muito relevante \\
\hline Processo 8: & Pouco relevante & Relevante & Muito relevante \\
\hline Processo 9: & Pouco relevante & Relevante & Muito relevante \\
\hline Processo 10: & Pouco relevante & Relevante & Muito relevante \\
\hline Processo 11: & Pouco relevante & Relevante & Muito relevante \\
\hline Processo 12: & Pouco relevante & Relevante & Muito relevante \\
\hline Processo 13: & Pouco relevante & Relevante & Muito relevante \\
\hline Processo 14: & Pouco relevante & Relevante & Muito relevante \\
\hline Processo 15: & Pouco relevante & Relevante & Muito relevante \\
\hline Processo 16: & Pouco relevante & Relevante & Muito relevante \\
\hline Processo 17: & Pouco relevante & Relevante & Muito relevante \\
\hline Processo 18: & Pouco relevante & Relevante & Muito relevante \\
\hline
\end{tabular}


Processo 19:

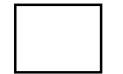

Pouco relevante

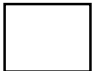

Relevante

$+$

Muito relevante

Processo 20:

Pouco relevante

$\square$

Relevante

$\square$

Muito relevante

Processo 21:

Pouco relevante

Relevante

Muito relevante

Processo 22:

Pouco relevante

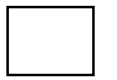

Relevante

Muito relevante

4. Após analisar o Modelo de Atores e Recursos apresentado, qual sua conclusão?

Concordo plenamente

Concordo parcialmente e sugiro as seguintes modificações:

Discordo totalmente, pelos seguintes motivos:

5. Após analisar o Modelo de Componentes e Requisitos Técnicos apresentado, qual sua conclusão?

Concordo plenamente

Concordo parcialmente e sugiro as seguintes modificações:

Discordo totalmente, pelos seguintes motivos: 


\section{Após analisar o Modelo de Conceitos apresentado, qual sua conclusão?}

\begin{tabular}{|c|c|c|c|}
\hline Conceito 1: & Pouco relevante & Relevante & Muito relevante \\
\hline Conceito 2: & Pouco relevante & Relevante & Muito relevante \\
\hline Conceito 3: & Pouco relevante & Relevante & Muito relevante \\
\hline Conceito 4: & Pouco relevante & Relevante & Muito relevante \\
\hline Conceito 5: & Pouco relevante & Relevante & Muito relevante \\
\hline Conceito 6: & Pouco relevante & Relevante & Muito relevante \\
\hline Conceito 7: & Pouco relevante & Relevante & Muito relevante \\
\hline Conceito 8: & Pouco relevante & Relevante & Muito relevante \\
\hline Conceito 9: & Pouco relevante & Relevante & Muito relevante \\
\hline Conceito 10: & Pouco relevante & Relevante & Muito relevante \\
\hline Conceito 11: & Pouco relevante & Relevante & Muito relevante \\
\hline Conceito 12: & Pouco relevante & Relevante & Muito relevante \\
\hline Conceito 13: & Pouco relevante & Relevante & Muito relevante \\
\hline Conceito 14: & Pouco relevante & Relevante & Muito relevante \\
\hline Conceito 15: & Pouco relevante & Relevante & Muito relevante \\
\hline Conceito 16: & Pouco relevante & Relevante & Muito relevante \\
\hline Conceito 17: & Pouco relevante & Relevante & Muito relevante \\
\hline Conceito 18: & Pouco relevante & Relevante & Muito relevante \\
\hline Conceito 19: & Pouco relevante & Relevante & Muito relevante \\
\hline Conceito 20: & Pouco relevante & Relevante & Muito relevante \\
\hline Conceito 21: & Pouco relevante & Relevante & Muito relevante \\
\hline Conceito 22: & Pouco relevante & Relevante & Muito relevante \\
\hline Conceito 23: & Pouco relevante & Relevante & Muito relevante \\
\hline Conceit & Pouco relevante & Relevante & Muito relevante \\
\hline
\end{tabular}

